

\section{Environmental Evaluation and Global Development Institutions}

Evaluation is increasingly important for finding sustainable solutions for the people and the planet, based on a systematic analysis of what works, for whom, and under what circumstances, and to contribute to the achievement of the Sustainable Development Goals, as they pertain to the environment.

This book explores why the Global Environment Facility (GEF) invests in evaluation for accountability and learning to inform its decision-making on programming priorities, and how this leads to wiser funding decisions and better program performance on the ground. The book is based on real-life experiences of how to make evaluation count for international environmental action. Drawing upon comprehensive evaluations of the GEF, it provides unique insights from authors responsible for designing, implementing, and disseminating the findings of the evaluations. No other multilateral development or environment agency places evaluation fully at the center of their decision-making. The book outlines the trends in the global environment and the changing landscape of international environmental finance. It defines the role of the GEF and explains its institutional framework and the unique partnership that involves donor and recipient countries, multilateral development banks, UN agencies, nongovernmental organizations (NGOs), and national agencies in the developing countries. Further, it provides useful pointers to other organizations wishing to enhance evidence-based decision-making for improving their relevance, performance, and impact.

The book will be most suitable for graduate-level, specialized study in a variety of disciplines such as environmental and development economics, political science, international relations, geography, sociology, and social anthropology.

Geeta Batra is Chief Evaluation Officer and Deputy Director of the Independent Evaluation Office (IEO) of the Global Environment Facility (GEF), Washington, DC, USA. Geeta has 24 years of experience in international development across the World Bank, International Finance Corporation, and the Global Environment Facility. She spent eight years in advisory and lending 
operations, and 16 years in evaluation. Geeta has applied a spectrum of evaluation methods to enhance quality and use of evaluations to improve program design, development outcomes, and sustainability.

Juha I. Uitto is Director of the Global Environment Facility (GEF) Independent Evaluation Office (IEO). He has worked as an evaluator with the GEF and the United Nations Development Programme (UNDP) for more than two decades focusing on evaluation at the nexus of environment and development. For five years, he served as Executive Coordinator of the UN Evaluation Group. He spent the 1990s as research manager at the United Nations University. Educated at the Universities of Helsinki and Lund, Juha holds a PhD in Social and Economic Geography. He has published widely on topics related to sustainable development, environmental hazards, and evaluation. He has held visiting positions with Rutgers University and Kyoto University.

Osvaldo Feinstein is Professor at the Universidad Complutense de Madrid's Master in the Evaluation of Programs and Public Policies and Member of the International Advisory Panel of UNDP's Independent Evaluation Office. He is an editor and author of books and articles on evaluation, development, and economics. He is the former manager and adviser at the World Bank's Evaluation Department and consultant with the IDB, AfDB, WBG, GEF, ILO, UNESCO, MOPAN, DFID, IDR C, ILPES, CEPAL, UNDP, IFAD, CGIAR, CLEAR-AA, AEVAL, BdF EIPA, and IEF. He has experience in Latin American and Caribbean countries, and in Asia and Africa, Eastern Europe, France, Italy, and Spain. 


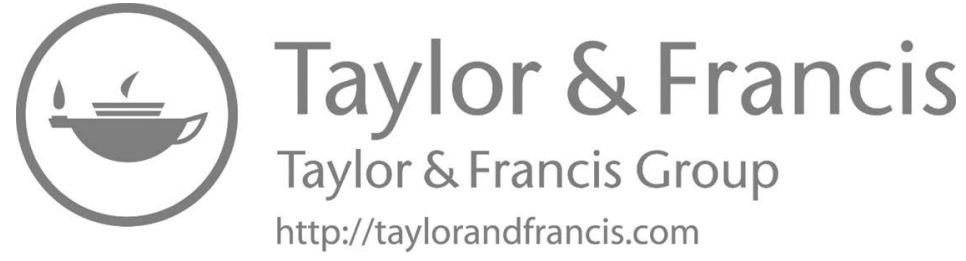




\section{Advances in Evaluation \& Development}

Series Editor: Osvaldo Feinstein, Professor at the Universidad Complutense de Madrid's Master in the Evaluation of Programs \& Public Policies and Member of the International Advisory Panel of UNDP's Independent Evaluation Office

This series aims to present the latest research and promising practices in evaluation and national \& international development. It is not confined to any particular method or school of thought and seeks to cover a broad range of topics, theories and issues.

\section{Evaluation and Development}

The Institutional Dimension

Edited by Robert Picciotto and Eduardo Wiesner

\section{Involuntary Resettlement}

Comparative Perspectives

Edited by Robert Picciotto, Warren van Wicklin and Edward Rice

\section{Evaluation and Poverty Reduction}

Edited by Osvaldo Feinstein and Robert Picciotto

\section{Making Development Work}

Development Learning in a World of Poverty and Wealth

Edited by Nagy Hanna and Robert Picciotto

\section{Managing a Global Resource}

Challenges of Forest Conservation and Development

Edited by Uma J. Lele

\section{Evaluation and Development}

The Partnership Dimension

Edited by Andres Liebenthal, Osvaldo Feinstein and Gregory K. Ingram

\section{Evaluating Development Effectiveness}

Edited by Osvaldo Feinstein

\section{Evaluating Climate Change and Development}

Edited by Rob D. van den Berg and Osvaldo Feinstein

\section{Evaluation for Inclusive and Sustainable Rural Transformation \\ Oscar A. García and Osvaldo Feinstein}

\section{Environmental Evaluation and Global Development Institutions}

A Case Study of The Global Environment Facility

Geeta Batra, Juha I. Uitto, and Osvaldo Feinstein

For more information about this series, please visit: https://www.routledge. com/Advances-in-Evaluation-Development/book-series/TRANWBSED 


\section{Environmental Evaluation and Global Development Institutions}

A Case Study of the Global

Environment Facility

Geeta Batra, Juha I. Uitto, and Osvaldo Feinstein 
First published 2022

by Routledge

2 Park Square, Milton Park, Abingdon, Oxon OX14 4RN

and by Routledge

605 Third Avenue, New York, NY 10158

Routledge is an imprint of the Taylor \& Francis Group, an informa business

(C) 2022 Geeta Batra, Juha I. Uitto, and Osvaldo Feinstein

The right of Geeta Batra, Juha I. Uitto, and Osvaldo Feinstein to be identified as authors of this work has been asserted by them in accordance with sections 77 and 78 of the Copyright, Designs and Patents Act 1988.

The Open Access version of this book, available at www.taylorfrancis.com, has been made available under a Creative Commons Attribution-Non Commercial-No Derivatives 4.0 license.

Trademark notice: Product or corporate names may be trademarks or registered trademarks, and are used only for identification and explanation without intent to infringe.

British Library Cataloguing-in-Publication Data

A catalogue record for this book is available from the British Library

Library of Congress Cataloging-in-Publication Data

Names: Batra, Geeta, author. | Uitto, Juha I., author. | Feinstein, Osvaldo

Néstor, author.

Title: Environmental evaluation and global development institutions: a case study of the global environment facility / Geeta Batra, Juha I. Uitto and

Osvaldo Feinstein.

Description: Abingdon, Oxon; New York, NY : Routledge, 2022. |

Series: Advances in Evaluation \& Development | Includes bibliographical references and index.

Identifiers: LCCN 2021026677 (print) | LCCN 2021026678 (ebook) |

ISBN 9781032076140 (hbk) | ISBN 9781032076195 (pbk) |

ISBN 9781003207979 (ebk)

Subjects: LCSH: Global Environment Facility. | Sustainable developmentDeveloping countries-Evaluation. | Economic development projects-

Developing countries-Evaluation. | Development economics-Developing countries-Evaluation. | World Bank.

Classification: LCC HC79.E5 B3727 2022 (print) | LCC HC79.E5

(ebook) | DDC 338.9/27-dc23

LC record available at https://lccn.loc.gov/2021026677

LC ebook record available at https://lccn.loc.gov/2021026678

ISBN: 978-1-032-07614-0 (hbk)

ISBN: 978-1-032-07619-5 (pbk)

ISBN: 978-1-003-20797-9 (ebk)

DOI: $10.4324 / 9781003207979$

Typeset in Bembo

by KnowledgeWorks Global Ltd. 


\section{Contents}

List of figures viii

Foreword ix

Acknowledgments xi

Abbreviations and acronyms xii

1 Introduction 1

2 Evaluation at the GEF 13

3 Evaluation and the replenishment process 21

4 Evaluation methods $\quad 40$

5 Performance, effectiveness, and sustainability $\begin{array}{ll}\text { of GEF interventions } & 64\end{array}$

6 Toward transformational change 93

7 Boosting the benefits: Use of GEF IEO evaluations 115

8 Lessons from the GEF experience 122

Appendix 1 Global Environment Facility Evaluation Policy 140

Appendix 2 OPS6 Independent Advisory Panel Statement 170

Appendix 3 Selected global environment facility evaluations and studies 173

Appendix 4 Global environment facility projects referenced in this book 176

$\begin{array}{ll}\text { Index } & 181\end{array}$ 


\section{Figures}

1.1 GEF projects by focal area $\quad 7$

1.2 The GEF partnership 8

2.1 Evaluation in the GEF 16

3.1 GEF funding by replenishment period 22

4.1 Explaining geospatial analysis 54

4.2 Use of geospatial analysis to assess relevance of GEF's

4.3 Using geospatial analysis to measure impacts: analysis of forest cover change from geospatial data $\quad 55$

4.4 GEF biodiversity project outcomes 59

4.5 GEF biodiversity project location valuations 59

5.1 Projects with outcomes in the satisfactory range, by GEF period 65

5.2 Projects with outcomes in the satisfactory range, by region 65

5.3 Projects with implementation rated in satisfactory range, by GEF period 67

5.4 Project M\&E design and implementation rated as satisfactory, by GEF period

5.5 Projects with likely sustainability, by GEF period 69

5.6 Projects with likely sustainability, by GEF region 69

5.7 Forest cover loss of $\mathrm{Ba} \mathrm{Be}$

5.8 Focal area outcomes and sustainability ratings 73

6.1 Generic theory of change for the GEF 94

6.2 Theory of change for GEF transformational interventions 97

6.3 Process of scaling up 105

7.1 IEO brief: evaluation of the GEF partnership and governance structure 


\section{Foreword}

Environmental matters have made it to the top of the political agenda. Public awareness is higher than ever, especially regarding climate change, and each year more public and private money is spent in an effort to restore or preserve our planet's balance. Having worked in the field of environment for more than three decades and from different perspectives - academia, private sector, civil society, multilateral development bank, and government these are encouraging developments. However, there are many questions, for which we all are seeking answers: are the actions commensurate? Are they tackling the root causes of environmental degradation? Are they leading to transformational outcomes? Are the pioneers in the field, such as the Global Environment Facility (GEF), still relevant and are they using the most impactful approaches and instruments? One thing, though, has become clear: the same old same old will not suffice. Hence, whoever develops strategies or takes concrete investment decisions will depend even more than before on evidence to assure that the limited resources are well used.

In the GEF, the evaluations by the Independent Evaluation Office (IEO), as well as studies by the Scientific and Technical Advisory Panel, are the primary sources of such evidence. Like other GEF Council members and other stakeholders of the "GEF family," I am a convinced advocate and user of evaluations. This is especially true for the periodic Comprehensive Evaluations of the GEF, which draw on many thematic or geographic evaluations, involve all stakeholders, and provide detailed and timely information that helps enlighten the replenishment process of the GEF every four years. Evaluations are usually very nuanced, requiring careful reading - no simple recipe books. While sometimes one would wish to get simpler black/white, good/bad answers, it is up to the reader to draw conclusions in view of policy decisions and improving the strategies and designs of programs and projects. And rightly so, because anything else would jeopardize two characteristics of evaluations: the credibility and the independence.

The three coauthors, Dr. Geeta Batra, Dr. Juha I. Uitto, and Prof. Osvaldo Feinstein, combine strong academic credentials with decades of practical experience in evaluating actions of multilateral organizations in the fields related to environment and sustainable development, both understood in a 


\section{$\mathrm{x}$ Foreword}

broad sense. Hence, this book condenses a wealth of knowledge and experience, including on new tools such as remote sensing and geospatial methods, which the GEF IEO has been pioneering in its evaluation work. To my knowledge, the GEF is the one multilateral environment or development organization that hardwires evaluations and decision-making more than any other does. This book, therefore, is recommended reading not only for evaluation specialists or those involved in GEF operations. Others will also find relevant information, including examples from the broad range of fields that the GEF is dealing with, such as climate change, biodiversity, land degradation, chemicals and waste, international waters, and forests, and the interdependence and interaction between them. These should attract great interest, since countless studies have highlighted that sustainable social or economic development requires the systematic integration of environmental aspects into strategy and project design. I trust that the book will find and inspire many interested readers.

Dr. iur. Stefan Schwager, former GEF Council Member, representing the Constituency of Azerbaijan, Kazakhstan, Kyrgyz Republic, Switzerland, Tajikistan, Turkmenistan, and Uzbekistan. 


\section{Acknowledgments}

The authors wish to express their appreciation to the staff of the Independent Evaluation Office (IEO) of the Global Environment Facility (GEF), the GEF Council, the GEF Secretariat, GEF Agencies, the GEF Scientific and Technical Advisory Panel (STAP), GEF political and operational focal points, civil society, stakeholders, and the external advisory panel who made substantive contributions in the preparation of Sixth Comprehensive Evaluation of the GEF (OPS6), on which this book is based. OPS6 was prepared by the IEO to provide evidence and lessons on the performance and impact of GEF programs and policies for the seventh replenishment of the GEF in 2017/18.

This book draws substantively on OPS6 and on the underlying individual evaluations conducted by the IEO staff. We acknowledge the evaluation team leads Anupam Anand, Carlo Carugi, Jeneen Garcia, Kyoko Matsumoto, Neeraj Negi, Kseniya Temnenko, Anna Viggh, and Baljit Wadhwa, and the contributions of the evaluation analysts Sara El Choufi, Molly Watts Sohn, and Peixuan Zhou. We also acknowledge the support of the administrative and communications staff: Juan Portillo, Francisco Grahammer, Malac Kabir, Manuella Koukoui, and Evelyn Chihuguyu.

OPS6 benefitted immensely from an external advisory panel who guided the preparation of the comprehensive report from the development of the approach paper through the interpretation of findings and the development of recommendations. We are grateful to Hans Bruyninckx, Holly Dublin, Osvaldo Feinstein, Sunita Narain, and Kazuhiko Takemoto for their guidance.

The authors also thank the GEF Council for their encouragement and generous support, which was instrumental to the completion of OPS6 in particular and the IEO work program in general. We gratefully acknowledge the members of the GEF partnership - the Secretariat, the Agencies, STAP, civil society network, and focal points - for their participation and active engagement throughout the OPS6 evaluation process and in the conduct of the individual component evaluations.

We specifically thank Katy O'Grady, our editor, for keeping track of all details and ensuring that the book project proceeded on schedule. Her professionalism and attention to detail were indispensable. 


\section{Abbreviations and acronyms}

$\begin{array}{ll}\text { APR } & \text { annual performance report } \\ \text { ARPA } & \text { Amazon Regional Protected Areas Program } \\ \text { CBD } & \text { Convention on Biological Diversity } \\ \text { CEO } & \text { Chief Executive Officer } \\ \text { CONANP } & \text { National Commission on Natural Protected Areas } \\ \text { CRESP } & \text { China Renewable Energy Scale-Up Program } \\ \text { CSO } & \text { Civil Society Organization } \\ \text { DAC } & \text { Development Assistance Committee } \\ \text { EGREE } & \text { East Godavari River Estuarine Ecosystem } \\ \text { FAO } & \text { Food and Agriculture Organization } \\ \text { GCA } & \text { Global Commission on Adaptation } \\ \text { GCIP } & \text { Global Cleantech Innovation Programme } \\ \text { GEF } & \text { Global Environment Facility } \\ \text { GEF/C } & \text { Global Environment Facility Council } \\ \text { GEFEO } & \text { Global Environment Facility Evaluation Office } \\ \text { GEF IEO } & \text { Global Environment Facility Independent Evaluation } \\ \text { IAP } & \text { Office } \\ \text { IEM } & \text { Integrated Approach Pilot } \\ \text { IEO } & \text { Integrated Environmental Management } \\ \text { IFAD } & \text { Independent Evaluation Office } \\ \text { IFC } & \text { International Fund for Agricultural Development } \\ \text { IPCC } & \text { International Finance Corporation } \\ \text { IWT } & \text { Intergovernmental Panel on Climate Change } \\ \text { LDCF } & \text { illegal wildlife trade } \\ \text { LDCs } & \text { Least Developed Countries Fund } \\ \text { LSMS } & \text { least developed countries } \\ \text { M\&E } & \text { Living Standards Measurement Survey } \\ \text { MAR } & \text { monitoring and evaluation } \\ \text { MDB } & \text { management action record } \\ \text { MEA } & \text { multilateral development bank } \\ \text { MENA-DELP } & \text { multilateral environmental agreement } \\ & \text { Middle East and North Africa Desert Ecosystems and } \\ & \text { Livelihoods Program } \\ \end{array}$


MOPAN

NASA

NDVI

NGOs

NIP

ODA

OECD

OPS

PAS

PEMSEA

PES

PMIS

POP

QCI

REDD+

ROtI

SCCF

SDG

SFM

SIDS

SINAP

STAP

STAR

TE

TOC

UN

UNCCD

UNDP

UNEP

UNFCCC

UNIDO

UWEP

VFM
Multilateral Organizations Performance Assessment

Network

National Aeronautics and Space Administration

normalized difference vegetation index

nongovernmental organizations

national implementation plan

official development assistance

Organisation for Economic Co-operation and

Development

overall performance study

Protected Areas Systems

Partnerships in Environmental Management for the Seas of East Asia

payment for ecosystem services

Project Management Information System

Persistent Organic Pollutant

Quasi-Experimental Geospatial Interpolation

reduced emissions from deforestation and degradation

review of outcomes to impacts

Special Climate Change Fund

Sustainable Development Goal

sustainable forest management

small island developing states

National System of Natural Protected Areas

Scientific and Technical Advisory Panel

System for Transparent Allocation of Resources

terminal evaluation

theory of change

United Nations

United Nations Convention to Combat Desertification

United Nations Development Programme

United Nations Environment Programme

United Nations Framework Convention on Climate

Change

United Nations Industrial Development Organization

Uruguay Wind Energy Program

value for money 


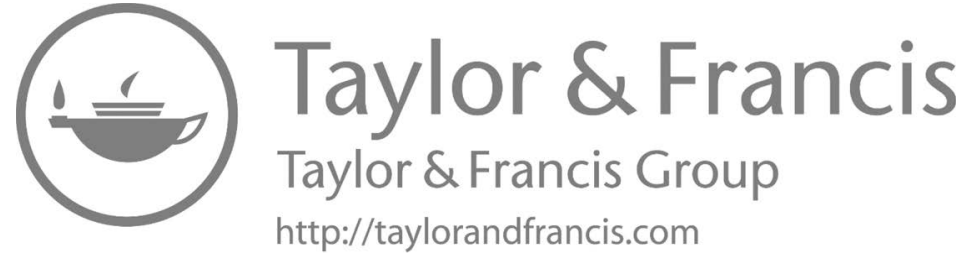




\section{Introduction}

Humanity is at a critical juncture of environmental, social, and economic factors. We know that human health and well-being are inextricably linked with a healthy natural environment, one with ecosystem integrity, clean air, and a stable climate. A stark illustration of this link is the COVID-19 pandemic, with its devastating impacts on both human health and the economies of developing - and developed - countries around the globe.

The SARS-CoV-2 coronavirus, which causes COVID-19, is one of the growing number of zoonotic viruses, which means it originated in animals and crossed over to humans. The increase in such viruses is directly linked to environmental exploitation - by encroaching into ecosystems we have never been exposed to before and altering interactions between animals and humans, we let new viruses enter our population (Berardelli 2020).

At this juncture of humanity, independent evaluation is critical. We emphasize the value of independent evaluation, which means that it is carried out by entities and persons free from the control of those responsible for the design and implementation of the development intervention, and, therefore, objective and impartial.

Evaluation provides valuable lessons and guidance for organizations and policy makers to better understand and consider the environmentalsocial-economic interlinkages in designing programs and policies. It also provides understanding based on evidence of what works, why, under what circumstances, and for whom. Evaluation answers essential questions such as: were the interventions the right ones and were they implemented to be effective? Did unintended consequences occur that were not conceived at the program design stage? In a world with limited resources, were the interventions designed and implemented efficiently to deliver value for money? Were the interventions sustainable well past implementation?

The human-environment nexus presents additional challenges and opportunities for evaluation. Evaluation must be able to provide evidence of how actions in the development domain affect the environment and vice versa. We need to be able to demonstrate the close interlinkages between social and economic development and the environment in light of evidence from 


\section{Introduction}

the real world. Evaluation must draw on scientific knowledge to complement analysis of real life from the field. This requires going beyond analysis of discrete interventions, often carried out in isolation, to assess them in the broader landscape and analyze how they interact with natural and human systems. Evaluators must adopt systems-based approaches to achieve and measure the impacts of interrelated interventions, recognizing the synergies and trade-offs that might exist.

The 2030 Agenda for Sustainable Development and the Sustainable Development Goals (SDGs) recognize the three pillars of sustainable development - social, economic, and environmental - and the interrelationships among them. Too often, a healthy natural environment is considered an afterthought to human health and sustainable development as a whole, despite their essential interconnection. With the onset of the COVID-19 pandemic, a shift in attitudes toward greater care for the environment is detectable, but powerful interests may still seek to pursue growth at any environmental cost. Even in the short period of this pandemic crisis, the slowdown in economic activity resulted in measurable environmental and associated health benefits. Should we return to environmental and development business as usual after the crisis subsides, we will pay the price and the next pandemic will be waiting in the wings. This crisis presents an opportunity to rethink our development path and priorities and build back better, restructuring economies toward more sustainability, respect for nature, equality, and participation.

This book draws on the findings from independent evaluation of environmental programs in developing countries implemented by the Global Environment Facility (GEF). The GEF was the first significant public fund established to address global environmental problems following the 1992 Earth Summit. Although other funds dealing with climate change have since emerged, the GEF remains virtually the only one focusing on biodiversity conservation and other terrestrial and marine environmental challenges. Throughout the GEF portfolio, we find significant overlap between various environmental domains and interlinkages to socioeconomic benefits and human health. Across the 27 years since its founding, the GEF has weathered health and economic crises across the globe. Evaluations of GEF programs, conducted by the organization's Independent Evaluation Office, draw on this long period of implementation and offer valuable evidence and insights on the human-environment nexus - with critical relevance for this pandemic. This book will also familiarize readers with approaches and current methods in environmental evaluation while presenting rich evidence on the impacts of environmental programs.

This book's authors are intimately involved in independent evaluation of the GEF and played an instrumental role in the Sixth Comprehensive Evaluation of the Facility. ${ }^{1}$ As independent evaluators, we are not part of GEF management and have a mandate to evaluate the performance, impact, and effectiveness of the GEF in an open manner, reporting directly to the GEF Council. 


\section{Trends in the global environment}

Fully understanding and interpreting the findings we present requires an appreciation of the current landscape within which the GEF is operating.

The global environment continues to deteriorate. In fact, in a number of areas, damage to the global environment has exceeded critical levels and threatens to lead to irreversible changes in global ecosystems. The long-term averages of four core components of a planet suitable for human life - known as "planetary boundaries" - have already been exceeded: human-driven climate change, land system change, high levels of phosphorous and nitrogen flowing into oceans due to increased fertilizer use, and loss of biosphere integrity (Steffen et al. 2015). All of these changes are leading the earth into a new state - and show no signs of slowing down. Despite efforts to achieve net-zero global carbon emissions by 2050, emission rates are still rising (World Economic Forum 2020). Several other global challenges will require significant public-private cooperation to address.

The top-of-mind challenge, of course, is the global pandemic that arose in 2020. Like the zoonotic coronavirus behind COVID-19, about two-thirds of all infectious diseases in humans originate in animals (Jones et al. 2008). Land mismanagement, habitat loss, overexploitation of wildlife, and human-induced climate change have created multiple pathways for pathogens to transmit from wildlife to domestic animals and humans. This pandemic has also revealed substantial vulnerabilities even in developed countries, with severe economic consequences.

Another daunting challenge is the expected global population increase of 2 billion by 2050, accompanied by a rapid increase in the global middle class, reaching 3 billion in the next two decades. This population growth accompanied by increased consumption will place unprecedented demands on natural resources and energy use and will result in further expansion in deforestation and transformation of land from nature to human uses. At the same time, we are seeing rapid growth in unemployment, income and wealth inequality within and across countries, and agrarian stress.

The threat of human-made environmental harm was highlighted in the World Economic Forum's Global Risk Report 2020, which named the top five global risks in terms of likelihood and severity of impact:

1 Extreme weather events with major damage to property, infrastructure, and life

2 Major biodiversity loss and ecosystem collapse (terrestrial or marine) with irreversible consequences for the environment

3 Failure of climate-change mitigation and adaptation by government and business

4 Major natural disasters such as earthquakes, tsunamis, volcanic eruptions, and geomagnetic storms

5 Human-made environmental damage and disasters, including environmental crime, such as oil spills and radioactive contamination 


\section{Introduction}

These trends will require the world to meet increased demands for food, energy, human habitat, transportation, and more - all placing direct pressure on the global environment.

The global landscape for environmental finance has evolved, especially with regard to climate finance. Today, with greater awareness of environmental issues, we have seen the launch of the SDGs, the Paris Agreement, and the Sendai framework for disaster risk management. In 2015, an ambitious plan to end poverty, protect the planet, and ensure prosperity for all was agreed upon unanimously by all countries: the 2030 Agenda for Sustainable Development (United Nations Department of Economic and Social Affairs, 2015). It includes 17 SDGs and 169 targets reflecting the scale and ambition of this new universal agenda. They are integrated and indivisible and balance the three dimensions of sustainable development - economic, social, and environmental. ${ }^{2}$ The Paris Agreement was the first-ever universal, legally binding global climate change agreement, adopted at the Paris Climate Conference (the 21st session of the Conference of the Parties) in December 2015. It sets out a global framework to avoid dangerous climate change by limiting global warming to well below $2^{\circ} \mathrm{C}$ and pursuing efforts to limit it to $1.5^{\circ} \mathrm{C}$. It also aims to strengthen countries' ability to deal with the impacts of climate change and support them in their efforts. ${ }^{3}$ The Sendai Framework for Disaster Risk Reduction 2015-2030 was the first major agreement of the post-2015 development agenda and provides member states with concrete actions to protect development gains from the risk of disaster. It works alongside the SDG Agenda and the Paris Agreement on Climate Change, was endorsed by the UN General Assembly following the 2015 Third UN World Conference on Disaster Risk Reduction, and advocates for "the substantial reduction of disaster risk and losses in lives, livelihoods and health and in the economic, physical, social, cultural and environmental assets of persons, businesses, communities and countries." The Sendai Framework recognizes that the state has the primary role to reduce disaster risk but that responsibility should be shared with other stakeholders, including local government, the private sector, and other stakeholders. ${ }^{4}$

Environmental issues are being mainstreamed across a broad range of organizations, including the multilateral development banks. However, these positive developments have been affected by the international environmental architecture of conventions, funds, programs, and donors that continues to show increasing fragmentation, making it more difficult to coordinate and harmonize funding for the implementation of environmental activities globally. Global funding flows in recent years have increasingly prioritized climate change and reduced emissions from deforestation and degradation (REDD+) over other environmental issues - notably biodiversity and transboundary waters. Further, the global landscape for climate change finance has changed significantly since the GEF become the first operating entity of the financial mechanism of the United Nations Framework Convention on Climate Change (UNFCCC) in 1996. The GEF was a principal source 
of donor financing for climate change in the 1990s, but the landscape has since expanded and fragmented, and the GEF has become a relatively smaller contributor to climate-related projects. New multilateral institutions such as the Climate Investment Fund and the Green Climate Fund have pledged amounts that far exceed those of the GEF, and many carbon finance facilities have become active. More and more, the private sector recognizes the economic, financial, and human risks posed by unchecked climate change and has increased its capital commitments across renewable energy and other sectors (UN 2015).

Despite the establishment of new funding sources and a commitment by the multilateral development banks, the global demand for environmental finance to address the risks far exceeds the resources made available by donors. The international community has committed and invested sizable resources each year to address the mounting environmental issues but needs are huge relative to available funding and remain largely unmet. According to Climate Policy Initiative estimates, investment required to achieve the low-carbon transition ranges from $\$ 1.6$ trillion to $\$ 3.8$ trillion annually between 2016 and 2050, for supply-side energy system investments alone (IPCC 2018). The Global Commission on Adaptation (GCA 2019) estimates adaptation costs of $\$ 180$ billion annually from 2020 to 2030 . Climate finance flows reached a record high of $\$ 612$ billion in 2017 , driven by increased renewable energy capacity in China, the United States, and India, and by increased public commitments to land use and energy efficiency. However, 2018 saw an 11 percent drop, to $\$ 546$ billion. The United Nations Intergovernmental Panel on Climate Change (IPCC) says that an annual investment of $\$ 2.4$ trillion - about 2.5 percent of the world's economy - is needed in the energy system alone until 2035 to limit temperature rise to less than $1.5^{\circ} \mathrm{C}$ (IPCC 2018). And the effort to tackle climate change goes beyond transforming energy systems: it must include spending on reforestation, coastal-defense systems, and many other efforts to cut emissions and adapt to rising temperatures. According to the Organisation for Economic Co-operation and Development, total public spending on climate finance was $\$ 56.7$ billion in 2017 (Yeo 2019). This in turn leveraged $\$ 14.5$ billion in private finance, for a total of $\$ 71.2$ billion, well short of the IPCC funding target requirements.

The response to these global environmental challenges has increased significantly in recent years, mainly in the area of climate change, but action still falls far short of the estimated funding required to meet both mitigation and adaptation requirements. Other environmental priorities such as biodiversity have received even less attention. The funding situation is further exacerbated by the 2020 COVID-19 pandemic, increasingly frequent famines and natural disasters attributed to accelerating climate change that require immediate assistance, global market volatility, competing bilateral programs for environmental finance, and political uncertainty created by the US withdrawal from the Paris Agreement. 


\section{Introduction}

\section{The GEF's global role}

With its broad focus that extends to the environment beyond climate change, the GEF occupies a unique space in the global environmental financing architecture and is even more important in the context of the COVID-19 pandemic. Despite limited funding of about $\$ 4.1$ billion every four years, the GEF is the only institution that addresses global environmental issues rather than climate change alone. With a history and established standing of nearly three decades, the GEF supports major multilateral environmental agreements beyond the UNFCCC, including the Convention on Biological Diversity (CBD), the Stockholm Convention on Persistent Organic Pollutants (POPs), the United Nations Convention to Combat Desertification (UNCCD), and the Minamata Convention on Mercury. The GEF also funds projects in the international waters focal area, contributing to the implementation of many global and regional agreements, and supports sustainable forest management initiatives that are consistent with the objectives of the United Nations Forum on Forests. GEF interventions also directly relate to SDG Goals 2, 6, 11, 13, 14, and 15 on zero hunger, clean water and sanitation, sustainable cities and communities, climate action, life under water, and life on land. The GEF's responses to the SDGs are mainly through its support to the conventions. Through its programmatic approaches and multifocal projects, the GEF can - and does - create interlinkages and synergies across focal areas and planetary boundaries.

The GEF strategy has continued to evolve to address growing environmental challenges and the drivers of environmental degradation, with an emphasis on integration. The GEF implements programs and projects in the focal areas of biodiversity, land degradation, climate change mitigation and adaptation, chemicals and waste, and international waters, with integrated programs addressing sustainable forest management, sustainable cities and food systems, and land use and restoration. Beginning in 2014, the GEF introduced these integrated approaches to assist recipient countries in meeting commitments to more than one global convention or thematic area by tackling underlying drivers of environmental degradation. These programs are designed to promote complementarities and synergies in seeking environmental benefits across various focal areas (multiple environmental benefits). Synergy refers to multiple benefits that are achieved either simultaneously through a single intervention or through the interaction of outcomes of at least two interventions.

The COVID-19 pandemic spotlights the GEF's importance today. The scientific literature makes clear how destroyed habitats provide ideal conditions for such viruses to thrive. "We invade tropical forests and other wild landscapes, which harbor so many species of animals and plants - and within those creatures, so many unknown viruses," David Quammen, author of Spillover: Animal Infections and the Next Pandemic, recently wrote in The New York Times. "We cut the trees; we kill the animals or cage them and send them to markets. We disrupt ecosystems, and we shake viruses loose from their natural hosts. When that happens, they need a new host. Often, we are it" (Quammen, 2020). 
GEF Projects by Focal Area

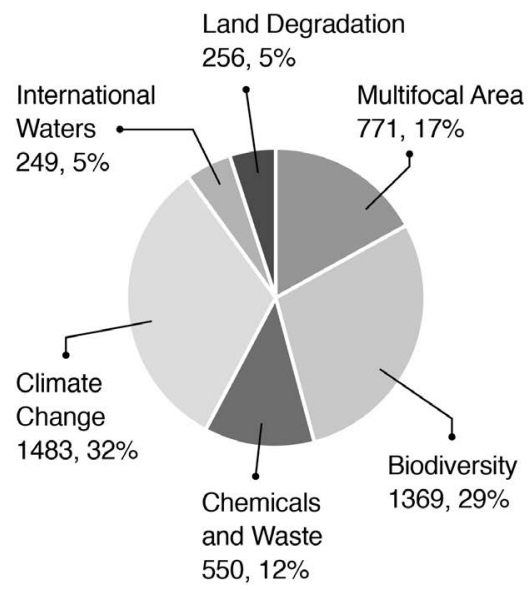

Grant by Focal Area

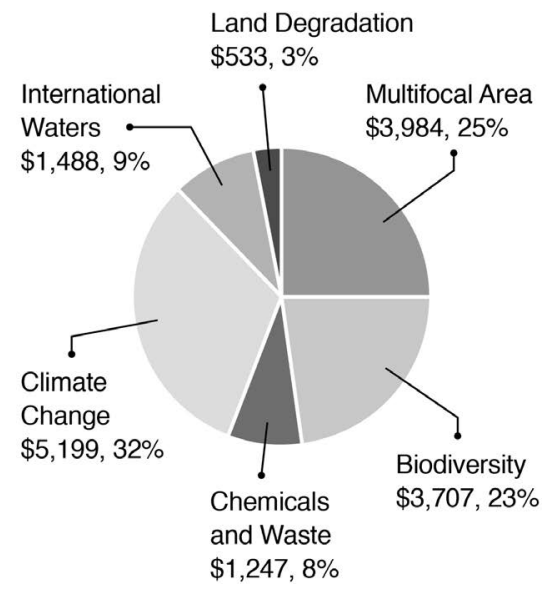

Figure 1.1 GEF projects by focal area

Against this backdrop, the GEF plays a very important role in reducing environmental stresses, improving biodiversity, and reducing deforestation. Since 1992, the GEF has invested over $\$ 16.1$ billion and leveraged $\$ 94.2$ billion in additional resources for more than 4,500 projects in 170 countries (GEF 2020). Through four funding modalities - full-size projects, medium-size projects (less than $\$ 2$ million), enabling activities, and the Small Grants Programme - the GEF implements targeted interventions in its five focal areas and three integrated approach program categories. Figure 1.1 shows the distribution of GEF's resources in its various focal areas - biodiversity, climate change, land degradation, chemicals and waste, and international waters, along with projects that cut across more than one focal area, referred to as multifocal projects. ${ }^{5}$

\section{The GEF institutional framework}

The GEF was set up in 1991 as a pilot program within the World Bank. In 1992, after the Rio Earth Summit, the GEF was restructured with three initial implementing agencies: the World Bank, the United Nations Development Programme (UNDP), and the United Nations Environment Programme (UNEP). Over the years, the GEF structure, governance, and partnership framework have evolved, including a gradual and significant increase to 18 agencies. The expansion of the partnership aimed to increase choice, access, and availability for numerous underserved countries, especially least developed countries (LDCs) and small island developing states (SIDS), based on agency comparative advantage. The GEF continues to be the world's largest funder of public projects and programs that benefit the global environment. 


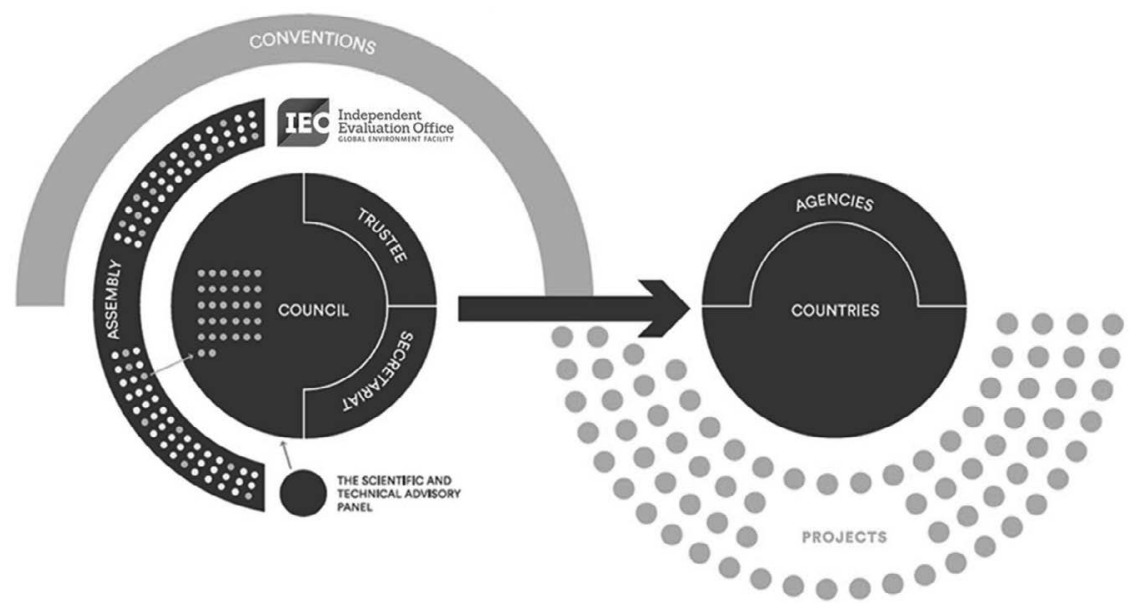

Figure 1.2 The GEF partnership

\section{The GEF partnership structure}

The GEF partnership is an arrangement comprising several entities, as presented in Figure 1.2.

\section{Assembly}

Each of the 183 member countries, or Participants, has a representative at the ministerial level in the GEF Assembly. It meets every three to four years to review general policies; review and evaluate the GEF's operation based on reports submitted to the Council; review the membership of the Facility; and consider, for approval by consensus, amendments to the governing instrument of the GEF.

\section{GEF Council}

The Council is the GEF's main governing body and comprises 32 Members appointed by constituencies of GEF member countries (14 from developed countries, 16 from developing countries, and two from economies in transition). Council Members rotate every three years or until the constituency appoints a new Member. The Council meets twice annually to develop, adopt, and evaluate the operational policies and programs for GEF-financed activities. It also reviews and approves the work program (projects submitted for approval), making decisions by consensus.

\section{Conventions}

The GEF provides funding to assist developing countries in meeting the objectives of international environmental conventions. The GEF serves as a financial mechanism to five conventions: the CBD, the UNFCCC, 
the Stockholm Convention on POPs, the UNCCD, and the Minamata Convention on Mercury. The conventions provide broad strategic guidance to the GEF Council and Assembly. The GEF Council converts this broad guidance into operational criteria for GEF projects.

\section{The Scientific and Technical Advisory Panel}

Six internationally recognized experts in the GEF's key areas comprise the Scientific and Technical Advisory Panel (STAP), which advises the GEF on policies, operational strategies, programs, and projects. STAP members are supported by a global network of experts and institutions. The STAP interacts with other relevant scientific and technical bodies, particularly with the subsidiary bodies of the CBD, the UNFCCC, the UNCCD, and the Stockholm Convention on POPs. The UNEP, which hosts the STAP Secretariat, acts as its liaison with the GEF.

\section{The Independent Evaluation Office}

The GEF Independent Evaluation Office (IEO) is the core of the GEF partnership-wide evaluation function. The IEO has the central role of ensuring the independent evaluation function within the GEF and operates as an organizational unit independent of GEF Secretariat management or agency. The IEO prepares the overall evaluation policy for the GEF to be endorsed by the Council, sets the minimum requirements for evaluation in the GEF partnership, sets an evaluation agenda for approval by the Council, validates the terminal evaluations of projects and programs by agencies, conducts a broad spectrum of independent evaluations, shares evaluative evidence and lessons learned within and outside the GEF, and develops recommendations for the partnership to improve the effectiveness of GEF policies and programs. The IEO works in close partnership with the global evaluation community to remain on the cutting edge of emerging and innovative methodologies in environmental evaluation. It consults and collaborates with all relevant partners to foster a network of evaluation professionals who may add value to GEF operations and results (GEF IEO 2019). Chapter 2 explores the origins and the role of the IEO.

\section{Trustee}

The World Bank serves as the GEF Trustee, administering the GEF Trust Fund of contributions by donors. Among its responsibilities, the Trustee helps mobilize resources for the trust fund, disburses funds to GEF Agencies, prepares financial reports on investments and use of resources, and monitors application of budgetary and project funds.

\section{The GEF Secretariat}

The Secretariat coordinates overall implementation of GEF activities and is led by a Chief Executive Officer (CEO)-Chairperson, who is appointed for 
a four-year term by the Council, renewable for one additional term. The Secretariat implements decisions of the Assembly and the Council. Among other responsibilities, it coordinates and oversees programs, ensures policies are implemented in consultation with the GEF Agencies, chairs interagency group meetings to ensure effective collaboration among the GEF Agencies, and coordinates with Secretariats of the conventions.

\section{GEF Agencies}

The Agencies are the operational arm of the GEF. They work closely with project proponents - government agencies, civil society organizations, and other stakeholders - to design, develop, and implement GEF-funded projects and programs.

\section{GEF Focal Points}

Each of the GEF member countries has designated government officials responsible for GEF activities who serve as the liaison with the Secretariat and the GEF Agencies. All of the GEF member countries have Political Focal Points, who focus mainly on governance, including policies and decisions, and relations between member countries within their constituencies.

Recipient countries eligible for GEF support also have Operational Focal Points, who are responsible for operations of GEF activities within their countries. This includes reviewing and endorsing project proposals to ensure that they are in line with national priorities and strategies.

\section{Conflict Resolution Commissioner}

Working directly with member countries, GEF Agencies, and affected stakeholders, the Commissioner helps resolve disputes and address complaints and other issues relevant to GEF operations. The Commissioner reports directly to the CEO and allows the CEO to expand feedback and respond more quickly to issues and concerns that may arise in GEF-funded projects.

\section{Organization of this book}

To explore the relevance, effectiveness, and efficiency of environmental interventions and explore the links between environment and socioeconomic outcomes in developing countries, we draw primarily on the Sixth Comprehensive Evaluation of the GEF (OPS6), completed in 2017, and the component evaluations conducted by the GEF IEO. OPS6 presented rich evidence on the impacts of environmental interventions and the policies that support the implementation of such programs through a partnership arrangement. As noted in the description of the GEF structure, independent evaluation in the GEF is not influenced by program or agency implementation 
units. It reports directly to the Council, which approves the IEO work program and budget. Although the IEO engages with other constituents of the GEF partnership to enhance the utility of evaluation, it is financially and behaviorally independent in the conduct of its evaluations. As such, the results and the cases we present in this book have not been influenced by program participants.

Chapter 2 provides a historical perspective and discusses evolution of the evaluation function in the GEF. It demonstrates the shift in evaluation from management to an independent unit and the importance of the IEO within the overall GEF structure.

The evaluation process is an important determinant of the quality of evaluation. Development of the approach paper, stakeholder engagement throughout the process, and a well-developed report with evidence and clear communication of findings are important processes. Chapter 3 presents the framework and the approach of the Sixth Comprehensive Evaluation on which this book is based and discusses the crucial role of evaluation in the GEF replenishment process.

Chapter 4 describes the methods and tools the IEO uses and explores their links with the evaluation questions. We demonstrate the usefulness of remote sensing and geospatial methods for measuring environmental impact: they provide reliable and cost-effective baseline information, help detect changes over time, and track progress toward the achievement of environmental and other development targets. These methods complement our other evaluation approaches, and we discuss the advantages of a mixed-methods approach.

Chapter 5 presents the overall performance results of the GEF portfolio and various factors driving these results. We look deeper by exploring performance ratings by region and consider the attributes affecting performance: project design, quality of implementation and execution, and cofinancing. The chapter also explores the longer term impacts and sustainability of GEF interventions and the channels through which these are achieved. Central to success for impact and sustainability is the concept of broader adoption, which occurs when governments and other stakeholders adopt, expand, and build on GEF interventions, based on their initial success.

In its 2020 Strategy, the GEF recognized that incremental environmental strategies alone are not sufficient given the unprecedented nature of the pressures facing the earth's ecosystems; rather, transformative change is imperative. Chapter 6 develops a framework for evaluating transformative change and presents evidence from the GEF experience.

Evaluations must be timely and of good quality to be useful. Chapter 7 discusses the usefulness of OPS6 and its role in the replenishment process of the GEF. We underscore the importance of delivering an evaluation in a timely manner with good quality and stakeholder participation to influence future programming and financing.

In the final chapter, we reflect on the results of GEF programs and present lessons learned from the IEO's program of evaluations over a period of 


\section{Introduction}

five years. These lessons are relevant for evaluators, environmental practitioners, and policymakers and applicable to the current pandemic situation.

\section{Notes}

1. Geeta Batra and Juha Uitto managed the component evaluations that were conducted by staff and consultants of the IEO and drafted the overall comprehensive evaluation (OPS6). Osvaldo Feinstein is an independent consultant and was part of the advisory panel for OPS6.

2. https://sustainabledevelopment.un.org/post2015/transformingourworld.

3. https://unfccc.int/process-and-meetings/the-paris-agreement/the-paris-agreement.

4. https://www.undrr.org/implementing-sendai-framework/what-sendai-framework.

5. Data as of June 30, 2020.

\section{References}

Berardelli, J. 2020. "Human Impact on the Environment May Make Pandemics More Likely, Experts Warn." CBS News April 2, 2020. www.cbsnews.com/news/ coronavirus-environment-pandemic-infectious-diseases/

GCA. 2019. Adapt Now: A Global Call for Leadership on Climate Resilience. https://cdn.gca. org/assets/2019-09/GlobalCommission_Report_FINAL.pdf

GEFIEO. 2019. GEF Evaluation Policy 2019. Washington, DC: GlobalEnvironment Facility Independent Evaluation Office. www.gefieo.org/evaluations/gef-me-policy-2019.

IPCC. 2018. Global Warming of $1.5^{\circ} \mathrm{C}$. IPCCSpecial Report. www.ipcc.ch/sr15/

Jones, K.E., N.G. Patel, M.A. Levy, A. Storeygard, D. Balk, J.L. Gittleman, and P. Daszak. 2008. "Global Trends in Emerging Infectious Diseases." Nature 451: 990-993.

Quammen, D. 2020. "We Made the Coronavirus Epidemic." The New York Times January 28, 2020. www.nytimes.com/2020/01/28/opinion/coronavirus-china.html

Steffen, W., K. Richardson, J. Rockström, S.E. Cornell, I. Fetzer, E.M. Bennett, R. Biggs, S.R. Carpenter, W. De Vries, C.A. De Wit, C. Folke, D. Gerten, J. Heinke, G.M. Mace, L.M. Persson, V. Ramanathan, B. Reyers, and S. Sörlin. 2015. "Planetary Boundaries: Guiding Human Development on a Changing Planet." Science 347: 736, 1259855.

UN. 2015. Trends in Private Sector Climate Finance. Climate Change Support Team of the UN Secretary General. https://reliefweb.int/sites/reliefweb.int/files/resources/SGTRENDS-PRIVATE-SECTOR-CLIMATE-FINANCE-AW-HI-RES-WEB1.pdf

United Nations Department of Economic and Social Affairs. 2015. "Transforming Our World: The 2030 Agenda for Sustainable Development." https://sdgs.un.org/ 2030agenda

World Economic Forum. 2020. The Global Risks Report 2020. www.weforum.org/reports/ the-global-risks-report-2020

Yeo, S. 2019. "Where Climate Cash Is Flowing and Why It's Not Enough." Nature 573: 328-331. www.nature.com/articles/d41586-019-02712-3\#: :text=The\%20OECD's\% 20latest $\% 20$ assessment $\% 2$ C $\% 20$ released,a\%20total $\% 20$ of $\% 20 \% 2471.2 \% 20$ billion $\% 20$ 


\section{Evaluation at the GEF}

For an organization such as the Global Environment Facility (GEF), which assists numerous partners across the world in addressing some of the most pressing concerns of our era, a thorough grasp of the outcomes and impacts of its work is essential in planning and making sustainable progress. The purpose of evaluation is to understand why, how, and to what extent intended and unintended results accrue from interventions (whether policies, strategies, programs, or projects) and their impact on various categories of stakeholders. Evaluation provides accountability for the achievement of results and institutional performance and is an important source of knowledge and organizational learning.

\section{The evolving role of evaluation in the GEF}

The GEF evaluation function has evolved significantly over the more than quarter century of the fund's existence. When the Facility was established in 1991 to provide new and additional funding to assist developing countries and countries with economies in transition in meeting their obligations under the new Convention on Biological Diversity (CBD) and the United Nations Framework Convention on Climate Change (UNFCCC), the GEF operated as a pilot facility under the auspices of the World Bank. The World Bank also acted as the trustee for the newly established fund, a role that continues today. The projects were developed and managed by the United Nations Development Programme (UNDP), the United Nations Environment Programme (UNEP), and the Bank according to eligibility criteria. The three implementing agencies were also in charge of monitoring and evaluation (M\&E) of their respective GEF-funded portfolios. The GEF was designed as a partnership between the three agencies, managed by a chairman assisted only by a GEF operations coordinator. In April 1991, a GEF administrator within the World Bank Environment Department started work.

At the end of the three-year pilot phase, at the request of the GEF participants, the three agencies commissioned an independent evaluation to learn from the experiences during the initial period of the GEF and to guide future 
planning (UNDP, UNEP, and World Bank 1994). At this stage, an estimated $\$ 939$ million had been allocated from the GEF trust fund and cofinancing to 112 projects involving 63 countries. The projects were in the four initial focal areas of biodiversity conservation, climate change mitigation, international waters, and reducing ozone-depleting substances. The evaluation had a unique structure that followed the structure of the GEF. Each agency assembled a separate evaluation team with its own coordinator, staff, and evaluation manager from the agency. An independent panel of experts, the Scientific and Technical Advisory Panel (STAP), also was established to guarantee independence and completeness of coverage, and to incorporate the views of nongovernmental organizations (NGOs).

The evaluation of the pilot phase recognized a lack of comprehensive $M \& E$ and dissemination in the GEF, noting that:

The major missing function of the Administrator's Office is a systematic effort to capture and disseminate the experience of the pilot phase. Planning for this work should have been laid out at the beginning of the pilot phase and developed as the program progressed. Although the World Bank started work in February 1993 on a database for its projects, neither UNDP nor UNEP had done so. This work may not fall directly under a communications strategy but a comprehensive GEF monitoring, evaluation, and dissemination strategy and operations plan for the GEF as a whole [emphasis in the original] is essential (UNDP, UNEP, and World Bank 1994, 123-124).

The evaluators further identified this deficiency as one of their main concerns. The report noted that accountability at policy, program, and project levels was diffuse. It recommended the establishment of a GEF Secretariat that was organizationally, administratively, and functionally independent of the implementing agencies. The pilot phase evaluation also recommended making the STAP independent. These recommendations were implemented when the GEF continued as a regular mechanism after the pilot phase.

Recognizing the weakness identified at the pilot phase regarding $M \& E$, the GEF Council in May 1995 decided that the work program would include "operational monitoring and evaluation, scientific and technical monitoring and evaluation, and evaluation of strategic and cross-program issues."1 An M\&E unit was established in April 1998 as part of the GEF Secretariat, headed by a senior M\&E coordinator. ${ }^{2}$ To ensure adequate independence, the coordinator would report directly to the Council on evaluation matters, while being administratively managed by the CEO of the GEF.

In the meantime, the Council was working to strengthen independent evaluation as the partnership grew. ${ }^{3}$ The $\mathrm{M} \& \mathrm{E}$ unit was converted into an $M \& E$ office and its first director ${ }^{4}$ started his initial five-year term in 2005, reporting directly to the Council. The first $M \& E$ policy was approved by the Council through a written procedure on February $6,2006 .{ }^{5}$ This policy took 
the minimum standards approach for GEF-funded activities, covering project design, application of $\mathrm{M} \& \mathrm{E}$ at the project level, and requirements for terminal evaluations for all projects above $\$ 500,000$. The policy also required concrete and fully budgeted M\&E plans with indicators, baselines, and designated responsibilities for all projects. The $\mathrm{M} \& \mathrm{E}$ policy confirmed the independence of the $M \& E$ Office and its direct reporting relationship to the Council. In October 2013, the Council approved the change of the office's name to the GEF Independent Evaluation Office (IEO). The IEO's role was to conduct independent evaluations of the GEF's performance and impact, and to set and validate the standards for the evaluation function within the partnership. The independence of IEO has been further codified in the GEF Instrument. ${ }^{6}$

The M\&E policy was revised in 2010 to include reference to the GEF results-based management system, a better definition of the roles and responsibilities for the different actors in the partnership, reference to programs and jointly implemented projects, and emphasis on knowledge management. ${ }^{7}$ In 2019, the M\&E policies were separated, retaining the IEO as custodian of the evaluation policy ${ }^{8}$ while placing monitoring under the purview of the GEF Secretariat. This decision to differentiate the two functions followed international best practice and is similar to the way M\&E are organized in global development institutions such as UNDP and the World Bank. The evaluation policy also recognized the expanded GEF partnership, which by this time comprised 18 agencies, including some international environmental NGOs and national and regional organizations in major recipient countries.

\section{Evaluation architecture in the GEF}

In the GEF partnership, evaluation is a shared responsibility. The IEO is the custodian of the function and is in charge of independent evaluation, but the agencies are responsible for evaluating their own projects and programs. The IEO provides guidance to the agencies regarding the design and conduct of the evaluations to ensure that all project and program evaluations use similar approaches to cover key aspects, notably the achievement of global environmental objectives.

Because the IEO work program and budget are approved by the GEF Council and the IEO director reports directly to the Council, a feedback loop is built in with policymaking, a factor that is essential in ensuring use of evaluation. Figure 2.1 provides a schematic presentation of how evaluation is positioned in the GEF.

With responsibility for evaluating the projects and programs they implement, the GEF Agencies are organized in myriad ways. One challenge is that each of the GEF Agencies has a unique strategy and organizational structure for evaluation. In some cases, such as UNEP, a dedicated evaluation office conducts all project evaluations. In others, such as UNDP and the World Bank, the independent evaluation units validate project-level evaluations conducted or commissioned by the operational units in the agencies. 
- Semi-annual evaluation reports

- Comprehensive Evaluation of the GEF

- Annual Work Program and budget GEF Council

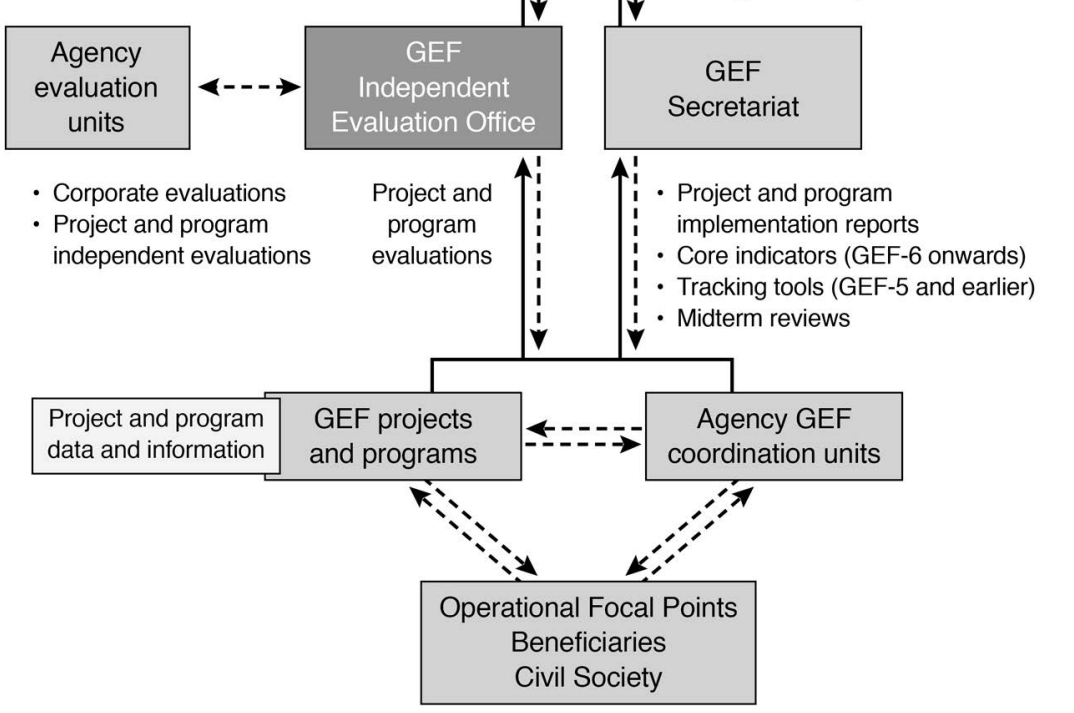

Figure 2.1 Evaluation in the GEF

Several other agencies have no IEO. In all cases, the agencies must ensure that all GEF-funded projects are subject to a terminal evaluation.

The IEO receives the terminal evaluation reports from the agencies, either through their evaluation unit or, in most cases, directly from the agency GEF coordination unit. The IEO then validates the reports. The terminal evaluations serve as building blocks for the IEO's own evaluations, most important of which is the annual performance report that draws upon the project evaluations to analyze GEF performance in terms of outcomes achieved and their likely sustainability. The terminal evaluation reports also allow the IEO to evaluate the quality of the project M\&E systems.

The IEO conducts a variety of types of evaluations, ranging from performance and organizational evaluations to analyses of the impact of GEF-funded projects and programs. The unit of analysis may be a focal area or a specific theme (for instance, biodiversity mainstreaming or fisheries), or it may be a country or a strategic cluster of countries (such as least developed countries or small island developing states). On the policy side, the IEO evaluates the design and implementation of policies related to crosscutting themes, including gender and indigenous peoples. Process evaluations focus on institutional and procedural issues as they affect the GEF's effectiveness and efficiency. 
The IEO maintains a relationship with the evaluation offices of the agencies where these are in place. Apart from validation of terminal evaluation reports, the IEO cooperates with other evaluation units in setting evaluation standards and conducting joint evaluations. Although not a joint evaluation in a strict sense, the evaluation of the role of local benefits in global environmental programs (GEFEO 2006) brought together participants from several GEF partners, including UNDP, the World Bank, and the GEF Secretariat. The first real joint evaluation focused on the GEF activity cycle, a topic that was of considerable interest to all agencies and thus involved all of them (GEFEO 2007). Since then, the IEO has conducted several joint evaluations, usually with one partner evaluation unit from an implementing agency. Joint evaluations can be challenging because they require additional coordination efforts; this can increase transaction costs or result in cost savings, such as by sharing the costs of surveys. Another challenge is that each of the agencies tends to see projects and programs from its own unique perspective. Yet, for the same reason, joint evaluations can also be enriching (Carugi and Bryant 2019).

All evaluations conducted by the IEO are presented to the GEF Council alongside a management response prepared by the GEF Secretariat. The Council makes decisions on the required follow-up after considering the evaluation and management response together. The IEO monitors the implementation of the decisions and reports back to the Council on an annual basis.

The culmination of the IEO work is the Comprehensive Evaluation of the GEF (formerly the Overall Performance Study [OPS]) conducted every four years as a prelude and input to the replenishment negotiations for the GEF trust fund.

In its independent assessment of the GEF, the Multilateral Organizations Performance Assessment Network (MOPAN) identified six strengths, two of which correspond to the IEO: "Strategies are responsive to wider guidance and informed by a comprehensive and independent evaluation" and "The IEO plays an important role in delivering comprehensive, independent evaluations and in ensuring the quality of monitoring and evaluation systems" (MOPAN 2019, 39, Box 4).

\section{Overall Performance Studies of the GEF}

In October 1996, the GEF Council requested that the senior M\&E coordinator undertake a study of the GEF's overall performance. The M\&E unit commissioned a group of independent consultants to conduct the OPS, advised by a senior advisory panel of experienced and knowledgeable persons in equal numbers from the global north and south (Porter et al. 1998). However, the study was unable to assess the effectiveness of the M\&E program, because it was still in early stages of implementation at the time (Porter et al. 1998, 90).

In time, such studies were institutionalized and became the backbone of the evaluation work programs tied to the four-year replenishment cycle of the GEF. 
The second OPS (GEF 2002) was again commissioned by the senior M\&E coordinator, conducted by an independent team of consultants, ${ }^{9}$ and supported by the M\&E unit. The unit at that time consisted of the senior M\&E coordinator, three M\&E specialists, and support staff. ${ }^{10}$ OPS2 was charged with gauging the GEF results and impacts during the first ten years of the Facility's existence, a task that had eluded the earlier evaluations. This second evaluation was much more ambitious than the previous ones, as the core team of eight and a large group of national consultants embarked on verifying the results on the ground, traveling to 11 recipient countries.

Although OPS2 shed considerable light on GEF operations at the country level, its findings and conclusions pertained mostly to processes. The GEF Council was becoming impatient with regard to learning about the actual results in terms of environmental improvements. At the same time, the Council had concerns about the independence of the M\&E unit, which was an integral part of the GEF Secretariat. When the senior M\&E coordinator was launching OPS3 in 2003, the Council requested that the evaluation be conducted by a group of consultants not associated with the GEF or its implementing agencies. The Council approved terms of reference for the evaluation in April $2004^{11}$ and, following a bidding process, assigned the project to a US-based consulting firm, ${ }^{12}$ which set out to assess progress toward environmental results (GEF 2005). OPS3 also assessed the effects of GEF structures on the Facility's performance. During OPS3, the M\&E unit was converted into the independent M\&E Office (the GEF Evaluation Office [GEFEO]), which later became the IEO. The evaluation recommended that the $M \& E$ Office must "continue to evolve the understanding of $M \& E$ within the GEF" and that, together with the GEF Secretariat, the M\&E Office and implementing and executing agencies should "ensure that M\&E are covered at all levels," including project, portfolio, country, network, and global environmental management (GEF 2005, p. 57).

Consequently, with the technical strengthening and the enhanced independence of the central evaluation function, future OPSs were entrusted to the GEFEO. OPS4 (GEFEO 2010) was the first study undertaken by the GEFEO with its staff in charge of conducting specific evaluations and studies and the director fully responsible for the results. It was also the first OPS to tackle the impact of completed GEF-funded projects. The study innovated with a ROtI (review of outcomes to impacts) evaluation framework, which used a theory-based approach to track project results beyond their completion (GEFEO 2009; Vaessen and Todd 2008).

OPS5 took the approach further in assessing the performance, institutional effectiveness, and impact of the GEF (GEF IEO 2014a). Building up to OPS5, the IEO had begun taking a more systematic approach to the question of impact. The IEO conducted impact evaluations for a geographically based cluster of projects and programs around the South China Sea and adjacent areas (GEFEO 2012), projects and programs related to climate change mitigation (GEF IEO 2014b), and, later, protected areas and protected area systems (GEF IEO 2016). 
OPS5 also made the point that in other organizations, evaluations of such a broad scope tended to be called "comprehensive evaluations."

Taking the cue from OPS5 and recognizing that these evaluations go far beyond the performance of the GEF - they also cover policies, impacts, institutional effectiveness, and governance of the partnership - the next study was named the Sixth Comprehensive Evaluation of the GEF (GEF IEO 2018). What follows delves deeper into the findings and conclusions of this comprehensive evaluation, the process of its development and implementation, and the factors that enhanced its utility and guaranteed its use by the various stakeholder groups.

\section{Notes}

1. General Requirements for a Coordinated GEF-wide Monitoring and Evaluation System. Council document GEF/C.04/06 May 1995.

2. Jarle Haarstad.

3. The initial three Implementing Agencies (UNDP, UNEP, and the World Bank) expanded to ten with the addition of FAO, IFAD, UNIDO, African Development Bank, Asian Development Bank, European Bank for Reconstruction and Development, and the Inter-American Development Bank.

4. Rob D. van den Berg.

5. GEF M\&E Office: Progress Report of the Director. GEF/ME/C.28/1.

6. The GEF shall have an Assembly, a Council, and a Secretariat including an independent evaluation office. In accordance with paragraph 24, a STAP shall provide appropriate advice. Paragraph 11. Instrument for the Establishment of the Restructured Global Environment Facility. GEF September 2019.

7. Revision of the GEF Monitoring and Evaluation Policy. GEF/ME/C.39/06/Rev.01.

8. The GEF Evaluation Policy. GEF/ME/C.56/02/Rev.01.

9. The team leader was Leif Christoffersen, a former senior World Bank Officer.

10. One of the current authors, Juha Uitto, joined the unit as M\&E specialist in 1999 at a time leading up to OPS2.

11. GEF/C.23/4.

12. ICF.

\section{References}

Carugi, C., and H. Bryant. 2019. "A Joint Evaluation with Lessons for the Sustainable Development Goals Era: The Joint GEF-UNDP Evaluation of the Small Grants Programme." American Journal of Evaluation 41 (2): 182-200. https://doi.org/10.1177/ 1098214019865936.

GEF. 2002. The First Decade of the GEF. Second Overall Performance Study. Washington, DC: Global Environment Facility.

GEF. 2005. OPS3: Progressing toward Environmental Results. Third Overall Performance Study of the Global Environment Facility. Washington, DC: Global Environment Facility.

GEFEO. 2006. The Role of Local Benefits in Global Environmental Programs. Evaluation Report No. 30. Washington, DC: Global Environment Facility Evaluation Office.

GEFEO. 2007. Joint Evaluation of the GEF Activity Cycle and Modalities. Evaluation Report No. 33. Washington, DC: Global Environment Facility Evaluation Office. 


\section{Evaluation at the GEF}

GEFEO. 2009. The ROtI Handbook: Towards Enhancing the Impacts of Environmental Projects. Methodological Paper \#2. Washington, DC: Global Environment Facility Evaluation Office. GEFEO. 2010. OPS4: Progress towards Impact. Fourth Overall Performance Study of the GEF. Washington, DC: Global Environment Facility Evaluation Office \& Conservation Development Center.

GEFEO. 2012. The GEF in the South China Sea and Adjacent Areas. Evaluation Report No. 75. Washington, DC: Global Environment Facility Evaluation Office.

GEF IEO. 2014a. OPS5: At Crossroads for Higher Impact. Fifth Overall Performance Study of the GEF. Washington, DC: Global Environment Facility Independent Evaluation Office.

GEF IEO. 2014b. Impact Evaluation on Climate Change Mitigation: GEF Support to Market Change in China, India, Mexico, and Russia. Evaluation Report No. 90. Washington, DC: Global Environment Facility Independent Evaluation Office.

GEF IEO. 2016. Impact Evaluation of GEF Support to Protected Areas and Protected Area Systems. Washington, DC: Global Environment Facility Independent Evaluation Office.

GEF IEO. 2018. The GEF in the Changing Environmental Finance Landscape. Sixth Comprehensive Evaluation of the GEF. Washington, DC: Global Environment Facility Independent Evaluation Office.

MOPAN. 2019. Global Environment Facility (GEF) 2017-18 Performance Assessment. Multilateral Organisation Performance Assessment Network. www.mopanonline.org/ assessments/gef2017-18/GEF\%20Report.pdf.

Porter, G., R. Clémençon, W. Ofosu-Amaah, and M. Philips. 1998. Study of GEF's Overall Performance. Washington, DC: Global Environment Facility.

UNDP, UNEP, and World Bank. 1994. Global Environment Facility: Independent Evaluation of the Pilot Phase. Washington, DC: The World Bank.

Vaessen, J., and D. Todd. 2008. "Methodological Challenges of Evaluating the Impact of the Global Environment Facility's Biodiversity Program." Evaluation and Program Planning 31: 231-240. 


\section{Evaluation and the replenishment process}

Most Global Environment Facility (GEF) funding takes the form of grants to recipient countries; thus, the fund needs to be replenished periodically. Taking place in a highly political context, the replenishment process is an extended technical and financial negotiation in which evaluation has a significant role that has expanded greatly since the inception of the GEF almost three decades ago.

\section{The replenishment context}

The GEF provides funding to developing countries in the form of grants, with the exception of a small portion provided through the non-grant instrument financing window. The Facility operates through a four-year funding cycle, at the end of which the donors replenish the fund. Seven replenishments of the GEF have occurred to date, showing a general upward trend in the amounts of funding provided to the GEF, followed by a slight decline in later replenishments (see Figure 3.1).

Despite this generally positive trend in funding, each replenishment process has been a challenging exercise taking place against the political and financial backdrop of the time. Economic downturns tend to shrink the pot of money available for international cooperation and, consequently, reduce donor governments' willingness and capacity to dole out funding. Like all international initiatives, the GEF has also had to deal with the vagaries of trends in international cooperation that tend to be reflected in financing priorities.

Although the GEF was established explicitly to bring new and additional money to the table, this has, in fact, proven an illusion. At the Earth Summit ${ }^{1}$ in 1992, the GEF became the official financial mechanism to the newly minted Rio Conventions, with emphasis that the funding provided would be over and above official development assistance (ODA). The developing countries would be responsible for identifying projects to meet their own interests and ODA would support these efforts. The intended role of the GEF was to ensure that the development would become environmentally sound. This was in the global interest and the industrialized countries would be responsible for covering the costs. This reflected the historical responsibility 


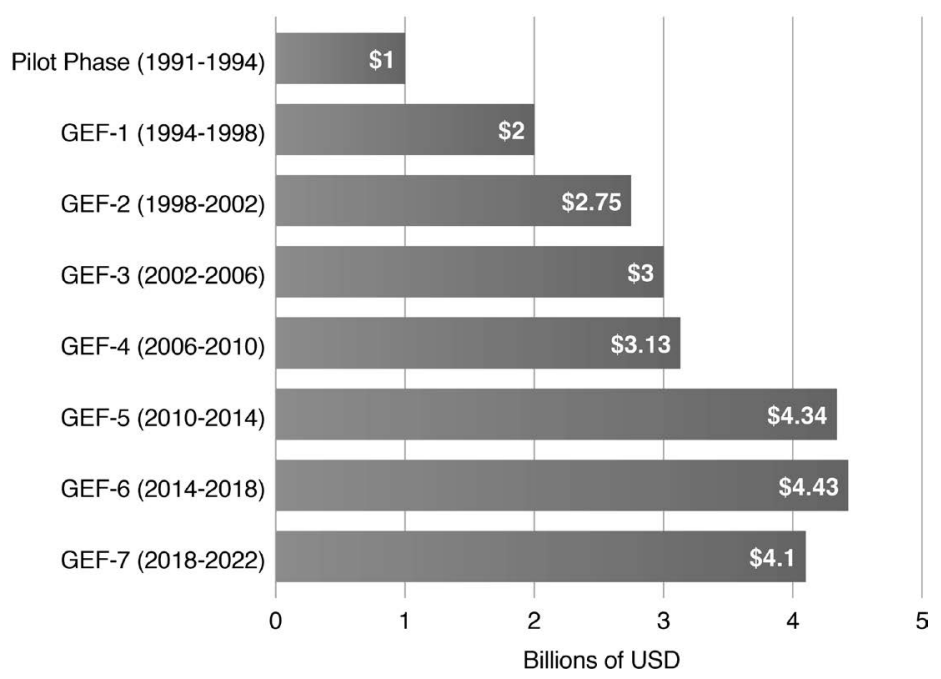

Figure 3.1 GEF funding by replenishment period

of the developed countries for climate change, which led to the inclusion of the principle of "common but differentiated responsibilities" embedded in the UN Framework Convention on Climate Change. ${ }^{2}$ The developing countries had a legitimate claim to development funding; protecting the global environment was seen not as part of development but as a separate objective. Some developing countries and civil society organizations, in fact, perceived the GEF as a donor instrument to dictate a Northern environmental agenda upon the Global South (Gupta 1995). In the donor countries of the Global North, however, politicians and the general public found this distinction to be rather academic: aid for the developing countries and countries with economies in transition to protect the global environment was still aid, and the money would most often be channeled through ODA mechanisms. Soon after the Earth Summit, an economic downturn diminished support for foreign aid in many countries and reduced the overall flows. Money channeled to the GEF was, in practice, taken away from somewhere else. And that was acceptable, because one of the purposes of the GEF was the greening of ODA.

The GEF has always had to compete for funding with other priorities, both within and outside ODA. Despite the urgency and massive needs for tackling global environmental degradation, biodiversity conservation, harmful chemicals management, and climate change, there was a limit as to how large the GEF pie could grow. Nominal formulas were established to determine the level of participating countries' contributions in relation to how much the largest contributor ${ }^{3}$ put into the fund (Clémençon 2006). Particularly in earlier years, with perceptions of a clearer division between economic development and environmental protection, the GEF was seen as niche funding for the global environment. 
Today the international development community better understands the close interlinkages between environment and development - indeed, the Sustainable Development Goals (SDGs) stand on three pillars: social, economic, and environmental. However, the GEF-8 replenishment process in 2021-2022 will be taking place under the shadow of recovery from the global stress generated by the COVID-19 crisis, and the GEF will be competing for funding with organizations and programs dealing more directly with health.

Within the GEF, the different environmental priorities have had to compete with each other for a funding share in what is essentially a zero-sum game. In early years, the allocations were made simply between the focal areas of biodiversity, climate change, and international waters, as well as support to the phasing out of ozone depleting substances. As the GEF has grown more complex, the allocation process has become more multifaceted, but the key question remains: how to prioritize between the different areas and types of intervention within a limited financial envelope?

\section{Replenishment requires evaluation}

Making informed decisions about the GEF programing focus requires knowledge of what has proven effective in tackling the global environmental challenges in the organization's purview. Systematic evaluation is one of the best ways of generating evidence of past performance; factors contributing to results (or lack thereof); and the likelihood of achieving desired outcomes and impacts in the most effective, efficient, and sustainable manner. Each of the replenishments has been preceded by a comprehensive evaluation, an overall performance study (OPS) as described in Chapter 2.

The negotiations for the GEF's seventh replenishment (GEF-7) illustrate the vital role of evaluation. The Sixth Comprehensive Evaluation of the GEF (OPS6) became one of the three key documents informing the process. The other two were the GEF-7 Policy Agenda and Programming Directions that were prepared by the GEF Secretariat - these documents initially took into account evaluative evidence emerging from the ongoing OPS6 and were modified until the very end of the replenishment process based on the replenishment participants' deliberations, which were also informed by evaluation.

Participants in the replenishment process are countries that commit to investing a minimum of $\$ 3$ million into the GEF trust fund. This opens the door to allow developing countries to become replenishment participants while still remaining recipients of GEF support. In the case of GEF-7 replenishment, countries such as Brazil, China, Côte d'Ivoire, Ethiopia, India, and South Africa made these contributions, in addition to the traditional donors from the Global North.

Of course, each of the countries and groups of countries has its own priorities that it seeks to promote for either technical or political reasons. A partnership like the GEF also has other interested groups advocating for their own interests. The most important group is the recipient countries that are 
represented in the replenishment meetings through country constituency groupings. Another important stakeholder group consists of the 18 agencies that have direct access to GEF funding and implement GEF-funded projects and programs.

A fundamental issue in replenishment pertains to country allocations. Proceeding entirely on the basis of where the biggest issues affecting the global environment can be tackled most effectively might lead to favoring large, megadiverse countries such as Brazil, host to the largest part of the world's most significant rainforest, where environmental benefits can be achieved on multiple fronts by addressing biodiversity conservation, deforestation, land degradation, carbon sequestration, water management, fisheries, etc. Attention also must be paid to countries that have fewer resources of their own, including least developed countries (LDCs) and small island developing states (SIDS). Supporting this latter point is the fact that many donors consider GEF funding as part of their ODA, which often focuses on reducing poverty. This has also led to discussions about the funding share that goes to middle-income countries. In response, the GEF established an elaborate resource allocation system, originally the Resource Allocation Framework and later modified into the System for Transparent Allocation of Resources (STAR).

The role of evaluation under these circumstances is to provide technical and scientific evidence regarding past performance, allowing the replenishment participants to make informed decisions regarding policies and programs within the current socioeconomic and political context. The evaluative evidence pertains to the achievement of impacts, organizational performance, and the effectiveness of institutional and governance arrangements.

\section{How the process incorporates evaluation}

Setting up the evaluation agenda to contribute to such a complex process as the GEF replenishment requires considering several important factors in detail. The evaluation must address all of the key aspects that have a bearing on the policies and programing directions of the next GEF phase. The evaluative evidence presented must be credible - and be perceived as such. Extensive effort and consultation go into defining the focus, scope, approach, and methodologies of the overall evaluation and all the component studies that contribute to it. The analyses conducted by the GEF Independent Evaluation Office (IEO) must encompass as broad a set of evidence as possible to allow for triangulation of findings (Carugi 2016). The IEO must also be seen as independent and impartial in posing the evaluation questions and providing answers to them.

Another key aspect of utility is timeliness. We may produce detailed evidence based on unassailable and thorough analysis, but if it comes too late, it will be unusable (Uitto 2016). This poses a difficult dilemma. On one hand, conducting the evaluations as late in the process as possible will reflect the latest development in programing and give outcomes time to emerge. On the 
other, decision-makers need evaluation results as early as possible to make the best use of them. These issues are considered in more detail in Chapter 7.

Our development of OPS6 started with a comprehensive approach paper (GEF IEO 2016) that first set the stage for the evaluation, including the environmental context. It further defined the scope of the evaluation, including the main aspects to be covered in terms of results and impact, and organizational, institutional, and governance topics. It presented the specific questions that the evaluation would seek to answer and the approach taken. The approach paper also identified all the sources of evidence to be used, including the component evaluations and studies that would feed into the larger comprehensive evaluation. Finally, the approach paper provided a detailed timeline for the evaluation.

We also set up an independent advisory panel consisting of five internationally renowned experts, carefully selected for their expertise in a range of relevant subject matters, evaluation itself, and institutional knowledge. The panel also had good geographic and gender balance. Their first job was to review and comment on the approach paper and they played a critical role in finalizing the full evaluation and helping the IEO to craft the recommendations. Their presence also added to the credibility of the evaluation.

The IEO developed the approach paper in a consultative mode, seeking the inputs and feedback from key stakeholders including the GEF Secretariat and agencies. We circulated the approach paper for advance review and presented it to the GEF Council for debate and decision-making in June 2016. This was an important step because it allowed the Council to take ownership of the evaluation and to advise the IEO of additional items the Council wanted to emphasize. This also created the opportunity for consensus on the timeline for presenting findings to the replenishment process.

We identified the key audiences for the evaluation as the Council, the replenishment participants (also represented within the Council), and the GEF Secretariat, who would need to use the emerging evaluation findings in developing the Policy Agenda and Programming Directions documents for GEF-7. Other primary audiences included the GEF Agencies and civil society organizations in the GEF network. Secondary audiences included interested outside parties, such as academics focused on the global environment.

In parallel with the preparations for OPS6, the Council agreed on the replenishment schedule. There would be four meetings:

- March 2017, hosted by the World Bank as the GEF Trustee in its Paris office

- October 2017, hosted by the Government of Ethiopia in Addis Ababa

- January 2018, hosted by Government of Brazil in São Paulo

- April 2018, hosted by the Government of Sweden in Stockholm

To make the greatest use of the data, the Council requested that the IEO present early emerging findings at the Paris meeting - only nine months after 
the approval of the approach paper. This presented a challenge to the IEO to focus on completing as many of the component evaluations as possible. This was a departure from the earlier practice of presenting a draft OPS report to the replenishment meetings only once all component evaluations had been assembled. The old practice did provide the replenishment participants with a complete view of GEF performance, but the inputs came late for inclusion in the policy and programing documents. We saw the benefits of the new approach and concentrated on completing as many of the component evaluations as possible within the timeline.

By the first replenishment meeting, we had completed or nearly completed every component evaluation and study. Many were not in final report form that could be shared, so we decided to prepare a four-page note on every evaluation. This note explained what the evaluation was about, the approach taken and the portfolio and case studies covered, and the findings and conclusions (also see Chapter 7). For evaluations of projects or programs in their early stages, we included only the emerging findings of which we could be quite confident. These four-page notes were shared with the replenishment participants at the first meeting with a lengthy presentation by the IEO director. The presentation led to an even longer discussion as the replenishment participants wanted to spend adequate time to understand the implications of each evaluation that was presented.

This meeting was a very influential moment in the GEF-7 replenishment process. It enhanced the participants' understanding of the issues and of the GEF's strengths and weaknesses. It also allowed all of this evaluation information to flow into the preparation of the Policy Agenda and Programming Directions documents.

In the following months, the IEO completed all of the component evaluations and compiled a full draft OPS6 report during the summer of 2017. A critical component of the preparation was a workshop in June 2017 with the advisory panel, in which the panel members collaborated with IEO management and staff to tease out the large themes that the evidence brought out. Following the workshop, IEO management and staff wrote the summary report that became OPS6 (GEF IEO 2017).

The completed draft evaluation report was presented at the second replenishment meeting in Addis Ababa in October 2017, when the replenishment participants discussed the policy and programing lines for GEF-7. The evaluation was the key document to inform these discussions. Following the meeting in which the participants scrutinized the final draft and asked some further questions for elaboration, the IEO finalized the OPS6 report, including a note by the independent advisory panel. It was then presented to the GEF Council meeting in December 2017 for endorsement.

At that point, the evaluators' job was done. IEO management participated in the third meeting in Brazil in January 2018 to be available for any clarifications and answer any detailed questions. At this meeting, the participants thrashed out the Policy Agenda and Programming Directions documents 
and the detailed allocation of funds between the different programs and focal areas for GEF-7. OPS6 fulfilled its purpose: throughout the meeting, the donors referred repeatedly to the document in making decisions between various alternatives.

At the fourth and final meeting in Stockholm, all of the replenishment participants confirmed their pledges to the GEF trust fund for GEF-7.

\section{The OPS6 component evaluations and synthesis}

The evaluations underpinning OPS6 commenced after the replenishment in 2014 with the approval of the IEO work program and budget for the sixth replenishment. However, early in the GEF-6 replenishment period, the theme for OPS6 was not finalized and the IEO work program was designed more as a collection of interesting evaluation topics intended to address gaps in previous years or continue evaluations that had begun during the previous replenishment period. A change in IEO management in fall of 2014 initiated the actual planning for OPS6: the report was to be delivered in October 2017 with early findings due in March 2017. We had two years to make sure we had enough evidence on performance and impacts of the GEF and on the institutional issues addressing GEF governance and policies. We revisited the work program in fall 2015 and embarked on several studies simultaneously to be able to meet the timeline. A few work planning retreats helped us develop a theme for OPS6 that focused on the GEF's role in the environmental finance landscape, review how various ongoing evaluations would contribute to the comprehensive evaluation, and assess the evaluation gaps we needed to fill. As described above, the approach paper ${ }^{4}$ for OPS6 was developed through a broad consultative process and was approved at the June 2016 GEF Council meeting.

In response to the consultative process, OPS6 focused on two related themes:

1 Relevance of the GEF strategy and the global contribution of the GEF, including governance and institutional issues

2 Performance and impact of the GEF

One of the main reforms that the GEF introduced during GEF-6 consisted of a set of pilot programmatic approaches aimed at addressing the main global environmental challenges through an integrated approach. This new approach included programing of GEF funds to help recipient countries meet their commitments to more than one global convention or thematic area by addressing the underlying drivers of environmental degradation. The GEF-6 Programming Directions set out a rationale for the Integrated Approach Pilot (IAP) programs to address discrete, time-bound, global environmental challenges in line with the targets and goals of the multilateral environmental agreements that the GEF serves (GEF 2014). 
Three IAPs launched during GEF-6 and introduced this new dimension of programing that emphasized integration as a key organizing principle for GEF financing. These programs are structured around major drivers of global environmental degradation. Two programs are global, with one focused on urbanization (the Sustainable Cities IAP) and one on commodity-driven deforestation (the Commodities IAP); the third program addresses sustainability and resilience for food security in Sub-Saharan Africa drylands (the Food Security IAP). GEF financing for these programs was not "siloed" by focal area but was designed to be invested coherently to promote synergies in generating multiple global environmental benefits while also ensuring that any environmental progress does not negatively affect other related socioeconomic objectives. Leading into the seventh replenishment, the GEF Council was very eager for the IEO to provide early insights into the design and implementation of the IAPs, despite the limited time since their implementation.

The IEO responded to the Council's request for early insights into the design and implementation of the IAP programs. Because the IAPs were designed to enhance the GEF's relevance and contribution to increasing global environmental benefits, the IAP evaluation addressed one overarching themes of OPS6: the GEF's relevance and contribution. Since these programs were recently approved, we could not assess the performance, but design elements were reviewed that provided insights into the likelihood for good performance and sustainability. The next section presents the questions addressed under the two main themes addressed in OPS6: GEF relevance and contribution and the GEF's performance and impact - and the evaluative sources of evidence.

\section{Theme 1: GEF relevance and contribution}

The themes addressed under the rubric of the relevance and the global contribution of the GEF included:

- Global relevance and the relevance of the GEF-6 strategy with its focus on integrated programing

- Focal area strategies, relevance to conventions, and results

- Governance and health of the partnership

- Development and implementation of cross-cutting policies on gender, safeguards, and indigenous peoples

- Engagement with the private sector

- The GEF's attention to civil society organizations

- Resource allocation mechanism (STAR)

- GEF systems for results-based management and knowledge management

Table 3.1 shows various questions addressed under the first theme and the sources of evidence used to address the questions. 
Table 3.1 Relevance and the global contribution of the GEF

\begin{tabular}{|c|c|c|}
\hline Key issue & Evaluation questions & Sources of evidence \\
\hline $\begin{array}{l}\text { Global relevance of the } \\
\text { GEF }\end{array}$ & $\begin{array}{l}\text { To what extent is the GEF relevant globally and how } \\
\text { could its global relevance be enhanced? What would be } \\
\text { the comparative advantage of the GEF in the changing } \\
\text { landscape? }\end{array}$ & $\begin{array}{l}\text { Environmental/scientific literature; patterns of government } \\
\text { spending; interviews with governments, international } \\
\text { development agencies, and research institutions }\end{array}$ \\
\hline GEF-6 strategy & $\begin{array}{l}\text { To what extent is the GEF-6 strategy achieving its } \\
\text { objectives? What does the early evidence suggest on } \\
\text { the integrated approaches? }\end{array}$ & $\begin{array}{l}\text { GEF-6 programing directions, evaluations of focal area } \\
\text { strategies, country portfolio evaluations, formative } \\
\text { evaluation of IAPs, evaluation of transformational change } \\
\text { and multiple benefits }\end{array}$ \\
\hline $\begin{array}{l}\text { Continuing relevance and } \\
\text { effectiveness of the } \\
\text { current GEF business } \\
\text { model and health of the }\end{array}$ & $\begin{array}{l}\text { To what extent is the current GEF business model } \\
\text { effective and still relevant? Does the current business } \\
\text { model optimize the capabilities within the GEF } \\
\text { partnership? }\end{array}$ & $\begin{array}{l}\text { Strategy documents, interviews, evaluation of multifocal } \\
\text { area projects, a study on governance and relationships } \\
\text { within the GEF }\end{array}$ \\
\hline
\end{tabular}

Funding structure of the GEF

To what extent has the disproportionate share of funding flowing to climate change in recent years been addressed to create balance in GEF allocations to the focal areas? Have the issues related to the substantial donor areas been addressed? What are the implications of the interlinkages between the multilateral environmental agreements (MEAs) for GEF financing? How has the STAR allocation mechanism deepened country ownership?

Governance of the GEF To what extent does the governance of the GEF continue to follow good practices?

Focal area strategies and results

Are the focal area theories of change realistic? Do they align meaningfully with the objective of supporting integrated solutions?

Multiple benefits of GEF support

To what extent has the GEF support generated multiple benefits?
Evaluation of the funding structure and resource allocation

An evaluation on governance; the formative evaluation of the IAPs

Focal area strategy evaluations, evaluations of the GEF's results framework

Evaluation of multiple benefits of GEF support 


\begin{tabular}{|c|c|c|}
\hline Key issue & Evaluation questions & Sources of evidence \\
\hline Programmatic approaches & $\begin{array}{l}\text { What has been GEF's experience with programmatic } \\
\text { approaches? How effective have these approaches been } \\
\text { in different contexts and what have they contributed to } \\
\text { global environmental benefits? What is the early } \\
\text { evidence on the IAPs? }\end{array}$ & Evaluation of programmatic approaches, IAPs \\
\hline $\begin{array}{r}\text { Results-based } \\
\text { management }\end{array}$ & $\begin{array}{l}\text { To what extent is the results-based management system } \\
\text { in a position to capture the impacts of GEF } \\
\text { interventions? To what extent does this system support } \\
\text { adaptive management? }\end{array}$ & $\begin{array}{l}\text { An evaluation of the GEF's results framework, results-based } \\
\text { management system, and tracking tools }\end{array}$ \\
\hline Gender mainstreaming & $\begin{array}{l}\text { To what extent have gender issues and evaluation of } \\
\text { GEF gender policy effectiveness been mainstreamed } \\
\text { into the GEF's work since the development of the } \\
\text { gender policy? }\end{array}$ & $\begin{array}{l}\text { Meta-analysis sub-studies on gender for OPS5, gender } \\
\text { policy of the GEF, project and country program } \\
\text { evaluations }\end{array}$ \\
\hline Role of the private sector & $\begin{array}{l}\text { To what extent has the GEF played a catalytic role in } \\
\text { mobilizing private-sector financing in addressing global } \\
\text { environmental benefits? How has the GEF engaged the } \\
\text { private sector to identify opportunities and leverage } \\
\text { them effectively? How is the non-grant instrument } \\
\text { performing? }\end{array}$ & $\begin{array}{l}\text { An evaluation of the GEF's engagement with the private } \\
\text { sector at the project level and in the IAPs }\end{array}$ \\
\hline $\begin{array}{l}\text { Role of civil society } \\
\text { organizations and } \\
\text { indigenous peoples } \\
\text { participation }\end{array}$ & $\begin{array}{l}\text { What has been the role of civil society organizations in } \\
\text { the GEF's work? To what extent has the use of } \\
\text { traditional knowledge been promoted in and by GEF } \\
\text { activities? }\end{array}$ & $\begin{array}{l}\text { An evaluation of the involvement of civil society } \\
\text { organizations at the project level }\end{array}$ \\
\hline Knowledge management & $\begin{array}{l}\text { Is the GEF performing as a major data and information } \\
\text { provider and are there any systemic issues to be } \\
\text { addressed? What is the extent to which knowledge has } \\
\text { been effectively managed and shared across the } \\
\text { partnership? }\end{array}$ & $\begin{array}{l}\text { A review of the GEF knowledge management strategy and } \\
\text { the effectiveness of the implementation of the strategy }\end{array}$ \\
\hline
\end{tabular}




\section{Theme 2: program performance and impact}

The evaluations of program performance and outcomes/impacts considered the following key themes:

- Outcome and sustainability ratings for completed GEF projects as emerging from the 2013-2017 period

- Progress toward impact of completed GEF projects for the period 2013-2017

- Trends in the catalytic role of the GEF as characterized by projects that focus on demonstration, scaling up, or investment

- Trends in country ownership and the GEF's role in contributing to policy and regulatory improvements in countries

- An understanding of the long-term impact of the GEF

- Trends in performance issues including quality at entry, cofinancing, and supervision

- Trends in implementation and achievement of the focal areas of the GEF

During OPS5, a major effort was the assembly, clean-up, and validation of a database of GEF interventions. This database, with updates, served as a starting point for necessary OPS6 data on performance and progress toward impact. Thematic evaluations included in-depth analysis of GEF's strategies and performance in the focal areas of biodiversity, climate change, chemicals and waste, international waters, and land degradation, as well as an analysis of programs that cut across focal areas with the potential for delivering greater environmental benefits through synergies. These evaluations and studies of GEF support to policy reforms and GEF support for transformational change provided evidence on the GEF's long-term impacts. We conducted an initial, formative evaluation of the IAPs to assess the relevance and coherence of their link to GEF-6 focal area strategies, their alignment with convention guidance, and the synergies between focal area strategies and country needs and ownership (GEF IEO 2018). This formative evaluation also looked at the IAPs' initial uptake in participating countries and the efficiency of the launch process. During the GEF-6 period, the IEO also tested new evaluative approaches to measure the efficiency of GEF interventions in land degradation and biodiversity through a value-for-money analysis (see Chapter 4 for a discussion of this approach).

Table 3.2 presents the matrix of issues related to program performance and impact, with key evaluation questions and the sources of evaluative evidence.

\section{Bringing it all together into OPS6}

OPS6, the comprehensive report, addressed the role and comparative advantage of the GEF in the global landscape for environmental finance. The report discussed the issues of the GEF's relevance to the conventions and countries; 


Key issue
Continuing relevance of the GEF to
multilateral environmental agreements
(MEA)

Project-level accomplishments

Progress toward impact of completed GEF projects

Catalytic role of the GEF

Focal area achievements
Evaluation questions

How relevant is the GEF to the guidance of the conventions, as emerging from the evaluations in the period 2013-2017? What are the implications of the focus on integrated approaches?

What are the outcome and performance ratings on outcomes and sustainability of completed GEF projects for which terminal evaluations are available (20132017)? To what extent have the ratings improved?

To what extent are the ratings on progress toward impact of completed GEF projects for the period 2013-2017 better or worse than the full cohort of OPS4 and OPS5 completed projects? What are some of the factors responsible for the observed trends?

What trends are discernible on the catalytic role of the GEF as characterized by foundation, demonstration, and/or investment projects?

What are current trends in the implementation and performance of focal area support of the GEF as synthesized from thematic, country portfolio, and impact evaluations?
Sources of evidence

Terminal evaluations of projects, country portfolio evaluations, thematic and impact evaluations

Terminal evaluations of projects, country portfolio evaluations, impact evaluations, annual performance reports (APRs)

Terminal evaluations of projects with review of outcomes to impact

Country program, thematic, and impact evaluations; demonstration, foundation, and investment portfolio analysis; APRs; evaluation of transformational change

Focal area strategies, meta-analyses based on thematic and impact evaluations, terminal evaluations, value-for-money analysis of GEF interventions 
Country ownership and the GEF's

contribution to changes in country policy and regulations

Addressing drivers of global environmental change

GEF performance
What trends are evident from the country portfolio evaluations with respect to country ownership?

To what extent and in what forms has GEF support addressed drivers of environmental degradation (including positive and negative drivers)? What is the role of the GEF in policy matters such as UNFCCC and the SDGs?

To what extent has performance in the GEF improved, especially with respect to the following?

- The GEF project cycle

- Co-funding

- Management costs and fees

- Quality at entry

- Supervision

- LDCF-SCCF

What are the challenges in addressing these?
Project terminal evaluations, country portfolio evaluations, evaluation of GEF support to policy reforms, thematic evaluations, impact evaluations Impact evaluations, thematic evaluations, APR

Portfolio analysis; terminal evaluations; APRs; LDCF/SCCF annual evaluation reports; governance, transformational change, and health of the partnership studies 
the comparative advantage, performance, impact, and transformational change of the GEF; and the effectiveness of the institutional framework, governance, and policies. The IEO conducted a total of 29 evaluations over the GEF-6 replenishment period that provided the evidence for these themes and the related questions presented in Tables 3.1 and 3.2. Some evaluations were predominantly desk-based knowledge products, such as the evaluation of GEF support for transformational change, and several involved field visits to gather beneficiary data. We used a mix of qualitative and quantitative methods, including geospatial analysis, and formative approaches in the evaluations; we discuss these in Chapter 4 . In all, the IEO visited 43 countries to collect data on the ground, analyzed 1,184 project terminal evaluations and covered a GEF portfolio of 4,433 projects - the entire GEF portfolio at the time.

OPS6 and the component evaluations had limitations with respect to data and timing that are not unique to IEO evaluations. The terminal evaluations we analyzed often belonged to projects that commenced in previous GEF replenishment periods but still offered useful lessons. The GEF's project management information system (PMIS) had incomplete and often outdated information on the status of various projects, requiring investment of considerable time and effort in ensuring the accuracy of project and monitoring data, including baselines and outcome information. Very little information was available on the implementation of the recently launched IAPs, yet the Council was very eager for information on this new programing approach. To mitigate some of the limitations, we used a formative evaluation approach focusing on the quality of design and early implementation of the IAPs, and we applied geospatial approaches to fill in data gaps on baselines, outcome, and impact information on important environmental variables of interest.

Pulling together a comprehensive effort of this magnitude and doing so with quality requires following systematic and consistent processes and using appropriate evaluation methods. Every component evaluation - and the overall OPS6 - followed the guidelines of good practice in evaluation process: the development of a concept note or approach paper, discussions with key stakeholders and reference groups, a peer-review process, competitive hiring of expert consultants, linking the findings and conclusions to draft recommendations, and discussion of recommendations with the GEF Secretariat and agencies prior to the finalization of the evaluation and presentation to the Council. While recommendations of the individual evaluations addressed the operational level, we drafted OPS6 recommendations at the strategic level to influence the GEF's programing directions more broadly.

\section{OPS6 strategic conclusions and recommendations: inputs for the replenishment process}

The overall conclusions of OPS6 encompass the GEF's relevance in the global environment; the performance and outcomes of GEF initiatives and policies; and the organization's financing, governance, and systems (GEF IEO 2017). 


\section{Relevance in the global environment}

With its broad focus and as a financial mechanism for important environmental conventions, OPS6 confirmed the unique space occupied by the GEF in the global environmental financing architecture. Despite limited funding, the GEF is the only institution that addresses global environmental issues beyond climate change alone, and it is the only global financial mechanism for several of the focal areas it addresses - including international waters, land degradation, and chemicals and waste. The GEF is the principal financial mechanism for the Convention on Biological Diversity, the United Nations Framework Convention on Climate Change, the Stockholm Convention on Persistent Organic Pollutants, the United Nations Convention to Combat Desertification, and the Minamata Convention on Mercury. The GEF also funds projects in international waters and sustainable forest management that support the implementation of a number of global and regional multilateral environmental agreements. As the financial mechanism for the Convention on Biological Diversity, the GEF is seen as a significant and reliable resource for funding for biodiversity, which attracts relatively few other funds. It also implements multifocal projects and programmatic approaches in recipient countries to help them meet commitments to more than one global convention or thematic area by tackling underlying drivers of environmental degradation. OPS6 illustrated how these projects and programs are designed to promote complementarities and synergies in seeking multiple environmental benefits, while avoiding trade-offs between competing objectives. The GEF focal area strategies are also responsive to other major international environmental and development initiatives such as the SDGs of the 2030 Agenda for Sustainable Development.

The GEF distinguishes itself by its ability to work through 18 agencies in more than 140 recipient countries. Through the STAR mechanism, and through programs and set-asides, these countries can access GEF resources to address environmental issues of national priority. GEF focal area interventions are strongly aligned with country priorities, GEF support has often been instrumental in setting national priorities in the environmental sector, and the GEF provides unique and critical support for countries in meeting their obligations under various conventions. The OPS6 conclusions also addressed the focus of GEF funding between the middle income countries and the LDCs and SIDS.

\section{Performance and impact}

The component evaluations that contributed to OPS6 demonstrated the strong track record of the GEF in delivering overall good project performance, while also illuminating the extent to which sustainability is a challenge. We explore the performance and impact of GEF programs and projects in detail in Chapter 5. Outcome and impact analysis confirmed that GEF interventions have contributed to decreasing environmental stress - biophysical changes that reflect reduction of threats emanating from human actions. 
The GEF has played an important catalytic role and supported transformational change primarily through mainstreaming; scaling up and market change have had limited success. Our analysis showed that transformational change occurs where projects aspire to drive change; market barriers are addressed through sound policy, legal, and regulatory reforms; private-sector engagement is encouraged through targeted capacity building and financial incentives; and mechanisms are put in place for future financial sustainability through the market, government budgets, or both.

Chapter 5 also discusses specific impacts and areas for improvement associated with the GEF policies on gender, safeguards, and indigenous peoples. The Policy on Gender Equality has advanced the GEF's efforts to strengthen gender mainstreaming in the organization's programing and operations in a systematic manner. GEF policies and guidance on safeguards and indigenous peoples have supported efforts in these areas, but gaps exist relative to good practice in partner agencies and in implementation.

\section{Financing, governance, and systems}

The strategic conclusions in OPS6 addressed how exchange rate volatility, fragmentation in donor funding, and impediments to scaling-up non-grant instruments have affected GEF financing and, as a result, programs and allocations to countries. The study also identified how operational restrictions, lack of awareness of the GEF, and conflicting understandings and needs affected engagement with the private sector.

Overall, OPS6 reported that the GEF partnership is well governed. Concerns continue to exist on matters related to representation, efficiency, accountability, and transparency, and the final OPS6 report explores these areas through both quantitative and qualitative data. From a systems standpoint, the comprehensive evaluation found progress in the GEF's PMIS, results-based management system, and knowledge management; we also identified the ways in which the availability and quality of information in these systems needs further improvement.

In summary, OPS6 confirmed that the changing landscape for environmental finance presented an opportunity for the GEF to build on its comparative advantage and make strategic choices. The establishment of new funds such as the Climate Investment Funds, the Green Climate Fund, the Asian Infrastructure Investment Bank, and the New Development Bank present an opportunity for the GEF to expand its presence in focal areas beyond climate change. Sources of comparative advantage for the GEF include its mandate to serve the conventions; its strong record of performance over 26 years; and its ability to address interlinkages and synergies across focal areas, implement policy and regulatory reforms in countries to create an enabling environment that attracts investment, deliver innovative financing models and risk-sharing approaches, and support lower income countries and SIDS. 


\section{Strategic recommendations}

Based on the findings and conclusions, the strategic recommendations of OPS6 included:

\section{Strengthening strategic positioning}

The GEF should more strongly position itself in the focal areas that have limited financing sources and few players with the GEF's depth of knowledge and experience. Within climate change, the GEF needs to redefine its niche, emphasizing its work with the enabling environment and measures to support market transformation. Other important emphases are innovative projects and piloting and demonstrating technologies and financial approaches. The GEF should explore its potential to be an incubator for countries to test and refine approaches prior to seeking large-scale financing through other partners.

\section{Promoting transformational change}

In any focal area, the GEF must design for transformation, promote policy and regulatory reform, and build institutional capacity in recipient countries. A project's potential for transformation should be assessed at the design stage using clear criteria.

\section{Continuing the focus on integration}

Intervention design for integration must follow a strong, cogent rationale based on demonstrated additionality, GEF experience, GEF comparative advantage, innovative contributions, environmental need, and national relevance.

\section{Improving financial management}

The GEF needs to expand the number and variety of donors from both Organisation for Economic Co-operation and Development countries and middle-income countries. To secure its financing, the GEF should implement foreign exchange risk management.

\section{Engaging the private sector}

The GEF should engage the private sector in areas beyond finance, such as by facilitating certifications and research and addressing sourcing and production practices along the supply chain. Long-term regulatory and policy intervention by the GEF can help prime the pump to catalyze private-sector investment. 


\section{Promoting gender equality}

The GEF's Policy on Gender Mainstreaming must align more closely with international gender mainstreaming practice standards, with a comprehensive results or accountability framework and progress tracking.

\section{Revising safeguard policies}

Review of the policy on safeguards and rules of engagement with indigenous peoples should assess gaps against good practices and be updated accordingly, with supporting implementation and monitoring.

\section{Strengthening operational governance}

Establishing ground rules for cooperation among agencies will support multifocal area efforts and program expansion, with clear communication of criteria for program, project, country, and agency selection. Addressing the potential for conflicts of interest is imperative.

\section{Improving systems}

Improvements to systems for project management information, results, and knowledge will enable the GEF to demonstrate its results and enhance learning. Systems must deliver timely and accurate project information, good quantitative data on performance with a focus on impacts, and information to support project design, implementation, and monitoring.

All of the recommendations were endorsed by the replenishment group and were reflected in the GEF-7 programing directions.

\section{Notes}

1. Officially the United Nations Conference on Environment and Development, at the time the largest gathering of heads of state and government to address a global challenge.

2. The text of the Convention states: “...the global nature of climate change calls for the widest possible cooperation by all countries and their participation in an effective and appropriate international response, in accordance with their common but differentiated responsibilities and respective capabilities and their social and economic conditions" (UN 1992).

3. Initially the United States until Japan became the largest donor. The formula was later loosened.

4. www.gefieo.org/sites/default/files/documents/council-documents/c-50-me-07. pdf.

\section{References}

Carugi, C. 2016. "Experiences with Systematic Triangulation at the Global Environment Facility." Evaluation and Program Planning 55: 55-66.

Clémençon, R. 2006. "What Future for the Global Environment Facility?" The Journal of Environment and Development 15 (1): 50-74. 
GEF. 2014. GEF-6 Programming Directions. Washington, DC: Global Environment Facility. GEF IEO. 2016. Sixth Comprehensive Evaluation of the GEF (OPS6) Approach Paper. Washington, DC: Global Environment Facility Independent Evaluation Office.

GEF IEO. 2017. The GEF in the Changing Environmental Finance Landscape (OPS6). Final Report. Washington, DC: Global Environment Facility Independent Evaluation Office. GEF IEO. 2018. Formative Review of the Integrated Approach Pilot Programs. Washington, DC: Global Environment Facility Independent Evaluation Office.

Gupta, J. 1995. "The Global Environment Facility in Its North-South Context." Environmental Politics 4 (1): 19-43.

Uitto, J.I. 2016. "Evaluating the Environment as a Public Good." Evaluation 22 (1): $108-115$.

UN. 1992. "United Nations Framework Convention on Climate Change." http:// unfccc.int/files/essential_background/convention/background/application/pdf/ convention_text_with_annexes_english_for_posting.pdf. 


\section{Evaluation methods}

\section{Why we evaluate}

Evaluation plays an important role in the Global Environment Facility (GEF) in enhancing the effectiveness of the organization's interventions in the pursuit of global environmental benefits. At its simplest level, our evaluation seeks to address the question "Is this GEF project or program making a difference?" Within the GEF specifically, the goal of independent evaluation is twofold (see Appendix 1):

1 To promote accountability for the achievement of GEF objectives through the assessment of results, effectiveness, processes, and performance of the partners involved in GEF-financed activities; GEF results are evaluated for their contribution to global environmental benefits.

2 To promote learning, feedback, and knowledge sharing on results and lessons learned among the GEF and its partners as a basis for decision-making on projects, programs, program management, policies, and strategies; and to improve performance.

The GEF Independent Evaluation Office (IEO) seeks to maintain a balance between the accountability and learning objectives. The purposes of evaluation in the GEF include understanding why, how, and the extent to which intended and unintended results are accrued, and their impact on stakeholders. Evaluation, when effective, is used to improve the design and performance of a planned or ongoing project or program (a formative evaluation); to make an overall judgment about the effectiveness of a completed project or program; and to generate knowledge about what works and why. Evaluations in the GEF feed into management and decision-making processes regarding the development of policies and strategies, and into the programming, implementation, and reporting of activities, projects, and programs. Thus, evaluation in the GEF contributes to institutional learning and evidence-based policy-making, accountability, development effectiveness, and organizational effectiveness. It informs the planning, programming, budgeting, implementation, and reporting cycle. In a nutshell, it aims to improve the institutional 
relevance and achievement of results, optimize the use of resources, and maximize the impact of the GEF investment.

The IEO continuously strives to push the frontiers of environmental evaluation through application of recently developed evaluation approaches, testing a variety of methods and using big data. Recent publications in peer reviewed journals reflect IEO contributions to advancing the evaluation approaches in sustainability:

- Exploring the Socioeconomic Co-benefits of Global Environment Facility Projects in Uganda Using a Quasi-Experimental Geospatial Interpolation (QGI) Approach, Journal of Sustainability (Runfola et al. 2020)

- The Use of Remote Sensing Analysis for Evaluating the Impact of Development Projects in the Yellow Sea Large Marine Ecosystem, Journal of Sustainability (Sidman et al. 2020)

- A Joint Evaluation with Lessons for the Sustainable Development Goals Era: The Joint GEF-UNDP Evaluation of the Small Grants Programme, American Journal of Evaluation (Carugi and Bryant 2019)

- Improving International Development Evaluation through Geospatial Data and Analysis, International Journal of Geospatial and Environmental Research (Lech et al. 2018)

\section{How we evaluate}

Evaluations in the IEO cover a broad spectrum ranging from project-level validations to comprehensive evaluations that address a broad spectrum of institutional and impact themes and involve a variety of quantitative and qualitative methods (see Box 4.1).

Our evaluation approaches in the IEO have evolved to adapt to changes in GEF interventions and in response to the Council's needs for information on recently designed pilot programs and real-time information. For example, while the GEF continues its interventions in focal areas, it is shifting toward more multifocal projects and integrated programming to address the drivers of environmental degradation. With the advent of the Sustainable Development Goals (SDGs), recognition of the synergies (and/or trade-offs) between environmental and human systems has grown. To accommodate these shifts, the IEO has adjusted its work program to provide insights into the early design and implementation of the integrated programs and to delve into evidence on socioeconomic outcomes. This has involved expanding the suite of evaluation types and the methodologies we employ, as reflected in the GEF Evaluation Policy (see Appendix 1).

We have used formative evaluation methods to assess the integrated approach pilots (IAPs) for relevance and design before their full roll-out. We conduct process/implementation evaluations to determine whether policies - such as those on gender, safeguards, and indigenous peoples - or programs have been implemented as they were intended. Our outcome/ 
Box 4.1

\section{Evaluations conducted by the IEO}

Validations of project evaluations at the completion of the project implementation (terminal evaluation), mainly conducted by GEF Agencies.

Program evaluations of a coherent set of interventions to attain specific global, regional, country, or sector objectives; these include evaluations of the GEF focal areas, programmatic approaches, and GEF corporate programs.

Performance evaluations of the GEF's portfolio of completed projects to assess the relevance, efficiency, and effectiveness in delivering the expected results.

Country and country cluster evaluations of one or more agencies' portfolio of projects and activities, and the assistance strategy behind them, in a country or cluster of countries. Strategic cluster evaluations focus on a limited set of strategic issues across country portfolios.

Process evaluations of the functioning of participating organizations, instruments, mechanisms, and management practices; these include evaluations of institutional and procedural issues across GEF focal areas and assessments of experience with GEF policies, criteria, and procedures. Process evaluations may be conducted during the design or implementation of an intervention.

Impact evaluations of the long-term effects produced by an intervention, intended or unintended, direct or indirect. Impact may be assessed at the project, program, portfolio, ecosystem, or country level and includes global environmental benefits.

Thematic evaluations of a selection of interventions addressing a specific theme, issue, or focal area across the GEF portfolio; these include evaluations that assess cross-cutting issues.

Comprehensive evaluations of the GEF (commonly referred to as an overall performance study, or OPS) inform the GEF replenishment cycles and address performance and results in terms of global environmental benefits of GEF projects and programs. They also assess GEF institutional arrangements, policies, strategies, and priorities. The earlier evaluations feed into the comprehensive evaluations.

effectiveness evaluations measure project and program effects by assessing the progress in environmental outcomes against the approved objectives. Finally, our impact evaluations assess the long-term net effectiveness of the GEF's programs in achieving their ultimate goals of delivering global environmental benefits. The units of analysis for these various evaluations are projects, programs, or countries. Or, an evaluation could address a specific theme, issue, or focal area that cuts across the entire GEF portfolio. We bring together all of these individual evaluations in preparing the comprehensive 


\section{Box 4.2}

\section{OECD DAC criteria}

Relevance: Is the intervention doing the right things?

The extent to which the intervention objectives and design respond to beneficiaries', global, country, and partner/institution needs, policies, and priorities, and continue to do so if circumstances change.

Coherence: How well does the intervention fit?

The compatibility of the intervention with other interventions in a country, sector, or institution.

Effectiveness: Is the intervention achieving its objectives?

The extent to which the intervention achieved, or is expected to achieve, its objectives; the intervention's results, including any differential results across groups.

Efficiency: How well are resources being used?

The extent to which the intervention delivers, or is likely to deliver, results in an economical and timely way.

Impact: What difference does the intervention make?

The extent to which the intervention has generated or is expected to generate significant positive or negative, intended or unintended, higher level effects.

evaluation of the GEF, conducted every four years as part of the funding replenishment cycle, to provide strategic insights into the performance and results of GEF projects and programs, and into GEF institutional arrangements, policies, and priorities.

Various evaluations address a broad spectrum of questions. These may pertain to identifying where a problem lies; a problem's definition, scope, and scale; the appropriateness of an intervention to address a problem; the GEF's additionality; or a project's or program's outcome effectiveness, impacts, and potential for transformational change. To provide a systematic lens to address such questions, we, like other global development institutions, apply the framework of evaluation criteria from the Organisation for Economic Co-operation and Development's Development Assistance Committee (OECD DAC; see Box 4.2). The purpose of the evaluation criteria is determining an intervention's merit, worth, or significance. These criteria aid us in looking at the processes by which change happens and at the results of the change (OECD DAC 2019).

\section{How we evaluate: framework and recent innovations}

We conduct a broad spectrum of evaluations in the IEO as presented in Box 4.1. Within the context of the GEF, project- and program-level terminal evaluations are the responsibility of the implementing agencies and 


\section{Evaluation methods}

are mandated according to the GEF evaluation policy and the minimum standard requirements. The data from the terminal evaluations underpin all performance, thematic, country, and impact evaluations the IEO conducts. Field visits, interviews with stakeholders, geospatial analysis, and surveys are other important sources of evidence in the thematic evaluations we conduct. We continue to develop and apply new approaches and tools as GEF programming evolves and as the field of evaluation progresses. We have recently developed frameworks for assessing project and program additionality, transformative change, and efficiency - core themes at the heart of the GEF 2020 and GEF-7 strategies - and have mainstreamed the use of geospatial analysis within our suite of evaluation tools.

\section{Terminal evaluations}

The implementing agencies conduct terminal evaluations according to the relevant GEF Guidelines (GEF IEO 2017). The guidelines cover the roles and responsibilities for the agencies, evaluation units of the agencies, the IEO, and operational focal points, and address the content of the evaluation report. The terminal evaluations are required to assess:

- $\quad$ project theory of change (TOC)

- $\quad$ effectiveness along the OECD DAC criteria

- progress toward impact

- $\quad$ sustainability

- design and implementation of monitoring and evaluation

- quality of implementation and execution

- lessons learned

The terminal evaluation guidelines also provide the criteria for rating various performance dimensions. Given the importance of these evaluations, the IEO validates the terminal evaluations of GEF projects from all agencies. ${ }^{1} \mathrm{We}$ aggregate the ratings from the terminal evaluations along various dimensions and report them in the Annual Performance Report of the IEO - the aggregate report card for the GEF. With the shift toward programs, the terminal evaluations for the "child projects" (individual projects under the umbrella of a larger program) must follow the terminal evaluation guidelines, which require the child projects to demonstrate contribution toward the larger program. At the program level, the terminal evaluations should demonstrate both overall effectiveness and generation of program additionalities beyond the sum of the contributions of the individual projects.

\section{Additionality: what environmental difference did our funds make?}

A central concern for the GEF, as for other development institutions, is the attribution of its support to environmental impact. Whether funding 
programs directly or through other implementing agencies, most development institutions focus on increasing the total flow of resources toward a particular cause. The GEF IEO must evaluate the additionality that GEF funding generates. In other words, did GEF funds displace other funding that would have materialized? Equally important, what outcomes can truly be attributed to the GEF funding, and what part of these outcomes would have happened even without additional funding?

The GEF has for several years addressed these considerations through the incremental cost approach. The aim is to ensure that GEF funds do not substitute for existing development financing, instead providing additional funding to produce agreed-upon global environmental benefits. For many institutions, the GEF still serves as the leader in defining additionality and pointing to an implementable framework. Institutions also recognize that the GEF is a special case in which the baseline (i.e., the without-GEF scenario) is expected to show additionality compared with the current situation in which no intervention has taken place. Thus, while typical projects assess their impact based on a counterfactual and a baseline analysis, the GEF defines its additionality as the incremental contribution from the GEF involvement above and beyond the additionality that would have occurred in the absence of the GEF. This "double increment" has most often been used in the climate finance area related to the offsets of emissions of greenhouse gases and to the program of payment for ecosystem services.

However, our 2006 evaluation of the incremental cost approach (GEF IEO 2006) found that it added little to the operational aspects of project preparation, was often poorly understood in its concept, and, at times, could even lead to operational modifications that ran counter to other environmental benefits or good development practices. The GEF is a unique partnership that thrives on pursuing environmentally effective projects with attributable outcomes, while also bringing to bear its influence and the agreements reached through global environmental conventions in shaping how global environmental commons are protected and nurtured. Therefore, the GEF's environmental additionality cannot be measured with a one-size-fits-all approach but requires recognition of the direct and indirect ways the GEF shapes the impact on global environmental benefits through its financial and nonfinancial roles.

In parallel, the literature and practices in assessing additionality have evolved significantly toward accounting for factors beyond the immediate project objectives. Considering that the incremental contribution arising from the work of development institutions (multilateral, bilateral, and civil society and nongovernmental organizations) often remains difficult to define, the existence of a significant body of literature and a variety of practices to draw on is not surprising. The term "additionality" is based on the project and program evaluation principles of establishing a strong counterfactual to derive the true impact on development outcomes of a project or program. At the project level, extensive literature has been developed in recent years with 
the help of multilateral development banks. ${ }^{2}$ Establishing the preconditions to accurately assess the impact of projects requires early development of monitoring systems and clear counterfactuals - a challenge for most development institutions. Beyond the general agreement on the relation to a counterfactual, however, little progress has been made in reaching a common definition, or measurement (Oxfam International 2017).

Institutions are also recognizing the value of separating financial additionality - such as drawing private-sector investment into solving developmental problems through commensurate public policies or investments - from developmental additionality, such as regulator reform, capacity building, and other factors associated with positive long-term development outcomes. The OECD DAC, for example, studied carefully the role of drawing in private-sector investments through public development interventions (Benn et al. 2017).

In light of the need for a more robust approach to assessing the GEF's environmental and other additionalities, and the recent evolution toward a more encompassing definition of additionality, the IEO developed a framework to align the additionality concept with current strategies and practices (GEF IEO 2018a).

Additionality is defined in this framework as:

- Changes in the attainment of direct project outcomes at project completion that can be attributed to GEF interventions; these can be reflected in an acceleration of the adoption of reforms, the enhancement of outcomes, or the reduction of risks and greater viability of project interventions.

- Spillover effects beyond project outcomes that may result from systemic reforms, capacity development, and socioeconomic changes.

- Clearly articulated pathways to broaden the impact beyond project completion that can be associated with GEF interventions.

The six dimensions of the GEF's additionality are presented in Box 4.3. We now apply these regularly in the IEO's thematic evaluations, and the GEF encourages application of the framework at the project design stage. The evaluation policy now requires clear articulation of the GEF's additionality.

A study demonstrating the utility of the additionality framework is an evaluation of the GEF-United Nations Industrial Development Organization (GEF-UNIDO) Global Cleantech Innovation Programme (GCIP), released in April 2020 (GEF IEO 2020). Serving small and medium enterprises, this program encourages cleantech entrepreneurial solutions to pressing environmental and economic challenges. To provide stakeholders with insights into the GCIP and lessons for similar future projects and programs, the evaluation assessed the program's relevance, additionality, outcomes, and sustainability in eight countries. The evaluation framework supported a mixed-methods approach that drew on internal and external factors, including document 


\section{Box 4.3}

\section{Six areas of the GEF's additionality}

Specific environmental additionality: The GEF provides a wider range of value-added interventions and services to achieve the global environmental benefit.

Question: Has the project generated global environmental benefits that would not have happened without the GEF's intervention?

Legal/regulatory additionality: The GEF helps stakeholders achieve transformational change to environmentally sustainable legal/regulatory reforms.

Question: Has the project led to legal or regulatory reforms that would not have occurred in the absence of the project?

Institutional additionality/governance additionality: The GEF supports the transformation of existing institutions to increase their efficiency and impact on environmental sustainability.

Question: Has the project strengthened institutions to provide a supportive environment for achievement and measurement of environmental impact?

Financial additionality: The GEF provides incremental funding to transform projects' benefits from a national/local scale to a global scale.

Question: Has the involvement of the GEF led to greater flows of financing than would otherwise have been the case from private-or public-sector sources?

Socioeconomic additionality: GEF activities help individuals improve their livelihood and social benefits.

Question: Can improvements in living standards among population groups affected by environmental conditions be attributed to the GEF contribution?

Innovation additionality: The GEF provides efficient/sustainable technology and knowledge to overcome existing social norms/barriers/ practices.

Question: Has the GEF involvement led to a fast adoption of new technologies, or the demonstration of market-readiness for technologies that had not previously demonstrated their market viability?

review and interviews with GEF Secretariat and UNIDO staff, government representatives, and private-sector stakeholders.

The evaluation noted the GEF's additionality in several areas through its promotion and results in innovation for clean technology, socioeconomic returns, institutional capacity, realization of financing for some startups, and business support to enterprises, the products and services of which have environmental benefits. However, GCIP did not realize policy and regulatory strengthening additionality in a meaningful way because these project activities were limited, under-resourced, and generally begun at a later stage of implementation. 
GCIP's focus on cleantech business acceleration was new, unique, and a value-add for the innovation ecosystem. Despite recognition that the cleantech concept could stimulate economic growth, few such projects existed, and those that did tended to operate in silos. GCIP business assistance (primarily to early-stage entrepreneurs) filled a gap. One-to-one interactions with mentors under the GCIP allowed for tailored advice and were conducive to the development of close, long-term relationships between mentors and teams. The strategy of approaching alumni (entrepreneurs who had "graduated" from previous GCIP rounds) to serve as mentors, judges, and local trainers was novel, and many who took up these roles were motivated to give back to other early-stage entrepreneurs. The start-ups had privileged access to local private experts. GCIP stressed the importance of a risk-taking mindset and encouraged local solutions. Box 4.4 shows an example of a GCIP participant enterprise.

\section{Box 4.4}

\section{Pakistani solution for low-cost, quickly built housing}

Karachi-based ModulusTech designed mobile, low-cost, earthquake- and cycloneresistant, energy-efficient housing that can be assembled within a few hours, with plumbing and electricity included. Having set its sights on solving housing problems for displaced people, the team originally thought about targeting international charities and the refuge community. To its surprise, the company found its first customer in the mining industry, where its innovation is being used to fulfill a need for temporary accommodation.

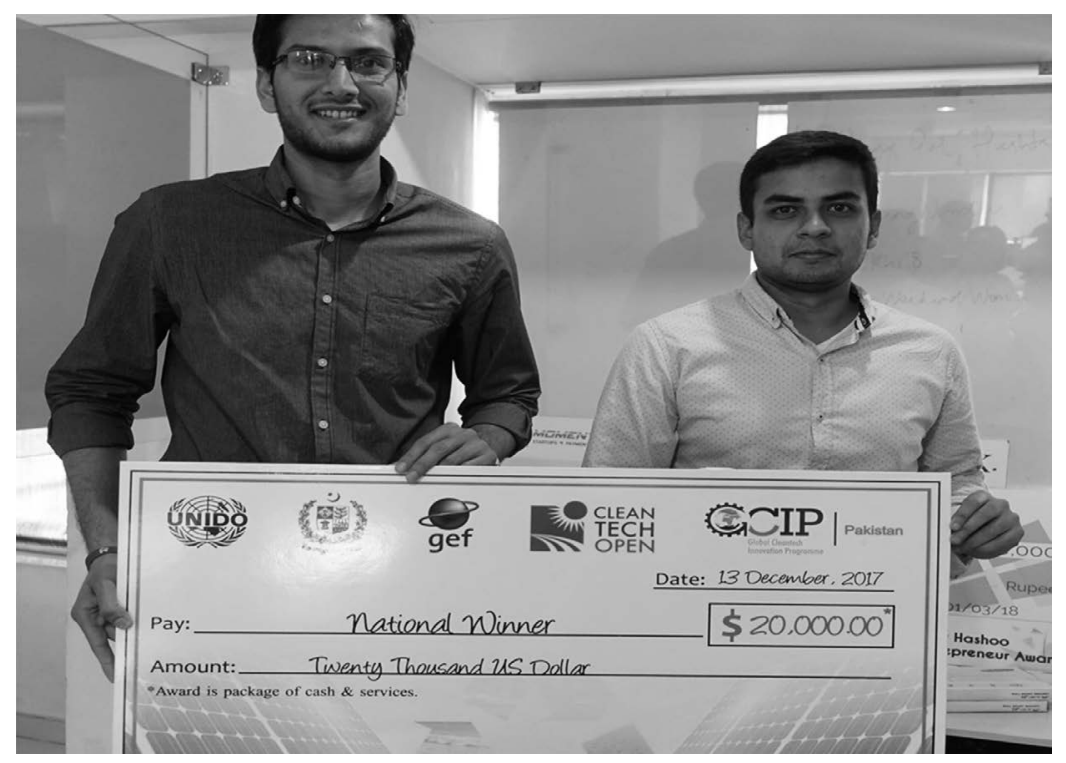


GCIP also promoted indigenous technology development, which allowed for reduced costs of equipment for the entrepreneurs and easier adoption for urgent development priorities such as access to clean and affordable energy, clean water, and climate resilient agriculture. The program fostered social inclusiveness in ways such as including youth and Black entrepreneurs in South Africa, and women in Pakistan. Under the GCIP framework, entrepreneurs have developed and commercialized ideas with meaningful social and economic impact. Examples include innovations in sanitary pads (developed by Gracious Nubian in South Africa and Saathi Eco Innovations in India) that have provided affordable solutions for women and girls, especially in rural areas, who were previously prevented from working and attending school during menstruation. GCIP was able to leverage private-sector finance to support promising cleantech solutions. The start-ups had more success in gaining access to venture capital through the national-level investor.

A second evaluation in which we applied the additionality framework was the Evaluation of GEF Support to Mainstreaming Biodiversity, completed in December 2019 (GEF IEO 2019a). The evaluation was based on a portfolio analysis of 471 relevant projects and in-depth case studies from Colombia, India, and South Africa, and used methods including review of documentation and literature; site visits; and interviews with key stakeholders such as government officials, implementing and executing agency staff, civil society organizations, and project beneficiaries. The evaluation found that the GEF biodiversity mainstreaming portfolio has contributed to legal, regulatory, governance, and socioeconomic additionalities that go beyond incremental cost benefits. These include innovative approaches based on multistakeholder partnerships linking grassroots organizations to regional research institutions, advocacy platforms, and national environmental authorities. Landscape management practices are validated on the ground and elevated to influence national policy and legislative-regulatory reform. Several projects have contributed to landmark biodiversity legislation; transformed core institutional/ sector practices; and achieved measurable conservation impacts in forest cover, pasture, and other biodiversity indicators. However, capturing other additionalities - such as socioeconomic and environmental impacts deriving from the GEF's support for biodiversity mainstreaming in productive landscapes and seascapes - has been a challenge.

\section{Transformational change: moving beyond the incremental}

As the GEF's vision statement (GEF 2012) lays out, the unprecedented nature of the pressures faced by the earth's ecosystems in the coming decade means that incremental environmental strategies alone will not suffice. These pressures "compel the GEF to equip itself to promote transformational change." The GEF 2020 Strategy Paper identifies market transformation as one of the areas requiring a systematic effort to capture lessons learned from past project 
experience and to leverage this knowledge to guide users and scale up the GEF's impact (GEF 2015).

To better understand what drives transformational change and to improve the identification, design, and implementation of future operations to support transformational change, the IEO developed a framework (see Chapter 6, Figure 6.2). The transformational change mechanism generates catalytic effects through mainstreaming, demonstration, and replication and can result in changes at the market or systems level. Internal factors influencing transformational change are the quality of implementation and execution, capacity building, and donor partnerships. External factors driving change include government ownership and support, implementation capacity of local institutions, adequacy of the policy environment, civil society, private sector and local community participation, and enabling economic and market conditions. We have applied this framework in several evaluations, including the previously discussed biodiversity and the cleantech evaluations, to understand whether and how GEF projects have been transformative.

\section{Application of the transformational change framework}

\section{Lighting Africa: promoting market-based solutions to advance energy access}

About 600 million people in Africa have no access to grid electricity, and this number is expected to rise to about 700 million by 2030. These people rely on polluting and dangerous sources of lighting such as kerosene lamps, candles, and battery-powered torches. Fuel-based lighting is generally of low quality and expensive, impeding learning and economic productivity.

Given advances in technology and increased competition, portable modern lighting devices have become more affordable. This created an opportunity for people living in off-grid areas to replace kerosene lamps with higher quality, safer, and more affordable modern lighting products such as solar lamps. However, despite the benefits of solar lamps, the market was not developing as quickly as expected. To understand why, the International Finance Corporation (IFC)/World Bank undertook a market appraisal (World Bank Group 2007) and identified six barriers inhibiting market growth:

- Consumers did not trust the solar products available. Some solar lamps were already available in the market when the Lighting Africa program began, but many of these products were poorly made and did not work properly.

- Consumers did not know the benefits of solar lamps, how to use them, or where to buy them. Some consumers were unaware that solar lamps existed.

- Manufacturers and designers did not know consumer preferences for the design and function of a solar lamp.

- Supply chain entities did not know each other. Solar lamp manufacturers entering the market to serve lower income consumers in developing 
countries did not have an established distribution network and were unsure how to identify reliable distributors.

- Lack of finance was a big problem. Designers and manufacturers, distributors and importers, and retailers needed financing to purchase and move products to the end users. Lower income consumers needed microloans to help with the upfront cost of purchasing a solar lamp.

- Long customs processes and import tariffs on solar lamps were common concerns among manufacturers who considered importing solar lamps to African markets.

The Lighting Africa program was created to transform the off-grid market by removing these barriers. Its goal was to help catalyze markets for quality, affordable, clean, and safe off-grid lighting and, ultimately, to create a sustainable commercial platform that would realize the vision of providing 250 million people with modern off-grid lighting by 2030. The overall approach was to demonstrate the viability of the market by providing market intelligence, developing a quality assurance infrastructure, facilitating businessto-business interactions, helping governments address policy barriers, providing business development services, and facilitating access to finance for manufacturers, local distributors, and consumers. The program received about $\$ 22$ million in donor contributions from 2007 to 2013, with the GEF the largest donor, providing more than one-third of the funds (World Bank and Independent Evaluation Group 2015). ${ }^{3}$

In 2014, the final evaluation of the Lighting Africa program concluded that the program had played a crucial role in transforming the market (Castalia Strategic Advisors 2014). The program was effective and made an impact. A few of the key accomplishments were:

- Through the program's quality assurance efforts, 183 solar lamp models were tested and 66 received the Lighting Africa quality certification.

- The program hosted 1,157 forums during its consumer education campaigns, directly reaching more than 36,000 people in Kenya.

- More than 680,000 Lighting Africa-certified lamps were sold in Kenya, 135 percent more than the Kenya program's target. Furthermore, almost 2 million lamps were reported to have been sold in other African countries - 185 percent above the target. More work is needed to determine the extent to which these sales can be attributed to the program, as noted in the evaluation, because this estimate does not take into account a counterfactual of what would have occurred without the program. However, interviews with retailers, consumers, and manufacturers confirmed that Lighting Africa was a very important influence on market development, so the true impact may well have been higher.

The evaluation also concluded that the benefits achieved by the program were sustainable after donor funding stopped, with interviews suggesting 
that people who have used solar lamps will continue to do so and suppliers will continue to supply. The extent to which the market transformation process itself will continue, however, remains to be seen. Although the program has laid the groundwork for continued market transformation through arrangements with an industry association and a Kenyan nongovernmental organization to take over and continue the program activities, these organizations are still partially reliant on donor support.

Based on the findings of the evaluation, three main factors were instrumental in Lighting Africa's success, and their maintenance will be essential for continuing the transformation:

- The first and obvious success factor was the program's operation in areas with a proven, strong demand for improved off-grid lighting solutions.

- The second was having a carefully designed set of interventions that simultaneously targeted all major market barriers. Because barriers differ from market to market, the program started with a basic program design but tailored the components to address the specific barriers identified in the target countries.

- The third was the program's focus on market transformation. The Lighting Africa program did not fund solar lamps - it funded activities that created effective markets in which consumers spent their own money to buy solar lamps. To sustain this success factor, organizations must resist the temptation to purchase lamps for poor people and instead vigorously pursue pro-market interventions such as microfinance to assist the purchase of solar lamps.

\section{Choosing our tools: evaluation methods}

The evaluation questions we pursue guide our choice of evaluation methods. Most IEO evaluations aim to either determine project effectiveness after implementation or improve project design and implementation as they are developing. Are GEF interventions relevant? Do GEF interventions work or not work? Why do they work? What are the factors influencing outcomes and performance? How do these factors influence each other within the system of interest? To answer these questions, we often apply both quantitative and qualitative methodological approaches while adopting a systems approach to evaluation.

\section{A systems approach to evaluation}

Our evaluations typically begin with developing a TOC to establish the link between GEF interventions and their intended outcomes. This linear approach, however, is rather simplistic. GEF projects operate in complex systems marked by interconnectedness among myriad factors. Within these systems, interventions may have unintended or secondary consequences that could affect impacts but may not be considered - or cannot be - during project design or within the linear TOC. Thus, IEO evaluations go beyond 
the intervention's TOC to examine the complex system within which the intervention has taken place. We also consider specific elements of an intervention's TOC and the larger system in determining which evaluation questions need to be asked. This systematic basis allows us to use appropriate evaluation methods and adapt our approaches to integrate new or evolving knowledge throughout the process (Garcia and Zazueta 2015).

\section{Mixed methods}

Quantitative data provide rich information on the "what" and the "who" of a project or program - the outcomes, reach, and cost efficiency - and are collected through the GEF's results monitoring system. This system incorporates surveys conducted during an evaluation and, more recently, remote sensing and satellite data. Our suite of quantitative tools includes:

- $\quad$ simple statistical measures to observe patterns of performance

- multivariate regression analysis

- $\quad$ regression discontinuity analysis

- quasi-experimental approaches to compare GEF units with those that have not received GEF assistance

- machine learning algorithms and causal trees to explain factors influencing environmental outcomes

- $\quad$ valuations of carbon stocks

Several IEO evaluations now apply remote sensing and geospatial methods, which we have found to be useful and innovative tools for measuring environmental impact. These tools provide reliable and cost-effective baseline information that is often missing in project documents, help detect changes over long periods of time, and assist in tracking progress toward the achievement of environmental and other development targets (Lech et al. 2018). Our applications of geospatial data include:

- better understanding the relevance of GEF interventions

- measuring returns on GEF investments

- $\quad$ assessing environmental effectiveness on forest cover, habitat quality, and carbon sequestration

- evaluating socioeconomic co-benefits of GEF projects

- addressing the long-term impacts of GEF interventions through sustainability analysis

Figures 4.1 and 4.2 illustrate the application of geospatial data in biodiversity to answer important evaluation questions. Figure 4.2 presents how geospatial analysis is used to assess the relevance of GEF interventions. We created a spatial overlay of globally distributed GEF-supported protected areas with sites of conservation importance. This geospatial analysis shows that the GEF-supported protected areas are located in biodiversity hot spots (GEF IEO 2016). Figure 4.3 illustrates the impact of GEF projects by measuring 

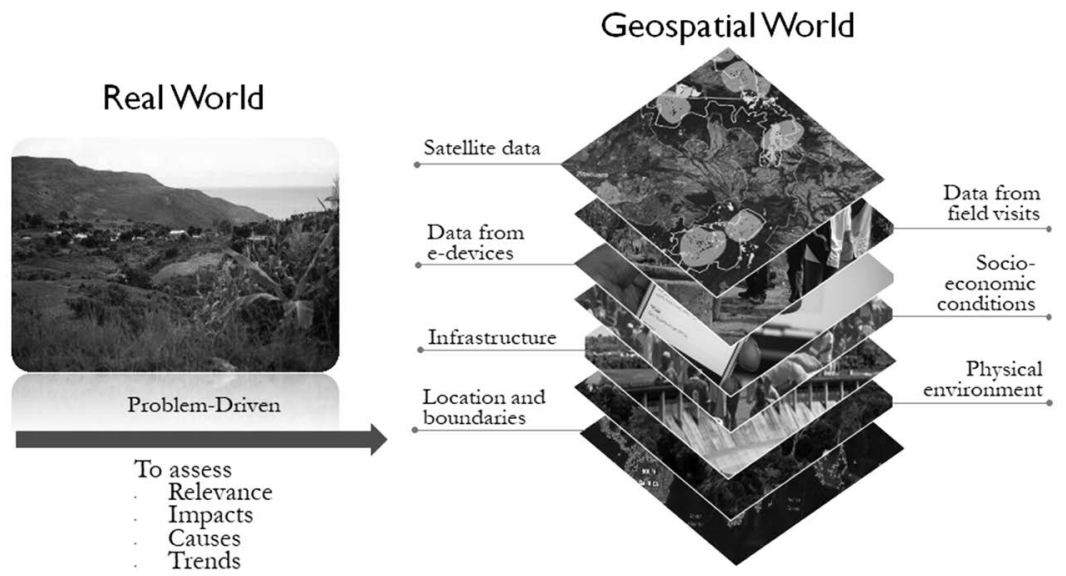

Spatial analysis focuses on the statistical analysis of patterns and underlying processes

Figure 4.1 Explaining geospatial analysis

forest cover change in protected areas. Over the last 25 years, the GEF has provided more than $\$ 3.4$ billion in grants and an additional $\$ 12$ billion in raised cofinancing for the protection of almost 2.8 million $\mathrm{km}^{2}$ of the world's terrestrial ecosystems. A substantial portion of the GEF's support is dedicated to strengthening protected areas and protected area systems and ensuring their sustainability. Our impact evaluation of the GEF's long-term support to protected areas and protected area systems using remotely sensed satellite data analysis demonstrated that GEF-supported protected areas had, in general, better conservation outcomes (less forest loss) compared to their buffers - protected areas that were not supported by the GEF - and compared to the overall respective country averages (GEF IEO 2016).

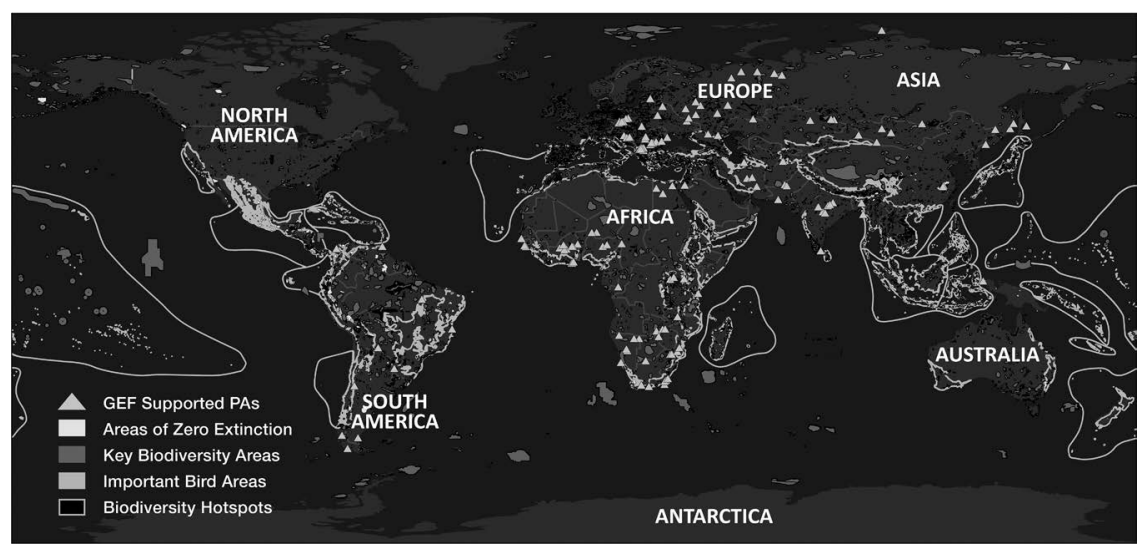

Figure 4.2 Use of geospatial analysis to assess relevance of GEF's biodiversity interventions 

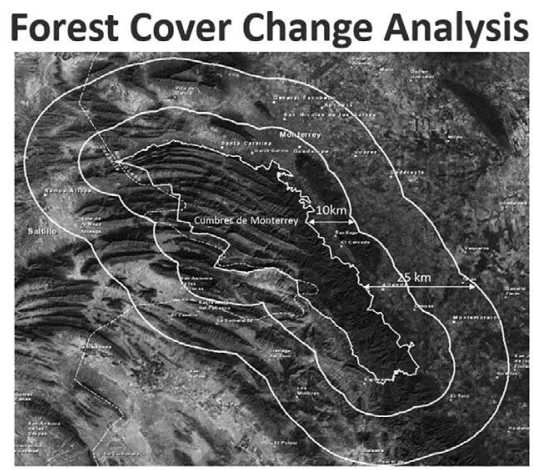

Percent Tree Cover (2000) PA-25km(excluding the inner)

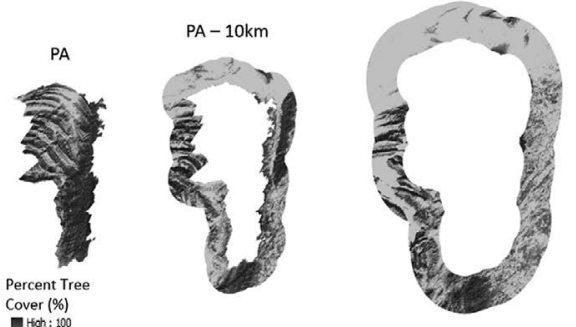

Cumbres de Monterrey, MEXICO

Decadal Forest Cover, Gain and Loss (2000-2012)

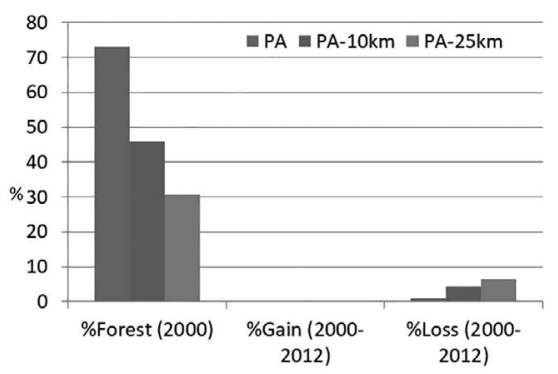

Yearly Percent of Forest Loss (2000-2012)

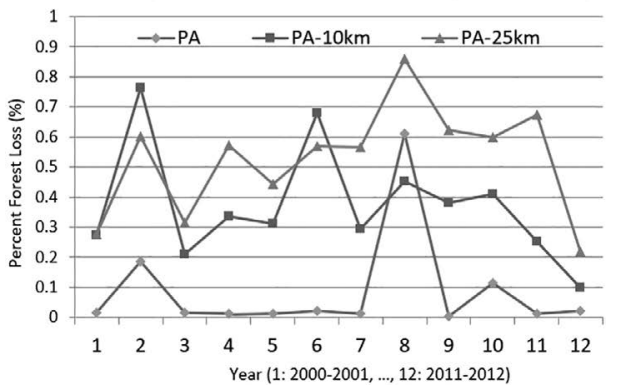

Figure 4.3 Using geospatial analysis to measure impacts: analysis of forest cover change from geospatial data 
Figure 4.3 uses an example from a protected area in Mexico to illustrate the forest change data used for the global analysis. It shows the protected area boundary and the buffer area; the forest cover for the base year; and charts of forest cover, forest gain, and forest loss.

Together, applying geospatial data and our array of quantitative methods has helped us address common methodological challenges such as lack of baseline data, low survey response rates, sampling bias, difficulties in selecting appropriate counterfactuals, and accounting for the impact of multiple scales and contexts on processes and interventions. This has strengthened our evidence, allowing us to deliver robust analysis.

\section{Application of geospatial analysis to measure efficiency: a value-for-money analysis}

For development interventions and projects, particularly in a situation of scarce resources, a key question among donors remains: do interventions deliver value for money? To address this question for GEF interventions, we brought together economists, computer scientists, and geographers with expertise in remote sensing and impact evaluation to apply a value-for-money (VFM) assessment to the case of GEF land degradation and biodiversity projects (GEF IEO 2018). This approach explicitly quantified the causally identified impact attributable to GEF project locations using three indicators: capturing vegetation productivity, forest fragmentation, and forest cover change. It also demonstrated the VFM achieved by these GEF projects in terms of carbon sequestration. The research team conducted a series of quasi-observational experiments contrasting land degradation and biodiversity project locations with geographic locations at which no known intervention occurred and that were similar in qualities such as initial environmental state, proximity to infrastructure, and environmental characteristics. We used these contrasted locations in conjunction with hybrid econometric propensity score matching and machine-learning techniques to account for both potential variation in treatment effects across different sociopolitical and environmental conditions and uncertainty in underlying assumptions and data.

Recent work (see Athey and Imbens 2015; Shen et al. 2016; The PLOS ONE Staff 2014) has illustrated that, with certain adjustments, evaluators can use machine learning approaches to identify how the causal effects of an intervention (e.g., international aid, a medical treatment) vary across key parameters. This approach's relevance in top-down or global-scope analyses makes it applicable to GEF projects because they are unlikely to have the same effect across highly variable geographic contexts, and the drivers of such variation may not be known. We leveraged a wide range of environmental, socioeconomic, and project characteristic covariate information to ensure that comparisons were between similar sets. This included distance to roads, rivers, urban areas (travel time), nighttime light intensity, slope, elevation, temperature, and precipitation ranges. It also included geographic 
factors such as latitude and longitude to promote matches that were reasonably geographically proximate - matched locations were within $50-250 \mathrm{~km}$ of each other. After constructing impact estimates following the causal tree approach, we estimated valuations in a two-step procedure:

1 First, we used the National Aeronautics and Space Administration's (NASA's) carbon storage data set and the Intergovernmental Panel on Climate Change's (IPCC's) Tier-1 Global Biomass Carbon Zones to translate the impact of GEF projects on the three indicators into estimates of carbon sequestration using a linear modeling approach that accounts for regional differences in the relationship between flora and the indicators.

2 We then used value transfer to approximate valuations for both carbon sequestration and biodiversity. In this approach, the value of nonmarket services is approximated based on previous studies of similar services. Although primary data collection on valuation can provide strong, in-situ measurements of valuation, evidence suggests that the density of literature on similar services - and the cost-effective nature of the value transfer approach - positions value transfer as a strong second-best strategy.

\section{Land degradation impacts}

This study identified a global positive impact of GEF land degradation projects along all indicators examined, but also noted considerable heterogeneity in these impacts across different geographic contexts. Findings included:

- A lag time of 4.5-5.5 years was an important inflection point at which larger impacts were observed.

- Projects with access to electricity tended to have some of the largest relative positive impacts.

- The initial state of the environment is a key driver in GEF impacts, with GEF projects tending to have a larger impact in areas with a poor initial condition.

- Projects in Africa and Asia had generally positive impacts on average.

- Projects in Latin America and the Caribbean, North and South America, and Oceania all had positive impacts on all three indicators.

The analysis identified a range of values consistent with previous analyses of the value of land degradation projects. Because considerable uncertainty exists, the range of potential benefits from a single-focal area land degradation project is estimated at $\$ 52-\$ 143 /$ ha affected in terms of carbon sequestration alone; soil retention promotes an additional value of $\$ 10-\$ 43 / \mathrm{ha}$, for a total valuation of $\$ 62-\$ 186 /$ ha across degradation projects. After accounting for costs, the IEO estimated that the per-dollar return on investment for land degradation projects is approximately $\$ 1.08$ per dollar invested. This is likely to be an underestimate, since it only captures two ecosystem services. 
For valuation, we used a six-step procedure:

1 Generate precise geospatial data for every site at which a GEF land degradation project operated.

2 Use satellite information to derive long-term measurements of each of the three outcomes at each geographic location.

3 Integrate the data generated in steps 1 and 2 with a wide set of geographically varying ancillary data - such as nighttime lights, population, and distances to roads and rivers - to match project locations to "control" locations where no intervention occurred.

4 Use a novel propensity score matching approach, causal trees, to examine the impact of project locations on each indicator of interest.

5 Use observed patterns between these indicators and carbon sequestration to estimate the contribution of each project location in terms of tons of carbon sequestered.

6 Apply a value transfer approach to enable users to valuate individual project locations alongside a presentation of reference values found in the literature. ${ }^{4}$

Across the entire globe, within $25 \mathrm{~km}$ catchment areas, GEF land degradation projects:

- Increased normalized difference vegetation index (NDVI) by approximately 0.03 (average NDVI is 0.55 ),

- $\quad$ reduced forest loss by 1.3 percent (global mean of forest loss in all areas is 2.4 percent), and

- increased the average size of forest patches by $0.25 \mathrm{~km}^{2}$ (global mean size is $7.3 \mathrm{~km}^{2}$ ).

The estimated carbon sequestered by the GEF was - on average $43.52 \mathrm{tC} / \mathrm{ha}$. This equates to an estimated 108,800 tC sequestered by each land degradation project location. ${ }^{5}$ Across the 8,093 valuations of carbon identified as a part of the value transfer approach (Costanza et al. 2014) used to estimate project location valuations (deflated to 2014), we identified a median dollar value of $\$ 12.90 / \mathrm{t}$, drawing on academic, industrial, and government reports. Using this value, we estimated that GEF land degradation projects contributed $\$ 7.5$ million (2014) on average to sequestration alone - well above the average cost (approximately $\$ 4.2$ million) of most such projects.

\section{Biodiversity impacts}

This analysis extended the VFM methodology we applied to the land degradation case to GEF biodiversity projects, identifying their globally positive impact on vegetation productivity and forest cover (see Figure 4.4). Findings included:

- Globally, GEF biodiversity projects tend to have a positive impact on both indicators assessed. 


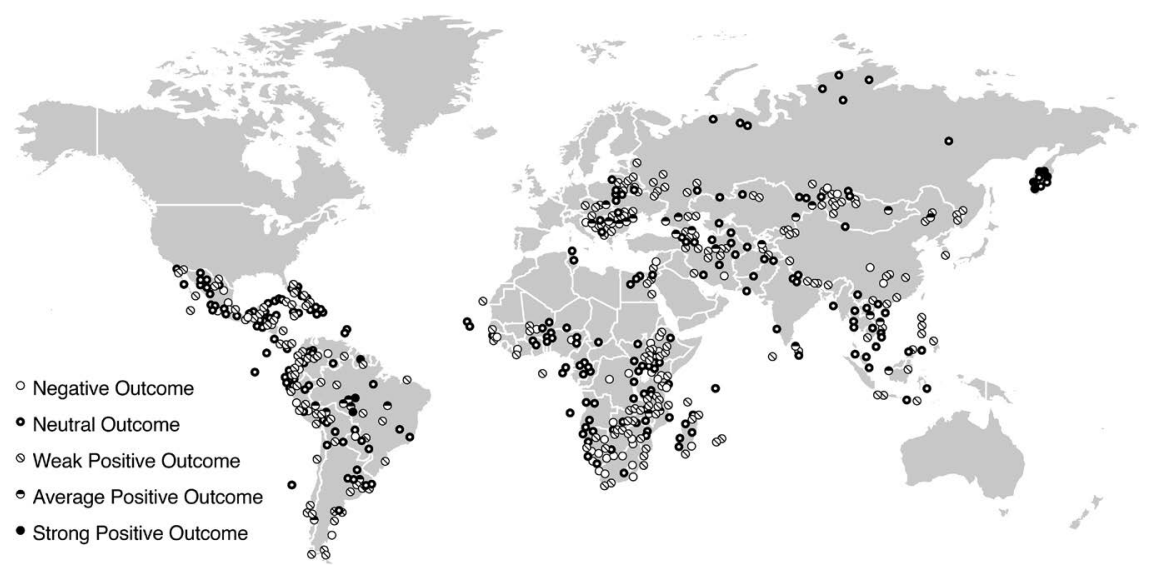

Figure 4.4 GEF biodiversity project outcomes

- Performance improved as projects increased in size, with the strongest positive outcomes in the top 20 percent of funded projects.

- Biodiversity projects had noticeable impacts after the first year of implementation.

- Biodiversity projects are sensitive to access to electricity.

We conducted valuation of biodiversity projects using the same approach as for land degradation activities (see Figure 4.5). Following this methodology, evaluators estimated a range of $\$ 60-\$ 166 /$ ha of affected area for carbon sequestration with an additional value of $\$ 10-\$ 41$ attributable to soil retention benefits, for a total of $\$ 70-\$ 207 /$ ha. On average, we found a return of $\$ 1.04$ per dollar invested, although considerable uncertainty remains around this value. Geographically, impacts on forest cover were relatively homogeneous;

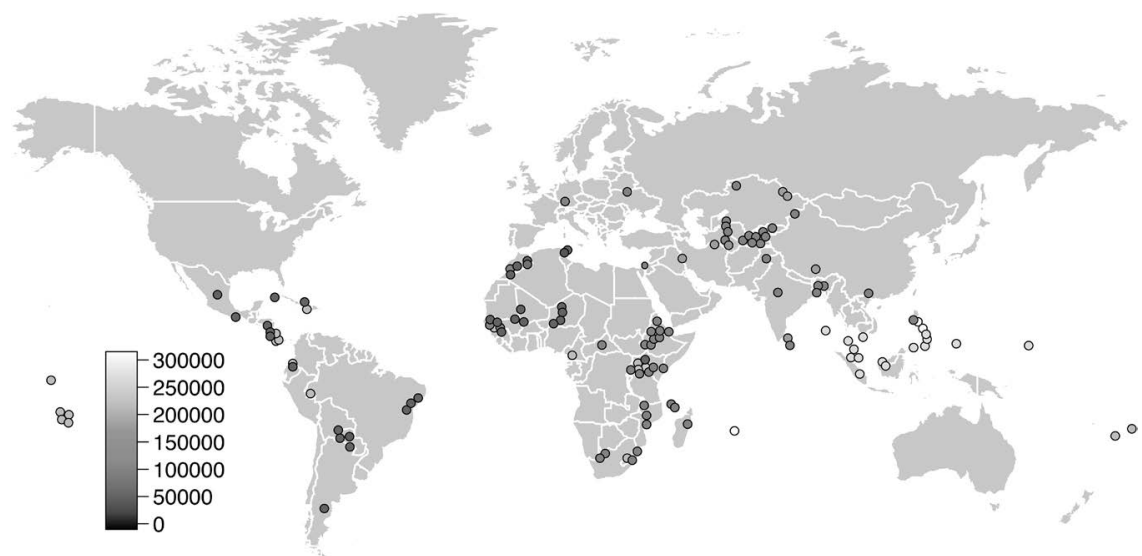

Figure 4.5 GEF biodiversity project location valuations 
however, significant geographic heterogeneity existed in the case of vegetation productivity.

\section{Measuring socioeconomic co-benefits}

Evaluations drawing on a variety of data sources and methods are particularly useful as we expand our analyses to better understand the socioeconomic co-benefits of the GEF's environmental projects. Such approaches also help offset the biases and limitations of one method with the strengths of another.

The IEO combined geospatial data with other data sources to measure socioeconomic co-benefits of GEF sustainable forest management (SFM) projects in Uganda. We expanded the VFM analysis to assess the impact and global environmental benefits of GEF investments and technical support through SFM interventions. This study assessed the impacts of SFM interventions on environmental and biophysical variables, the co-benefits measured in terms of socioeconomic indicators, and the estimation of monetary values of ecosystem services based on the principle of natural capital accounting. The majority of GEF SFM project sites are in Sub-Saharan Africa, Latin America, and the Caribbean. Madagascar, Colombia, and Brazil have the largest number of GEF SFM project sites, which were in locations with very high initial conditions of deforestation. The GEF projects were targeted not toward areas that might maximize socioeconomic co-benefits, but those that were more likely to improve environmental outcomes.

\section{Effectiveness and valuation}

We estimated that the GEF SFM interventions ${ }^{6}$ avoided approximately $4,875 \mathrm{~km}^{2}$ of deforestation over their respective implementation periods (an average of $2.5 \mathrm{~km}^{2}$ per intervention location). Combined with improvements in vegetation density, this project cohort contributed additional sequestered above-ground carbon of $1.33 \mathrm{tC} / \mathrm{ha}$ /year, worth $\$ 727,990$ annually on average (under a conservative valuation of carbon at $\$ 12.90 / \mathrm{Mt}$ ), compared to locations with no GEF interventions. This conservative estimate represents only the 1,924 project locations for which precise geospatial information was available. If valuation is extrapolated to cases for which such information was not available but a known site of implementation exists $(3,585$ intervention locations), the estimate is $\$ 1.36$ million/year. This contrasts to an average implementation cost of $\$ 5.9$ million, resulting in a break-even point of 4.5 years if only above-ground biomass is considered in valuation.

\section{Positive socioeconomic impacts}

A portfolio level global-scope analysis of economic and social co-benefits of GEF SFM projects suggest a small, positive impact on socioeconomic benefits indicated by nighttime light intensity. A majority of SFM interventions, especially since 2014, were designed to address multiple focal area objectives. These interventions not only achieved the carbon sequestration described earlier, but 
showed evidence of positive effect on nighttime lights, a proxy for economic development, that was not previously discernible. These findings may underestimate the true impacts across the GEF SFM portfolio because they exclude projects for which the descriptions lacked high-precision geographic data.

GEF SFM projects are also associated with an increase in household assets. The local-scope case study of Uganda (GEF IEO 2019b) provided more direct estimates of economic impacts, leveraging the World Bank Living Standards Measurement Survey (LSMS) to detect the impact of GEF projects on households within $50 \mathrm{~km}$. By matching LSMS locations proximate to GEF interventions to those far away from GEF interventions, the local analysis showed that GEF SFM projects were associated with an increase in household assets between $\$ 163$ and $\$ 353$ (within $40-60 \mathrm{~km}$, respectively). The Uganda case study shows that households within $50 \mathrm{~km}$ of a GEF implementation site tended to experience improvements in assets approximately $\$ 310$ higher than those not proximate to a GEF implementation site.

Despite their many advantages, particularly during crises such as that presented by COVID-19, remote sensing and other forms of quantitative information do not address the "how" and the "why" behind the "what." They do not provide an understanding of a program's context, and they cannot explain the relationships and interactions among various factors that influence the complex systems within which GEF interventions take place. These methods need to be complemented by other forms of data collection such as interviews, case studies, and field verification to provide context for interpretation. As part of our thematic and country evaluations, we collect such qualitative information through interviews, focus group discussions during field visits, case studies, and relevant documents. We use text analytics, qualitative comparative analysis, and rapid-impact evaluation methods to understand the causal contribution of different conditions and factors. We have applied tools such as Nvivo to existing project documents to help identify a portfolio of interventions under specific themes of interest to extract information from documents and conduct analysis showing the linkages among interventions, outcomes, and contextual factors.

A mixed-methods approach, applying a combination of quantitative and qualitative methods, and drawing on data from a variety of sources, has helped us offset the limitations of using these methods separately, particularly in explaining outcomes and influencing factors within a system of interest. By triangulating results from various methods, we can establish integrity, validity, and reliability of evaluation findings and provide sound evidence for conclusions and recommendations.

\section{Notes}

1. In other global development institutions, such as the World Bank and UNDP, operational staff conduct or manage terminal evaluations. The World Bank's Independent Evaluation Group validates those terminal evaluations; the process varies across UN agencies. 
2. For example, the World Bank brought out a practical guide based on extensive experience (Gertler et al. 2011), and, more recently, the Asian Development Bank issued a similar book with updated practices and material (White and Raitzer 2017).

3. According to GEF's Project Management Information System, the GEF grant was $\$ 5.4$ million.

4. http://labs.aiddata.org/gef.

5. This estimate is based solely on the additive impact of GEF land degradation projects on additional sequestration, that is, the total tons sequestered due to each GEF project that otherwise would not have been sequestered. This only includes estimates of gains due to changes along the three indicators examined (forest fragmentation, NDVI, and forest land cover) and thus may not represent the full envelope of all sequestration that is attributable to GEF projects.

6. Subset of project implementation sites that met the inclusion criteria.

\section{References}

Athey, S., and G. Imbens. 2015. "Recursive Partitioning for Heterogeneous Causal Effects." Papers 1504.01132, arXiv.org. https://ideas.repec.org/p/arx/papers/1504.01132.html.

Benn, J., C. Sangaré, and T. Hos. 2017. "Amounts Mobilised from the Private Sector by Official Development Finance Interventions-Guarantees, Syndicated Loans, Shares in Collective Investment Vehicles, Direct Investment in Companies, Credit Lines." www.oecd-ilibrary.org/development/amounts-mobilised-from-the-private-sectorby-official-development-finance-interventions_8135abde-en.

Carugi, C., and H. Bryant. 2019. "A Joint Evaluation with Lessons for the Sustainable Development Goals Era: The Joint GEF-UNDP Evaluation of the Small Grants Programme." American Journal of Evaluation 41 (2): 182-200. https://journals.sagepub. com/doi/abs/10.1177/1098214019865936?journalCode=ajec.

Castalia Strategic Advisors. 2014. Evaluation of Lighting Africa Program-Final Report. Report to International Finance Corporation. Washington, DC: Castalia Strategic Advisors.

Costanza, R., R. de Groot, P. Sutton, S. Van der Ploeg, S.J. Anderson, I. Kubiszewski, S. Farber, and R.K. Turner. 2014. "Changes in the Global Value of Ecosystem Services." Global Environmental Change 26: 152-158. https://doi.org/10.1016/j. gloenvcha.2014.04.002.

Garcia, R.J., and A. Zazueta. 2015. "Going Beyond Mixed Methods to Mixed Approaches: A Systems Perspective for Asking the Right Questions." IDS Bulletin 46 (1). www.gefieo. org/documents/staff-publication-going-beyond-mixed-methods-mixed-approaches.

GEF. 2012. "Time for Transformational Change: The Role of the GEF." www.thegef. $\mathrm{org} /$ sites/default/files/publications/GEF-vision-Ishii_0.pdf.

GEF. 2015. GEF 2020: Strategy for the GEF. Washington, DC: Global Environment Facility. www.thegef.org/publications/gef-2020-strategy-gef.

GEF IEO. 2006. Evaluation of Incremental Cost Assessment. GEF/ME/C.30/2. Washington, DC: Global Environment Facility Independent Evaluation Office.

GEF IEO. 2016. Impact Evaluation of GEF Support to Protected Areas and Protected Area Systems (PAS). Washington, DC: Global Environment Facility Independent Evaluation Office. www.gefieo.org/evaluations/impact-pa-support-2016.

GEF IEO. 2017. Guidelines for GEF Agencies in Conducting Terminal Evaluation for Full-Sized Projects. Washington, DC: Global Environment Facility Independent Evaluation Office. www.gefieo.org/evaluations/gef-guidelines-te-fsp-2017. 
GEF IEO. 2018a. An Evaluative Approach to Assessing GEF's Additionality. Washington, DC: Global Environment Facility Independent Evaluation Office.

GEF IEO. 2018b. IEO Brief: A Value for Money Analysis of GEF Interventions in Land Degradation and Biodiversity. Washington, DC: Global Environment Facility Independent Evaluation Office. www.gefieo.org/evaluations/synopsis/vfm-2016-land-degradation-brief.

GEF IEO. 2018c. Value for Money Analysis for GEF Land Degradation Projects. Washington, DC: Global Environment Facility Independent Evaluation Office.

GEF IEO. 2019a. Evaluation of GEF's Support to Mainstreaming Biodiversity. Washington, DC: Global Environment Facility Independent Evaluation Office.

GEF IEO. 2019b. Value for Money Analysis of GEF Interventions in Support of Sustainable Forest Management. Washington, DC: Global Environment Facility Independent Evaluation Office.

GEF IEO. 2020. Evaluation of the GEF-UNIDO Global Cleantech Innovation Programme. Evaluation Report No. 135. Washington, DC: Global Environment Facility Independent Evaluation Office.

Gertler, P., et al. 2011. Impact Evaluation in Practice. Washington, DC: World Bank.

Lech, M., J.I. Uitto, S. Harten, G. Batra, and A. Anand. 2018. "Improving International Development Evaluation through Geospatial Data and Analysis." International Journal of Geospatial and Environmental Research 5 (2). https://dc.uwm.edu/ijger/vol5/iss2/3.

OECD DAC. 2019. "Evaluation Criteria." OECD DAC Network on Development Evaluation. www.oecd.org/dac/evaluation/daccriteriaforevaluatingdevelopmentassistance. htm.

Oxfam International. 2017. Private-Finance Blending for Development-Risks and Opportunities. Oxford: Oxfam GB.

Runfola, D., G. Batra, A. Anand, A. Way, and S. Goodman. 2020. "Exploring the Socioeconomic Co-Benefits of Global Environment Facility Projects in Uganda Using a Quasi-Experimental Geospatial Interpolation (QGI) Approach. Sustainability 12 (8): 3225. www.mdpi.com/2071-1050/12/8/3225.

Shen, C., Y. Hu, X. Li, Y. Wang, P.-S. Chen, and A.E. Buxton. 2016. "Identification of Subpopulations with Distinct Treatment Benefit Rate Using the Bayesian Tree." Biometrical Journal 58 (6): 1273-1566. DOI: 10.1002/bimj.201500180.

Sidman, G., S. Fuhrig, and G. Batra. 2020. “The Use of Remote Sensing Analysis for Evaluating the Impact of Development Projects in the Yellow Sea Large Marine Ecosystem." Sustainability 12 (9): 3628. www.mdpi.com/2071-1050/12/9/3628.

The PLOS ONE Staff. 2014. "Correction: Inferring Tree Causal Models of Cancer Progression with Probability Raising." PLoS One 9 (12): e115570.

White, H., and D. Raitzer. 2017. Impact Evaluation of Development Interventions-A Practical Guide. Mandaluyong: Asian Development Bank.

World Bank and Independent Evaluation Group. 2015. World Bank Group Support to Electricity Access, FY2000-2014-An Independent Evaluation-Volume II: Together for Energy: How Partnership Programs Support Energy Access. Washington, DC: World Bank.

World Bank Group. 2007. Lighting Africa Year 1: Progress and Plans, Annual Report, September 1, 2007-August 31, 2008. Washington, DC: World Bank Group. www.ifc.org/ wps/wcm/connect/e44329fc-4259-47c5-802b-51b6836e5366/LightingAfrica_r3\% 2B-\%2BFINAL.pdf?MOD=AJPERES \&CACHEID=ROOTWORKSPACE-e44329fc4259-47c5-802b-51b6836e5366-jqets.U. 


\section{Performance, effectiveness, and sustainability of GEF interventions}

Since its founding in 1991, the Global Environment Facility (GEF) has implemented projects and programs to enhance global environmental benefits in climate change, biodiversity, land degradation, chemicals and waste, and international waters. In fact, the GEF is the only public, international institution that addresses global environmental issues beyond climate change alone. More recently, the GEF has implemented projects that cut across focal areas (multifocal) and through a more integrated approach. These interventions are designed to deliver environmental benefits in more than one focal area and may also generate socioeconomic co-benefits. Across all GEF work, the projects and programs take into account the significance of gender, indigenous peoples, and the important role of the private sector in the issues we address. As described in previous chapters, the GEF Independent Evaluation Office (IEO) exists to ensure through evaluation that GEF projects and programs achieve their aims and make a lasting difference. To that end, we evaluate the performance, effectiveness, and sustainability of the work.

In this chapter, we first present the overall performance results of the GEF portfolio (GEF IEO 2017c) and the various factors driving these results. We look deeper into the results by exploring performance ratings by region and consider the attributes affecting performance: project design, quality of implementation and execution, and cofinancing. We also evaluate the impacts of GEF policies, including those on gender and indigenous peoples.

The second part of the chapter explores the longer term impacts and sustainability of GEF interventions and the channels through which these are achieved. Central to success for large-scale, long-term impacts is the concept of broader adoption, which occurs when governments and other stakeholders adopt, expand, and build on GEF interventions, based on initial success.

\section{Overall performance}

\section{Satisfactory project outcomes}

Of the 1,706 projects completed since the GEF's inception, 80 percent have had outcomes in the satisfactory range. ${ }^{1}$ These ratings confirm almost 30 years 
$100 \%$

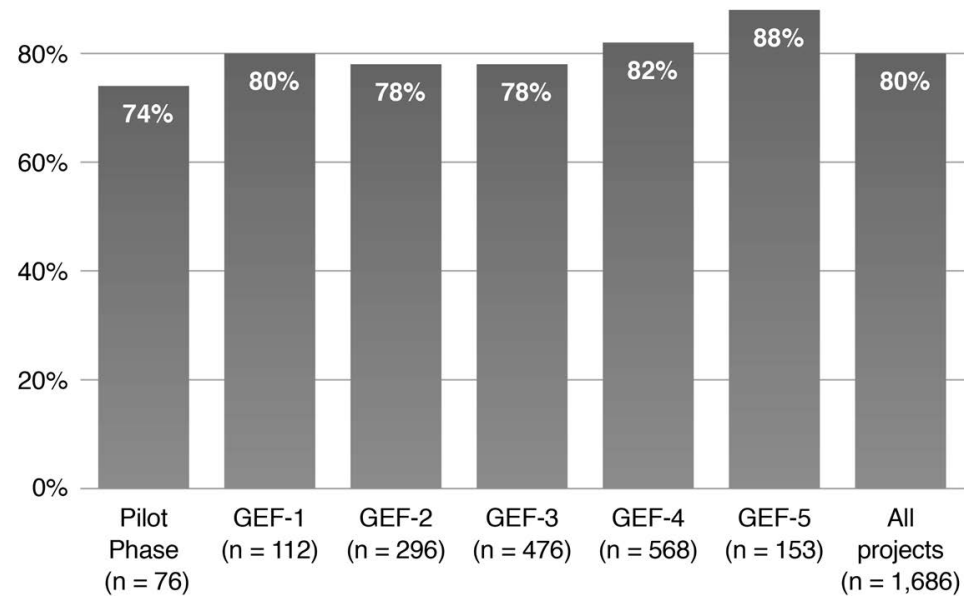

Figure 5.1 Projects with outcomes in the satisfactory range, by GEF period

of GEF project success in steadily delivering expected short- to medium-term results (see Figure 5.1). Our assessment of results draws primarily on data from the terminal evaluations submitted by the agencies and validated by the IEO. Most GEF-6 projects are still under implementation, thus terminal evaluations are not yet available.

Project performance heterogeneity by regions

In evaluating projects, we first consider groupings by region to provide a highlevel understanding of project outcome success (Figure 5.2). The one region

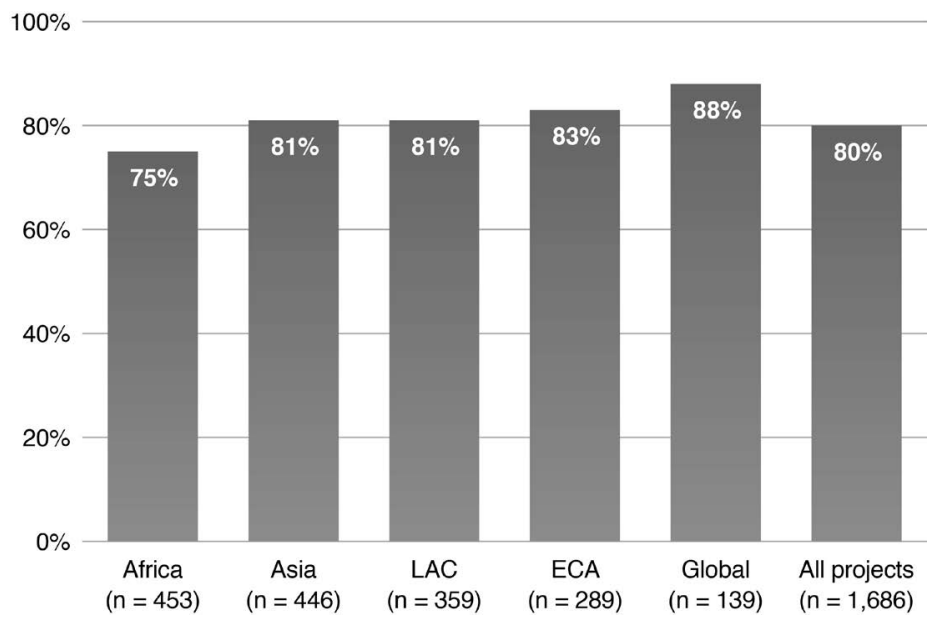

Figure 5.2 Projects with outcomes in the satisfactory range, by region 
that has a significantly lower percentage of projects earning a satisfactory rating (75 percent) is Africa. However, performance varies across subregions within Africa. In North African countries, outcomes of 90 percent of GEF projects were rated in the satisfactory range, while only 69 percent and 62 percent of the projects in East Africa and West Sub-Saharan countries, respectively, were rated in the satisfactory range. ${ }^{2}$ This underscores the impact of the country context on development outcomes. Components of that context can include

- Government ownership and support

- Implementation capacity

- Policy environment

- Nongovernmental organization and community participation

- Private-sector participation

- Economic and market conditions

When we consider project outcomes by country groups, 87 percent of projects implemented in the middle income countries, including Brazil, China, India, Mexico, and Russia, were in the satisfactory range, as compared with 72 percent and 65 percent in the least developed countries and the small island developing states, respectively.

Although several factors drive project performance, statistical analysis indicates a strong correlation between the quality of implementation and execution, level of cofinancing that ultimately materializes, and outcome performance. Weaknesses in project design contribute to poorer outcomes; these can include overly ambitious objectives, inadequate budgets for planned activities and arrangements to facilitate follow-up, weak institutional arrangements and government and stakeholder support, and poor monitoring and evaluation (M\&E) design (GEF IEO 2014a).

\section{Implementation}

A project's rating for quality of implementation reflects the extent to which the GEF has performed its role satisfactorily in project identification and preparation, start up, supervision, application of the GEF policies and procedures, and project M\&E. It also reflects the extent to which the GEF took timely actions to correct any identified gaps in project design and implementation. National executing agencies, which can be either governmental or sometimes nongovernmental, are typically responsible for carrying out the project activities on the ground under the supervision of the GEF. These activities include implementing project design, procurement, stakeholder consultations, and project monitoring. Parallel to the increase in overall project satisfaction, the quality of implementation of GEF projects has also improved over time. Overall, 81 percent of projects received satisfactory ratings in project implementation, with the performance improving over the course of the GEF periods (Figure 5.3). 


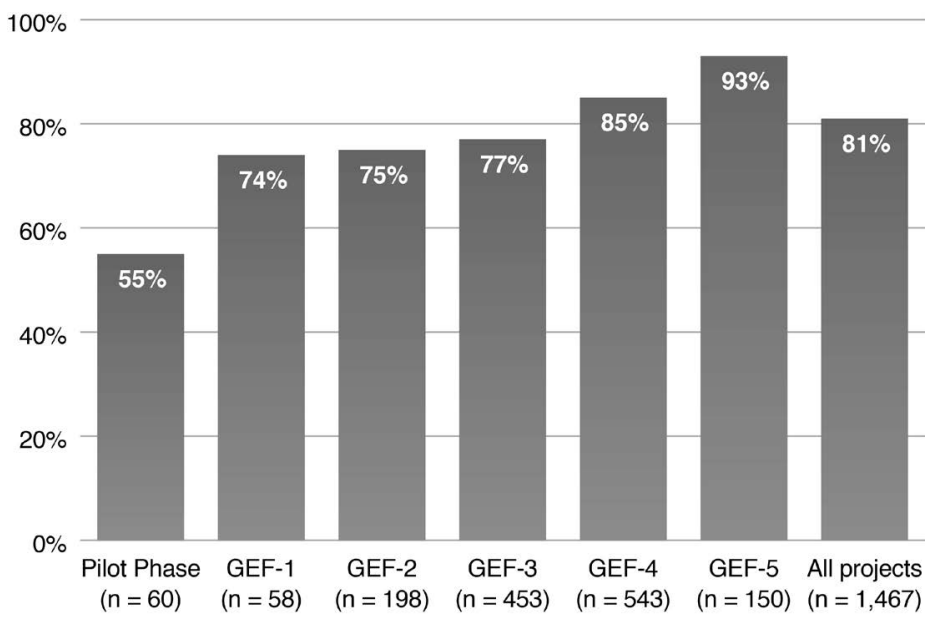

Figure 5.3 Projects with implementation rated in satisfactory range, by GEF period

Another crucial component of project performance is raising additional financing from governments or the private sector. This demonstrates commitment to a project and supports the long-term financial sustainability of interventions. The GEF Co-Financing Policy (GEF 2014a), ${ }^{3}$ operationalized during GEF-6, targets a 6:1 level of cofinancing for the overall GEF portfolio. On average, cofinancing of $\$ 6.49$ per dollar materialized in that period. In 61 percent of the projects completed in the GEF's three decades, at least 90 percent of the promised cofinancing actually materialized. Realized cofinancing is higher in China, Brazil, India, Mexico, and the Russian Federation, at 82 percent, compared with 56 percent in least developed countries and 67 percent in the small island developing states, where raising extra resources from the government or the private sector is a bigger challenge. Meeting cofinance targets is a challenge in Africa, which is reflected in the lower project outcome ratings for that region.

Project monitoring involves the design and implementation of an $\mathrm{M} \& \mathrm{E}$ plan by GEF Agencies to track implementation progress and achievement of results. An M\&E plan specifies indicators to track processes and results, responsibilities, frequency of data collection, reporting procedures, and a budget for monitoring activities. The plan may need to be updated or modified during implementation. Because the quality of M\&E design and implementation influences project performance, our rating reflects the extent to which an M\&E plan was well designed and well implemented. (See Chapter 6 for more discussion of M\&E design and implementation.) Overall, 67 percent of GEF projects have received a satisfactory rating for $M \& E$ design, with clear improvement occurring over GEF periods (Figure 5.4). However, ratings have generally been lower for overall implementation of M\&E plans than for design since GEF-3. 
Project M\&E Design Rated as Satisfactory
Project M\&E Implementation

Rated as Satisfactory

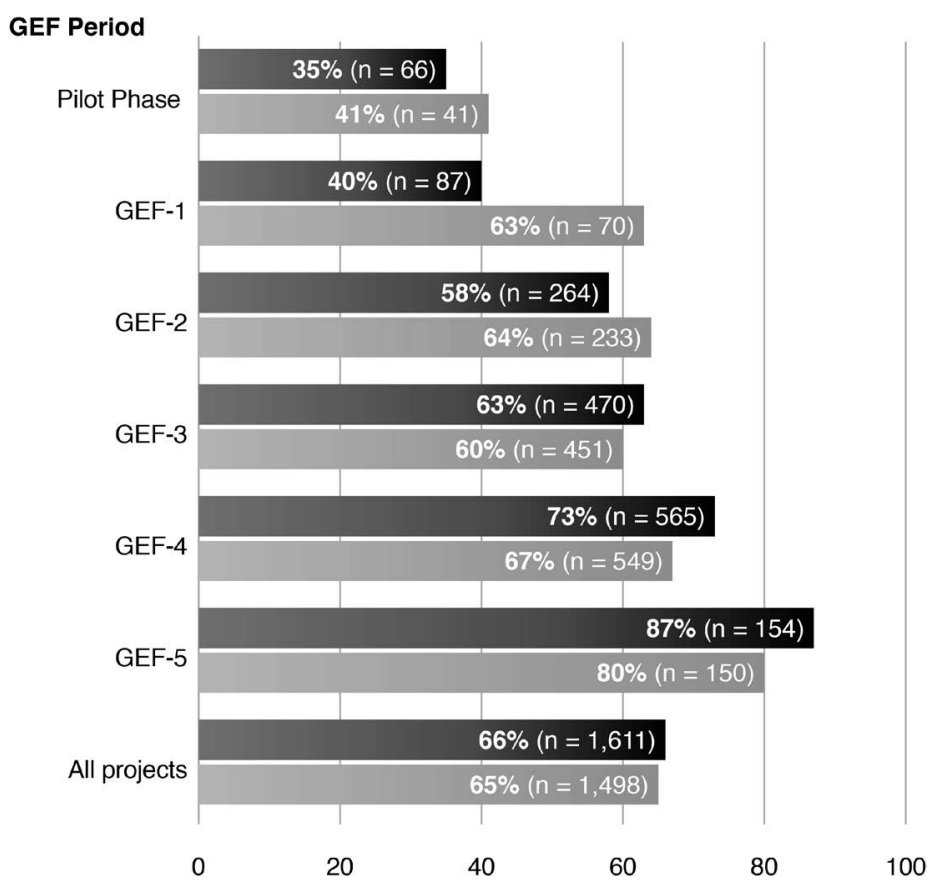

Figure 5.4 Project M\&E design and implementation rated as satisfactory, by GEF period

\section{Sustainability outcomes: achievements and limitations}

Donors and funding recipients are interested in achieving project outcomes, but are even more concerned with long-term sustainability of these outcomes. Sustainability is influenced by the quality of project preparation, country context, government support, quality of implementation and execution, M\&E, and the actual amounts of realized cofinancing (GEF IEO 2018a). An analysis of terminal evaluations for GEF projects shows improvement in ratings for sustainability of outcome across the GEF replenishment periods (see Figure 5.5); 62 percent of the completed GEF projects were rated in the "likely" range for outcome sustainability. However, this means that roughly 4 out of 10 projects face considerable risks to continuation of their benefits. Among the regions, Africa has a significantly lower percentage of projects that are rated as likely to be sustainable, reflecting differences in regional and country capacities (see Figure 5.6). Within Africa, countries in North Africa have a higher percentage of sustainable projects $(64$ percent) than those in East Africa and West Sub-Saharan Africa (35 percent). ${ }^{4}$ Considering sustainability of projects in select country groups, 85 percent in China, Brazil, India, Mexico, and the Russian Federation were rated in 
$100 \%$

$80 \%$

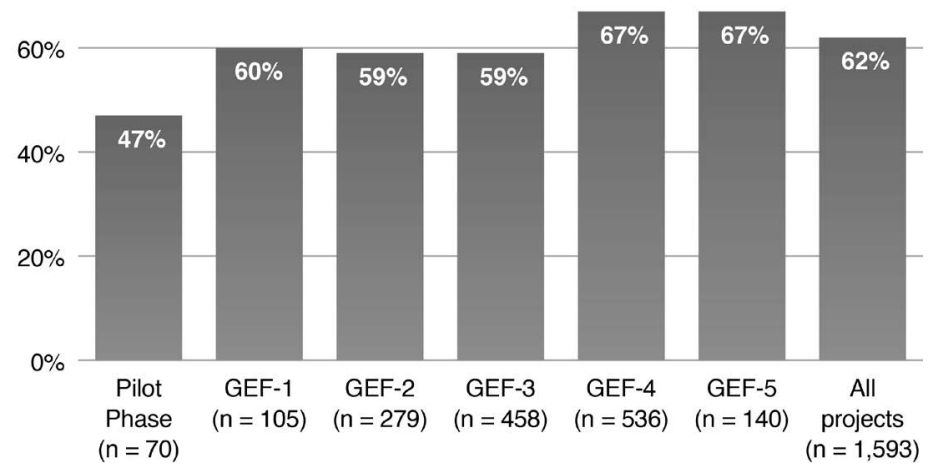

Figure 5.5 Projects with likely sustainability, by GEF period

the likely range for sustainability compared to 44 percent in least developed countries. Projects in landlocked developing countries and small island developing states closely tracked the portfolio performance for sustainability, at 58 percent and 64 percent.

These findings on sustainability are not unique to the GEF - the percentage of GEF completed projects with a likelihood of sustainability at project completion is comparable with other multilateral organizations. These organizations have differences in terms of their mandate, geographical coverage, and

$100 \%$

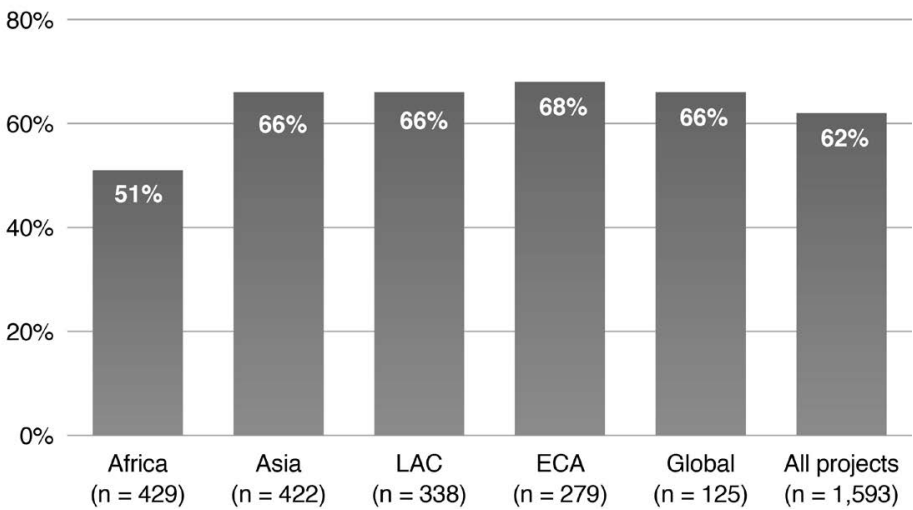

Figure 5.6 Projects with likely sustainability, by GEF region 
scale of activities, but their percentages of projects rated in the likely range for sustainability are within a 12 -point range:

- African Development Bank: 52 percent

- Asian Development Bank: 66 percent

- International Fund for Agricultural Development: 60 percent

- Inter-American Development Bank: 62 percent

- World Bank: 65 percent

- GEF: 62 percent

The only outlier is the United Nations Environment Programme, where the percentage of projects with likely sustainability is 79 percent. $^{5}$

\section{Sustainability beyond project closure}

To fully grasp whether a GEF project's outcomes are sustainable, an evaluation at the time of closure may be too soon. For most GEF projects, outcomes are sustained during the post-completion period. In fact, a high percentage of projects achieve environmental stress reduction and broader adoption after the project is completed, rather than during implementation. This suggests that achieving and observing sustainability takes time, often extending beyond the project implementation period. The key factors that contribute to this sustainability after completion include high stakeholder buy-in, political support, availability of financial support for follow-up, and sustained efforts from the executing agency.

The closure of a project may be too early for project outcomes to manifest fully: a change in a protected area's environmental status can take more than a decade, and policy measures or new technologies implemented during projects also may achieve outcomes past closure. For example, stakeholder involvement in the Conservation and Sustainable use of the Mesoamerican Barrier Reef System Project led to an assessment by the United Nations Educational, Scientific, and Cultural Organization two years after the project's completion, resulting in the official placement of the Belize Barrier Reef World Heritage Site on the list of endangered sites. Another project, the bikeshare system introduced in Rosario, Argentina, by the Latin America and the Caribbean Regional Sustainable Transport and Air Quality Project, had higher usage rates three years after project completion than at the completion date, with rates expected to increase further with planned expansion. Box 5.1 presents details on outcome sustainability for a project in the $\mathrm{Ba} \mathrm{Be}$ Protected Area.

\section{Implementation of GEF policies}

The GEF Policy on Gender Equality (GEF 2017a) has advanced the GEF's efforts to strengthen gender mainstreaming in GEF programming and operations in 


\section{Box 5.1}

\section{Outcome sustainability in Ba Be Protected Area}

The GEF project Promotion of Sustainable Forest and Land Management in the Vietnam Uplands, implemented from 2010 to 2013, supported sustainable forest management in $\mathrm{Ba}$ Be National Park. Threats to the forest include fragmentation of habitat, conversion of forest land for infrastructure and agriculture, illegal hunting, and overuse for non-timber forest products. The project was focused on local communities and piloted several approaches:

- improved systems for animal husbandry and conservation of sloping lands

- bio-energy applications

- payment for ecosystem services including participatory approaches to forest protection

- eco-tourism

Remote sensing data showed that forest cover in Ba Be Protected Area has remained stable after project completion due to the community-focused project design, attention to income-generation activities, and sustained support from provincial governments (see Figure 5.7).

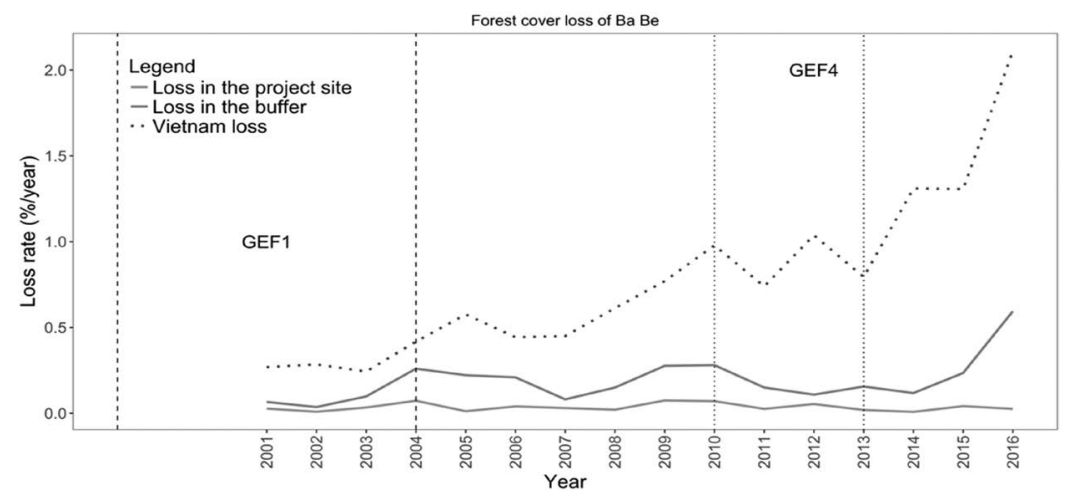

Figure 5.7 Forest cover loss of $\mathrm{Ba} \mathrm{Be}$

a systematic manner, and there is further room for improvement in implementation. Since the policy's implementation in 2017, project documentation has shown that gender consideration at the point of chief executive officer project endorsement/approval rose from about 57 percent to almost 98 percent. The GEF Gender Partnership is slowly developing into an effective platform on which to build a wider constituency on gender and the environment, providing a forum for leveraging the broad range of member skills and experiences on gender equality and women's empowerment. 
OPS6 identified specific shortcomings and aspects for improvement in this policy. First, it stops short of providing a compelling rationale for why gender matters in environment-focused interventions. It also does not provide a rationale as to how the inclusion of gender equality in environmental projects would generate benefits beyond effectiveness and efficiency. The policy could reference the gender-related mandates or decisions of the five conventions the GEF serves. Although gender performance in GEF interventions has improved since the introduction of the policy, only about 14 percent of projects at entry included a gender analysis, which is integral to mainstreaming.

The GEF policies and guidance on safeguards and indigenous peoples have advanced the GEF's efforts in these areas; however, gaps exist in the policy frameworks relative to good practice in partner agencies and in implementation. The adoption of the GEF Policy on Agency Minimum Standards on Environmental and Social Safeguards in 2011 prompted several agencies to develop or revise their own safeguard systems. By design, these improvements have occurred principally during the accreditation process for new agencies and compliance review for existing agencies. Gaps exist in the framework in relation to recent updates made in GEF partner agencies, and no guidance addresses ongoing reporting or monitoring on safeguard-related issues during project implementation. Most GEF Agencies comply with the obligations specified under GEF Minimum Standard 4: Indigenous Peoples. These principles and guidelines reinforce GEF policies toward indigenous peoples, but lack practical guidance on project design and indicators, or a list of requirements that could aid in operationalizing the minimum standard and other relevant GEF policies.

\section{Focal area performance}

In the course of the OPS6, we considered the outcomes and sustainability of the projects in each of the GEF's five focal areas and multifocal projects. This section explores each of the focal areas: its definition, project success rates on various metrics and across regions, and progress in broader adoption and mainstreaming. This takes place when information, lessons, or specific results of GEF interventions are incorporated into broader stakeholder mandates and initiatives such as laws, policies, regulations, or programs. We also consider the focal areas' success in achieving catalytic effects through the steps on the catalytic chain: production of a public good, demonstration, replication, and scaling up (see Figure 5.8).

\section{Biodiversity}

Changing the trajectory of biodiversity loss means addressing its five primary drivers: habitat change, overexploitation or unsustainable use, invasive alien species, climate change, and pollution. All of these are intensifying, particularly habitat loss driven by the expansion of agriculture. 
Outcomes (share of projects in the satisfactory range)
Sustainability (share of projects in the likely range)

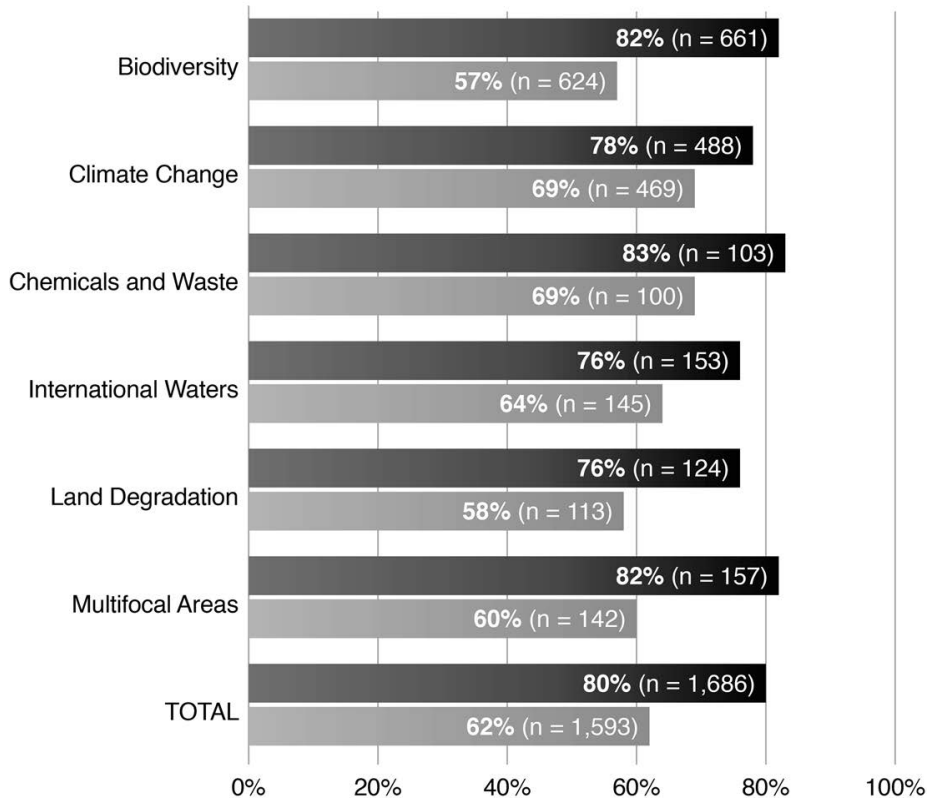

Figure 5.8 Focal area outcomes and sustainability ratings

The GEF's biodiversity strategy aims to maintain globally significant biodiversity in landscapes and seascapes. To achieve this, the GEF provides financial resources for developing countries and countries with economies in transition to implement the Convention on Biological Diversity. GEF investments in this focal area focus on:

- Mainstreaming biodiversity across sectors, landscapes, and seascapes

- Addressing direct drivers to protect habitats and species

- Further developing biodiversity policy and institutional frameworks

Our evaluation of the biodiversity portfolio using 554 terminal evaluations found that 83 percent of projects in this focal area had satisfactory outcome ratings. The biodiversity portfolio performed slightly better than the overall GEF portfolio on all counts except sustainability; 57 percent of biodiversity projects were rated in the likely range for sustainability. When considering this focal area by region, we found that projects in Eastern Europe, Central Asia, and global projects tend to have the highest ratings on all indicators, while projects in Africa have the lowest ratings for outcomes, sustainability, $M \& E$ design and implementation, and quality of project implementation and 
execution. In all regions, average execution quality and average implementation quality are rated substantial to high, but overall sustainability of projects is rated low to modest.

\section{Protected areas and protected area systems}

Most GEF biodiversity interventions focus on strengthening protected areas and protected area systems and ensuring their sustainability through strategic expansion, improved management, sustainable financing, and targeting factors in biodiversity loss beyond the protected areas. These interventions have contributed to preserved habitats, positive trends in species population, and reduction of threat. Of the 1,292 protected areas supported by the GEF, 58 percent are classified as key biodiversity areas, 31 percent do not hold that classification but have received international designations of high biodiversity and/or cultural value, ${ }^{6}$ and the remaining 11 percent are of local or national significance. This points to the high relevance of GEF investments in areas with significant biodiversity.

Our analysis methods demonstrate how GEF support contributes to biodiversity conservation by helping reduce habitat loss in protected areas. A geospatial analysis of data between 2001 and 2012 showed that forest loss in GEF-supported protected areas was half the loss in those without GEF support in the same biomes and countries. The results also showed that countries with long-term GEF support had better conservation outcomes. Through targeted interventions at the site level, GEF-supported protected areas generally see positive trends in species populations and reduced pressures to biodiversity, such as from agriculture, cattle ranching, and tourism. Overall, GEF support contributed to change in key factors affecting biodiversity conservation in protected areas - such as building stronger management capacities, promoting participatory planning and stakeholder support, improving technical capacities, mainstreaming biodiversity and sustainable use, and demonstrating social and economic benefits. Box 5.2 presents an illustrative case for Mexico.

Although determining the returns to GEF interventions has often been a challenge, it has always been a priority area for donors. The IEO piloted an approach to determine the efficiency or "value for money" of GEF projects using a value transfer approach, which uses natural capital accounting to estimate the value of land degradation and biodiversity in terms of the amount of carbon sequestered. We applied this approach to 550 GEF biodiversity projects across 3,095 project locations. The analysis estimated the impacts along multiple indicators to capture changes in natural capital in three ecosystem services: carbon sequestration, recreation, and soil retention. We found that GEF biodiversity projects generate positive returns on investment across the board. The overall value of a GEF biodiversity project was estimated at $\$ 6,065.59 /$ ha. On average, it generated a return of $\$ 1.04$ per dollar invested, a figure that is likely an underestimate. 


\section{Box 5.2}

\section{Mexico: assessing GEF support's impact on forest preservation}

In Mexico, the GEF has supported the National System of Natural Protected Areas (SINAP) for nearly 25 years through three projects. The first was originally intended to strengthen protected area management in up to 17 Mexican reserves. It was restructured to include a flexible endowment for long-term funding to support high-quality staffing and operations in 10 protected areas. It also provided funds for workshops and knowledge exchanges. Over time, this model of learning by doing and exchange of knowledge led to the strengthening of Mexico's National Commission on Natural Protected Areas (CONANP), an institution now highly respected in the country's public administration system. In 2008, the Mexican government decided to bring all CONANP staff under the government budget, and made available endowment funds previously dedicated to supporting 23 protected areas to civil society organizations implementing strategic projects in these areas. Thus, GEF support to Mexico's protected area system was mainstreamed through strengthened government institutions.

Given the GEF's long-term support to Mexico and fewer gaps in identifying GEF-supported protected areas, we conducted a robust, quasi-experimental analysis to assess the impact of GEF funding. Using propensity score matching, we used satellite data products to compare GEF-supported protected areas with similar protected areas that did not receive GEF support. We found that, from 2001 to 2012, GEF-supported areas in Mexico avoided up to 23 percent more forest loss than those that did not receive direct GEF support.

(Source: GEF IEO 2016a)

Projects that have mainstreaming with other components or mainstreaming alone had more sustainable and more satisfactory outcomes than those focused exclusively on protected areas. Box 5.3 presents an example in India. Eighty-nine percent of the biodiversity mainstreaming projects with the combination of forestry and agriculture have satisfactory ratings, as do 86 percent of the projects in the agriculture sector. In comparison, 56 percent of fisheries projects, which do not address mainstreaming, have satisfactory outcome ratings. In terms of sustainability, 90 percent of the projects in the agriculture sector, which incorporate mainstreaming, were rated satisfactory, as compared to 50 percent in fisheries.

\section{Climate change}

Action on climate change requires ambitious programs to limit emissions of greenhouse gases while supporting communities' adaptation to the unavoidable impacts of existing climatic changes. It also means embracing the potential of the green economy that balances economic, social, and environmental priorities. 


\section{Box 5.3}

\section{India: demonstrating impacts in the East Godavari River Estuarine Ecosystem}

Habitat destruction, pollution, and overexploitation of coastal and marine resources pose major threats to the biologically and economically important East Godavari River Estuarine Ecosystem (EGREE). The EGREE includes the Coringa Wildlife Sanctuary, the second largest extension of mangroves on the eastern coast of India. It is also a fast-growing development hub, including manufacturers, industries, and offshore oil and gas exploration. EGREE ecosystem services directly provide livelihoods to around 100,000 people in the 44 villages surrounding the sanctuary. Major activities include fisheries, aquaculture, and agriculture. The Godavari estuary, comprising 62,000 ha, lost 1,250 ha of mangroves in between 1992 and 2004, primarily due to anthropogenic pressures (Satapathy et al. 2007).

The Mainstreaming Coastal and Marine Biodiversity Conservation into Production Sectors in the East Godavari River Estuary, Andhra Pradesh child project, aimed to enable a governance environment that would prevent further degradation of coastal and marine ecosystems, allowing the continuous flow of ecosystem goods and services - such as coastal protection and fisheries - while preserving an ecosystem of unique biological value. The approach included mainstreaming biodiversity into public- and private-sector plans and developing cross-sector institutional mechanisms to harmonize development and conservation of biodiversity.

We used data derived from daily satellite observations to examine the long-term spatial and temporal patterns of vegetation to assess the project's impact on the local ecosystem. The results suggest no net loss of vegetation cover in the project area. In fact, we estimated an overall minor increase in mangrove density when comparing the project period 2011-2015 to the pre-project period 2007-2009.

(Source: GEF IEO 2017a)

The GEF serves as part of the Paris Agreement's financial mechanism, helping to ensure transparency and assisting countries in meeting their goals. The GEF's strategies address both climate change mitigation (supporting developing countries' transformational shifts toward low-emission development pathways) and climate change adaptation (supporting climate-resilient development pathways while reducing exposure to the immediate risks posed by climate change).

The GEF's strategies for climate change mitigation programming focus on promoting innovation and technology transfer and creating an enabling environment. Approximately 77 percent of completed projects in the climate change mitigation portfolio have overall outcome ratings in the satisfactory range, with some themes performing better than others. Sustainability remains a challenge; these ratings were linked to projects' 
financial stability and cofinancing did not fully materialize for nearly three quarters of these projects.

The GEF supports scaling-up of public and especially private climate investment by strengthening the enabling environment. Capacity-building and policy activities can leverage significant impact, according to our 2014 evaluation of GEF climate change mitigation support in China, India, Mexico, and Russia (GEF IEO 2014b). GEF climate change projects frequently focus on reforming policy and regulations, building public- and private-sector capacity, and raising awareness to reduce information barriers and support market change. GEF support has been limited but critical for development of some countries' energy policies and laws, primarily regarding energy efficiency and renewable energy. For successful private-sector engagement, technical assistance and capacity building are critical, particularly in projects piloting financial models to scale up energy efficiency and renewable energy adoption. These lessons are significant in light of the climate change focal area's substantial private-sector portfolio.

Most GEF climate change projects have shown some evidence of catalytic effects. The most common evidence was mainstreaming (primarily through policy or regulatory reform) in about 70 percent of closed projects. Performance was less strong for replication, scaling up, and market changes. The most impactful GEF mitigation projects in China, India, Mexico, and Russia are those using comprehensive approaches to address market barriers and specifically targeting supportive policy frameworks. Success in scaling up typically involved follow-on funding from the GEF or other multilateral or bilateral donors, or support for nationally owned programs via projects with significant multilateral development bank (MDB) cofinancing. We found similar catalytic effects in the Least Developed Countries Fund and Special Climate Change Fund (LDCF/SCCF) portfolio, where virtually all 27 completed projects achieved production of a public good and demonstration, but performance was not as strong in replication and scaling up (GEF IEO 2016b, 2017b).

Typical GEF support in this focal area includes aid to countries in meeting their convention obligations; flexible grant financing; focus on the enabling environment to support scaled-up climate investment; emphasis on demonstrating technologies and financial approaches, including innovative and risk-sharing approaches; and the ability to fund integrated projects across environmental issues. Other potential niches for the GEF include focusing on upstream activities to develop supportive conditions through capacity building, technical assistance, and policy and regulatory reform to accelerate market development. The GEF may also contribute by piloting innovative technologies and market mechanisms.

\section{Climate change adaptation and the LDCF/SCCF}

The interventions of the 297 projects in the LDCF/SCCF portfolio are highly relevant to decisions by the United Nations Framework Convention 
on Climate Change, GEF objectives, and the GEF strategic pillars for climate change adaptation:

- Reduce vulnerability and increase resilience through innovation and technology transfer for adaptation

- Mainstream adaptation and resilience for systemic impact

- Foster enabling conditions for effective and integrated adaptation

Our quality-at-entry review showed that 98.4 percent of LDCF/SCCFfunded projects have a high to very high probability of delivering tangible adaptation benefits. Of 27 completed LDCF/SCCF projects, those focused on farming were most typical, such as introducing and demonstrating drought-resistant crop varieties. Projects' primary constraint to scaling up was securing sufficient resources after implementation and/or mainstreaming the work, such as within national budgets. Among the complete projects, 75 percent were rated likely to achieve sustainable outcomes, while the remaining projects were rated moderately unlikely.

Despite the continued relevance of the funds and evidence that projects are delivering tangible adaptation results, LDCF/SCCF resources have been completely inadequate to meet demand. Unpredictability of funding creates uncertainty for GEF Agencies and countries that rely on LDCF/SCCF support to implement their primary climate change adaptations. It also negatively influences stakeholders' perception of the funds' transparency and affects the funds' efficiency.

\section{Chemicals and waste}

Present in all of Earth's ecosystems, toxic chemicals affect biodiversity, agricultural production, water quality, and human health. Numerous international agreements address the production, use, and disposal of chemicals, but all three are rapidly increasing in developing countries and countries in economic transition. These rapid changes increase economic opportunities but must be matched by enhanced initiatives for sound chemicals and waste management to prevent significant harm to humans, wild species, and ecosystems.

The GEF has two strategic objectives in this focal area:

1 Develop the enabling conditions, tools, and environment for the sound management of harmful chemicals and wastes

2 Reduce the prevalence of harmful chemicals and waste and support the implementation of clean alternative technologies/substances

Ambitious Sustainable Development Goal targets related to the environmentally sound management of chemicals and waste make this focal area increasingly important. Its projects adhere to the guidance of the conventions for which it is the financial mechanism and support the goals of related 
multilateral environmental agreements, including the Strategic Approach to International Chemicals Management, the Basel and Rotterdam Conventions, the Montreal Protocol, and the Minamata Convention.

Projects in this focal area have largely performed on par with those in other focal areas in terms of achievement of outcomes: among 23 closed projects, 79 percent of national projects and 80 percent of global projects have satisfactory outcomes. By region, success rates were higher in Asia (91 percent) and Europe and Central Asia (79 percent), and lower in Latin America and the Caribbean (67 percent) and Africa (50 percent). Performance data indicate potential challenges for chemicals and waste projects with regard to the sustainability of persistent organic pollutants (POPs) results and the outcomes, sustainability, and quality of implementation of multicountry projects. Seventy-four percent of the projects demonstrated strong country ownership, which is one driver of success among projects addressing POPs; the other is private-sector commitment.

More than 80 percent of chemicals and waste projects engaged the private sector, primarily large national and multinational corporations, in cofinancing, capacity building, direct support, or participation in project design and implementation. One ongoing challenge is a deficiency of incentives, or sometimes scope, to combine chemicals-related issues to promote sector-wide approaches, such as updating legislation to fully address chemicals and waste, rather than just PCBs, or to address solid waste management more broadly, rather than just POPs waste. Some multifocal area projects - notably, the Sustainable Cities Integrated Approach Pilot (IAP) Program - focus broadly on solid waste management, with benefits to climate change mitigation and other toxic substances. This challenge affects scaling up; broader institutional infrastructure may be needed to support hazardous waste or chemicals management. This challenge also can affect cofinancing or mainstreaming into larger investment projects.

Balancing hard outcome targets (such as tons of POPs and mercury disposed) against the importance of soft activities and outcomes (such as support for developing policy and regulatory frameworks and institutional strengthening) is difficult. In our evaluation, many interviewees noted the lessons learned from the Montreal Protocol in terms of the value of strong regulatory regimes to support ozone-depleting substance phaseout and ensure that the private sector continues to implement the good practices that individual projects demonstrated. A related challenge is the trade-offs sometimes necessary between hard outcome targets and political realities, such as tackling the biggest problem sites to meet convention targets versus prioritizing countries that may not have yet received funding for their national implementation plan (NIP) or funding lower tonnage projects in Africa.

The most common form of broader adoption among chemicals and waste projects was mainstreaming, with limited success in scaling up or replication. Mainstreaming was achieved primarily through the adoption and enforcement of laws and regulations at national and local levels. Until recently, 
projects have not sufficiently focused on approaches to scale up or replicate successes. Many completed projects have demonstrated the collection and destruction of POPs and reduced environmental stress in a relatively straightforward manner but have not established sustainable strategies and financial mechanisms to scale up those results. Among the few exceptions are several GEF POPs interventions in China. For example, the project Improvement of DDT-based Production of Dicofol and Introduction of Alternative Technologies including IPM for Leaf Mites Control in China finalized an integrated pest management national replication program prior to project completion. Replication activities have been initiated at several provincial locations and are expected to expand nationwide and to cover additional crops. Factors in the success of this program are availability of financial resources and technology support.

The GEF cannot finance the collection and destruction of every ton of legacy POPs, nor can it fund the conversion of every industrial facility to cleaner production processes. A more robust theory of change is needed for how the GEF's demonstration activities will catalyze broader action and impact in the chemicals and waste focal area. This may involve the development of innovative private-sector partnerships, economic instruments, and financial models, as envisioned in the GEF-6 Chemicals and Waste Focal Area Strategy.

\section{International waters}

While not serving one specific international agreement, the international waters focal area contributes to the enhancement of regional security and supports the sustainable use and protection of transboundary waters, their living resources, and dependent ecosystems. Projects in this focal area also help ease tensions between riparians, improve livelihoods of the vulnerable, and sustain economic and social development, consistent with the 2030 Agenda for Sustainable Development.

The international waters focal area follows a stepwise, long-term, ecosystem-based approach to building transboundary cooperation and the restoration and protection of transboundary water bodies. With a reliance on science and knowledge management and a systemic view of the many interconnected variables controlling water, this approach places the focal area in a unique position as a catalyst of integration. International waters foundational projects have demonstrated that solutions to water concerns lie not just in improving water supply and treatment, or in protecting aquatic ecosystems and environmental flows, but also - and often primarily - in distant sectors such as food and energy production, trade, land use and urban planning, industrial processes, and forests management.

Among 127 completed projects related to international waters, 79 percent of regional projects have satisfactory outcomes, as do 64 percent of national projects. On a regional basis, success rates were highest in Asia (80 percent) and lowest in Europe and Central Asia (65 percent). 
A unique feature of this focal area is the prevalence of projects (11 percent, receiving 6 percent of focal area funding) directed at learning, improving project quality, capturing existing knowledge on water issues, assessing global international waters priority concerns, and making available to all project knowledge and experiences. Through building databases, innovating knowledge management, thinking across jurisdictions and focal areas, and linking freshwater with marine environments, this focal area has achieved significant outcomes in learning from its own experiences and in systematic exchange among projects and partners. The GEF has had considerable success in promoting transboundary cooperation around freshwater basins and is the only multilateral fund in this space. Solutions to transboundary water concerns require national actions in multiple dimensions and GEF focal areas. Through its ecosystem approach and transboundary diagnostic analysis-strategic action program consensus-building process, the international waters focal area provides countries with the framework to direct part of their investments of GEF System for Transparent Allocation of Resources (STAR) funds where they are most needed to balance transboundary water uses.

\section{Land degradation}

Land degradation - the deterioration or loss of the productive capacity of the soils for present and future use - is a global challenge and a pressing environmental problem that will worsen without rapid remedial action. It contributes significantly to climate change and reduced productivity of croplands and rangelands worldwide. The GEF works to arrest and reverse desertification and deforestation across sectors from crop and livestock production to water resource management.

The focal area strategy closely reflects convention guidance and, since 2016, has integrated into its programs and priorities the United Nations Convention to Combat Desertification's (UNCCD's) objective of achieving land degradation neutrality. ${ }^{7}$ Although land degradation problems are most obvious in desert margins and other arid lands, GEF support for tackling land degradation continues to pursue geographical balance and to include non-dryland areas. The land degradation focal area addresses unsustainable land management practices and degradation issues as driven by country priorities and needs, going beyond arid, semiarid, and dry subhumid areas.

Integrated landscape projects have increased, but restoration activities are limited. Agricultural lands, rangelands, degraded productive lands, and desert lands are the most frequent land types in single focal area projects, with fewer projects addressing urban lands. Since the early 2000s, projects have shifted toward more holistic, integrated landscapes with an almost 30 percent increase in integrated landscapes over that time frame. Most GEF efforts are focused on sustainable land management, and restoration is slowly gaining attention.

Performance of this focal area portfolio is slightly lower than the GEF average, with satisfactory outcome ratings for 76 percent of projects. Land 
degradation focal area investments have led to positive impacts on UNCCD targets, specifically reducing forest loss and forest fragmentation, and increasing vegetation productivity. A geospatial impact analysis and a value-formoney analysis showed important reductions in fragmentation and forest loss and an increase in vegetation productivity and carbon sequestration.

Improvements in vegetation cover from land degradation projects also generated environmental benefits through higher levels of carbon sequestration. Based on our value-for-money analysis, an estimated average of 108,800 tC is sequestered in each land degradation project location. At a valuation of $\$ 12.90 /$ t (GEF IEO 2018d), individual land degradation projects contributed $\$ 7.5$ million on average to sequestration - well above the average cost of most of these focal area projects.

GEF land degradation projects yield overall positive returns on investment. Between carbon sequestration and soil retention values, we estimate benefits from a single focal area land degradation project at $\$ 62-\$ 186 /$ ha. After accounting for costs, the per-dollar return on investment for land degradation projects is approximately $\$ 1.08$ per dollar invested, and this is likely an underestimate because it captures only two ecosystem services.

Project duration, infrastructure access, and initial conditions are correlated with effectiveness. A time lag of 4.5-5.5 years was an important inflection point at which we observed impacts. This highlights the length of time it takes to observe actual environmental improvements on the ground, a factor that poses challenges both to evaluators and to project proponents expecting quick solutions. Projects with access to electricity tend to have some of the largest relative positive impacts, potentially due to better infrastructure and access to energy sources for irrigation. Understandably, GEF projects tended to have a larger impact in areas with poorer initial environmental conditions. However, this does not necessarily mean that investments should focus on the most degraded areas, because priority areas for restoration may lie elsewhere.

Developing multistakeholder partnerships, improving income generation, and addressing climate risks are important for project success in this focal area. Evidence from case studies demonstrates the value of effective partnerships between government agencies, civil society, the private sector, and grassroots organizations in addressing policy issues such as land tenure rights, environmental issues such soil erosion, and loss of land productivity. Project activities that focus on income and market access - and that teach adaptive practices to cope with climate risks - improve both environmental and socioeconomic outcomes and influence residents' decisions not to migrate to urban areas.

\section{Multifocal area projects}

Multifocal area programs and projects are funded through allocations from more than one focal area, or are labeled as such. The 250 multifocal area projects account for 10 percent of the GEF portfolio, equivalent to 13 percent of total GEF grants. The most common combinations in multifocal area 
projects include biodiversity and land degradation (54 percent); half of these also include climate change.

The great majority of multifocal area projects adhere to convention guidance and address both global and national priorities by targeting environmental and socioeconomic objectives together. The multifocal area portfolio reflects global trends toward integration across sectors and between environmental and socioeconomic goals stated in the three Rio Conventions and the Sustainable Development Goals (SDGs). Multifocal area projects also respond to national priorities with flexibility in jointly addressing global environmental commitments and national sustainable development goals through integrated approaches including integrated ecosystem management, integrated landscapes, protected area systems, and production landscapes. These projects allow countries to achieve multiple focal area and livelihood objectives simultaneously.

Among completed multifocal area projects, 77 percent were rated moderately satisfactory or higher. The large majority reported interconnected environmental and socioeconomic benefits and broader adoption of intermediate outcomes. The most common positive environmental outcomes were reduction in environmental stress or threats (90 percent) and improvements in ecosystem cover or quality (71 percent). Increased income or greater access to capital was the most frequently reported socioeconomic outcome (79 percent). Eighty percent of projects reported that broader adoption had taken place or begun by project end, primarily as mainstreaming and sustaining of outcomes, and replication. Engagement of key stakeholders, good project design, and coordination with related initiatives were among the factors most frequently cited as contributing to success. Poor achievement of outcomes and adoption in multifocal area projects were linked primarily to low institutional capacity among executing agencies.

Multifocal area projects have the potential for producing synergies and mitigating trade-offs. Synergy refers to multiple benefits that are achieved either simultaneously through a single intervention or through the interaction of outcomes of at least two interventions. A trade-off is defined as a reduction to one benefit in the process of maximizing or increasing another benefit. We identified synergies across focal areas and socioeconomic priorities in tree planting, clean energy technologies that reduced fuelwood use, sustainable agriculture practices such as the use of organic waste as fertilizer, and ecosystem protection and rehabilitation. Trade-offs were identified between environmental and socioeconomic benefits, between objectives within or among focal areas, between short- and long-term objectives, between beneficiaries, and between local and national benefits. Three types of mitigating measures have reduced potential losses from trade-offs: compensation, compromise, and value addition. Compensation involves direct payment or replacement of income to address the loss of socioeconomic benefits. Compromise occurs when the benefit to one focal area was decreased to reduce the anticipated loss to another focal area or socioeconomic aspect. Value addition occurred 
when an intervention not only addressed the trade-off, but also created focal area and socioeconomic benefits beyond the status quo, essentially producing synergies. We found that projects generate more synergistic benefits when the set of interventions serves multiple objectives; involves multiple sectors in decision-making; or is delivered through integrated spatial units, such as a village, landscape, or watershed.

Multifocal area projects also have efficiency trade-offs. They can create opportunities to fulfill global and national commitments simultaneously, leverage focal area funding, streamline project management costs, and increase multisectoral interaction. The option to integrate funds from multiple focal areas has allowed each focal area's priorities to be addressed in more interventions while using less of each focal area's allocation, especially for the land degradation focal area, which typically receives much lower funding. Although the involvement of more actors at all levels makes the project design and approval more complex, it provides valuable interaction among sectors. The typically larger size of multifocal area projects also allows economies of scale in project management.

Costs are incurred with losses of efficiency, mainly during project design, review, and monitoring, due to the greater number of stakeholders and sectors involved. Multifocal area projects require more focal area expertise and agreement among stakeholders in their design and approval. Whether at the country or corporate level, the involvement of more actors leads to more complex and time-consuming decision-making. In some cases, this has created competition for funding rather than coordination of activities. Current reporting requirements for multifocal area projects increase operating costs, yet often do not capture synergies generated and trade-offs.

\section{Factors influencing program outcomes}

Programmatic approaches have been part of operations since the GEF's establishment and were formally introduced in May 2008. Initially, programs were de facto projects funded through phases with subsequent financing tranches. Clustered programs, introduced after May 2008, included a set of "child projects" designed to contribute to the overall objective of the parent program. In 2015, the GEF introduced the IAP Programs, which focus on the main drivers of environmental degradation and support broad coalitions of committed stakeholders and innovative, scalable activities. Over time, programs have evolved from a narrow approach, largely focused on mitigating the negative effects of food and energy production on biodiversity loss, land degradation, and climate change, toward applying an integrated approach encompassing a wider set of drivers such as food and energy production and consumption, buildings and infrastructure, construction, and transportation.

The GEF portfolio of programs is sizable, diverse, and growing, accounting for 8.7 percent of the total GEF funding as of April 2016. Compared 
to stand-alone projects, programmatic projects performed better, but program complexity matters for outcomes. ${ }^{8}$ Child projects in programs generally performed better than stand-alone projects on all rating dimensions, especially on execution quality, sustainability, and M\&E design. However, performance declined with increased complexity. Although complex programs are designed with a long-term perspective, they are substantially more difficult to execute than simple ones. The India Coastal and Marine Program is an example of a single-country, single-agency, single-focal area program composed of two homogeneous child projects, which successfully demonstrated multisectoral approaches to mainstreaming biodiversity conservation into economic activities in two marine ecoregions of the country. Both child projects have informed national policy actions.

In comparison, the multifocal, multicountry Middle East and North Africa Desert Ecosystems and Livelihoods Program (MENA-DELP) was a nonhomogeneous collection of individual national projects loosely related to each other through a regional "glue" project; these did not realize any additional benefits from their participation in MENA-DELP. We found that the aggregate outcomes and potential impacts of MENA-DELP do not differ from the sum of those of its child projects, apart from some inadequately aggregated $M \& E$ information and limited sharing of lessons learned among child project stakeholders (GEF IEO 2018c).

Designing projects for broader adoption, a central concept for programmatic approaches, has improved substantially, but only limited actions toward its implementation tend to occur. Our analysis of terminal evaluations in programmatic approaches found that 31 percent of child projects indicated intent to promote broader adoption at the design stage, but only 13 percent took concrete steps toward this and 6 percent actually implemented broader adoption actions. The most frequently observed forms of broader adoption are mainstreaming (see Box 5.4) and replication. Scaling up has had little or no broader adoption, despite its being a leading rationale of program design, or effect on market change.

Single-country programs, with stronger ownership and better alignment with country priorities, perform better than multicountry programs. With the exception of programs addressing transboundary issues (notably international waters), GEF programs have progressively shifted over time from a single-country to a multicountry focus. STAR funds are a substantial share of total program resources, regardless of geographic scope. In general, the smaller the country's STAR funds, the higher the share of its total STAR allocation is given to a program. This helps countries maximize their investments and returns in terms of global environmental benefits.

Program/child project coherence in objectives has improved in recent programs, as the design of both programs and their child projects pays greater attention to broader adoption and program objectives are better defined. This improved coherence is notable in the design of highly complex programs, under which projects more specifically address program outcomes. 


\section{Box 5.4}

\section{Demonstrating program impacts through mainstreaming}

The China Integrated Environmental Management (IEM) Drylands Program aimed to address desertification, deforestation, and biodiversity loss resulting from land degradation in China's western dryland provinces. The national government at that time was looking for solutions to massive soil erosion that had led to fatal floods in the lower Yellow River. The program introduced IEM, which brings together different sectors to address multiple environmental and socioeconomic issues in an integrated manner. Through interventions demonstrating IEM, beneficiaries reported improvements in ecosystem protection and vegetation productivity. While achieving these environmental outcomes, local incomes also increased through higher value and more diverse crops. These positive results prompted local governments to mainstream IEM principles into provincial, state, village, and township planning systems. Planning approaches in four out of six provinces have shifted from a top-down to a multisector integrated approach. Recommended IEM actions served as inputs to 26 county development plans, which have been incorporated into provincial and national budgets.

(Source: IFAD 2016)

Cost-effectiveness and efficiency decline as programs become more multidimensional. We analyze cost-effectiveness in the GEF through three factors:

1 Program and child project approval times as per the GEF project cycle

2 Program financing and cofinancing

3 Program effectiveness and efficiency, expressed by terminal evaluation ratings

With this approach, if the costs of a program are less than the alternative (standalone project/cluster of projects), then the program is still more cost-effective. Overall, project cycle analysis shows no major differences between programmatic and stand-alone projects. Our analysis of terminal evaluations found that child projects scored higher on effectiveness and efficiency, and leveraged higher cofinancing than stand-alone projects (at 1:10 vs. 1:7), but efficiency ratings declined with increased program complexity. GEF Agencies' diversity in terms of mandates and operational approaches makes collaboration challenging. Program coordination is an added cost that increases with complexity.

M\&E has improved in the design of recent programs but still faces challenges. Child projects achieved higher ratings for M\&E design compared to stand-alone projects but show weaker implementation of $M \& E$ than their stand-alone counterparts. We have found that $M \& E$ ratings for projects in highly complex programs decline from design to implementation stages. Program M\&E evidence would demonstrate the value addition of a program over a set of projects, but its availability is limited. Box 5.5 illustrates how design affects program outcomes and results. 


\section{Box 5.5}

\section{The GEF Global Wildlife Program: lessons from design}

Of most direct relevance to the COVID-19 pandemic is the GEF's program to combat illegal wildlife trade. The supply chain of wildlife and wildlife products from source areas, and transportation through local, national, and international networks to distant markets, allows for natural spillover and spread of zoonotic disease. Unsafe handling and other practices allow pathogens to pass from wildlife to humans. These conditions and practices are even more challenging to monitor - and impossible to regulate - in illegal wildlife trade. Illegal wildlife trade generates $\$ 26$ billion per year, making it the fourth most profitable illegal industry in the world. Stopping illegal trade has been a difficult endeavor, and unfortunately, as long as there is a demand for wildlife products, there will be trade.

Several GEF-funded projects include activities related to combating illegal wildlife trade and address the drivers of biodiversity loss.

Launched in 2015 and designed to be implemented over seven years, the Global Wildlife Program takes on the issue of illegal wildlife trade in a coordinated and comprehensive way. It involves 20 child projects in Asia and Africa, including one global coordination and knowledge management grant. The program takes a three-pronged approach to address illegal wildlife trade: stop poaching, stop trafficking, and reduce demand. Its main interventions have included supporting protected area management, reducing poaching of target species, engaging communities in managing human-wildlife conflict, improving performance across the enforcement and criminal justice chain, establishing partnerships, and knowledge management. Its success requires collaboration with other partners and international organizations, some of which are not GEF Agencies.

The Global Wildlife Program's comprehensive theory of change addresses the source of wildlife traded illegally, its shipment and transportation, and the market demand, with this supply chain unfolding in source range countries, transit countries, and destination countries. The theory of change also encompasses both short-term and long-term interventions to address illegal trade and ensure that wildlife resources are sustainably used.

The IEO conducted a formative assessment of the program in 2017 (GEF IEO $2018 b)$. At that point, the program was in its early stages of implementation, and the evaluation provided insights into what works, why and under what circumstances, for whom, and the extent of the benefits. The lessons learned from the formative assessment allowed for timely improvements in program implementation.

Our program evaluation found gaps in geographic and species coverage. For example, the program includes no countries from the Latin America and Caribbean region, even though substantial illegal wildlife trade occurs there. This is because the program emerged from a focus on the plight of charismatic megafauna in other regions, specifically the trafficking of elephant ivory, rhinoceros horn, and large cats.

Most Global Wildlife Program funding is aimed at fighting illegal wildlife trade at the source through bolstering support for protected areas, supporting law enforcement efforts, creating opportunities for local communities to benefit from 
conserved wildlife (rather than poached or traded wildlife), and development of alternatives and sustainable livelihoods for local communities. Minimal funding has been allocated to demand reduction and to transit countries, and this focus on source countries risks ignoring trafficking in species that originate outside a country. The global nature of illegal wildlife trade requires addressing cross-boundary issues, in which transportation and logistics sectors - shipping lines, airlines, freight forwarders, and express couriers - all play a critical role.

In another component of program design, the Global Wildlife Program only requires reporting of indicator data on arrests, prosecutions, and convictions as they are relevant to the individual project. Requiring reporting on all these components of the criminal justice system would enhance GEF efforts to combat corruption and build political will.

Moreover, the evaluation underscored the need for a comprehensive approach along the entire supply chain - from sources to global markets - to contain the spread of illegal trade.

\section{Integrated Approach Pilots: innovations and challenges}

The GEF introduced three programs in 2015 to achieve systemic change at scale by addressing the major drivers of global environmental degradation in a holistic way (GEF 2014b). These pilot programs, focused on cities, food security, and commodities, will test the delivery of more integrated approaches that address discrete, time-bound, global environment challenges. The IAPs incorporate multiple GEF and non-GEF Agencies, countries, and interventions designed to be integrated across focal areas. This section presents lessons from the formative review of the three pilots, and highlights key good practices and areas for improvement from our analysis of this pilot experience to date.

The three IAPs are designed to build on existing linkages and connections across focal areas to address global environmental issues more holistically. The IAPs aim to support activities in recipient countries that help generate benefits that correspond to more than one global environmental objective by tackling the underlying drivers of environmental degradation (GEF 2020).

The Sustainable Cities IAP Program (the Cities IAP) recognizes the challenges and opportunities of rapid urbanization in developing countries. The program initially engages 23 cities in 11 countries to promote the integration of environmental sustainability in urban planning and management.

The Sustainability and Resilience for Food Security in Sub-Saharan Africa IAP Program (the Food Security IAP) aims to support countries in safeguarding and maintaining ecosystem services by investing to improve smallholder agriculture and food value chains. The program targets 10 million hectares of production landscapes with 2-3 million beneficiary households in drylands ecosystems of 12 Sub-Saharan African countries.

The Taking Deforestation out of Commodity Supply Chains IAP Program (the Commodities IAP) has been designed through a supply chain lens for each of the three commodities responsible for 70 percent of tropical 
deforestation globally - soy, palm oil, and beef (Brack et al. 2016). It will support activities in the four producing countries of Brazil, Paraguay, Liberia, and Indonesia, and in demand markets. This IAP aims to engage particularly with the private sector.

In these three priority themes, the GEF has an important convening role to support and mainstream environmental management and perspectives. The hub projects can provide a regional forum for participating agencies, countries, and others to discuss coordination, common strategy development, specific technical and institutional assistance to countries, and a strategic learning agenda. The GEF is also vital in bringing together cofinancing resources.

The three IAPs and related child projects have coherent designs in terms of alignment of program and child project objectives, results-based management frameworks, and M\&E systems. However, alignment between project/ program results frameworks and tracking tools in terms of outcomes and indicators is lacking and uneven across the three IAPs.

\section{Designed for innovation}

Innovative features of the IAPs begin with their theories of change. The Commodities IAP has incorporated elements in its design and theory of change that address the major causes of deforestation in a holistic fashion by integrating the entire supply chain. The Food Security IAP theory of change integrates local and landscape natural resource management practices by promoting partnering and enabling policies (Engage), scaling-up of best integrated natural resource management practices (Act), and common measurements and learning (Track). This model has enabled a strong coherence in the formal design and multiscale approach of the child projects. At the child projects level, innovation in the Food Security IAP includes scaling up of new technologies and best practices in new areas, and broadening perspectives to a landscape approach. The Cities IAP is one of many interventions for urban sustainability, but aims to link with as many relevant initiatives as possible. An important innovation for the GEF is direct work with subnational governments for the implementation of Cities IAP child projects. Both the Cities and Food Securities IAPs bridge gaps between the ministries of environment and other government entities in the countries involved.

The introduction of specific knowledge platforms and networks for cross-learning among child projects is a new approach for the GEF and a primary pilot feature in the three IAP Programs. National/global platforms and partnerships will need a strong evidence base to assess whether they can provide the support and momentum necessary to influence activities, perceptions, and sustainability. For the Cities IAP hub project, needed work includes creating a common framework across the child projects, development of a baseline set of indicators, and defining the hub's role in capacity building. The Commodities IAP is a knowledge generation program primarily for the stakeholders involved at the global and national levels. The Food 
Security IAP design supports knowledge exchange and enables the engage/ partnership component of the theory of change.

The design of all three IAPs emphasize broader adoption, which is a primary reason countries participate in the IAPs. We found that all of the IAP child projects include plans for sustaining project interventions and almost all outline specific measures for planned broader adoption of outcomes, replication, and scaling up.

The IAPs have addressed cross-cutting issues in their designs. Gender has been considered in most child projects and more than half of the projects have a gender mainstreaming strategy or plan in place, with specific targets for women's participation in the child projects as beneficiaries and inclusion of gender-specific indicators. Resilience considerations are embedded in the IAPs and resilience is an integrating concept in almost all IAP child projects.

Although most of the IAP projects show well-designed M\&E systems, alignment between program/project results frameworks and tracking tools is needed in terms of outcomes and indicators. Inconsistencies in the expression and measurement of global environmental benefit targets risk hampering program-level M\&E. Data on these targets is scattered throughout program and project documents, and calculation methods vary.

\section{Complexity and challenges}

Designing and launching such complex programs raises challenges, including time required for approval and engagement with a wide set of stakeholders at the design stage. The three IAPs are complex programs - they are multifocal area and multicountry endeavors that engage with multiple GEF Agencies. Moreover, they seek to work at local, landscape, national, and regional levels, which adds considerable challenges to their implementation. Although complex programs may have better longer term sustainability and better $M \& E$ design, they are substantially more difficult to execute than are simple ones (GEF IEO 2017b, 13). Absence of clear criteria in country selection and agency selection based on comparative advantage for program implementation, limited success in harnessing private-sector financing, and a wider set of stakeholders make the processes cumbersome and challenging.

\section{Notes}

1. Performance is measured on a six-point scale: $1=$ highly satisfactory, $2=$ moderately satisfactory, 3 = satisfactory, $4=$ unsatisfactory, $5=$ moderately unsatisfactory, and $6=$ highly unsatisfactory (GEF 2017b).

2. The North African countries are Algeria, Egypt, Libya, Morocco, and Tunisia; the East African countries are Comoros, Djibouti, Eritrea, Ethiopia, Kenya, Madagascar, Mauritius, Rwanda, Seychelles, Somalia, South Sudan, Sudan, Tanzania, and Uganda; the West Sub-Saharan countries are Benin, Cote d'Ivoire, Ghana, Guinea, Liberia, Nigeria, Sierra Leone, and Togo. These subregions correspond to a GEF constituency of member countries and are each represented in the GEF Council. 
3. Cofinancing Policy (GEF/C.46/09), GEF Council Documents, May 2014.

4. This includes three GEF constituencies that consist of following countries: Benin, Cote d'Ivoire, Ghana, Guinea, Liberia, Nigeria, Sierra Leone, and Togo; Burundi, Cameroon, Central African Republic, Congo, Congo DR, Equatorial Guinea, Gabon, Sao Tome and Principe; and Burkina Faso, Cabo Verde, Chad, GuineaBissau, Mali, Mauritania, Niger, Senegal, and The Gambia.

5. The UNEP Annual Performance Report 2018 (UNEP 2018) has a detailed analysis on project sustainability.

6. World Wildlife Fund priority areas, Conservation International biodiversity hotspots, Alliance for Zero Extinction sites, Important Bird Areas, Ramsar sites, or UNESCO World Heritage Sites.

7. The definition of land degradation neutrality was approved by COP12 (July 2015).

8. Complexity is a function of the degree of homogeneity of a program's child projects and whether they belong to one or multiple countries, agencies, and/or focal areas. Tested for statistical significance, the relation between the outcome ratings from available terminal evaluations and the four complexity factors has shown that complexity is a good predictor of outcomes and is inversely related to the outcomes: the higher the complexity, the lower the outcomes (GEF IEO 2017b).

\section{References}

Brack, D., A. Glover, and L. Wellesley. 2016. Agricultural Commodity Supply Chains: Trade, Consumption and Deforestation. Research Paper. London: Chatham House.

GEF. 2014a. GEF Co-Financing Policy (GEF/C.46/09). Washington, DC: Global Environment Facility.

GEF. 2014b. GEF Replenishment Meeting Document GEF/R.6/20/Rev.04. Washington, DC: Global Environment Facility.

GEF. 2017a. GEF Policy Series-GEF Policy on Gender Equality. Washington, DC: Global Environment Facility.

GEF. 2017b. Guidelines for GEF Agencies in Conducting Terminal Evaluation for Full-Sized Projects. Washington, DC: Global Environment Facility. www.gefieo.org/evaluations/ gef-guidelines-te-fsp-2017.

GEF. 2020. Integrated Approach Pilots. Washington, DC: Global Environment Facility. www.thegef.org/topics/integrated-approach-pilots.

GEF IEO. 2014a. Annual Performance Report. Washington, DC: Global Environment Facility Independent Evaluation Office.

GEF IEO. 2014b. Climate Change Mitigation Impact Evaluation. Washington, DC: Global Environment Facility Independent Evaluation Office.

GEF IEO. 2016a. Impact Evaluation of GEF Support to Protected Areas and Protected Area Systems (PAS). Washington, DC: Global Environment Facility Independent Evaluation Office. www.gefieo.org/evaluations/impact-pa-support-2016.

GEF IEO. 2016b. Program Evaluation of the Least Developed Countries Fund (LDCF) 2016. Washington, DC: Global Environment Facility Independent Evaluation Office.

GEF IEO. 2017a. Evaluation of Programmatic Approaches in the GEF. Washington, DC: Global Environment Facility Independent Evaluation Office. www.gefieo.org/evaluations/ programmatic-approaches-2016.

GEF IEO. 2017b. Program Evaluation of the Special Climate Change Fund (SCCF) 2017. Washington, DC: Global Environment Facility Independent Evaluation Office.

GEF IEO. 2017c. The GEF in the Changing Environmental Finance Landscape (OPS6). Final Report. Washington, DC: Global Environment Facility Independent Evaluation Office. 


\section{GEF interventions}

GEF IEO. 2018a. Annual Performance Report 2017. Washington, DC: Global Environment Facility Independent Evaluation Office.

GEF IEO. 2018b. Biodiversity Focal Area Study 2017. Washington, DC: Global Environment Facility Independent Evaluation Office. www.gefieo.org/evaluations/ biodiversity-study-2017.

GEF IEO. 2018c. Evaluation of Programmatic Approaches in the GEF, Volume 2: Technical Documents. Washington, DC: Global Environment Facility Independent Evaluation Office. www.gefieo.org/sites/default/files/documents/council-documents/c-52-meinf-01-vol-2.pdf.

GEF IEO. 2018d. Value for Money Analysis for GEF Land Degradation Projects. Washington, DC: Global Environment Facility Independent Evaluation Office. www.gefieo.org/ evaluations/vfm-2016-land-degradation.

IFAD. 2016. An Integrated Ecosystem Management Approach to the Conservation of Biodiversity in Dryland Ecosystems. Terminal Evaluation Review. www.thegef.org/sites/default/files/ project_documents/GEF\%25202369\%2520TER\%2520CHINA\%25202017_0.pdf.

Satapathy, D.R., R.J. Krupadam, L.P. Kumar, and S.R. Wate. 2007. "The Application of Satellite Data for the Quantification of Mangrove Loss and Coastal Management in the Godavari Estuary, East Coast of India." Environmental Monitoring and Assessment 134 (1-3): 453-469. https://doi.org/10.1007/s10661-007-9636-z.

UNEP. 2018. Annual Report 2018: Putting the Environment at the Heart of People's Lives. United Nations Environment Programme. www.unenvironment.org/annualreport/ 2018/index.php. 


\section{Toward transformational change}

Incremental environmental strategies alone will not suffice given the unprecedented nature of the pressures faced by the earth's ecosystems over the coming decade. As stated in the 2020 vision statement of the Global Environment Facility (GEF), these pressures "compel the GEF to equip itself to promote transformational change and to achieve global environmental benefits on a larger scale" (GEF 2012). One way the GEF specifically aimed to achieve this vision was by supporting innovative activities that "are scalable across multiple countries, regions, and sectors through policy, market, or behavioral transformations." However, when the statement was developed in 2012, the GEF had only a limited framework or evidence to understand the mechanisms and factors influencing such transformative change and the process of scaling up. The GEF's additionality - the outcomes that can be truly attributed to a GEF project or program - had been expressed and measured through the concept of incremental cost reasoning, which does not address the underlying mechanisms of transformative change or scaling up. To fill this knowledge gap, the GEF Independent Evaluation Office (IEO) developed an enhanced framework for understanding the GEF's additionality, going beyond the incremental cost principle. Building on this improved concept of additionality, the IEO explored the underlying mechanisms that influence the outcomes to impact pathways, and contributing factors, through a review of GEF experiences in promoting transformational change and scaling up (GEF IEO 2018a). In fact, we find that the crucial mechanisms influencing the two processes are closely related; transformational chance and scaling up can be considered steps in a continuum, with scaling up as one possible outcome of transformational change.

\section{Beginning with additionality}

\section{The GEF theory of change}

Figure 6.1 presents the GEF generic theory of change that responds to the focal area strategies to support the achievement of global environmental benefits (GEBs). At the same time, however, the theory of change has been an under-documented aspect of the GEF's work, complicating assessment of the full additionality - or 


\section{GEF areas of contribution}

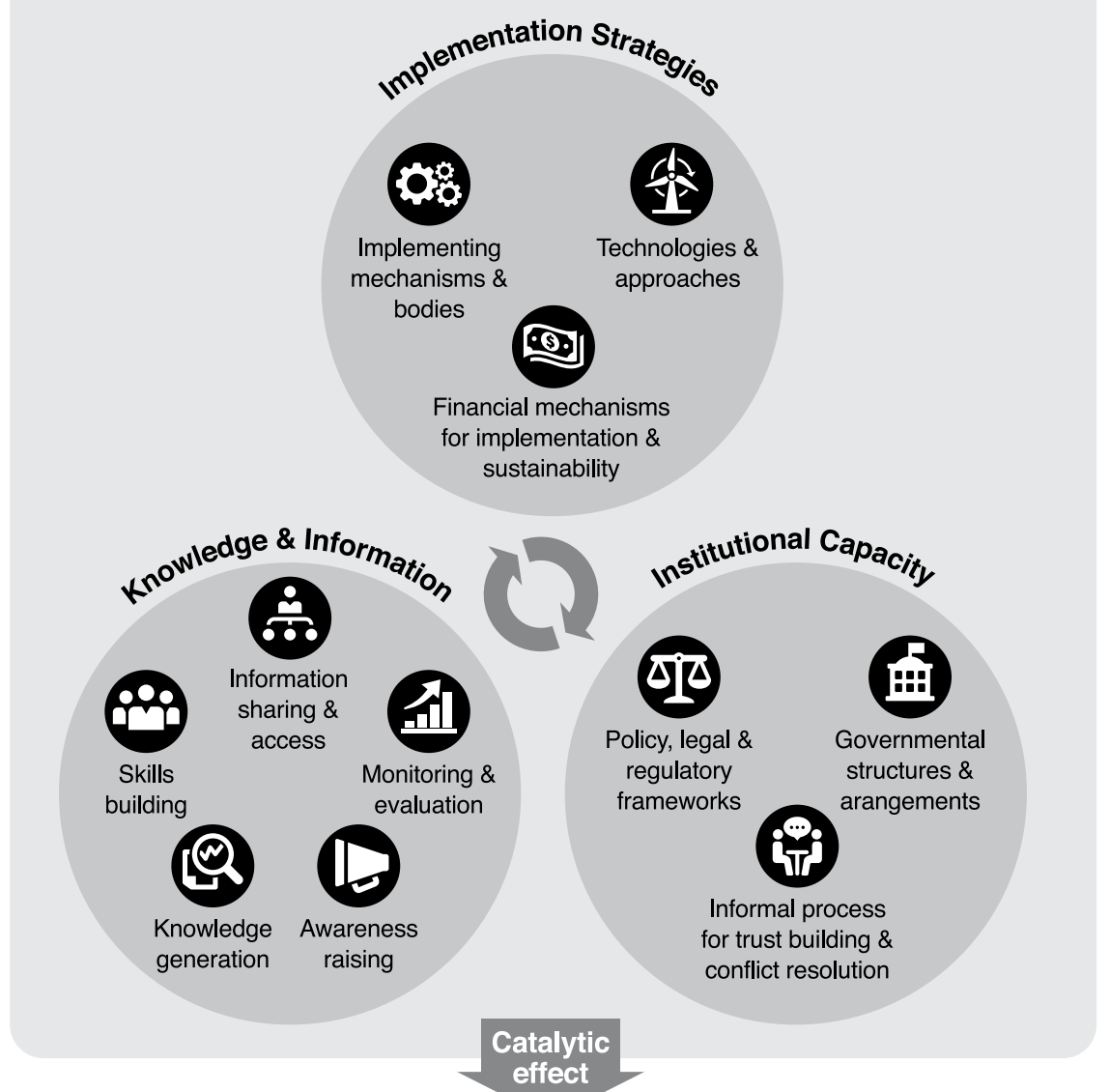

\section{Progress toward impact}

\section{Impact}

Broader
adoption $\quad \begin{aligned} & \text { Behavioral } \\ & \text { change }\end{aligned}$

- Sustaining

- Mainstreaming

\section{Criteria:}

- Economically

- Replication

- Scaling-up

- Market change feasible

- Socially acceptable

- Environmentally sound
Technologies \& pproaches

\section{inancial mechanisms}

$$
\text { sustainability }
$$


transformational change - that GEF interventions provide. GEF additionality also hinges on the link between the direct areas of GEF contribution and the environmental impact, raising the question of how the GEF supports broader adoption that leads to a positive cycle and strengthens environmental benefits.

Drawing on recent thinking on additionality and the GEF theory of change, the IEO developed an enhanced framework for assessing the GEF's additionality that goes beyond the concept of incremental cost reasoning and provides a basis for understanding the processes of transformational change and scaling up. As stated in Chapter 4, we define additionality as:

- Changes in the attainment of direct project outcomes at project completion that can be attributed to GEF interventions; these can be reflected in an acceleration of the adoption of reforms, the enhancement of outcomes, or the reduction of risks and greater viability of project interventions

- Spill-over effects beyond project outcomes that may result from systemic reforms, capacity development, and socioeconomic changes

- Clearly articulated pathways to broaden the impact beyond project completion that can be associated with GEF interventions

The GEF expects that specific areas of contribution - achieved through GEFfunded projects - will have a catalytic effect that leads to broader adoption of successful interventions. This catalytic effect, and its broader adoption and behavioral change, then generates a virtuous cycle of environmental impact. Progress in GEBs is assumed to foster further behavioral change and expansion of sound environmental practices.

Full additionality encompasses both a project's outcomes and a project's impact. Although not all projects can be linked to impact on GEBs that extends beyond the project outcomes, we can use this framework to distinguish projects with potential for a high impact, scaling up, or transformational change. Outcome additionality is directly attributable to project interventions. In contrast, impact additionality is the establishing of a plausible pathway for the project's contribution to GEBs, recognizing that many of the benefits may only materialize following the completion of the project. Additionality typically results either from focusing entirely on GEBs, with no other funding sources available, or by enhancing viability, speeding up, and greening (see an example in Box 6.1).

\section{Creating transformational change}

Engagements that help achieve deep, systemic, and sustainable change with large-scale impact are regarded as transformational. Four specific criteria differentiate transformational interventions from those that are "merely" highly successful, complex, or large in size:

1 relevance

2 depth of change

3 scale of change

4 sustainability 


\section{Box 6.1}

\section{Enhancing viability and speeding up}

The project Reducing Transboundary Degradation in the Kura-Aras Basin, a regional project in Armenia, Azerbaijan, and Georgia, aimed to create an enabling framework for the long-term, sustainable, integrated management of the river basin. This framework would follow integrated water resources management principles and prevent overuse and conflicting uses of water resources.

The GEF project provided a regional framework and help in aligning planning procedures at the national level, which supported development of a Kura Aras Environmental Program and formulation of a strategic action program and national integrated water resources management plans. Without the GEF project and its support, delivery of key global environment benefits, such as improved hydrological flows and reduction of persistent toxic substances, would have been delayed and perhaps even lost to the detriment of both the river basin and the Caspian Sea.

By strategically identifying and selecting projects that address environmental challenges of global concern and are specifically designed to support fundamental changes in key systems or markets, the GEF engages in interventions that are more likely to have a sustainable, large-scale impact. However, project impact assumes supportive contextual conditions and good implementation.

To assess specifics of whether and how GEF projects achieve transformational change, the IEO undertook an evaluation using a purposive sample selected from 156 completed projects nominated by GEF Agencies ${ }^{1}$ as having achieved transformational change, verified through independent, project-level evaluations (GEF IEO 2017). We developed a framework for understanding the process and the factors influencing transformative change, presented in the underlying theory of change in Figure 6.2. We screened the projects against this framework and also reviewed their characteristics against the established additionality parameters (see Chapter 4, Box 4.2). For the evaluation, we selected eight illustrative projects, taking into account their diversity in focus, regional distribution, and agency:

\section{Lighting Africa}

2 China Renewable Energy Scale-Up Program, Phase I (CRESP-I)

3 Uruguay Wind Energy Program (UWEP)

4 Sanjiang Plain Wetlands Protection Project (China)

5 Sustainable Land, Water, and Biodiversity Conservation and Management for Improved Livelihoods in Uttarakhand Wind Sector Project (SLEM; India)

6 Strengthening the Protected Areas Systems (PAS) in Namibia

7 Amazon Regional Protected Areas Program, Phase I (ARPA-I; Brazil) 

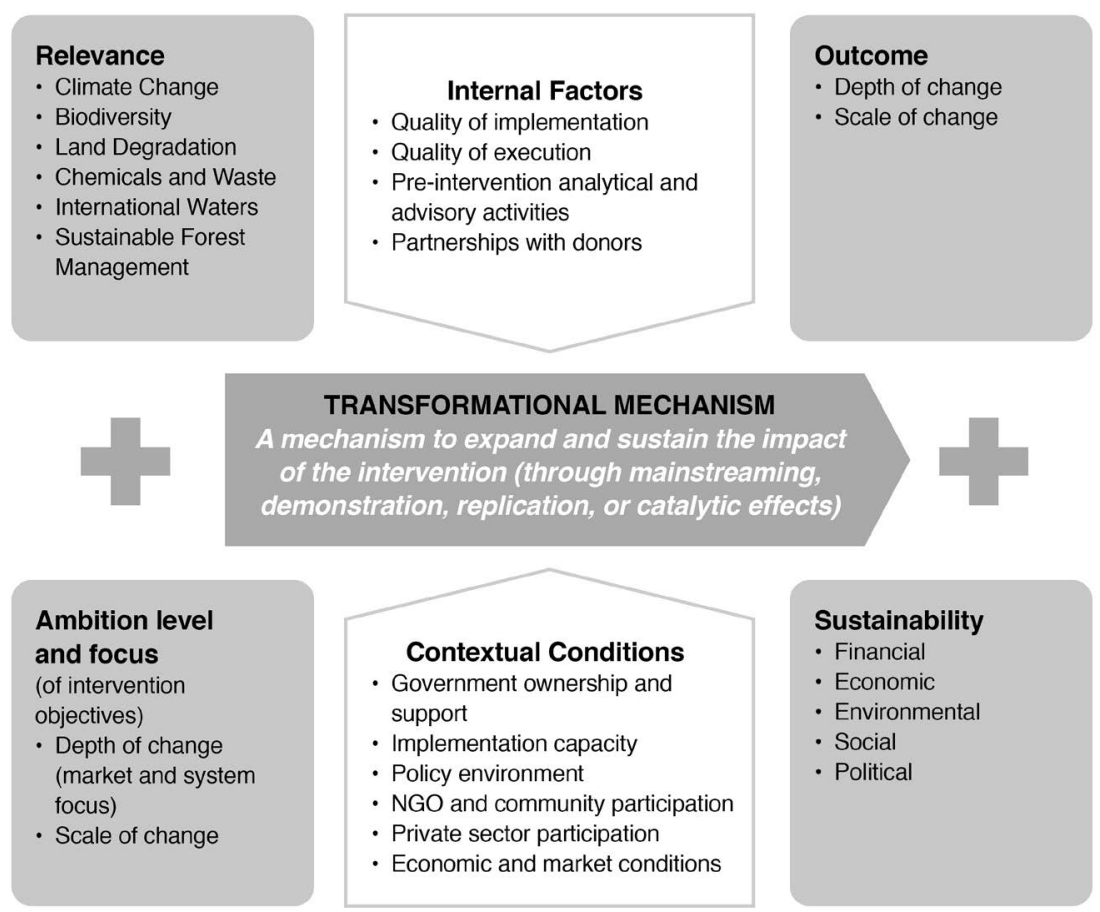

Figure 6.2 Theory of change for GEF transformational interventions

8 Promoting Payments for Environmental Services and Related Sustainable Financing Schemes in the Danube Basin

The evaluation used a cross-case analysis in combination with a meta-analysis of the project-level evaluations for each of the projects to assess the conditions (and combinations of conditions) that support transformational change. Based on the analysis, the IEO was able to identify four factors common to these projects that provide lessons for the future.

\section{Design with ambition}

First, these interventions that achieved transformational change had clear ambition at design. Their objectives aimed at profound, fundamental change in addressing a market distortion or a systemic bottleneck that was a root cause for a global environmental concern. Four of the cases focused primarily on system-wide transformation, taking a comprehensive approach to modifying the functioning of a collection of components (economy, public sector, private sector, community) whose interactions have environmental consequences. In the four other cases, the primary thrust was on transforming a 
market (i.e., the supply and demand of goods and services) associated with environmental impacts of global concern.

\section{Address policies for market and system changes}

Second, the adequacy of the policy environment had an important impact on the depth and scale of reforms promoted by the transformational interventions. All of the projects, thus, addressed market and system changes through policies. In three cases, the interventions had a major role in helping define and implement the main policies essential to trigger and sustain transformational change. In China and Uruguay, the projects had a strong influence on policies that effectively stimulated development of renewable energy. In Namibia, the project provided technical support for the drafting of new policies for the Ministry of Environment and Tourism, affecting the protected area systems. In three other cases, the interventions played a modest role in strengthening the policy framework needed to support transformational change. These ranged from discussing with the governments of Ghana and Kenya lowering impact taxes as an enabling environment for the solar lamps market, to proposing prohibition of animal grazing and fishing in all nature reserves in the Sanjiang Plain in China, to mainstreaming payment for environmental services concepts into national fisheries policies in Bulgaria and Romania. In India, the state government of Uttarakhand granted the local rural government formal legal recognition for watershed development planning. In Brazil, ARPA-I used the existing legal context for protected areas to involve many government agencies and financing partners to demonstrate the practicality of a participatory approach to the establishment and management of protected areas.

\section{Build for financial stability}

Third, these transformational interventions established a mechanism for financial sustainability by integrating within government budgetary systems or by leveraging market forces and key stakeholders' economic interests. In China, CRESP-I supported a feed-in tariff for renewable energies that provided financial returns attractive enough to encourage state-owned and private enterprises to accelerate their investment in renewable energy. In Uruguay, wind power investment licenses were allocated through a fair bidding process that guaranteed access to the grid. The resulting prices were competitive with those of fossil fuel alternatives and have gradually declined further as a result of growing efficiencies and technological improvements. In Uttarakhand, project beneficiaries have an incentive to maintain water harvesting structures, namely, their own investment through cost sharing. In the Sanjiang Plain, a portion of local county revenues generated from forest development activities is used to meet the financing requirement for nature reserve management. 
In four cases, the funds provided by the GEF were supplemented with important financial contributions from international donor partners, which enabled the projects to expand their scope and scale. In the remaining interventions, the GEF's support was supplemented by funding from the implementing agencies and the governments and in one case by counterpart funding from the government alone.

\section{Focus on implementation quality}

The fourth common feature was that all interventions were well implemented in terms of quality of project design, supervision by the GEF Agency, and effectiveness of the executing agencies. Some of the salient features that drove implementation quality included comprehensive diagnostic assessments to identify barriers; coherent designs to target all identified barriers; and early involvement of strong executing agencies that would own the project objectives and be willing to learn, adjust, and adapt the design, scope, and management as needed to ensure success.

Several other factors contributed to achieving transformational change. These included government ownership of and support for the project, implementation capacity of local institutions (other than the main executing agency), civil society and local community participation, private-sector participation, and economic and market conditions.

Six of the sample cases demonstrated strong government ownership that contributed significantly to the projects' satisfactory outcomes. The Lighting Africa project was specifically designed to catalyze a private-sector-driven sustainable market transformation. It was not country-specific and did not involve the governments except to discuss policy changes, such as the lowering of import taxes. However, even with relatively limited public policy dimensions, securing buy-in from local governments can greatly reduce risks of a national government setting adverse expectations and incentives. Thus, the program's success in Kenya was facilitated by some support from the government, while in Ghana, the government's focus on grid extension promises and relatively dismissive attitude toward portable off-grid solar solutions likely dampened private-sector interest in the market.

The implementation capacity of local institutions can play a major role in project outcomes, especially when the activities are spread over a range of sites and local jurisdictions. The CRESP, Sanjiang Wetlands, Namibia PAS, and Uttarakhand SLEM projects included targeted activities to strengthen the local institutional capacity, all of which were effective in contributing to the projects' success.

The Namibia PAS projects engaged local civil society and community organizations in key contributing roles by supporting engagement between park personnel and neighboring communities. An important catalyst for cooperation between the two groups was funding for game translocations from protected areas to conservancies. The communal and private conservancies' 
rights to use and benefit from wildlife on their land gave them a direct interest in cooperating with the protected areas that supply their wildlife.

Uttarakhand SLEM had a high level of community participation in its various components, which increased the likelihood that the activities would be continued after project completion. Fifty-five partner agencies supported outreach to build this community connection, including NGOs, academic institutions, and the private sector. They provided overall project implementation support, social mobilization, participatory monitoring and evaluation (M\&E), and technical assistance.

The impact of private enterprises on the effectiveness of the transformational interventions was mainly defined by the extent of their (supply-side) response to the changes the project created. As expected, the response was strongest where market change was at the center of the interventions. Thus, CRESP and UWEP contributed to the successful transformation of the wind energy market in China and Uruguay, respectively, by addressing the barriers that had constrained the market's development, most importantly by helping establish a feed-in power tariff that made it financially attractive for private investors to invest in wind energy. The Lighting Africa program helped catalyze the market by creating awareness and demand for quality, affordable solar lamps while also stimulating the supply chain by providing market intelligence; developing a quality assurance infrastructure; helping government address policy barriers; and facilitating access to finance for manufacturers, local distributors, and consumers.

Interestingly, transformation can be achieved by projects of different size. While most of the projects included in the sample were multimillion-dollar efforts with long durations, the projects in Uruguay (see Box 6.2) and the Danube Basin were relatively small with a limited duration but targeted important barriers and worked with key stakeholders at the right time. The evaluation framework and findings can help the GEF - and potentially other organizations - gauge project concepts in advance to determine their probability for supporting transformative change and enhance project designs.

\section{Transformational outcomes}

Our evaluation found that transformational outcomes were achieved through mainstreaming, replication, and catalytic effects.

Mainstreaming refers to the integration of the practices, policies, and programs promoted by the project into those of the country or local jurisdictions, as appropriate. The successful mainstreaming of environmentally positive policies and programs is perhaps best illustrated by the ARPA-I project, which supported the creation and consolidation of protected areas and the establishment of an endowment fund to meet a portion of their operational costs. Upon completion, the project had not only doubled the area of Brazilian Amazon under strict protection, but also proven to all major stakeholders - including federal and state governments, local peoples, NGOs, 


\section{Box 6.2}

\section{Creating the wind power market in Uruguay}

In 2000, Uruguay's power system depended fully on hydropower and imported fossil fuels. With the country's hydropower potential practically exhausted, its growing electricity demand would require gas-fueled power plants, which not only rely on imported energy but transmit impacts of international gas price fluctuations onto the national economy and increase greenhouse gas emissions. Facing this situation, the government of Uruguay recognized the long-term potential in developing local energy resources - such as wind and biomass - and established the legal basis and framework for promoting them. Barriers to this development included:

- Insufficient or inappropriate regulations for the installation and operation of wind farms, including grid access and dispatch

- Lack of an enabling policy framework for power purchase agreements between wind power suppliers and the national power company ${ }^{2}$

- Underdevelopment of technical standards, building codes, and environmental guidelines for wind energy systems

- Financially unattractive returns for private wind energy projects

- Insufficient wind energy knowledge and capacity among both public- and private-sector actors

- Lack of a mandate for the national power company to promote and deploy wind energy systems

- Lack of financial resources and technical equipment to gather data on Uruguay's wind resources

In 2007, UWEP launched to establish a 5-MW demonstration project, with activities expressly aimed at removing each of the identified barriers. Specifically, UWEP supported the creation of an enabling policy framework for wind energy, including regulations for construction and operation of wind farms, access and dispatch to the network, technical codes, and financial incentives. It strengthened capacity and business skills to prepare and implement wind energy technology with public and private delivery models. It also addressed technological barriers by providing measuring equipment and implementing a pilot 5-MW wind power plant connected to the grid. Following UWEP's completion in 2012, the final evaluation report (Rodríguez 2013) concluded:

With the decisive participation of this project, an enabling legal and regulatory framework was established for the development of wind energy in the country. A transparent market for wind power was created and 43.45 MW have been introduced in the country through December 2013, and several projects are in development which by December 2015 are expected to total $990 \mathrm{MW}$, far exceeding project goals and converting wind power into a major energy source for the country. 
This change in energy source directly avoided annual carbon emissions estimated at 0.86 million tons of $\mathrm{CO}_{2}$ in 2015, an increase from zero tons avoided in 2007.

Key factors in the project's transformational success included:

- The quality of the project's design, which reflected a coherent, logical framework from the identification of barriers to the planning for their removal through specific activities, with appropriate institutional arrangements and implementation strategy

- The timing of the project, which came at an unusual moment when the government had made a strong commitment to renewable energy, as reflected in its establishment of an enabling legal and regulatory framework and its willingness to leverage the GEF medium-size project by cofinancing a major share of project costs

- The creation of a competitive and transparent wind energy market with a stable framework for investments and adequate tariff incentives that elicited a strong private-sector response

- The project's inclusion and strengthening of a core of wind power specialists at the national power company, who helped with the preparation of technical standards and enabled the company to positively respond to the wind energy development mandate through both its own (public) and private investments

private-sector organizations, and international donors - that effective protected area creation and management could have a real impact in reducing deforestation and protecting not only biodiversity but the rights of local peoples. Thus, the federal and state governments were fully committed to implementing the protected areas staffing and management plans instituted under the project, and donors and private enterprises continued to contribute to the endowment fund that covers most of the operating costs of these areas. Largely as a result, replication of the ARPA model continued in Phase II of the program.

Demonstration and replication occur when the process or transmission channel established by the intervention continues to expand the outcome beyond the initial target area. Most of the projects achieved a substantial demonstration effect (i.e., initial impact): the practices and programs introduced by the project were adopted and replicated in similar contexts across an expanding geographical scope. For example, the integrated watershed management and conservation model introduced by the Sanjiang Wetlands project was adopted by six additional reserves beyond the initial six supported by the project. In the Lighting Africa program, the overall approach that was initially piloted and successfully demonstrated in Kenya (albeit less successfully in Ghana) is currently being replicated in ten additional countries in Africa.

Catalytic effects are aspects that extend beyond the intervention, such as synergies and complementarities among different instruments and interventions that lead to impacts greater than the sum of the interventions. The 
most notable examples of catalytic effects involve the transformation of the market or system for renewable energy development. CRESP-I is credited with contributing substantially to the transformation of China's renewable energy sector from an early piloting and demonstration stage to its status as a global leader in wind energy generation and the manufacture of wind power generation equipment. With an original target of $10 \mathrm{GW}$ of installed wind power capacity, the project supported policy reforms, capacity building, and technology improvement that that resulted in an actual capacity increase to 29.6 GW by 2010 and 129.3 GW by 2015. Similarly, UWEP has decisively supported the establishment of a legal and regulatory framework that catalyzed the creation of the wind energy market in Uruguay, which grew from virtually nothing in 2007 to $43.4 \mathrm{MW}$ by the end of the project in 2013, and reached $990 \mathrm{MW}$ in 2015 (see Box 6.2). Finally, Lighting Africa catalyzed the creation of a commercial market for quality, affordable solar lighting in Africa; by 2014, more than 680,000 Lighting Africa-certified lamps had sold in Kenya, and almost 2 million lamps in other African countries.

In this sample, the cases that produced catalytic effects were the three projects focused on renewable energy and climate change, and none of the others. These indicate a link between large-scale catalytic effects and technological improvements with benefits that can be captured by harnessing an effective market demand. Thus, the decline in costs of renewable energy in relation to those of conventional fossil fuel electricity opened up new and economically feasible market opportunities that the interventions were able to exploit, with their attendant synergistic or catalytic effects. In other types of interventions - such as those focused on biodiversity protection and land conservation - the projects' support for cutting-edge science and technologies faced greater challenges in capturing and monetizing the related benefits. As a consequence, their transformational impacts appear linked mostly to establishing and mainstreaming institutional support mechanisms, with only partial reliance on market-based approaches.

\section{A closer look at scaling up transformational change}

Over 25 years, the GEF has made a clear shift from site-level pilot projects toward projects and programs implemented on larger scales. This is due in part to a better understanding of what interventions work based on the portfolio of demonstration projects implemented during the GEF's early phases.

The GEF 2020 Strategy (GEF 2015) particularly emphasized that largescale impact can be achieved in three ways: through GEF interventions being scaled up by others, through market or behavioral transformation, and by the intervention working directly at a large scale. The strategy envisioned the GEF's contribution to scaling up to be:

- mainstreaming environmental priorities into broader policies, strategies, programs, and actions; 
- $\quad$ working on supply chains and with industry-wide approaches;

- implementing larger programs; and

- cofinancing and leveraging via innovative financial instruments.

The strategy also identified several enabling conditions for scaling up impact, including incentives, policies and regulations, institutions and institutional capacity, partnerships and coordination, financing, learning, and M\&E. To operationalize this strategy, the GEF introduced the integrated approach pilots in GEF-6 and the impact programs in GEF-7, which began implementation recently and, thus, have only limited evidence on outcomes.

To better understand the scaling-up process in depth and the influencing factors and conditions, the IEO developed a framework for scaling up building on the understanding of GEF additionalities and the process of transformational change. We also conducted quantitative and qualitative analyses on a purposive sample of successful and less successful cases of GEF support for scaling up.

The GEF defines scaling up impacts increasing the magnitude of GEBs and/or expanding the geographical and sectoral areas where they are generated to cover a defined ecological, economic, or governance unit. Scaling up is a continuous process that often takes place over longer time horizons; as such, scaling-up objectives need to be continually set and achieved until impacts are generated at the magnitude and scope of the targeted scale.

\section{Scaling up mechanisms}

The GEF contributes to the scaling-up process in two ways:

1 Funding the implementation - including the piloting - of interventions that generate GEBs

2 Supporting enabling conditions that allow these interventions to generate impact at scale

In addition to the replication and mainstreaming mechanisms mentioned in the previous discussion of transformational change, linking interventions is another channel through which impacts are scaled up. Linking refers to implementing different types of interventions across the multiple components (geographic locations, administrative levels, or sectors and institutions) of an ecological, economic, or governance system. For example, within value and supply chains, linking takes place between interventions that address causes and effects, such as working both in countries where deforestation or wildlife poaching occurs and in countries with high demand for forest and wildlife resources. Market change may be one form of linking within value chains when it addresses both supply and demand sides. Scaling up through creation of links can also involve implementing multiple interventions under 


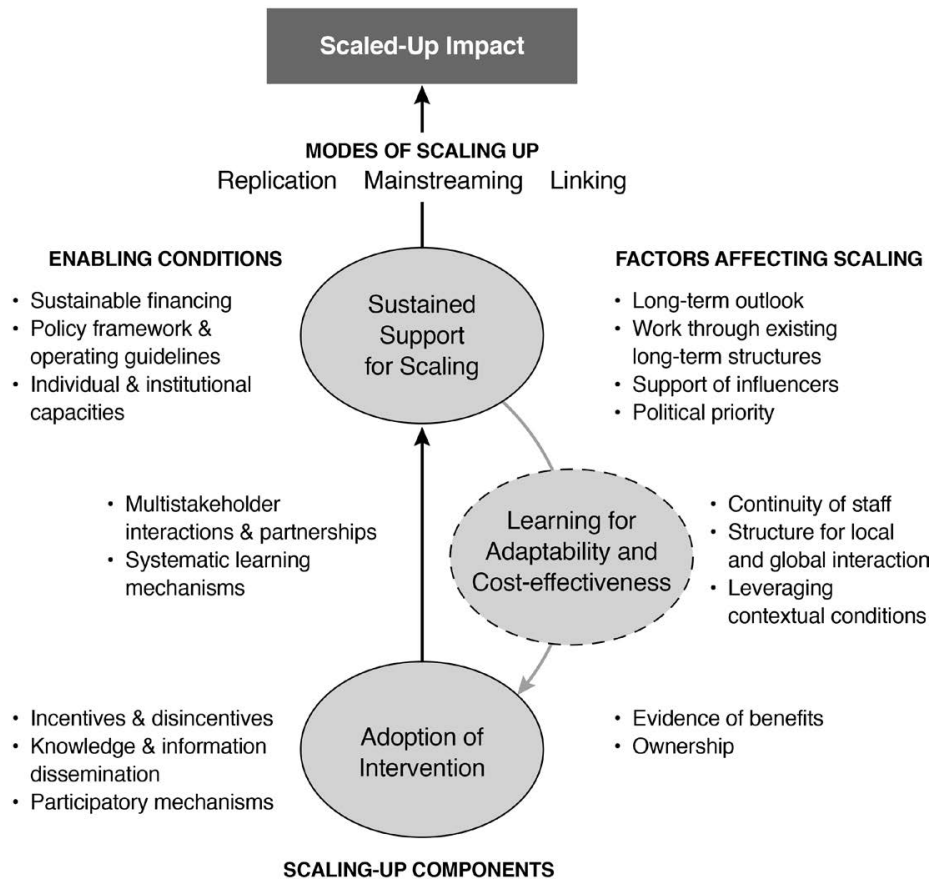

Figure 6.3 Process of scaling up

a common theme or transboundary issue, such as water pollution or fisheries. Approaching scaling up through linking is consistent with the GEF's shift toward addressing drivers rather than symptoms of environmental degradation to achieve more sustainable impacts at scale. With this focus, the programmatic approaches have increased GEF support to multistakeholder platforms at the regional and global levels.

Although contextual factors affect the scaling-up process, GEF support can influence these factors in selecting partner individuals and institutions and by leveraging changes in the social-ecological context to align with scaling-up objectives. The GEF also influences contextual factors to be more favorable toward scaling up by supporting enabling conditions. Figure 6.3 shows which enabling conditions are most relevant for each component of the scaling-up process to influence the corresponding contextual factors.

We analyzed 20 cases covering 38 projects in our evaluation of GEF support to scaling up (GEF IEO 2019); see Table 6.1 (projects within these cases are included in Appendix 4).

The cases analyzed cover a time span of 20 years from the pilot phase of the GEF to GEF-5; the earliest project, Mexico ILUMEX, started implementation in 1994. The most recent project in the study, the second phase of the Philippines CCA case, started in November 2014. 
Table 6.1 Cases in the evaluation of GEF support to scaling up impact, 2019

\begin{tabular}{|c|c|c|c|}
\hline Scaling-up case & Focal area & Scaling targets & Target geographical scale \\
\hline $\begin{array}{l}\text { Bangladesh } \\
\text { IDCOL }\end{array}$ & $\begin{array}{l}\text { Climate Change } \\
\text { Mitigation }\end{array}$ & Expand access to solar home systems in rural areas & Country \\
\hline Brazil ARPA & Biodiversity & Expand and consolidate the protected areas system & Amazon region \\
\hline Brazil Rio Rural & $\begin{array}{l}\text { Land Degradation/ } \\
\text { Multifocal }\end{array}$ & $\begin{array}{l}\text { Demonstrate and increase adoption of biodiversity-friendly and climate- } \\
\text { friendly agricultural practices through integrated ecosystem management }\end{array}$ & $\begin{array}{l}\text { Northwest region of } \\
\text { the state of Rio de } \\
\text { Janeiro }\end{array}$ \\
\hline China CHUEE & $\begin{array}{l}\text { Climate Change } \\
\text { Mitigation }\end{array}$ & $\begin{array}{l}\text { Develop partnerships and capacities for a commercially sustainable delivery } \\
\text { mechanism for energy efficiency projects }\end{array}$ & Country \\
\hline China CRESP & $\begin{array}{l}\text { Climate Change } \\
\text { Mitigation }\end{array}$ & $\begin{array}{l}\text { Demonstrate and increase installed renewable energy capacity to reduce } \\
\text { carbon emissions }\end{array}$ & Country \\
\hline China DDT & $\begin{array}{l}\text { Chemicals and } \\
\text { Waste }\end{array}$ & $\begin{array}{l}\text { Dispose of DDT waste, eliminate production and consumption of } \\
\text { dicofol, demonstrate and replicate integrated pest management }\end{array}$ & Country \\
\hline
\end{tabular}

$\begin{array}{ll}\text { China IEM } & \begin{array}{c}\text { Land Degradation/ } \\ \text { Multifocal }\end{array} \\ \begin{array}{ll}\text { China Termite } \\ \text { Control }\end{array} & \begin{array}{l}\text { Chemicals and } \\ \text { Waste } \\ \text { Costa Rica PES }\end{array} \\ \text { Biodiversity }\end{array}$

Ethiopia SLM

Indonesia COREMAP

Multifocal

Biodiversity dicofol, demonstrate and replicate integrated pest management technology, commercialize alternatives to DDT and TBT in antifouling paint

Demonstrate and establish enabling conditions for adoption of integrated ecosystem management in agricultural areas adjacent to protected areas

Eliminate production and consumption of chlordane and mirex by termite professionals

Increase the area of forest under protection and sustainable management through payments for environmental services in private lands adjacent to protected areas

Increase area of agricultural land under sustainable land management

Land Degradation/
Demonstrate and establish framework for community-based coral reef management
Dryland ecosystems

\section{Country}

Country

Vulnerable watershed areas in country

Country 


\begin{tabular}{|c|c|c|c|}
\hline Scaling-up case & Focal area & Scaling targets & Target geographical scale \\
\hline Macedonia PCB & $\begin{array}{l}\text { Chemicals and } \\
\text { Waste }\end{array}$ & Demonstrate cheaper alternative for treating PCBs & Country \\
\hline Mauritius POPs & $\begin{array}{l}\text { Chemicals and } \\
\text { Waste }\end{array}$ & $\begin{array}{l}\text { Dispose of DDT and PCB, treat contaminated soils, establish integrated } \\
\text { vector management system as alternative to DDT }\end{array}$ & Country \\
\hline Mexico Ilumex & $\begin{array}{l}\text { Climate Change } \\
\text { Mitigation }\end{array}$ & $\begin{array}{l}\text { Demonstrate feasibility of energy-efficient lighting and replicate demand-side } \\
\text { management }\end{array}$ & Country \\
\hline $\begin{array}{l}\text { Namibia } \\
\text { NACOMA }\end{array}$ & Biodiversity & $\begin{array}{l}\text { Strengthen and finance the protected area system and mainstream biodiversity } \\
\text { conservation in adjacent lands }\end{array}$ & $\begin{array}{l}\text { Terrestrial and marine } \\
\text { protected area } \\
\text { systems }\end{array}$ \\
\hline Philippines CCA & $\begin{array}{l}\text { Climate Change } \\
\text { Adaptation }\end{array}$ & Build capacity for and promote adoption of weather-based insurance index & Country \\
\hline Romania IW & International Waters & $\begin{array}{l}\text { Increase use of agricultural practices that reduce nutrient discharge to the } \\
\text { Danube River and the Black Sea }\end{array}$ & Country \\
\hline Senegal Ecovillages & Multifocal & $\begin{array}{l}\text { Demonstrate integrated approach to reduce carbon emissions, protect } \\
\text { biodiversity, and create livelihood opportunities in rural areas }\end{array}$ & Country \\
\hline Uganda PA & Biodiversity & Strengthen institutional capacity for long-term biodiversity conservation & Protected area system \\
\hline $\begin{array}{l}\text { Uruguay Wind } \\
\text { Energy }\end{array}$ & $\begin{array}{l}\text { Climate Change } \\
\text { Mitigation }\end{array}$ & $\begin{array}{l}\text { Demonstrate wind power plant and remove barriers to commercial } \\
\text { investments in wind energy }\end{array}$ & Country \\
\hline
\end{tabular}

Source: GEF IEO 2019 
In these cases, the GEF has provided scaling-up support in four distinct ways:

1 Piloting and scaling up were planned for and implemented within the same project through different components.

2 Piloting and scaling up were planned for at the design stage of the pilot project, and implemented through multiple consecutive or parallel projects.

3 Piloting and scaling up were implemented through consecutive GEF projects based on results of the pilot stage.

4 Piloting was supported by GEF projects, while the scaling-up stage was funded through other sources based on results of the pilot stage.

In a majority of projects, scaling up was not planned and budgeted for at the outset, but was contingent on the success of the pilots.

\section{Scaled outcomes}

We found that scaling up was achieved in 95 percent of the cases analyzed through replicating interventions over a wider geographical area. At the same time, 16 of the 20 cases also aimed to mainstream the implementation of interventions within plans and programs at different levels of government, and in some cases across different government agencies. Only four cases used linking in addition to the two other modes to scale up impact. These four cases addressed specific environmental issues through multiple sectors, although linking was not planned from the beginning in all cases. This is not surprising and reflects earlier GEF project designs; only in 2014 did the GEF increase focus on scaling up through linking interventions across sectors.

The extent of GEF support for scaling up and the rate at which outcomes are scaled up vary across focal areas but typically take place over more than five years. They generate higher outcomes per GEF dollar per year during the scaling-up stage than the pilot stage. Within cases where project documents specified GEF support for distinct piloting and scaling-up stages, measurable outcomes per dollar per year during the scaling-up stage were 1.1-74.5 times larger than during the pilot stage, indicating greater cost-effectiveness and higher cofinancing leveraged per GEF dollar.

For example, in Senegal, the GEF supported the piloting of 10 Ecovillages. During the course of the project, initial successes allowed the national government to replicate the approach in 84 more villages without additional GEF funding by reallocating GEF funds mainly toward training and livelihoods and by tapping civil society and private-sector funds for renewable energy infrastructure. By the end of the project, the national government had scaled up the approach at the national level by initiating replication in an additional 400 villages through an agency created specifically for this purpose.

The ARPA-I project, a transformative project, is credited with helping to double the area of Brazilian Amazon under strict protection - from 
12 million ha in 2004 to more than 25 million ha in 2009. UWEP supported the creation of the wind energy market in Uruguay, supplying about 33 percent of the nation's electricity needs in 2016, up from 0 percent in 2008. The Namibia PAS projects improved the management effectiveness of 98 percent of the country's protected areas, while estimated populations of the lion, leopard, cheetah, and wild dog doubled from 2004 to 2012.

In the case of interventions in payment for ecosystem services (PES) in Costa Rica, the first GEF project brought 130,900 ha of land under PES contracts in six years with $\$ 8$ million in GEF grants. The second project placed another 166,004 ha of land under PES contracts in five and a half years with $\$ 10$ million in GEF grants. The rate at which forests were protected under PES contracts was 11 percent higher during the scaling-up stage than the pilot.

In the case of climate change adaptation in the Philippines, 607 farmers benefited over six and a half years with an initial $\$ 5$ million GEF grant, while the scaling-up project covered 2,413 beneficiaries in three years of implementation with $\$ 1.1$ million in GEF grants. The rate of beneficiaries covered during the scaling-up project was almost 40 times higher than that during the pilot project. Nearly half of the farmer beneficiaries (46 percent) were women.

\section{Factors influencing the scaling-up process}

The GEF has supported scaling up by establishing enabling conditions, choosing the appropriate influencers and institutions to work with, establishing sustainable sources of financing, strengthening institutional capacities and gaining political support through participatory processes, and leveraging contextual conditions at the right time. GEF funding supports eight types of enabling conditions that contribute to the scaling-up process:

- To motivate adoption of interventions: (1) knowledge and information dissemination, (2) participatory processes, and (3) incentives and disincentives

- To allow sustained support for scaling: (4) institutional and individual capacities, (5) policy framework and operating guidelines, and (6) sustainable financing

- To allow the scaling-up process to be adaptable and cost-effective in the face of changing contextual conditions: (7) multistakeholder interactions and partnerships and (8) systematic learning mechanisms

\section{Motivating adoption}

We found that governments often made scaling up a priority because the intervention was part of their existing development plans and policies or was a response to urgent external events. Other important drivers for scaling 
up include commitments to the global environmental conventions, requirements for European Union accession, national laws for which implementation is mandated, or even loans that need to be paid back to the World Bank and other financial institutions. In some cases, the political priority to scale up was further motivated by an external event such as a national crisis or international pressure to expand interventions that would generate both environmental and social benefits. For example, in Bangladesh, a GDP growth of more than 6 percent created an increasing demand for electricity access. However, the electricity grid was growing slowly and often experienced supply shortages. This made the promotion of solar home systems a priority for the government. High political priority can also sustain scaling-up activities. In Brazil, for example, Congress voted to undermine the ARPA program's gains by degazetting federal protected areas in the Amazon in 2017. But pressure from national and international stakeholders, especially civil society, contributed to the president vetoing that decision in the same year.

Participatory processes and evidence of benefits disseminated through knowledge-sharing activities can contribute to scaling up becoming a political priority. For example, in China's Hai Basin, farmers in pilot counties earned more income from farming while reducing groundwater use as a result of GEF support introducing the use of remote sensing analysis to assess existing resources against water needs. Consequently, the government moved to scale up the intervention with additional GEF support. In contrast, despite a high level of engagement of farmers in India under the SLEM program, at least one project did not engage the district and state governments, leading to participatory land use plans not being incorporated into laws and guidelines. The program has likewise not achieved its objective of scaling up sustainable land management at the national level.

\section{Sustaining support}

In 75 percent of the cases analyzed, the GEF helped develop a policy framework or operating guidelines for adopting an intervention at scale. In climate change mitigation, this typically took the form of regulations for reducing private-sector costs to invest in new technology and setting standards for manufacturing the technology. In biodiversity and land degradation projects, GEF support for policy frameworks allowed the mainstreaming of more sustainable approaches into plans at national and local government levels. In the international waters focal area, the strategic action program approach allows national-level activities to contribute to regional-level impacts. This approach also uses formal endorsement to secure countries' commitments to actions. A previous IEO study on the GEF's support for legal and regulatory frameworks found that this type of support has contributed to scaling up interventions (GEF IEO 2018b).

Advocates for implementation, at various administrative levels, ensure that efforts are sustained. In Senegal, for example, the main champion for the 
Ecovillages initiative was the country's president himself; in Costa Rica, having a technically competent champion in an influential position, such as the minister of environment, has proven to be an important driver for sustaining scaling-up support. That project also identified champions within GEF Agencies. In contrast, the SLEM program in India chose to work through state-level land use committees to develop land use plans, but these committees had no convening power. As a result, mainstreaming did not happen in other government agencies as planned. Another factor in gaining influencers' support is the comparative advantages of the agencies that the GEF selects as partners.

In all of the cases analyzed, GEF support contributed to building institutional and individual capacities for scaling up. This included establishing or strengthening government agencies that took on key roles for implementing an intervention at scale. In ARPA-I in Brazil, for example, very early GEF support helped establish FUNBIO, the organization that is now implementing GEF-supported projects on the ground. At the individual level, capacity building has included training stakeholders on how to implement an intervention, such as villagers in the use of solar panels for electricity, or staff of mining companies on careful handling of transformers with PCBs.

The use of existing structures and mechanisms for implementing an intervention are important for sustainable scaling up. Examples are the network of termite control stations in China to help eliminate chlordane use, and the microfinance institutions already active in rural Bangladesh to promote solar home systems. Such structures and mechanisms typically have a long-term presence and wide geographic coverage. They, therefore, have the capacity and experience to implement and follow-up on interventions over a large area beyond a project or program's duration. This approach is also more cost-effective. For example, when implementing Costa Rica's PES program, the government used its protected area field offices to house the forest engineers who would be reviewing applications from landowners. In Bangladesh, the existing network of microfinance institutions was a decisive factor in expanding solar home systems in rural areas.

Partnering with supporting institutions that have a long-term outlook is important for sustaining the momentum of the scaling-up process beyond one project. In most of the cases we analyzed, resources of other stakeholders supported scaling-up initiatives. These included not only bilateral donors but also civil society organizations and private companies. ARPA and COREMAP are examples of how donors' long-term outlook from the beginning led to support that has helped sustain scaling-up initiatives through severe political and economic crises, such as a presidential impeachment and budget freeze in Brazil and the Asian financial crisis in Indonesia. With GLOBALLAST, the GEF's sustained strategic vision to eliminate invasive alien species by managing ships' ballast water, successive replenishment phases supported project efforts over almost 20 years amidst extended negotiation processes among governments and shipping companies. Having a longterm outlook also allows partners to adapt how a project is implemented to 
keep it consistent with the long-term scaling-up objective despite temporary setbacks and unfavorable contextual conditions.

Sustainable financing of scaling-up efforts allows replication to continue and maintains other enabling conditions. Some GEF contributions have taken the form of market-based mechanisms, trust funds, or a mainstreamed government budget allocation; in other cases, sustainable financing was provided through government initiatives, donor projects, or other international donors. When a national government takes ownership of an intervention by making it a priority, it invests significant long-term funding. This investment signals a degree of stability that in turn attracts funding from other donors and the private sector. For example, under UNIDO's Program for Country Partnership, Ethiopia has invested $\$ 900$ million over four to five years for infrastructure projects and is actively pushing the program's agenda. This has led to longterm partnerships with the European Investment Bank, Food and Agriculture Organization (FAO), Italy, Switzerland, and others. At the regional level, one recent example of a GEF-supported sustainable financing mechanism is the private-sector partnership hub, which will allow integrated coastal management to be further scaled up in East Asian seas through the Partnerships in Environmental Management for the Seas of East Asia (PEMSEA). ${ }^{3}$

In the absence of sufficient financing, interventions planned with an explicit long-term outlook can fail. In Senegal, a GEF-supported project that introduced sustainable-use community nature reserves as part of the country's protected area system was designed to be implemented in three phases. The first two phases successfully established 26 community nature reserves that linked fragmented ecosystems across 270 villages and created a network of mutual savings groups that provided financing to local entrepreneurs. However, funding for the third phase fell through. Despite the project's initial socioeconomic benefits, many of the alternative livelihood activities were discontinued due to a lack of funds to purchase equipment that would allow community members to apply the training they received in the first two phases. Operations at the community reserves continue at present, but at a minimal scale.

Long-term sustainability of scaling-up activities is vulnerable to political and economic changes. An octopus fishing ban in Mauritius that was scaled up from the outer island of Rodrigues to the national level is now funded by the national government. The GEF and other donors invested in awareness campaigns and community training programs through multiple consecutive Small Grants Programme projects. However, the outcomes so far have been much lower than in the pilot for two reasons; first, the larger area needs a higher investment in enforcement efforts, and second, legislation at national level did not apply the ban to the entire supply chain, as was done in the pilot.

\section{Staying flexible and cost-effective}

Multistakeholder interactions and partnerships are important in coordinating multiple mandates, objectives, and activities among stakeholders, 
which in turn is essential in keeping implementation at scale cost-effective. For example, the PEMSEA series of projects, supported by the GEF's international waters focal area through the United Nations Development Programme (UNDP) for more than 25 years, has scaled up integrated coastal management from a few pilot sites to a region-wide intervention largely through multistakeholder partnerships. Among the PEMSEA activities are:

- Regional networks for local governments, research institutions, and legal experts

- Regional governance structures such as a high-level forum composed of environmental ministers of participating countries in the region and a partnership council with representatives from the national and local governments, communities, NGOs, research and educational institutions, the private sector, and regional and international organizations

- The triennial East Asian Seas Congress that allows regional stakeholders to have dialogues, share lessons, and formally endorse regional targets to which each of them contributes

Learning from previous projects can shape the design of subsequent projects. Systematic learning mechanisms in GEF projects are usually in the form of knowledge exchange networks and regular multistakeholder meetings. For example, the RERED project in Bangladesh integrated systematic learning in its design to scale up successful models adaptively. While incorporating lessons from previous experience in Bangladesh and other countries, the project design included a provision to scale up support for the model with the most promise. Throughout its implementation, the project continuously incorporated lessons from its own pilot approaches, and as the national demand for the solar home systems grew, the project shifted its focus to that component. Ultimately, the project scaled up support to the most successful model, which used microfinance ownership rather than a fee-for-service approach. Within this model, the project also used M\&E data from the field to incorporate new specifications and technologies (such as LEDs) in solar home systems to better serve lower income households, which in turn made the systems more attractive to a larger population (World Bank Group, IEG 2014).

\section{Notes}

1. The World Bank, UNDP, UN Environment, the FAO of the UN, and the Asian Development Bank.

2. In this case, the national power company refers to the National Administration of Power Plants and Electrical Transmissions (Administración Nacional de Usinas y Transmisiones Eléctricas).

3. www.pemsea.org/. 


\section{Toward transformational change}

\section{References}

GEF. 2012. "Time for Transformational Change: The Role of the GEF." www.thegef. $\mathrm{org} /$ sites/default/files/publications/GEF-vision-Ishii_0.pdf.

GEF. 2015. GEF 2020: Strategy for the GEF. Washington, DC: Global Environment Facility. www.thegef.org/publications/gef-2020-strategy-gef.

GEF IEO. 2018a. Evaluation of GEF Support for Transformational Change. Washington, DC: Global Environment Facility Independent Evaluation Office.

GEF IEO. 2018b. Impact of GEF Support on National Environmental Laws and Policies in Selected Countries 2017. Washington, DC: Global Environment Facility Independent Evaluation Office.

GEF IEO. 2019. Evaluation of GEF Support to Scaling up Impact 2019. Washington, DC: Global Environment Facility Independent Evaluation Office. www.gefieo.org/ evaluations/scaling.

IEG. 2014. World Bank Group Support to Electricity Access, FY2000-2014. Washington, DC: Independent Evaluation Group, World Bank Group. https://ieg.worldbankgroup.org/ evaluations/world-bank-group-support-electricity-access.

Rodríguez, H. 2013. "Programa de Energia Eolica en Uruguay (PEEU)." www.thegef.org/sites/default/files/project_documents/2826_UNDP_TE_Informe_Final_ PEEU_Espanol.docx. 


\section{Boosting the benefits Use of GEF IEO evaluations}

Although evaluations always have a cost, their benefit depends on use: no use, no benefit. The Global Environment Facility (GEF) Evaluation Policy ${ }^{1}$ spells out the many ways the organization can benefit from making use of its evaluations:

Evaluation can be used to improve the design and performance of a planned or ongoing project or program (a formative evaluation); to make an overall judgment about the effectiveness of a completed project or program, to ensure accountability; and to generate knowledge about good practices.... Evaluation feeds into management and decision-making processes regarding the development of policies and strategies; and the programming, implementation, and reporting of activities, projects, and programs.

Overall, evaluation contributes to the GEF's accountability and development effectiveness, its institutional learning and evidence-based policy-making, and its organizational effectiveness. The GEF uses evaluation results to inform its planning, programming, budgeting, implementation, and reporting cycle. Other global development institutions, such as the United Nations Development Programme (UNDP) and the World Bank, also use evaluation for these purposes. In particular, the GEF comprehensive evaluation (referred to as OPS, for overall performance study), completed every four years by the GEF Independent Evaluation Office (IEO), illustrates the implementation of this dimension of the evaluation policy.

Evaluation use depends on several factors. ${ }^{2}$ Given the GEF's context and experience, the following are crucial:

1 credibility (suitable methods)

2 timeliness (availability at the time that decisions are made)

3 relevance (responsiveness to demand)

4 engagement (of intended users)

5 clarity (user-friendly style) 
We addressed credibility in Chapter 4's presentation of the IEO's evaluation methods, including frameworks, measures of additionality, and selection of evaluation types, all of which are essential for credibility.

\section{Timeliness}

Of particular importance is the timeliness of reports and their evaluative information. As discussed in Chapter 2, which presents the history of evaluation in the GEF, the structure, scope, and development process for the comprehensive evaluations evolved and expanded over time as the IEO was formed. Most important, the Council members require that the OPS be completed, and provide conclusions and recommendations, to meet the timing of the replenishment process. During OPS6, the IEO established a process of regular feedback to the Council through a variety of report formats as input into the seventh four-year replenishment period (GEF-7), July 2018 through June 2022. This process included submission of a robust evaluation brief on every OPS6 evaluation, for both completed and ongoing projects and programs, to the March replenishment meeting. ${ }^{3}$ The comprehensive, timely, relevant, and credible inputs into the replenishment process contributed to the Council's approving an increased budget for the IEO.

The timeliness of completion of the reports and the dissemination of findings also played a critical role in the GEF's ability to take up the overall strategic recommendations from OPS6 and implement recommendations of individual evaluations As indicated in the 2019 Multilateral Organizations Performance Assessment Network (MOPAN) independent assessment of the GEF, "Timely sharing of evaluation findings with country and regional stakeholders has been enhanced by the creation of Evaluation Briefs, originally developed to share key messages from OPS6."

\section{Relevance and responsiveness}

The OPS comprehensive evaluation is an integral part of the financial replenishment process of the GEF. Often, in addition to the IEO's planned work program on institutional, performance, and impact issues, the Council requests the IEO to carry out specific studies as inputs into the replenishment process. Leading into GEF-7, the Council sought insights into the Integrated Approach Pilots that were recently launched in GEF-6 and into GEF governance; the IEO responded with evaluations in these two areas. Supplementary evaluations like these, which were not part of the original evaluation work program, often require the application of a variety of evaluation approaches, such as formative reviews in the case of recently approved programs that are early in the implementation process. The IEO is also responsible for providing the Council with updates on ongoing evaluations.

For the first GEF-7 replenishment meeting in March 2017, the IEO prepared a four-page evaluation brief on each ongoing and completed evaluation 
and provided updated results on interventions for which evaluations had progressed substantially. These briefs were very well received. The June 2017 regular Council meeting included presentation of completed evaluations. The IEO prepared OPS6 over the summer of 2017, completing it in time for the October 2017 replenishment meeting in Ethiopia that focused on content and programming for GEF-7. The IEO was allocated the first hour of the day to present the draft report. The discussion on OPS6 lasted five hours at the meeting and the replenishment group asked the GEF to reflect the recommendations from that discussion in the policy and programming directions for GEF-7.

The recommendations included additions of specific references to the IEO evaluation on transformational change, early findings from the evaluation of the Integrated Approach Pilot programs, and the focal area studies on climate change and biodiversity. The programming directions for GEF-7 were revised to reference transformational change several times. The IEO evaluations on safeguards and gender led to the redesign of GEF policies in those areas. Other influential evaluations were the Civil Society Organization (CSO) Network evaluation, which led to a reform of engagement with the network; the private sector evaluation, which led to the development of a new private sector strategy in the GEF; and the governance evaluation, which led to the formation of an ad-hoc governance working group in the GEF Council. Then, at the third replenishment meeting in January 2018 in Brazil, the replenishment group once again asked the GEF to include evaluation recommendations that had been missed in the policy document, particularly pertaining to governance.

\section{Engagement during evaluation}

Throughout the process of evaluation, the IEO engages with numerous stakeholder groups. GEF independent evaluations receive feedback from reference groups, usually from the GEF Secretariat and Agencies, sometimes including the Scientific and Technical Advisory Panel (STAP) and CSO Network members, and internal and external peer reviewers. These groups review draft reports and make recommendations that are discussed with the GEF Secretariat. The IEO presents the evaluations as working documents to the GEF Council, and the Council decisions reflect the adoption of the recommendations.

OPS6 involved stakeholder engagement throughout the evaluation. The IEO discussed topics and themes for the approach paper with the GEF Secretariat and Agencies, operational and political focal points, and civil society; we sought inputs throughout the year on process and other issues at the expanded constituency workshops with a broad range of stakeholders including country focal points, beneficiaries, and civil society representatives. The expanded constituency workshops also provided an excellent opportunity for the IEO to gather information on important issues related to the 
implementation and sustainability of GEF projects and programs. The individual evaluations that fed into OPS6 also engaged stakeholders throughout the evaluation process - from the development of approach papers through the sharing of evaluation findings. The findings of the individual evaluations and OPS6 were disseminated widely during the year preceding the Assembly, contributing to the increased use of the evaluations. Evaluation findings specific to the various country constituent units were also presented at the constituency meetings held as part of the Assembly in Vietnam.

Implementation of IEO evaluation recommendations is tracked through the management action record (MAR) system. The MAR tracks the level of adoption of GEF Council decisions that are based on the recommendations of the evaluations conducted by the IEO. The MAR serves two purposes: "(a) to provide Council a record of its decisions based on the evaluation reports presented by the GEF IEO, the proposed management actions, and the actual status of these actions; and (b) to increase the accountability of GEF Management regarding Council decisions” (GEF 2005, p. 3). The level of adoption of the decisions is reported every year in the IEO annual performance report. Peer reviews of the IEO have reflected on the inadequacies of this process and the need to reform the processes of adopting recommendations and the MAR.

\section{Clarity}

Through a multipronged approach, the IEO ensures the clarity of the evaluative information presented in reports and online, making them easier to use for the range of stakeholders. Reports are illustrated with infographics and briefs that highlight key messages in four pages or less, as illustrated in Figure 7.1. These documents and databases are available on the GEF IEO's user-friendly website, www.gefieo.org.

\section{IEO evaluation quality and use}

During 2019, IEO conducted a stakeholder survey and knowledge needs assessment to obtain feedback on the quality and use of IEO evaluations and knowledge products. Ninety-six percent of respondents were satisfied with the quality of IEO evaluation reports, and more than 90 percent were satisfied with the relevance, usefulness, ease of understanding, transparency and clarity of methodology, and objective analysis and findings. Respondents also indicated satisfaction with the strong link between conclusions and evidence and with the timeliness of the evaluations and knowledge products. The IEO's process of stakeholder engagement was satisfactory to 90 percent of respondents. When we considered responses by position, we found that GEF Council members and alternates, GEF Agencies, GEF operational and political focal points in the recipient countries, and GEF CSO Network members were most satisfied with the evaluations; the GEF Secretariat staff 

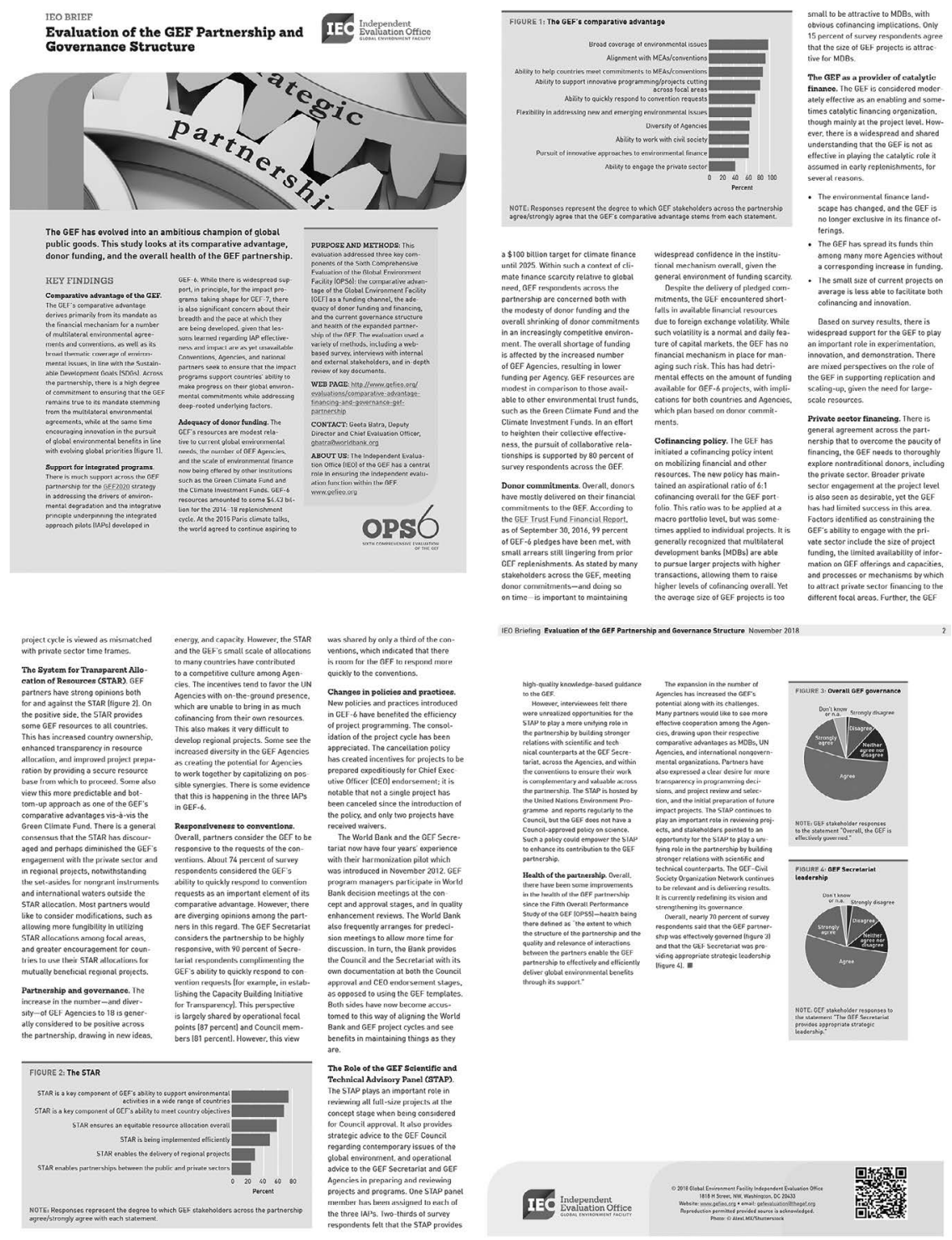

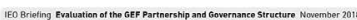

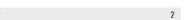

wet that the STAP provides

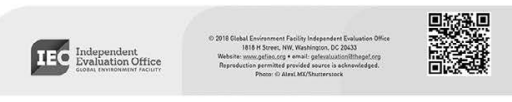

Figure 7.1 IEO brief: evaluation of the GEF partnership and governance structure

were the least. The total percentage of respondents who reported a high level of satisfaction with the overall quality of reports and timeliness has increased by eight percentage points since the last survey, in 2015, while the high level of satisfaction with the usefulness of conclusions and recommendations has increased by 10 percentage points. 
In terms of use, 80 percent of respondents reported using the evaluations to some extent. More than 75 percent of the respondents use the evaluations as reference material, in designing and modifying projects and programs, for assessing the performance and results of GEF-supported initiatives, and for providing advice to others in the GEF partnership and beyond. Council members and alternates use the evaluations to support their assessment of GEF performance and to make a case for a specific course of action. Members of the GEF partnership, such as the staff of the GEF Secretariat, GEF Agencies, GEF operational and political focal points, and GEF CSO Network, reported using IEO evaluations to design and modify programs and projects, as reference material, to share with others, and to design and modify policies and strategies. External stakeholders - including CSOs and national and local governmental agencies - use evaluation reports as reference material and for sharing with others as an input into the design and modification of their own initiatives.

Evaluation briefs, IEO presentations and workshops, the IEO website, and email announcements were rated as the most effective knowledge-sharing channels across stakeholder groups. Respondents indicated that, to learn about evaluations in the future, they would continue relying on these channels and on synthesis notes with lessons across evaluations. Multimedia, newsletters, and social media were rated as relatively less effective means of sharing knowledge (GEF 2019).

\section{Challenges}

As pointed out in the MOPAN (2019) independent assessment, "IEO could do more to ensure that the lessons derived from evaluations are absorbed by key actors." In particular, MOPAN pointed to the need for more face-to-face interactions between the IEO and Council members on the IEO work program and noted the limited capacity of Council members to devote to evaluations. One possible approach to address this is circulating very brief notes on lessons learned from evaluations on different topics to Council members on a periodic basis, particularly when new members join the Council.

\section{Conclusion}

The GEF and its stakeholders make extensive use of IEO evaluation reports, briefs, summaries, and other products. To improve interventions and understand where, how, and why they succeed or struggle; to support decision-making around policies and strategies; and to enhance communication with and connection between stakeholders - all of these uses ensure that the GEF's investment in evaluation pays off for progress in achieving its mission. Yet there is scope for improvement, to address the challenges mentioned above. 


\section{Notes}

1. See Appendix 1; this is the version approved in June 2020.

2. There is a vast evaluation literature in which evaluation use is discussed, e.g., Rogers (2018), Patton (2008), and Feinstein (2002).

3. www.gefieo.org/evaluations/ops6-report, see evaluation synopses.

\section{References}

Feinstein, O. 2002. "Use of Evaluations and the Evaluation of Their Use." Evaluation 8(4): 433-440.

GEF. 2005. Procedures and Format of the GEF Management Action Record. Washington, DC: Global Environment Facility. www.thegef.org/council-meeting-documents/ procedures-and-format-gef-management-action-record.

GEF. 2019. Semi-Annual Evaluation Report of the Independent Evaluation Office. Washington, DC: Global Environment Facility. www.thegef.org/sites/default/files/councilmeeting-documents/EN_GEF.ME_C57_01_SAER_Dec_2019_COUNCIL\%20.pdf.

MOPAN. 2019. Global Environment Facility (GEF) 2 017-18 Performance Assessment. Multilateral Organisation Performance Assessment Network. www.mopanonline.org/ assessments/gef2017-18/GEF\%20Report.pdf.

Patton, M.Q. 2008. Utilization-Focused Evaluation. Los Angeles, CA: SAGE.

Rogers, P. 2018. 7 Strategies to Improve Evaluation Use and Influence. www.betterevaluation. org/en/blog/strategies_for_improving_evaluation_use_and_influence. 


\section{Lessons from the GEF experience}

This final chapter draws on the findings and conclusions of recent evaluations from the Global Environment Facility (GEF) Independent Evaluation Office (IEO) and on the evaluation process to provide relevant lessons for environmental and evaluation practitioners. We address two key questions: how can we consider the environmental-social-economic interlinkages in designing programs and adopting systems-based approaches to evaluate the outcomes and impacts of interrelated or integrated interventions while recognizing potential synergies and trade-offs? What lessons do the independent evaluations $^{1}$ of the GEF offer for the design and evaluation of interventions dealing with global environmental issues?

\section{The context}

We are at a perilous historic juncture: the world is facing the multiple challenges of tackling a global pandemic, rising poverty and inequality between and within countries, and environmental degradation and global climate change that threaten the natural systems we depend on. The United Nations' 2030 Agenda for Sustainable Development was launched in 2015 to end poverty and set the world on a path of peace, prosperity, and opportunity for all on a healthy planet, through transformational change. The world adopted the agenda's 17 Sustainable Development Goals (SDGs). However, even before the COVID-19 pandemic, progress remained uneven and we were not on track to meet the goals by 2030 (United Nations Department of Economic and Social Affairs 2020). Although we saw some gains in school attendance, access to drinking water, and reduction in the incidence of communicable diseases, more people are suffering from food insecurity, the natural environment continues to deteriorate at an alarming rate, and dramatic levels of inequality persist in all regions. COVID-19 has now exacerbated the situation in creating a health, economic, and social crisis that is threatening lives and livelihoods and erasing the modest progress made in recent years (Naidoo and Fisher 2020).

The COVID-19 pandemic is clear evidence of the inextricable link between the world ecosystem and human health. About two-thirds of all infectious diseases in humans have their origins in animals (Coker et al. 2011). Human 
activities have substantially expanded into previously undisturbed domains and have destroyed landscapes, fundamentally altering the interactions between animals and humans and affecting the dynamics of pathogen transmission (Tollefson 2020). Encroaching on new ecosystems lets new viruses enter our population. Land mismanagement, habitat loss, overexploitation of wildlife, and human-induced climate change have created multiple pathways for pathogens to transmit from wildlife to domestic animals and humans, impacting our health and well-being. If we do not change our behavior today, or if we do not learn from this pandemic, similar multidimensional crises with environmental, health, and socioeconomic impacts are likely to recur.

With the exception of the GEF, no other significant and reliable funding resources exist to address biodiversity and environmental issues other than climate change. In the course of its nearly three decades, the GEF has weathered health and economic crises while supporting a portfolio that simultaneously addresses environmental and human health benefits. Independent evaluations of GEF programs offer valuable insights relevant to the current pandemic, drawing on lessons learned from implementation.

Chapters 4-6 presented the findings on the continued relevance of the GEF in meeting countries' needs and assisting them in responding to requirements of international environmental conventions. These chapters also explored the GEF's strong track record in delivering overall good project performance and driving transformational change. This change includes a focus on gender equality and indigenous peoples, with support from institutional systems for results and knowledge management.

GEF interventions in all focal areas - biodiversity, climate change, international waters, land degradation, and chemicals and waste - have implications for improving human health and other socioeconomic outcomes. The shift toward more integrated programs, which cross focal areas to address drivers of environmental degradation and achieve transformational change at scale, highlights the importance of recognizing the synergies and trade-offs between environmental objectives and socioeconomic objectives. The SDGs emphasize that the interrelationships among the three pillars of sustainable development - social, economic, and environmental - are inseparable. All social and economic development rests on the biophysical foundation of the natural environment, which we as humans depend upon. This collective evidence of interconnection clearly points to the need to broaden the environmental discourse beyond climate change to take full account of biological resources, land, forests, water, oceans - and the interlinkages between these natural systems and the humans who inhabit them as part of the ecosystem. And pandemics must be incorporated into any future sustainable development discussions and plans (Di Marco et al. 2020). Finally, evaluating the outcomes and impacts of environmental interventions and understanding the interrelationships, synergies, and trade-offs between environmental outcomes, socioeconomic outcomes, and the SDGs will require a shift toward a more integrated and holistic evaluation framework. 


\section{The past informs the present: relevant lessons for the current pandemic}

Following its unique mandate, the GEF has implemented projects committed to providing global environmental benefits while also improving human health and well-being. The GEF portfolio has not only significant connection between the various environmental domains but also profound interlinkages to socioeconomic benefits and human health (GEF IEO 2020c).

\section{A global wildife program combats disease transmission}

Of most direct relevance to the current pandemic is the GEF's program to combat illegal wildlife trade. Wildlife trade - both legal and illegal - is a transmission pathway that exposes humans to zoonotic diseases (Swift et al. 2007). The supply chain of wildlife and wildlife products from source areas, and transportation through local, national, and international networks to distant markets, allows for natural spillover and spread. Unsafe handling and other practices allow pathogens to pass from wildlife to humans. And these conditions and practices are even more challenging to monitor - and impossible to regulate - in illegal wildlife trade. Illegal wildlife trade generates $\$ 26$ billion per year, making it the fourth most profitable illegal industry in the world. Stopping illegal trade has been a difficult endeavor, and, unfortunately, as long as demand persists for wildlife products, there will be trade.

Several GEF-funded projects include activities related to combating illegal wildlife trade and address the drivers of biodiversity loss. The GEF's first concerted effort to tackle illegal wildlife trade in a coordinated and comprehensive manner was the Global Partnership on Wildlife Conservation and Crime Prevention for Sustainable Development, launched in 2015. Covering 19 countries in Africa and Asia, the program aims to prevent the extinction of threatened species by reducing poaching, curbing trafficking, and reducing demand. Its main interventions have included supporting protected area management, reducing poaching of target species, engaging communities in managing human-wildlife conflict, improving performance across the enforcement and criminal justice chain, establishing partnerships, and knowledge management.

The IEO conducted a formative assessment of the program in 2017 (GEF IEO 2018c), when the program was in its early stages of implementation. The evaluation provided insights into what works, why and under what circumstances, for whom, and the extent of the benefits. The lessons learned from the formative assessment allowed for timely improvements in program implementation. Moreover, the evaluation underscored the need for a comprehensive approach along the entire supply chain - from sources to global markets - to contain the spread of illegal trade.

The COVID-19 outbreak has highlighted the issue of illegal wildlife trade and - more broadly - of habitat destruction and biodiversity loss. While 
maintaining their current global (and local) focus on immediate medical, health, and socioeconomic needs, all countries need to be better prepared to address and mitigate risks to environmental health and human well-being posed by climate change, biodiversity loss, and deforestation and degradation.

Lessons

- A globally coordinated approach. Often, initiatives are designed for single countries, but illegal wildlife trade by its very nature permeates jurisdictional boundaries, requiring cross-boundary strategies at the regional and global scales. Illegal wildlife trade, ultimately, is an international issue, and combating it requires a more cohesive approach with the inclusion of regional initiatives, cross-border activities within nationally implemented projects, and coordination among countries on transboundary issues.

- Greater attention to a broader spectrum of illegally traded species. Most programs are limited to certain threatened and endangered species and megafaunas. Species coverage needs to be strategically expanded to conserve the maximum number of species and save species from extinction. The GEF addressed this gap in its follow-on funding phase for the Global Wildlife Program by expanding interventions to include additional species. Thus, paying attention to more species has significance in public health surveillance and in assessing zoonotic risk.

- Appropriate focus on demand. Most interventions typically focus on reducing poaching of wildlife in source countries and fighting trafficking of illegal wildlife and derived products. Few initiatives focus on reducing demand for illegally traded wildlife in Asia, the European Union, and the United States, and this effort needs to increase. China has banned all forms of illegal wildlife trade and consumption in the context of the current pandemic and in response to growing indications that the COVID-19 outbreak stemmed from a coronavirus found in wildlife (Vaughan 2020). This response highlights the linkage between illegal wildlife trade and zoonoses, and the importance of working with countries with the greatest demand for wildlife and wildlife products.

- Explicitly addressing political will and corruption. A coordinated focus on political will and corruption will ultimately help strengthen legislation, law enforcement, and judicial systems in combating illegal wildlife trade.

- Enhancing livelihoods. Illegal wildlife trade is driven in large part by growing demand from expanding economies in Asia, often facilitated by transnational criminal networks. Poverty and absence of sustainable livelihoods drive communities to engage in poaching. Efforts should focus on the livelihood security of people living near wildlife, coupled with demand reduction strategies including public awareness and behavior change campaigns in major market hubs. 


\section{The health co-benefits of the GEF chemicals and waste portfolio}

Our recent study of the health co-benefits associated with GEF interventions offers useful lessons for the current pandemic (Hadjimichael and Batra 2019). As a result of globalization and the spread of the chemical manufacturing industry, the burden of disease due to pollution is significant and increasing in lower- and middle-income countries. Overall, analysis of these projects suggests that GEF interventions in the chemicals and waste portfolio, primarily in artisanal gold mining, have significant health co-benefits. The primary objective of the typical GEF chemicals and waste intervention is the elimination of harmful chemicals from the environment, which translates into direct health impacts - namely, decreased disease burden and mortality. This is not a trivial finding; the conservative global estimate of observable pollution-related deaths in 2015 was 9 million or 16 percent of total deaths.

Lessons

- Community health approach to better target interventions to the most vulnerable. Hands-on training enabled health-care workers to assess cases of mercury poisoning in a timely fashion and to effectively manage them, with protocols established to send any unclear diagnoses to the hospital. This success in building accurate community health surveillance neatly supplemented efforts to raise awareness of the health consequences of mercury use and exposure, mobilizing the community and leading to more sustained impact.

- Enhancing local agency through awareness, education, and knowledge dissemination. Personal health impacts are a great motivating factor for individuals on the ground. Raising awareness, education, and disseminating knowledge help break down exposure pathways and inequities in health. Awareness-raising activities around new technologies and building community help establish the commitment of communities.

- Industry formalization. Local stakeholder engagement demonstrated that the priority for action was formalizing the artisan gold mining industry with government support. This step is critical for advancement of community-level issues, advocacy, and long-term sustainability.

\section{Lessons from crisis management during the Ebola crisis}

Our case study of the West Africa Regional Fisheries Program (World Bank 2017) illustrates the GEF's continuous support for building resilience in Ebola-affected countries to buffer external shocks. The program also demonstrates the GEF's ongoing response to country needs for immediate recovery and long-term food security through improved governance of fisheries resources. 
The Ebola epidemic, which began in Guinea in late 2013 and spread to Sierra Leone and Liberia, affected the means of making a living for millions of the poorest and most vulnerable people in the region. The hardest hit areas were also among the most agriculturally productive regions of the three affected countries. Mandatory quarantine measures and fear of infection kept farmers from attending to their fields, resulting in considerable disruption of farming activities. Food trade between villages and bordering countries was slowed, resulting in food shortages.

The fishing industry helped feed the population when agricultural lands were abandoned during the 2014-2016 Ebola outbreak. Liberia and Sierra Leone were part of the initial phase of the GEF-funded regional fisheries program (implemented from 2010 to 2016), which aimed to strengthen the capacity of recipient countries to govern and manage targeted fisheries, reduce illegal fishing, and increase local value added to fish products.

The project's investments in fighting illegal fishing have had transformative results in Liberia and Sierra Leone. The exclusion of illegal trawlers from the six-mile inshore exclusion zone opened space for artisanal fishers, coastal communities experienced a change in fish availability, and incomes increased (World Bank 2017). During the Ebola outbreak, fish as a food source played a more central role as a protein supply for both coastal and inland communities, mostly in the form of smoked small pelagic fish transported by road through a marketing chain controlled by women fish smokers on the coast.

\section{Lessons}

- Flexibility and quick adaptation. The GEF recognized that marine fish resources represent valuable natural capital that could enhance communities' resilience in a time of crisis, if managed properly. When agriculture was impacted during the Ebola crisis, resulting in food shortages, the GEF reacted quickly to support the fishing industry through reducing illegal fishing and increasing local incomes.

- Long-term strengthening of governance and building resilience through sustainable interventions. Improved governance resulted in a reduction in illegal fishing, opening up the space for artisanal fishers. Coastal communities experienced greater fish availability and incomes increased. To ensure long-term financial sustainability in livelihoods and food security of fisher communities, the GEF approved an additional grant of $\$ 10$ million in 2016 to Guinea, Liberia, and Sierra Leone for further targeted support of their fisheries sector. All three countries prioritized conservation of their fish stocks for artisanal fisheries in their Ebola recovery plans. The additional financing project (implemented from 2017 to 2021) provides incremental funding by supporting a suite of interventions that address both immediate recovery strategies and long-term responses to strengthening fisheries governance and increasing resilience. 


\section{Promotion of innovative solutions for infectious waste}

During the 2014-2016 Ebola outbreak, Guinea, Liberia, and Sierra Leone faced challenges in safely disposing of a growing quantity of infectious waste. The waste generation rate was estimated at $240 \mathrm{~L}$ of infectious waste per Ebola patient per day (United Nations Development Programme [UNDP 2015]). The infected medical equipment and waste had to be properly treated to minimize the risk of transmission. However, in many hospitals and community care centers in affected countries, Ebola-contaminated waste was burned in barrels, burial pits, or low-tech incinerators that emitted dangerous fumes and created toxic ash.

With support from the GEF and UNDP, environmentally friendly sterilizing equipment was introduced to allow safe disposal of the vast amounts of infectious waste generated in treating Ebola patients. This equipment, the autoclave, was the first of its kind used in any of the Ebola-affected countries. The autoclave uses high temperature and pressure steam to disinfect the waste, allowing for safe disposal. Unlike burning or incinerating, it does not generate pollutants and has a much smaller carbon footprint.

The autoclave was designed under a GEF-funded project, Demonstrating and Promoting Best Techniques and Practices for Reducing Health-Care Waste to Avoid Environmental Releases of Dioxins and Mercury. This program was implemented from 2007 to 2012 in Argentina, India, Latvia, Lebanon, the Philippines, Senegal, Tanzania, and Vietnam. An important component of the project was to develop and disseminate affordable nonburn health-care waste treatment technologies that could be built and serviced in Sub-Saharan African countries using locally available supplies and skills. After completion of pilot activities and testing of the prototype in Tanzania, the new autoclave system was produced in partnership with a South African manufacturer, Medi-Clave.

During the Ebola outbreak, microbiological tests indicated that the virus was effectively destroyed by the autoclave system. UNDP immediately launched another project that provided 20 autoclaves to the three Ebola-affected countries that continued to be used for treating hospital waste in the post-Ebola recovery period (UNDP IEO 2013). The autoclave system demonstrated the synergy between health-care and environmental sustainability, which can lead to overall reduction in harm to both human health and the environment.

As a result of this project, non-incineration health-care waste treatment technologies and mercury-free medical devices were introduced in four Sub-Saharan African countries, Ghana, Madagascar, Tanzania, and Zambia, to reduce harmful releases from the health sector.

\section{Lessons}

- Adapting and promoting existing technologies to a new crisis situation. The solution of using autoclaves to dispose of hazardous waste brought significant and positive change to the Ebola-affected countries and has been sustained long after the crisis abated. 
- Taking risks and allocating resources based on project additionality to promote new technologies. With severe budget constraints, particularly in Ghana and Madagascar, national budget allocations and health-care facilities alone could not cover initial capital investments and start-up costs to migrate from current unsafe and environmentally polluting practices to non-incineration technologies and to phase out mercury-containing devices. Funding from the GEF and support from project cofinancers was critical for putting environmentally sound practices in place for health-care waste management and treatment (UNDP 2014). (Read more about additionality in Chapter 6.)

\section{Lessons for achieving transformational change and scaling up}

To overcome the unprecedented nature of the pressures faced by the earth's ecosystems, and to achieve impacts at scale, the 2020 GEF strategy (GEF 2015) recognized the need for promoting transformational change over incremental environmental strategies. Transformational interventions are defined as engagements that help achieve deep, systemic, and sustainable change with large-scale impact in an area of global environmental concern. Transformational change, and the process of scaling up, takes place through demonstration, mainstreaming, linking, and catalytic effects. The IEO evaluation highlighted the following criteria for achieving transformational change and scaling up impacts (GEF IEO 2017).

- Ambition. Transformative interventions have ambitious objectives explicit or implicit - to trigger and support a deep, fundamental change in addressing a market distortion or systemic bottleneck that is a root cause for an environmental issue of global concern.

- Effective mechanisms. Transformational interventions help to establish a mechanism - mainstreaming, demonstration and replication, and/or catalytic effects - to scale up and expand the activities supported by the intervention.

- Good-quality implementation and execution. These are important drivers of change in terms of the quality of project design, supervision, and assistance by the GEF Agency, and the effectiveness of the executing agency in performing its roles and responsibilities. Partnerships and stakeholder engagement play an important role.

- Ability to harness market forces. A strong private-sector response is important for achieving a fully completed transformation. This suggests that where an opportunity exists to harness market forces - by addressing removal of barriers through sound policy, encouraging sustainable supply, catalyzing potential demand, and encouraging civil society and community participation - it deserves careful attention in the identification and design of an intervention. 
- Size does not matter. Modest GEF medium-size projects can be just as transformational as major, multiphase investment projects.

- Transformation takes time. Transformational interventions and the process of scaling up can often take more than five years. Long-term sustainability of transformational change and scaling up requires establishing sustainable sources of financing and strengthening institutional capacities.

\section{Lessons for long-term sustainability of outcomes}

Although outcome performance is important, the long-term sustainability of an intervention's outcomes is perhaps even more critical. IEO internal analysis of the terminal evaluation data shows that projects cutting across focal areas have higher outcome ratings but lower sustainability. The Annual Performance Report (GEF IEO 2018a) and the country cluster evaluations on the small island developing states (GEF IEO 2019), the Africa biomes (GEF IEO 2020b), and the least developed countries (GEF IEO 2020a) provide useful lessons for enhancing sustainability of outcomes. Inherent in all of these lessons is the need to address this objective from the design stage.

- Demonstrating sustainability takes time. This underscores the importance of designing projects with due consideration to measures that increase the likely sustainability of outcomes.

- Plan for financial sustainability. The challenge of financial sustainability in the least developed countries highlights the importance of planning at the design stage to set up viable financial mechanisms and measures that can continue to deliver benefits after project completion.

- Attend to country considerations. Project design that promotes sustainability must consider a country's socioeconomic and political context, with attention to local conditions and knowledge. Particularly in fragile countries, design should include measures and activities designed to support - from both financial and institutional standpoints - the continuation of outcomes after the project's completion.

- Know the influence of synergies and trade-offs. Consideration must be given, again, at project design to how synergies and trade-offs between socioeconomic and environmental objectives influence the prospects for sustainability in the biomes. This underscores the importance of nexus thinking between environmental and socioeconomic objectives and between short-term and long-term planning in enhancing sustainability.

\section{Lessons for partnerships: policies, strong institutional systems, and governance}

The GEF partnership delivers its program through 18 implementing agencies. The effective performance, management, and operation of the partnership require a set of appropriate policies and procedures. The GEF policies and guidance on gender equality, safeguards, and indigenous peoples have 
advanced the GEF's efforts in these areas, but gaps exist in the frameworks relative to good practice in partner agencies and in implementation.

- Policies that reflect capacities and deliver guidance. For a partnership, policies must be based on the capacities of all agencies to implement principles and guidelines that reinforce policies. These should be accompanied by practical guidance on project design and indicators, or a list of specific requirements to aid in implementation of the policies.

- Streamlining for private-sector engagement. Partnerships with the private sector to address environmental problems have been a challenge for the GEF (GEF IEO 2017). Furthering private-sector engagement requires eliminating operational restrictions such as long timelines, approval processes, and documentation. The private sector should be engaged as partner in promoting environmental sustainability more broadly, rather than as a source of financing. Institutions such as the GEF should make country clients and private-sector stakeholders aware of the opportunities for engagement with one another, in finance and beyond. Country recipients need to be aware of the private-sector role in green finance, in accessing funds beyond the usual GEF grant instruments, or in other opportunities for engagement. Private-sector respondents need clarity to help them prepare for cooperation in partnerships and to help them understand the distinct role for multilateral institutions including the GEF in regulatory and policy interventions where conditions are still not ripe for investment.

- Components of good governance. Overall, the GEF partnership is effectively governed; concerns remain on matters related to representation, efficiency, accountability, and transparency. Lessons from the governance study (GEF IEO 2018b) point to key attributes for good governance: a high level of trust and goodwill, a sense of common purpose, a governing instrument that fully and accurately reflects how the partnership actually functions, a level of decentralized decision-making, transparency at all levels, and an independent chair.

\section{Lessons for better evaluations}

The GEF evaluation experience, particularly OPS6, offers valuable lessons to enhance the quality, credibility, and utility of evaluations. These lessons are consistent with the evaluation experience of other global development institutions, including the UNDP (2019), World Bank (IEG WBG 2019), and the International Fund for Agricultural Development (IFAD 2019).

\section{Timely delivery and evaluation quality}

\section{Balancing updated information with early delivery}

The GEF provides funding to developing countries largely in the form of grants and operates through a four-year funding cycle, at the end of which 
the donors replenish the fund. Evaluation is critical in the replenishment process. On the one hand, conducting the evaluations as late in the process as possible will reflect the latest developments in programming and give outcomes time to emerge. On the other, decision-makers need evaluation results as early as possible to make the best use of them. Balancing these two needs requires applying formative and real-time evaluation approaches to provide insights into recently designed or ongoing interventions, in addition to the traditional ex-post objectives-based evaluation.

\section{Completion of a quality report requires time and planning}

More than having complete individual evaluations, a good comprehensive report must allow sufficient time to bring findings together, analyze cross-cutting issues, confirm conclusions, and develop recommendations. Successful time planning made OPS6 useful to the replenishment process; with complete information from 29 evaluations, the analysis and writing took five months. Box 8.1 discusses the impact of early and comprehensive evaluation planning.

\section{Box 8.1}

\section{The impact of early and comprehensive evaluation planning}

Planning a comprehensive evaluation early is instrumental to a useful and timely evaluation.

The framework for OPS6 was designed in 2016 with the presentation of the approach paper. This document set the stage for the evaluation, laid out a detailed timeline, and defined the scope, including the main aspects to be covered in terms of results and impact, and organizational, institutional, and governance topics. It presented the specific questions that the evaluation would seek to answer and the approach and sources for finding those answers.

Planning allows for early consultation with stakeholders through mechanisms such as constituency workshops, which support design of the evaluation to ensure its use at key decision-making moments, such as the GEF replenishment. Planning also helps with early identification of gaps in sources of evidence. Some may be unavoidable due to program implementation timelines, but overall, good planning of deliverables and resource use is important. We explore the OPS6 planning process in detail in Chapter 3.

- Good evaluation practices support evidence-based decisions. Adhering to good evaluation practices is very important to quality: developing comprehensive concept notes, implementing a rigorous peer review and reference group process, pulling a strong evaluation team together, and presenting sound conclusions and recommendations grounded in evidence. For the GEF seventh replenishment, the endorsement of the recommendations in component evaluations at several Council meetings provided an evidence-based underpinning for OPS6. 
- Internal efficiency with external support. Evaluators must balance the efficiency of working internally with the increased value from external perspectives. Developing the approach paper internally is more efficient than developing it with external help, as we discussed in Chapter 3. However, regular periodic engagements with an external advisory panel may add significant value to the quality of the report. For example, the OPS6 external independent advisory panel played a critical role in ensuring important issues were not missed in the report. We shared the main outline and draft findings with the panel prior to embarking on writing the first version of the full report. This worked out well, but even better would have been their involvement from the beginning, even with the development of the approach paper. The panel's feedback on the first draft and the final report was extremely helpful in sharpening the focus of the conclusions and recommendations.

- Sharing the knowledge. Facilitating learning through knowledge management and dissemination of evaluation findings is as important as producing the report. Translating the evaluation findings into messages for a broader audience is worthwhile. Investing in briefs and in a variety of media channels, such as presentations, videos, maps, and graphical expositions, was helpful in disseminating the main findings of the component evaluations and OPS6. Making the results more context specific for various countries was also critical for take-up of the findings. Transparency, which requires disclosure of evaluation reports, is a necessary but not sufficient condition for wide knowledge sharing, which requires active dissemination in a broad range of ways.

\section{Political and global factors for evaluators}

Evaluation involves understanding, acknowledging, and managing competing stakeholder priorities and the financial environment of the times.

Like all international initiatives, the GEF must cope with changing trends in international cooperation that are reflected in financing priorities. Countries and groups of countries promote specific priorities for technical or political reasons, and other groups within a partnership like the GEF advocate for their own interests. The next GEF replenishment process, in 2021-2022, will take place in the midst of recovery from the global stress generated by the COVID-19 crisis, and the GEF will be competing for funding with organizations and programs dealing more directly with health and economic recovery. Under these circumstances, evaluation informs the political context with technical and scientific evidence regarding past performance. The evaluative evidence pertains to the achievement of impacts, organizational performance, and the effectiveness of institutional and governance arrangements.

\section{Evaluative evidence for decision-making}

Evaluators must understand internal priorities and help an organization make evidence-based decisions. 
Within the GEF, environmental priorities have had to compete with each other for a funding share in what is essentially a zero-sum game. The key question remains how to prioritize between the different areas and types of intervention within a limited financial envelope.

Making informed decisions about programming requires knowledge of what has proven effective in tackling the specific challenges in an organization's purview. Systematic evaluation is one of the best ways of generating evidence of past performance, factors contributing to results (or lack thereof), and the likelihood of achieving desired outcomes and impacts in the most effective, efficient, and sustainable manner.

\section{Ensuring credibility}

To have impact, the evidence presented in an evaluation must be credible and be perceived as such.

For every GEF evaluation, and particularly for the comprehensive evaluations, we put extensive effort and consultation into defining the focus, scope, approach, and methodologies of the evaluation itself and all of the component studies that contribute to it. Our analyses encompass as broad a set of evidence as possible to allow for triangulation of findings (Carugi 2016).

We ensure that stakeholders understand the IEO's independence and impartiality in posing the evaluation questions and providing answers to them. Independence, methodological rigor, and transparency are important dimensions of credibility.

\section{Emphasizing IEO independence}

As described in Chapter 2, the GEF Instrument specifies the independence of the GEF IEO. Our role is to conduct independent evaluations of the GEF's performance and impact and to set and validate the standards for the evaluation function within the partnership.

The IEO also provides guidance to the agencies, which are responsible for evaluating their own projects and programs. Our guidance addresses the design and conduct of the evaluations to ensure use of similar approaches to assess key aspects, particularly the achievement of global environmental objectives.

\section{Rigorous methodology and transparency promote credibility}

One way of ensuring rigor is the use of a systematic lens to address evaluation questions, applying the framework of evaluation criteria from the Organisation for Economic Co-operation and Development's Development Assistance Committee that address relevance, coherence, effectiveness, efficiency, impact, and sustainability (Chapter 4 describes how the IEO uses this framework). 
In OPS6, we applied the methods discussed in Chapter 4 as appropriate to the various evaluations. We have invested in promoting quantitative rigor in our evaluations, while also recognizing the importance of good qualitative analysis to interpret and provide contextual explanations for the quantitative results. Our mixed-methods approach offsets the limitations of using quantitative and qualitative methods separately, particularly in explaining outcomes and influencing factors within a system of interest. Triangulating results from both approaches helps establish integrity and validity of findings and provides sound evidence for conclusions and recommendations.

Throughout the OPS6 evaluation process, we shared the methods, data, and approaches for the comprehensive and component evaluations, ensuring transparency in all aspects of the evaluation.

\section{Stakeholder engagement promotes evaluation ownership}

Stakeholder engagement across the evaluation process is vital to benefit from stakeholder insights and concerns while also developing their ownership of the evaluation. Utilization-focused evaluation and related types of participatory evaluation (Cousins and Whitmore 1998) emphasize the importance of stakeholder involvement and iterative learning through evaluation as the foundation of utilization. For OPS6, the approach paper was developed with stakeholders in a consultative manner to address their interests. We shared the draft report of OPS6 and discussed the findings, conclusions, and recommendations prior to finalization and presentation to the Council. We also obtained stakeholder feedback throughout the evaluation process on all component evaluations and OPS6. The high level of stakeholder engagement throughout the OPS6 process contributed to the use and influence of the evaluation in the GEF-7 programming directions.

\section{Putting evaluations to work}

Unless it is used, an evaluation has no value. Utility of evaluations is enhanced by structured participation and timeliness. This involves stakeholders at various stages, from the development of the approach paper to the dissemination of findings. The OPS6 team discussed topics and themes for the approach paper with the GEF Secretariat and Agencies and held constituency workshops with a broad range of stakeholders including government officials, civil society representatives, and beneficiaries.

Further supporting use of IEO evaluations is a built-in feedback loop with policymaking, created through the GEF Council's approval of the IEO work program and budget and the IEO director reporting directly to the Council.

The most important element for utility is ensuring on-time delivery, such as preparing OPS6 to meet the timing of the replenishment process. As part of that process, we disseminated findings of individual evaluations and OPS6 
during the year leading into the final meetings, increasing the relevance and use of the evaluations.

\section{Applying a systems approach to understanding complex relationships}

Our experience from the GEF-7 replenishment process shows that evaluation can contribute significantly to devising strategies and designing interventions that address both environmental and socioeconomic challenges. Based on a rigorous analysis of experiences on the ground, evaluation helps us understand what works, why, and under what circumstances. Applying a systems approach helps address the shortcomings of traditional logic models. These will not be adequate for the complex systems in which all interventions take place, and linear causality between components of a system is often obscured by interdependencies and feedback loops between them. A systems approach also helps capture unintended consequences (which are not considered by an objectives-based evaluation), particularly in light of the possible trade-offs between environmental and socioeconomic goals.

Evaluating in complex situations requires improved approaches and methodologies to deal with both environmental and human/societal systems, and with their interactions. Evaluation questions must drive the choice of appropriate methods, rather than vice versa, as often is the case in impact evaluations that emphasize experimental designs. Therefore, use of multiple methods must become the norm. Evaluations also need to move beyond assessing whether individual interventions achieve their targets and outputs, and instead focus on the big picture - do the policies, strategies, and interventions designed make a dent in the areas that they are intended to benefit? In the global environment arena, the challenges are too large to focus on activities and outputs; evaluation must focus on outcomes and impacts. The SDGs also require us to go beyond monitoring and indicators, and build evaluation into the SDG processes to better understand what is happening and why, what causalities foster achievement of goals, and what barriers hamper it. Equally important is building in knowledge management so lessons from evaluating real-life experiences can inform the development of future policies, strategies, and interventions.

\section{Crises necessitate creativity}

The 2020 global pandemic has made evaluation even more important. While the global stress accentuated by the effects of COVID-19 has increased the need for evaluations to help in decision-making, the pandemic has restricted our ability to do evaluative fieldwork. The COVID-19 crisis has turned evaluators' lives upside down: suddenly, we can't visit the sites we are responsible for, interview participants in person, or otherwise conduct assessments as we normally would. As with much of the world economy, this necessitates a 
period of unprecedented creativity to ensure that the critical role evaluation serves is not neglected for the duration of the crisis.

One way we are engaging with continuing operations while under pandemic restrictions is by using Quasi-experimental Geospatial Interpolation, which combines satellite and other geospatial information with existing survey data collected by international organizations, showcased in a recent article in the journal Sustainability (Runfola et al. 2020). In the era of COVID-19, with field work halted and working from home as the new normal, such methods can help evaluators leverage open-source and readily available data to aid in determining the impact of projects. Working with geospatial data can help project evaluators maintain flexibility and encourages them to avoid designing new and often expensive data tools for every unique evaluation. While this method may not be a perfect fit for every evaluation, it provides a novel, replicable approach to the estimation of environmental and socioeconomic outcomes for some types of projects. We also employ tools and software such as NVivo for qualitative analysis of large portfolios and seek the assistance of networks of national consultants in our client countries.

For the next comprehensive evaluation, OPS7, we are increasing our planning time, engaging our advisory panel at the approach paper stage, and have instituted a series of quality control processes within our evaluations to enhance quality and validity of our findings. The pandemic has adversely affected traditional stakeholder engagement, particularly with respect to our beneficiaries, but we are applying a variety of mobile tools and applications to garner stakeholder feedback. We are in a time for innovation and greater collaboration in evaluations. In partnership with numerous universities and consulting firms, we continue to apply a variety of evaluation methods to assess the impact of interventions on the human-natural systems nexus.

\section{Note}

1. "Independent evaluation" is "An evaluation carried out by entities and persons free of the control of those responsible for the design and implementation of the development intervention." www.oecd.org/development/evaluation/2754804.pdf.

\section{References}

Carugi, C. 2016. "Experiences with Systematic Triangulation at the Global Environment Facility." Evaluation and Program Planning 55: 55-66.

Coker, R., J. Rushton, S. Mounier-Jack, E. Karimuribo, P. Lutumba, D. Kambarage, D.U. Pfeiffer, K. Stärk, and M. Rweyemamu. 2011. "Towards a Conceptual Framework to Support One-Health Research for Policy on Emerging Zoonoses." The Lancet Infectious Diseases 11: 326-331.

Cousins, J.B., and E. Whitmore. 1998. "Framing Participatory Evaluation." In: E. Whitmore (ed.), Understanding and Practicing Participatory Evaluation, New Directions for Evaluation. San Francisco, CA: Jossey-Bass, 80. 
Di Marco, M., M.L. Baker, P. Daszak, P. De Barro, E.A. Eskew, C.M. Godde, T.D. Harwood, M. Herrero, A.J. Hoskins, E. Johnson, W.B. Karesh, C. Machalaba, J. Navarro Garcia, D. Paini, R. Pirzl, M. Stafford Smith, C. Zambrana-Torrelio, and S. Ferrier. 2020. "Opinion: Sustainable Development Must Account for Pandemic Risk." Proceedings of the National Academy of Sciences of the United States of America 117(8): 3888-3892. www.pnas.org/content/117/8/3888.

GEF. 2015. GEF 2020: Strategy for the GEF. Washington, DC: Global Environment Facility. www.thegef.org/publications/gef-2020-strategy-gef.

GEF IEO. 2017. Evaluation of GEF Engagement with the Private Sector 2017. Washington, DC: Global Environment Facility Independent Evaluation Office.

GEF IEO. 2018a. Annual Performance Report 2017. Washington, DC: Global Environment Facility Independent Evaluation Office.

GEF IEO. 2018b. Comparative Advantage, Adequacy of Funding/Financing, Health of the Expanded GEF Partnership and Governance Structure 2017. Washington, DC: Global Environment Facility Independent Evaluation Office.

GEF IEO. 2018c. Biodiversity Focal Area Study. Washington, DC: Global Environment Facility Independent Evaluation Office. www.gefieo.org/evaluations/biodiversitystudy-2017.

GEF IEO. 2019. Small Island Developing States (SIDS) Strategic Country Cluster Evaluation (SCCE). Washington, DC: Global Environment Facility Independent Evaluation Office.

GEF IEO. 2020a. Strategic Country Cluster Evaluation of the Least Developed Countries. Washington, DC: Global Environment Facility Independent Evaluation Office.

GEF IEO. 2020b. Strategic Country Cluster Evaluation: Sahel and Sudan-Guinea Savanna Biomes. Washington, DC: Global Environment Facility Independent Evaluation Office.

GEF IEO. 2020c. The GEF Response to the Crisis-What Can We Learn from Evaluation? Washington, DC: Global Environment Facility Independent Evaluation Office. www. gefieo.org/documents/gef-response-crisis-what-can-we-learn-evaluation.

Hadjimichael, N., and G. Batra. 2019. A Study on the Health Co-Benefits of GEF Chemicals and Waste Focal Area. Washington, DC: Environment Facility Independent Evaluation Office. www.gefieo.org/sites/default/files/documents/co-benefits-cw-study-2019.pdf.

IEG WBG. 2019. IEG Annual Report 2019: Transforming Evidence into Better Outcomes. Washington, DC: Independent Evaluation Group, World Bank Group. https://ieg. worldbankgroup.org/evaluations/ieg-annual-report-2019-transforming-evidencebetter-outcomes.

IFAD. 2019. 2019 Annual Report on Results and Impact of IFAD Operations. Rome: IFAD Independent Office of Evaluation. www.ifad.org/en/web/ioe/evaluation/ asset/41391061.

Naidoo, R., and B. Fisher. 2020. "Sustainable Development Goals: Pandemic Reset." Nature 583: 198-201.

Runfola, D., G. Batra, A. Anand, A. Way, and S. Goodman. 2020. "Exploring the Socioeconomic Co-Benefits of Global Environment Facility Projects in Uganda Using a Quasi-Experimental Geospatial Interpolation (QGI) Approach.” Sustainability 12(8): 3225. www.mdpi.com/2071-1050/12/8/3225.

Swift, L., P.R. Hunter, A.C. Lees, and D.J. Bell. 2007. "Wildlife Trade and the Emergence of Infectious Diseases." Ecohealth 4(1): 25. www.ncbi.nlm.nih.gov/pmc/ articles/PMC7087654/.

Tollefson, J. 2020. "Why Deforestation and Extinctions Make Pandemics More Likely." Nature 584: 175-176. 
UNDP. 2014. Reducing UPOPs and Mercury Releases from the Health Sector in Africa. NewYork,NY:UnitedNations.www.thegef.org/sites/default/files/project_documents/ 5-19-2014_ID4611_ProjeDoc_0.pdf.

UNDP. 2015. Assessment and Recommendations Regarding Management of Ebola-Contaminated Waste. New York, NY: United Nations. https://noharm-global.org/sites/default/files/ documents-files/3127/Report $\% 20$ to $\% 20$ WHO $\% 20$ WASH $\% 20$ and $\% 20$ Geneva $\% 20$ on\%20Ebola\%20final.pdf.

UNDP. 2019. United Nations Development Programme Annual Report 2019. New York, NY: United Nations. www.undp.org/content/undp/en/home/librarypage/corporate/ annual-report-2019.html.

UNDP IEO. 2013. Global Project on Demonstrating and Promoting Best Techniques and Practices for Reducing Health-Care Waste to Avoid Environmental Releases of Dioxins and Mercury. Terminal Evaluation Report. www.thegef.org/sites/default/files/ project_documents/1802_UNDP_TE_00058547_-_POPs_MedicalWaste_-_ EoPEvaluation_-_Summary_LessonsLearnt.docx.

United Nations Department of Economic and Social Affairs. 2015. "Transforming Our World: The 2030 Agenda for Sustainable Development." https://sustainabledevelopment.un.org/post2015/transformingourworld.

United Nations Department of Economic and Social Affairs. 2020. The Sustainable Development Goals Report 2020. New York, NY: United Nations. https://unstats.un.org/ sdgs/report/2020/.

Vaughan, A. 2020. "Coronavirus: China Wildlife Trade Ban Could Become Law Within Months." New Scientist. www.newscientist.com/article/2239559-coronavirus-chinawildlife-trade-ban-could-become-law-within-months/.

World Bank. 2017. Terminal Evaluation of First Phase in Support of the West Africa Regional Fisheries Program (WARFP). Washington, DC: World Bank. www.thegef.org/sites/ default/files/project_documents/3558\%2520ICR_1.pdf. 


\section{Appendix 1 \\ Global Environment Facility \\ Evaluation Policy}

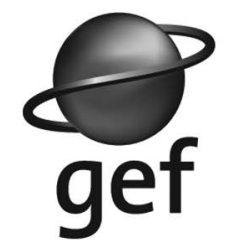

GLOBAL ENVIRONMENT FACILITY INVESTING IN OUR PLANET

GEF/ME/C.56/02/Rev.01

June 13, 2019

56th GEF Council Meeting

June 11th -13, 2019

Washington, D.C.

Agenda Item 11

The GEF Evaluation Policy

(Prepared by the Independent Evaluation Office of the GEF)

\section{Recommended council decision}

The Council, having reviewed document GEF/ME/C.56/02, "The GEF Evaluation Policy":

1 Approves the proposed GEF Evaluation Policy contained in Section 2 of this document, which supersedes the 2010 Policy on Monitoring and Evaluation as it relates to evaluation (Council document GEF/ ME/C.39/6/Rev.1)."

2 Authorizes the GEF Independent Evaluation Office to proceed with its dissemination and implementation.

\section{Table of contents}

Section 1: Background

Section 2: The GEF evaluation policy 
I. Evaluation in the GEF 145

1. Background 146

2. Evaluation: Purposes, use, and types 147

3. Follow-up to IEO Evaluations 149

4. Knowledge sharing from evaluations 150

II. Evaluation: Norms, principles, criteria, and minimum requirements

1. Principles 152

2. Criteria 154

3. Indicators 154

4. Minimum requirements $\quad 155$

III. Roles and responsibilities $\quad 159$

1. GEF Council 162

2. Independent evaluation office of the GEF 162

3. GEF Secretariat 165

4. GEF Agencies 166

5. Scientific and Technical Advisory Panel 167

6. GEF Operational Focal Points 167

$\begin{array}{ll}\text { 7. Other stakeholders } & 168\end{array}$

\section{Tables and figures}

Table

A1.1 Key roles and responsibilities of GEF partners in evaluation

Figures

A1.1 Simplified flowchart of monitoring and evaluation reporting in the GEF

A1.2 Monitoring and evaluation levels and responsible agencies in the GEF

\section{Section 1: Background}

1 In May 2014, the GEF Independent Evaluation Office (IEO) recommended an update to the GEF Monitoring and Evaluation Policy to the GEF Council, to ensure its continued relevance in the context of the evolution of the GEF partnership since 2010. ${ }^{1}$ In October 2015, the IEO analyzed all GEF Council decisions taken since the last M\&E Policy was issued in 2010. This analysis identified several gaps in the 2010 Policy including gender and safeguard standards, and program level evaluation, among others. ${ }^{2}$

2 Based on international good practice standards among organizations including global partnerships and multilateral development banks, the 2010 M\&E Policy has been split into two separate policies, one addressing monitoring, and the other evaluation. An Evaluation Policy defines the core principles, criteria, and the governance structure (key roles and responsibilities) of an organization's evaluation function. The monitoring 
and reporting function is an integral part of an organization's operations, which is consistent with its project cycle, and defines clear roles, responsibilities, and milestones on the provision of information and data for reporting.

3 The next section of this document presents the revised GEF Evaluation Policy that would supersede the provisions for evaluation contained in the 2010 M\&E Policy. This policy has been prepared with engagement of stakeholders across the GEF partnership. A separate GEF Monitoring Policy has been prepared by the GEF Secretariat. The IEO and the Secretariat have consulted to maintain continuity and coherence between the provisions of the two policies.

4 The main updates to the GEF Evaluation Policy include:

a Introducing the principle that evaluation in the GEF should apply a gender-responsive approach

b Introducing the requirement that terminal evaluations of GEF projects and programs should report on the GEF's additionality using the evaluative approach provided by the GEF $\mathrm{IEO}^{3}$

c Introducing the requirement that program evaluation should assess the coherence between program and child project theories of change, indicators, and expected/achieved results

$\mathrm{d}$ Establishing the principle that program evaluation should measure and demonstrate program value added over the same level of investment made through comparable alternatives

e Clarifying evaluation responsibilities for jointly implemented projects

f Introducing a requirement to collect (1) socio-economic co-benefits data, (2) sex-disaggregated and gender sensitive data, and (3) geographic coordinates of project sites whenever available/possible

\section{Section 2: The GEF Evaluation Policy}

\section{Key terms}

Agency fee: the financing provided to a GEF partner Agency in connection with a GEF project or program

CEO Approval: the approval of a fully developed medium-sized project or enabling activity by the GEF CEO

CEO Endorsement: the endorsement of a fully developed full-sized project by the GEF CEO

Child project: a project that forms part of a program, as set out in a program framework document

Co-financing: financing additional to GEF project financing, and that supports implementation of a GEF-financed project or program and the achievement of its objectives 
Evaluation: Evaluation is the systematic and impartial assessment of planned, ongoing, or completed activities, projects, programs in specific focal areas or sectors, policies, strategies and their implementation, or other topics relevant to the GEF partnership and organization ${ }^{4}$

Full-sized project: a project with GEF project financing exceeding US $\$ 2$ million

GEF additionality: the additional effects (both environmental and otherwise) that can be directly associated with a GEF-supported project or program GEF Agency: an agency eligible to request and receive GEF resources directly for the design, implementation, and supervision of GEF projects and programs

GEF Instrument: Instrument for the Establishment of the Restructured Global Environment Facility, effective July 7, 1994, as amended

Gender-sensitive indicator: an indicator that can be used at various levels to monitor and report on socioeconomic and gender-sensitive changes over time

GEF-financed activity (or intervention): any programmatic approach, full-sized project, medium-sized project, or enabling activity financed from any GEF-managed trust fund, as well as regional and national outreach activities

GEF Operational Focal Point: nominated by the recipient country, the GEF Operational Focal Point ensures that GEF proposals and activities in the country are consistent with country priorities and the country commitments under global environmental conventions; identifies project ideas to meet country priorities; endorses project proposals; facilitates broad based in-country consultations on GEF operational matters; and provides feedback on GEF activities, including implementation of projects ${ }^{5}$

Global Environmental Benefits: these relate to international conventions and commitments the GEF is mandated to serve. GEF projects must demonstrate that the project activities are delivering global environmental benefits Goal: a higher-order objective to which a GEF-financed project or program is intended to contribute

Knowledge Management: the process by which organizations within the GEF partnership generate value and improve performance from their intellectual and knowledge-based assets

Impact: the positive and negative, primary and secondary long-term effects produced by a project or program, directly or indirectly, intended or unintended

Indicator: a quantitative or qualitative factor or variable that provides a simple and reliable means to measure achievement, to reflect the changes connected to a project or program, or to help assess the performance of an organization

Lead Agency: The Agency that coordinates all activities under a program Medium-sized project: a project with GEF project financing of up to US $\$ 2$ million 
Midterm review: an assessment of a project or program's performance and results carried out for adaptive management purposes at the midpoint of a project or program's intended duration

Monitoring: a continuous or periodic function, carried out by project or program management, that uses a standardized and systematic process of collecting and analyzing data on specific indicators to provide decision-makers and management of a GEF-financed activity with information on progress in the achievement of objectives and in the use of allocated funds

Outcome: an intended or achieved short- or medium-term effect of a project or program's outputs

Output: a product or service that results from the completion of activities implemented within a project or program

Portfolio: a subset of projects focusing on a specific theme, GEF focal area, geographic region, country, or GEF Agency

Program: a coherent set of interventions designed to attain specific global, regional, country, or sector objectives, consisting of a variable number of child projects

Program's added value: the additional results brought in by the GEF funding delivered as a program compared with either a pre-existing or a hypothetical set of stand-alone full- and/or medium-sized projects or other comparable alternatives

Program framework document: the document that sets forth the concept of a program that is proposed for GEF financing

Result: Include intervention outputs, outcomes, progress toward longer-term impact including global environmental benefits, and should be discernible/ measurable

Stakeholder: an individual or group that has an interest in the outcome of a GEF project or program or is likely to be affected by it, such as local communities, indigenous peoples, civil society organizations, and private sector entities; stakeholders may include national project or program executing agencies, or groups contracted to conduct activities at various stages of the project or program

Stakeholder engagement: a process that begins with stakeholder identification and analysis, and includes planning; disclosure of information; consultation and participation; monitoring, evaluation, and learning throughout the project cycle; addressing grievances; and ongoing reporting to stakeholders

Terminal evaluation: evaluation of a project or program's design, performance, and results carried out at the end of implementation
Abbreviations
CEO
Chief Executive Officer
CSO
civil society organization
GEF
Global Environment Facility
IEO
Independent Evaluation Office 
NGO non-governmental organization

OFP Operational Focal Point

SMART specific, measurable, attributable, relevant, and time-bound

STAP Scientific and Technical Advisory Panel

\section{Evaluation in the GEF}

1 This Policy sets out the guiding principles and minimum requirements for evaluation across the Global Environment Facility (GEF) partnership and for all GEF-financed activities. This Policy is aligned with the GEF Instrument, which provides that "the Council shall...ensure that GEF policies, programs, operational strategies and projects are monitored and evaluated on a regular basis." 6

2 This Policy explains the concept, role, and use of evaluation within the GEF. It defines the institutional framework and responsibilities of stakeholders; and establishes the requirements for how projects and programs funded by the GEF should be evaluated in line with international principles, norms, and standards. The policy is designed to provide clarity on evaluation in the GEF. Revisions will be made when major changes in the GEF occur, affecting the evaluation function. In addition, to ensure that the Policy remains relevant to evolving circumstances and continues to conform to international principles, norms, and standards, it will be periodically reviewed and updated as necessary. Any proposals for changes in the Policy will be presented by the GEF Independent Evaluation Office (IEO) to the Council for decision after consultation with stakeholders.

3 Evaluation helps the GEF to become more effective in its pursuit of global environmental benefits. Evaluation in the GEF has the following two overarching objectives:

a Promote accountability for the achievement of GEF objectives through the assessment of results, effectiveness, processes, and performance of the partners involved in GEF-financed activities; GEF results are evaluated for their contribution to global environmental benefits.

b Promote learning, feedback, and knowledge sharing on results and lessons learned among the GEF and its partners as a basis for decision-making on projects, programs, program management, policies, and strategies; and to improve performance.

4 The broader framework of GEF Policies are consistent with this Policy. ${ }^{7}$ The evaluation sections of GEF Policies are in full alignment with the standards and minimum requirements of this Policy.

5 Monitoring and evaluation are two distinct, yet interconnected functions in the GEF. Monitoring, conducted as a systematic management function, informs whether a project, program, policy implementation, or the organization is achieving its intended objectives as planned. 
Evaluation is a systematic and objective assessment of an on-going or completed project, program, or policy, its design, implementation, effectiveness and results. Evaluation provides information that is credible and useful, enabling the incorporation of lessons learned into the decision-making process of both recipients and donors. Evaluation verifies and uses monitoring data in its analyses as one of its sources of information. Evaluation also provides evidence on how changes are taking place, and the strengths and weaknesses of the design of the projects, programs, or operational strategies embedded in the GEF results frameworks.

6 This Policy discusses monitoring only in its interrelations with evaluation. A separate GEF Monitoring Policy contains the basic provisions, standards, and requirements for monitoring in the GEF partnership.

\section{Background}

7 The GEF is a financial mechanism for international cooperation based on a partnership. It provides new and additional grant and concessional funding to meet the incremental costs of measures to achieve agreed global environmental benefits in five focal areas. These are biological diversity, climate change mitigation and adaptation, ${ }^{8}$ international waters, land degradation, and chemicals with sustainable forest management cross-cutting relevant focal areas-in developing countries and countries with economies in transition. In addition, the Integrated Approach Pilots in GEF-6, and the Impact Programs introduced in GEF-7, also use focal area allocations in an integrated manner for systems change. The GEF Council provides strategic and policy direction in these five focal areas, taking into account guidance from the conferences of the parties to the relevant global environmental conventions.

8 The GEF Instrument requires the GEF Council to ensure that GEF projects, programs, policies, and operational strategies are monitored and evaluated on a regular basis. Meeting this requirement entails feedback to the GEF decision-making processes at the institutional, policy, program, and project levels. Corporate monitoring and evaluation in the GEF is based on regular reporting for internal management purposes to the GEF Council, in support of decision making, policy making, and accountability (Figure A1.1).

9 Evaluation allows the GEF to track progress in fulfilling its mission of delivering global environmental benefits. GEF projects and programs are more likely to capitalize on their innovative and catalytic role when they are fully integrated with the GEF results frameworks and where management activities as well as post-completion decision making are informed by comprehensive and relevant evaluative evidence. Evaluation strengthens the GEF partnership and encourages ownership of GEF projects and programs, all of which are essential principles of GEF operations and policies. The GEF emphasizes the quality of its 


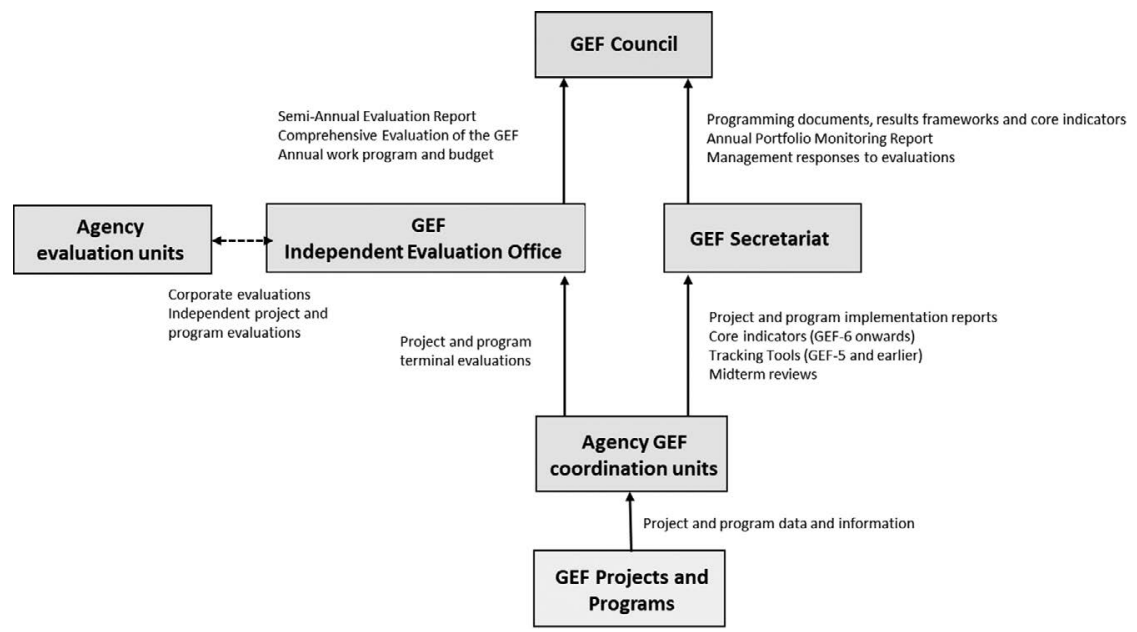

Figure A1.1 Simplified flowchart of monitoring and evaluation reporting in the GEF

evaluation function and ensures that evaluation findings are disseminated widely. The Independent Evaluation Office of the GEF (IEO) is directly accountable to the GEF Council and has the mandate to report on the performance and effectiveness of GEF projects and programs. In addition, the evaluation units of the Agencies are responsible for the conduct of project and program terminal evaluations in compliance with this policy and in accordance with the terminal evaluation guidelines.

10 The Policy shall be operationalized through guidelines on specific issues and standards developed by the IEO in consultation with partners. The IEO is authorized to publish and revise such guidelines, as required, in line with this Policy. The Policy and related guidelines will be shared with the GEF partners and the public through the IEO website.

\section{Evaluation: Purposes, use, and types}

11 Definition. Evaluation is the systematic and impartial assessment of planned, ongoing, or completed activities, projects, programs in specific focal areas or sectors, policies, strategies and their implementation, or other topics relevant to the GEF partnership and organization. In case of activities, projects, and programs, it aims at determining the relevance, efficiency, effectiveness and sustainability of the interventions and contributions of the involved partners. An evaluation provides evidence-based information that is credible, reliable, and useful, enabling the timely incorporation of findings, recommendations, and lessons into decision-making processes. In the context of the GEF, the evaluation function aims at assessing the relevance, efficiency, effectiveness, and-where 
feasible - sustainability of GEF interventions in the context of their contribution to global environmental benefits in GEF focal areas at the local and global levels.

12 Purpose. The purposes of evaluation include understanding why, how, and the extent to which intended and unintended results are accrued, and their impact on stakeholders. Evaluation is an important source of evidence of the achievement of results and institutional performance and contributes to knowledge and organizational learning. It serves as a driver of change and plays a critical role in supporting accountability. Evaluation can be used to improve the design and performance of a planned or ongoing project or program (a formative evaluation); to make an overall judgment about the effectiveness of a completed project or program, to ensure accountability; and to generate knowledge about good practices. Evaluation differs from other oversight mechanisms such as investigation and audit, which focus on the adequacy of management controls; compliance with regulations, rules, and established policies; and the adequacy of organizational structures and processes.

13 Use. Evaluation feeds into management and decision-making processes regarding the development of policies and strategies; and the programming, implementation, and reporting of activities, projects, and programs. Thus, evaluation contributes to institutional learning and evidence-based policy making, accountability, development effectiveness, and organizational effectiveness. It informs the planning, programming, budgeting, implementation, and reporting cycle. It aims to improve the institutional relevance and achievement of results, optimize the use of resources, and maximize the impact of the contribution provided.

14 Types. Within the context of the GEF, project/program level terminal evaluations relevant to the Agencies interventions are conducted by the Agencies. Agencies also conduct mid-term reviews of projects, and sometimes carry out impact evaluations. The IEO validates the terminal evaluations of GEF projects from all Agencies, and conducts a spectrum of evaluations covering thematic issues, focal areas, institutional policies and programs, and the comprehensive evaluation of the GEF, all of which cut across the entire GEF partnership. The main types of evaluations in the GEF include, but are not limited to the following:

a Project evaluations at the completion of the project implementation (terminal evaluation), mainly conducted by GEF Agencies.

b Program evaluations of a coherent set of interventions to attain specific global, regional, country, or sector objectives; these include evaluations of the GEF focal areas, programmatic approaches, and GEF corporate programs.

c Performance evaluations of the GEF's portfolio of completed projects to assess the relevance, efficiency and effectiveness in delivering the expected results. 
d Country and country cluster evaluations of one or more Agencies' portfolio of projects and activities, and the assistance strategy behind them, in a country or cluster of countries. Strategic cluster evaluations focus on a limited set of strategic issues across country portfolios.

e Process evaluations of the functioning of participating organizations, instruments, mechanisms, and management practices; these include evaluations of institutional and procedural issues across GEF focal areas and assessments of experience with GEF policies, criteria, and procedures. Process evaluations could be conducted during the design or implementation of an intervention.

f Impact evaluations of the long-term effects produced by an intervention, intended or unintended, direct or indirect. Impact may be assessed at the project, program, portfolio, ecosystem, or country level, and includes global environmental benefits.

g Thematic evaluations of a selection of interventions addressing a specific theme, issue or focal area across the GEF portfolio; these include evaluations that assess cross-cutting issues.

h Comprehensive Evaluation of the GEF, previously the Overall Performance Study (OPS), informing the GEF replenishment cycles, and addressing performance and results in terms of global environmental benefits of GEF projects and programs, as well as GEF institutional arrangements, policies, strategies, and priorities. The evaluations referred to in $\mathrm{a}-\mathrm{h}$, above, feed into the comprehensive evaluations.

\section{Follow-up to IEO evaluations}

15 All evaluation reports presented to the GEF Council by the IEO require a management response. The GEF Chief Executive Officer (CEO) coordinates the preparation of the management response with Agency stakeholders for GEF Council consideration, in response to the recommendations of each evaluation report. Management responses should clearly indicate whether management accepts, partially accepts, or rejects the IEO evaluation recommendations, and explain the reasons. The IEO may comment on the management response to ensure recommendations have been addressed. The GEF Agencies ensure that recommendations from IEO evaluations that are relevant and/or apply to them are considered for decision making and action within the Agencies. The Council discusses and reviews the evaluation reports, the recommended actions, and the management responses; takes any necessary decisions on the recommendations; and gives guidance to the GEF and Agencies on policies or on action plans with specific time frames.

16 There is systematic follow-up to the implementation of evaluation recommendations through the Management Action Record. 
There is also systematic follow-up on implementation of the evaluation recommendations accepted by management and/or the GEF Council, with periodic review and follow-up on their status. In consultation with the appropriate GEF partners, the IEO reports to the Council on the follow-up of Council decisions related to evaluation recommendations; these decisions and follow-on actions are compiled in its Management Action Record (MAR) and are provided to the Council on an annual basis in the Annual Performance Report.

\section{Knowledge sharing from evaluations}

17 Evaluation contributes to knowledge building and organizational improvement. Findings and lessons must be made accessible to target audiences in a user-friendly way. Evaluation reports must have a dissemination strategy tailored to the audience of each specific report; the strategy must be described in the relevant evaluation approach paper and in the terms of reference.

18 For the purposes of this Policy, knowledge management is the process by which organizations within the GEF partnership generate value and improve performance from their intellectual and knowledge-based assets. Knowledge sharing enables partners to capitalize on lessons learned by gaining insight and understanding from experience, and by applying this knowledge to generate new knowledge. Knowledge management helps the GEF create and transform knowledge into action, innovation, and change. Knowledge management is closely linked to performance enhancement.

19 The main purposes of knowledge creation and sharing of information from GEF evaluations are to:

a Promote learning through better outreach to the project, program, and country levels by providing easily accessible learning products;

b Promote the application of lessons learned to improve the performance and impact of GEF activities; and

c Promote feedback to improve the development of projects and programs.

20 Knowledge creation and sharing from evaluation supports policy making by building a comprehensive body of evidence, lessons learned, and good practices. Evaluation is closely linked to policy making, more informed management, and decision making for strategic planning. Evaluations could provide an effective way to improve the performance and impact of policies, programs, and projects, especially when they are conducted at the appropriate time and focus on issues of concern to policy makers and managers. 
21 Lessons from evaluations should be made available to stakeholders directly involved in project and program formulation and implementation for improved effectiveness. GEF partners are expected to seek out adaptive and interactive ways of disseminating findings from evaluations to a wide audience, including within and across GEF Agencies and the GEF partnership, environmental entities, academia, research institutions, civil society, and the general public. When lessons and findings are shared widely, evaluations have the potential to increase awareness of the importance of global environmental benefits, confidence in GEF work, and leverage support.

\section{Evaluation: Norms, principles, criteria, and minimum requirements}

22 Evaluation in the GEF context is guided by internationally recognized principles, norms, and standards. Specifically, the GEF and its Agencies refer to those principles, norms, and standards produced by the United Nations Evaluation Group (UNEG), the Development Assistance Committee of the Organization for Economic Co-operation and Development (OECD-DAC), and the Evaluation Cooperation Group (ECG) of the multilateral development banks (MDBs). Although there is general agreement around internationally recognized norms and standards, there is also a divergence resulting from the diverse goals and objectives of the individual Agencies. These differing goals lead to differences in emphasis and differences in the application of standards across Agencies. Guided by international norms and standards, the GEF Evaluation Policy considers these differences and establishes a set of key principles and criteria common across the GEF partnership. The Policy also establishes four mandatory minimum requirements Agencies must follow in conducting evaluations for GEF-financed activities.

23 Evaluation must be an explicit part of planning and budgeting of GEF-financed activities. A key international norm concerns the adequate provision of resources to enable evaluation functions to operate effectively. In line with this norm, the costing and budgeting of evaluation activities are addressed, as appropriate, in the budgetary planning of the IEO, the Agency fee system, and project and program budgets. This includes any additional financial implications of addressing the minimum requirements and responsibilities of this Policy. All GEF Agencies receive project/program allocations and Agency fees, to be used according to the provisions contained in the Fee Policy for GEF Agencies. Project allocations cover the requirement for monitoring and evaluation, including terminal evaluations. Consistent with good practice, budgetary resources should be allocated separately for monitoring and evaluation activities. 


\section{Principles}

24 Evaluation in the GEF context is guided by internationally recognized principles. The principles below are internationally recognized professional standards that should be applied in all evaluations of GEF-financed activities:

a Independence. Evaluations must be conducted independently from both the policy-making process and from the delivery and management of assistance. Evaluation team members should not have been personally engaged in the activities to be evaluated or have been responsible in the past for the design, implementation, or supervision/mid-term review of the project, program, or policy to be evaluated. Where evaluations are financed and/or managed by the GEF coordination units in GEF Agencies, these Agencies should ensure the behavioral independence of the evaluators. Behavioral independence requires that even if the evaluator is contracted by the Agency operational unit whose project or program is being evaluated, the unit should not interfere with or influence the process, or the interpretation and reporting of the evaluation findings.

b Credibility. Evaluations must be credible and based on reliable data and observations. Evaluation reports should reflect consistency and dependability in data, findings, judgments, and lessons learned, with reference to the quality of the instruments, procedures, and analysis used to collect and interpret information.

c Utility. Evaluations must serve the information needs of intended users. Partners, evaluators, and units commissioning evaluations should endeavor to ensure that the work is well informed, relevant, and timely, and that it is clearly and concisely presented so as to be of maximum benefit to intended users. Evaluation reports should present the evidence, findings, issues, conclusions, and recommendations in a complete and balanced way. They should be both results- and action-oriented.

d Impartiality. Evaluations must give a comprehensive and balanced presentation of the strengths and weaknesses of the project, program, policy, strategy, or organizational unit being evaluated. The evaluation process should reflect impartiality at all stages and consider the views of all stakeholders. Units commissioning evaluations should endeavor to ensure that the selected evaluators are impartial and unbiased.

e Transparency. An essential feature at all stages of the evaluation process, transparency involves clear communication concerning decisions for the program of work and areas for evaluation, the purpose of the evaluation, the criteria applied, the evaluation approach and methods, 
and the intended use of the findings. Documentation related to evaluations must be freely available, easily accessible, and readable for transparency and legitimacy.

f Integrity. Evaluations must provide due regard to the welfare, beliefs, and customs of those involved or affected, avoiding or disclosing any conflict of interest. Evaluators must respect the right of institutions and individuals to provide information on the facts confidentially. Evaluators must honor the dignity, well-being, and self-worth of individuals and acknowledge the influence of culture within and across groups. If evidence of wrongdoing is uncovered, the evaluator or manager shall report such cases discreetly to the IEO Director, who will take appropriate action such as informing the investigative body of the relevant Agency. Integrity requires that management and/or commissioners of evaluations communicate clearly, remain open to the findings, and do not allow vested interests to interfere with the evaluation.

g Participation. GEF evaluations must be inclusive, so that the diverse perspectives and the values on which they are based as well as the types of power and consequences associated with each perspective are represented. Evaluation teams should interact with representatives of all the stakeholders involved in the project, program, or topic being evaluated. The participation of in-country stakeholders, including the GEF Operational Focal Point (OFP) as well as other stakeholders such as project managers and civil society organizations (CSOs) involved in project implementation, and project beneficiaries should be ensured.

h Gender equality. Gender equality and women's empowerment is a strategic and operational imperative for the GEF. As a gender-responsive approach is applied throughout the GEF project cycle, it also applies to evaluations, as clearly stated in the 2017 GEF Policy on Gender Equality. Evaluations must assess whether and how men and women are affected by changes to natural resource use and decision making resulting from GEF outcomes. Wherever feasible, evaluations should provide sex-disaggregated and gender-sensitive data. Units commissioning evaluations should strive for gender balance in the composition of evaluation teams.

i Competencies and capacities. GEF evaluations require a range of expertise that may be technical, environmental, cultural, or within a social science or the evaluation profession. Units commissioning evaluations are responsible for selecting evaluators with sufficient experience and skills in the appropriate field/s, and for adopting a rigorous methodology for the assessment of results and performance. Evaluations of GEF activities shall make the best possible use of local expertise, both technical and evaluative. 


\section{Criteria}

25 Evaluations in the GEF explore four major criteria, in line with recent OECD-DAC guidance:

a Relevance - the extent to which the intervention design and intended results were consistent with local and national environmental priorities and policies and to the GEF's strategic priorities and objectives, and remained suited to the conditions of the context, over time.

b Effectiveness - the extent to which the intervention achieved, or expects to achieve, results (outputs, outcomes and impacts, including global environmental benefits) taking into account the key factors influencing the results.

c Efficiency - the extent to which the intervention achieved value for resources, by converting inputs (funds, personnel, expertise, equipment, etc.) to results in the timeliest and least costly way possible, compared to alternatives.

d Sustainability-The continuation/likely continuation of positive effects from the intervention after it has come to an end, and its potential for scale-up and/or replication; interventions need to be environmentally as well as institutionally, financially, politically, culturally and socially sustainable.

26 Other criteria may be considered on a case by case basis, depending on the specific evaluation as well as new developments in the international good practice standards for evaluation. ${ }^{9}$

\section{Indicators}

27 In the context of the results frameworks (and related core corporate indicators) introduced in each replenishment of the GEF, projects and programs shall adopt monitoring and evaluation systems with indicators that ensure evaluability. Indicators should be SMART-specific, measurable, attributable, relevant, and time-bound. These indicators will be reported in the terminal evaluations to assess performance against objectives and should have the following characteristics:

a Specific. The indicator measures only the design element (output, outcome, or impact) that it is intended to measure and captures the essence of the desired result by clearly and directly relating to the achievement of an objective, and only that objective.

b Measurable. There are practical ways to quantitatively and/or qualitatively measure the indicator, i.e. the indicator has the capacity to be counted, observed, analyzed, tested, verified, or challenged.

c Attributable. The indicators identify what changes occurred or are anticipated as a result of the intervention and whether the results are realistic. Attribution requires that changes in the targeted environmental and developmental issues can be linked to the intervention. 
d Relevant. The indicators establish levels of performance that are likely to be achieved in a practical manner, that reflect the expectations of stakeholders, and are plausibly associated with the activities, or the indicator is valid in describing the underlying issues and processes followed to tackle those issues.

e Time-bound, timely, trackable, and targeted. The indicators track progress in a cost-effective manner at appropriate intervals for a set period, with clear identification of the stakeholder group(s) to be affected by the intervention.

28 Results in the GEF are measured by global environmental benefit indicators, according to the results frameworks approved in each replenishment phase. Social and economic co-benefits achieved while contributing to global environmental benefits are also measured. As per the GEF Policy on Gender Equality, the collection of sex-disaggregated data and information on gender, and the use of gender-sensitive indicators, sex-disaggregated targets and results, as relevant, are to be regularly incorporated in monitoring and evaluation. Wherever possible, the geographic coordinates of project sites should be collected and used in monitoring and evaluation.

\section{Minimum requirements}

29 Four minimum requirements must be applied to evaluation at the project and program levels (Boxes A1.1-A1.4). Minimum Requirements 1 and 2 must also be applied to monitoring, as confirmed by the GEF Monitoring Policy. The objectives and intended results of GEF-financed activities should be specific and measurable, so as to make it possible to monitor and evaluate the project and program effectively. Baseline data should be developed for the key results indicators. Agencies should ensure timely monitoring and evaluation planning at the project preparation stage.

30 Terminal evaluations of programs and full- and medium-sized projects are to be conducted according to Minimum Requirement

3. Once in full compliance with the provisions contained in Minimum Requirement 3, Agencies are expected to apply their internal arrangements to the conduct of terminal evaluations and their cost to ensure that evaluation reports of GEF-financed activities conform to GEF evaluation principles. Evaluations should provide lessons learned and recommendations for future projects, programs, or policies.

31 Terminal evaluations will assess results (outputs, outcomes, and impacts) according to the criteria of relevance, effectiveness, efficiency (cost-effectiveness), and sustainability, as applicable. Terminal evaluations will also assess GEF additionality, defined as the additional outcome (both environmental and otherwise) that can be directly associated with the GEF-supported project or program. To do so, 


\section{Box A1.1}

\section{Minimum Requirement 1: design of monitoring and evaluation plans}

All projects must include a concrete and fully budgeted Monitoring and Evaluation Plan by the time of CEO endorsement for full-sized projects and CEO approval for medium-sized projects. Program Monitoring and Evaluation Plans describing the intended approach to monitoring and evaluation across the program, program rationale, the theory of change, results frameworks and indicators, and ways to ensure coherence across the child projects, must be included at program framework document (PFD) approval. Concrete and fully budgeted Program Monitoring and Evaluation Plans must be further detailed in the child project which supports the coordination, knowledge sharing, and monitoring and evaluation activities of the program, where applicable.

Logical frameworks and/or theories of change should align, where appropriate, to the GEF's results frameworks. Program Monitoring and Evaluation Plans must ensure coherence between program and child project objectives, indicators, and outcomes. Monitoring and evaluation Plans build in the possibility to adapt to changing conditions, if needed. Project and Program Monitoring and Evaluation Plans should contain the following:

- SMART indicators for results and implementation linked appropriately to the GEF results frameworks, and including the following:

- Applicable GEF indicators on global environmental benefits identified at each replenishment cycle

- Socioeconomic co-benefits and sex-disaggregated/gender-sensitive indicators (where relevant)

- Project site geographic coordinates (where feasible and appropriate)

- Additional process and/or performance indicators that can deliver reliable and valid information to management

- Project and program baselines, with a description of the problem to be addressed and relevant indicators

- Periodic implementation reports, midterm reviews, and terminal evaluations

- Organizational set-up and budgets for both monitoring and evaluation, where the budget for evaluation should be explicit and distinguished from monitoring activities

Agencies will apply the evaluative approach for assessing GEF's additionality approved by the GEF Council in December 2018. ${ }^{10}$

32 Terminal evaluations of programmatic approaches, which are by nature designed as a set of coherent and synergistic interventions to achieve broader and longer-term results, must also assess the 


\section{Box A1.2}

\section{Minimum Requirement 2: application of monitoring and evaluation plans}

Project and program monitoring will include implementation of the Monitoring and Evaluation Plan, comprising the following:

- The identified indicators are actively measured, or if not, a reasonable explanation is provided

- The baseline for the project or program is fully established and data are compiled to review progress, and evaluations are undertaken as planned

- The organizational set-up for monitoring and evaluation is operational, and its budget is spent as planned

\section{Box A1.3}

\section{Minimum Requirement 3: terminal evaluation of GEF-financed activities}

All full- and medium-sized projects and all programs will need to be evaluated at the end of implementation. The evaluation will have the following minimum requirements:

- The evaluation will be undertaken independent of project management, or if undertaken by project management, will be reviewed by the evaluation unit of the GEF Agency or by independent quality assurance mechanisms of the Agency

- The evaluation will apply the international standards and minimum requirements set forth in this Evaluation Policy

- The evaluation will assess at a minimum:

- Achievement of outputs and outcomes, and provide ratings for targeted objectives and outcomes, for projects. For programs, aggregated results will be reported.

- Likelihood of sustainability of outcomes at termination for projects and the overall program

- Whether Minimum Requirements 1 and 2 were met

- An assessment of GEF additionality

- An assessment of whether and how men and women are affected differently by changes to natural resource use and decision making resulting from GEF outcomes

In addition, for programs, the terminal evaluation will provide an assessment of the coherence between program and child project theories of change and objectives, 
indicators, and programmatic results achieved; these results must demonstrate the program's added value over comparable non-programmatic alternatives.

- The terminal evaluation report will contain at a minimum:

- Basic data on the evaluation, indicating when it took place, who was involved, its key questions, its methodology, including application of the four evaluation criteria (set forth in Subsection 2, above)

- Basic data on the project or program, including actual GEF and other expenditures

- Lessons for broader applicability

- Evaluation terms of reference (in an annex)

- The terminal evaluation report will be sent to the IEO immediately when ready, and at the latest, within 12 months of completion of project or program implementation

added value of implementing interventions as a program rather than as stand-alone projects or other comparable alternatives. Results must be measured according to Minimum Requirement 3.

33 The Monitoring and Evaluation Plan for programs shall, at PFD approval, include arrangements for program-level as well as child project-level terminal evaluation. Agencies participating in the program will conduct

\section{Box A1.4}

\section{Minimum Requirement 4: engagement of operational focal points}

Except for those GEF-financed activities for which OFP letters of endorsement are not required, all other projects and programs will engage the Operational Focal Points (OFPs) in monitoring and evaluation related activities. The following requirements shall be met:

- The monitoring and evaluation plan will specify how the project or program will keep the relevant OFP informed and, where applicable and feasible, involved, while respecting the independent nature of evaluation

- During implementation, the Agencies will inform the OFPs on monitoring and evaluation activities in the projects and programs that belong to their national portfolio

- The OFPs will be informed of midterm reviews and terminal evaluations and will, where applicable and feasible, be briefed and debriefed at the start and at the end of evaluation missions. They will receive a draft report for comment, will be invited to contribute to the management response (where applicable), and will receive the final evaluation report within 12 months of project or program completion

- The GEF Agencies will track application of the conditions specified here in their GEF-financed projects and programs. 
the terminal evaluations of the child projects they have implemented within the program. The Lead Agency will be responsible for submitting the terminal evaluation for the program, consistent with Minimum Requirement 3.

34 The evaluation plan of jointly implemented projects must include the evaluation arrangements agreed upon by the Agencies at CEO endorsement. Partners' responsibilities in ensuring evaluation of jointly implemented projects need to be discussed and agreed upon at the time of preparation to ensure cost-effectiveness, synergy, and avoidance of duplication in evaluation reporting. It is the responsibility of the Lead Agency of the jointly implemented project to guide this discussion and reach an agreement with all the other participating Agencies at design.

35 The IEO follows the World Bank Policy on Access to Information. ${ }^{11}$ The GEF Policy on Access to Information states that "The Ethics Committee, the Ethics Officer, the Independent Evaluation Office, the Secretariat, and the Trustee are subject to the World Bank Policy on Access to Information."12

36 The IEO shall be provided access by the Agency to the documentation and information it needs to conduct its evaluations of GEF-financed activities. Staff of the IEO shall have access to the Agencies' official records to enable their work as evaluators, in accordance with applicable Agency policies and rules governing such access. IEO staff shall also have access to Agency staff during evaluations. Relevant Agency representatives shall facilitate visits by IEO staff to project sites and meetings with stakeholders and government representatives.

37 Evaluations shall be disseminated in accordance with widely accepted international standards, by establishing effective feedback loops to policy makers, operational staff, beneficiaries, and the general public. The disclosure of evaluation reports shall be ensured through posting on websites and dissemination of findings through knowledge products and events. GEF-related evaluation reports should be broadly and freely shared, and findings and lessons learned made available to project management. Evaluation reports should provide transparent information on data sets, sources, methodologies, and approach.

\section{Roles and responsibilities}

38 Different partners and stakeholders within the GEF have different roles and responsibilities with respect to monitoring and evaluation. The GEF Council provides the overall framework for enabling monitoring and evaluation, starting with an agreement on the overall objectives and the corporate and focal area results frameworks. The GEF Secretariat develops and submits the plans and framework for monitoring progress against these objectives to the Council, and the IEO presents the overall evaluation work plan to report on the overall performance and effectiveness 
of the GEF, to the Council. The GEF Council approves the IEO work program and budget, receives the evaluation reports, and decides on the management actions to respond to the evaluation recommendations. The IEO prepares a Semi-Annual Evaluation Report every six months and a comprehensive evaluation of the GEF every four years. Based on this information, the Council makes strategic and policy-level decisions. The GEF Agencies and their partners execute project, program, and portfolio monitoring and evaluation plans. The GEF Scientific and Technical Advisory Panel (STAP) provides advice on indicators and targets at the stage when policies, strategies, programs, and projects are prepared, as well as evaluation approaches in response to specific requests by the IEO. Figure A1.2 and Table A1.1 provide the broad framework of the main roles and responsibilities of the key partners for monitoring and evaluation in the GEF.

39 Each GEF Agency has its own system of governance and rules and regulations governing the implementation of activities, as well as the evaluation of these activities. The GEF Council can adopt principles, norms, and standards for those parts of the GEF for

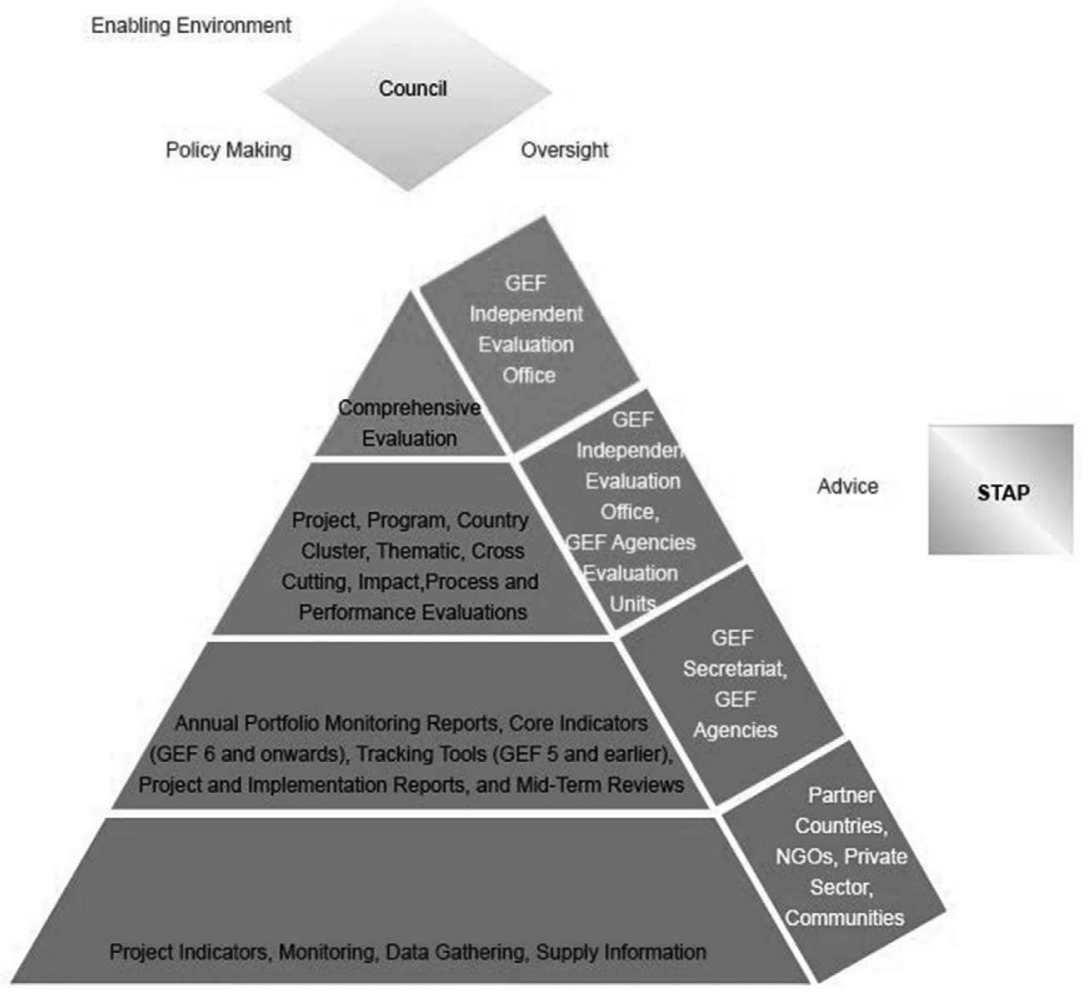

Figure A1.2 Monitoring and evaluation levels and responsible agencies in the GEF 
Table A1.1 Key roles and responsibilities of GEF partners in evaluation

\begin{tabular}{|c|c|}
\hline Partner & Key monitoring and evaluation roles and responsibilities \\
\hline Council & $\begin{array}{l}\text { - Develop the overall policy on monitoring and evaluation } \\
\text { - Provide an enabling environment for monitoring and } \\
\text { evaluation } \\
\text { - Oversee the evaluation function and guarantee IEO } \\
\text { independence } \\
\text { - Receive independent evaluation reports and decide on fol- } \\
\text { low-up actions to implement evaluation recommendations }\end{array}$ \\
\hline IEO & $\begin{array}{l}\text { - Conduct independent GEF evaluation } \\
\text { - Validate terminal evaluations prepared by Agencies } \\
\text { - Undertake post completion evaluation for a sample of projects } \\
\text { - Assess the quality of project and program evaluations } \\
\text { - Set minimum requirements for evaluation } \\
\text { - Prepare the Management Action Record } \\
\text { - Share and disseminate evaluative knowledge }\end{array}$ \\
\hline Secretariat & $\begin{array}{l}\text { - Set results frameworks at focal area and corporate levels } \\
\text { - Monitor the GEF portfolio across Agencies and focal areas } \\
\text { - Report on and incorporate lessons from portfolio monitoring } \\
\text { - Review monitoring and evaluation requirements in project } \\
\text { and program proposals }\end{array}$ \\
\hline $\begin{array}{l}\text { GEF Agency - } \\
\text { operational units }\end{array}$ & $\begin{array}{l}\text { - Monitor the Agency GEF portfolio } \\
\text { - Report Agency project, program, and portfolio progress, } \\
\text { results, and learning } \\
\text { - Ensure monitoring at the project and program levels, as } \\
\text { appropriate } \\
\text { - Manage project and program implementation adaptively } \\
\text { - Systematically involve national partners and share project } \\
\text { monitoring and evaluation information at the national level }\end{array}$ \\
\hline $\begin{array}{l}\text { GEF Agency } \\
\text { - evaluation units }\end{array}$ & $\begin{array}{l}\text { - Conduct and/or validate terminal evaluations of projects } \\
\text { and programs } \\
\text { - Conduct corporate Agency evaluations } \\
\text { - Mainstream the GEF into relevant Agency evaluations }\end{array}$ \\
\hline STAP & $\begin{array}{l}\text { - Advise on scientific/technical matters in monitoring and } \\
\text { evaluation } \\
\text { - Provide support on scientific and technical indicators }\end{array}$ \\
\hline GEF OFPs & $\begin{array}{l}\text { - Collaborate on monitoring and evaluation at project, pro- } \\
\text { gram, and portfolio levels }\end{array}$ \\
\hline $\begin{array}{l}\text { Other stakeholders } \\
\text { (CSOs, private sector, } \\
\text { communities) }\end{array}$ & $\begin{array}{l}\text { - Participate in monitoring activities } \\
\text { - Provide views and perceptions to evaluations }\end{array}$ \\
\hline
\end{tabular}

which it is directly responsible, such as the GEF Secretariat, the IEO, and the STAP. The Council can also require minimum standards and minimum procedures to be applied to the evaluation of the activities that it funds. Specific roles and responsibilities for evaluation are detailed for each partner in the following subsections. Specific roles and responsibilities for monitoring are detailed in the GEF Monitoring Policy. 


\section{GEF Council}

40 The GEF Council ensures accountability and oversight of GEF performance and results. The Council develops, adopts, and oversees the operational policies and programs for GEF-financed activities; reviews the operations of the GEF with respect to its purposes, scope, and objectives; and ensures that the GEF policies and work program, including operational strategies, programs, and projects, are monitored and evaluated on a regular basis. The Council also establishes the GEF Evaluation Policy for the GEF and approves the IEO's work program and budget. The Council receives the independent evaluations conducted by IEO, including the comprehensive evaluation of the GEF, and decides on follow up actions from evaluation recommendations. The Council uses independent evaluation to complement a larger system of financial oversight and accountability within the GEF Trustee and Agencies. On behalf of the Council, the GEF Trustee ensures the maintenance of appropriate records and accounts of the GEF trust fund and provides for their audit, in accordance with the rules of the Trustee.

41 The GEF Council provides an enabling environment for evaluation activities in line with internationally accepted standards and guarantees the independence of the IEO. The Council ensures that adequate resources are allocated to enable the independent evaluation function to operate effectively and with independence and that evaluators have the freedom to conduct their work without repercussions for career development. It also appoints a professionally competent director to lead the IEO. The Council promotes transparency, participation, and disclosure of evaluation findings, and ensures that sufficient time is dedicated to discussion of evaluation issues at Council meetings. The GEF Council, together with the GEF CEO and the IEO Director, is responsible for the use of evaluation products including the systematic consideration of findings, conclusions, and recommendations, and lessons, for decision making on GEF programs and policies.

\section{Independent evaluation office of the GEF}

42 The IEO has the central role of ensuring the independent evaluation function within the GEF. The IEO operates as an organizational unit independent of GEF Secretariat management or Agency. The IEO prepares the overall evaluation policy for the GEF to be endorsed by the Council; sets the minimum requirements for evaluation in the GEF partnership, sets an evaluation agenda for approval by the Council, validates the terminal evaluations of projects and programs by Agencies, conducts a broad spectrum of independent evaluations and shares evaluative evidence within and outside the GEF. 
43 The IEO pursues the goals of improved accountability and learning through two main functions:

a An evaluative function. The main function of the IEO is to independently evaluate the effectiveness of the GEF at the project, program, portfolio, and institutional levels.

b A normative function. The IEO is tasked to set minimum evaluation requirements, and evaluation standards within the GEF to ensure improved and consistent measurement of GEF results.

44 The IEO is independent from both the policy-making process and the delivery and management of assistance. This guarantees that data gathering and analysis and judgments on criteria, findings, and recommendations will not be influenced by conflicts of interest or undue interference by management at any level. The IEO requests feedback and comments on draft reports from all stakeholders consulted during the evaluation, ensuring due diligence and verification of any eventual evidence gaps. The Secretariat, Agencies, and other affected parties may receive, comment, and respond to draft and final evaluation reports, but cannot approve, hold back, request changes, or otherwise modify such draft and final evaluation reports. IEO evaluation reports are submitted directly and simultaneously to the GEF Council and the GEF Secretariat.

45 The independence of the IEO evaluation function is overseen by the GEF Council. The GEF Instrument, amended at the Fifth GEF Assembly in May 2014, states that "there shall be an independent evaluation office headed by a director, appointed by and reporting to the Council, whose responsibility it is to carry out independent evaluations consistent with decisions of the Council." 13 The term of the IEO Director will be determined by the Council. A Council Selection and Review Committee is formed to oversee the processes for appointing the Director and for conducting his/her performance objective reviews. The Director cannot join the GEF in any other capacity after completion of his/her mandate with the GEF. The Director is directly accountable to the GEF Council for the work of the IEO and may propose to the Council any measure he/she believes is necessary to ensure evaluation independence.

46 The Director manages the IEO and its budget by implementing strategic decisions by the GEF Council, providing overall direction and resource management, and strengthening institutional relationships. The Director is solely responsible for personnel decisions in the IEO in accordance with staff rules. In the exercise of these functions, the IEO Director participates in the GEF Council, the Assembly, and in the replenishment meetings on evaluation issues, and responds to Council requests on any related matters. The Council has direct access to the Director and his/her staff, and the Director may communicate directly with Council members during and between Council meetings or arrange special meetings 
as deemed appropriate and without prior clearance from anyone outside the IEO. Furthermore, the Director may propose decisions to the GEF Council on a no-objection basis between Council sessions.

47 To avoid conflict of interest, the Director establishes clear conflict-of-interest rules for the IEO staff. In this connection, an evaluation will not be entrusted to an IEO staff member who has been responsible in the past for the design, implementation, or supervision of the project, program, portfolio, strategy, or policy to be evaluated. The IEO does not engage consultants who have worked previously either as individuals or through private consulting firms and/or nonprofit organizations on the design or implementation of a project, program, portfolio, strategy, or policy to conduct evaluation analysis or prepare evaluation reports of the same.

48 Under the Director's leadership, the IEO has the responsibility for undertaking independent evaluations that involve a set of projects from more than one Agency. These evaluations are typically on a strategic level, on focal areas or programs, or on cross-cutting themes. Institutional evaluations are also undertaken. In addition, the IEO validates project terminal evaluations for those Agencies in which the evaluation function is not fully independent. It does so according specific evaluation guidelines. ${ }^{14}$ Where possible and to prevent duplication and to promote synergies, the IEO collaborates with evaluation units of the GEF Agencies. Within the GEF, the IEO facilitates cooperation with and among the GEF partners on matters of evaluation. This includes the establishment of procedures and guidelines on evaluation based on the internationally recognized good practice standards.

49 In support of the Council's oversight role and to promote accountability, the Director of the IEO reports directly and regularly to the Council on evaluation findings. The evaluative evidence is presented in Semi-Annual Evaluation Reports (SAER) which summarize the data and analyses, findings, conclusions, and recommendations of the individual evaluations completed in the semester being reported on. The SAER is presented as a working document and includes proposed Council decisions based on the recommendations from the evaluations. The evaluations themselves are submitted to the Council as information documents.

50 The evidence presented in the IEO's evaluations is either developed by the IEO itself or extracted and independently verified from evaluations by GEF Agency evaluation units. Data and information sources include monitoring data (once independently verified), the academic literature, primary data collected through interviews, field visits, remote- sensing, and other relevant credible sources. The IEO undertakes post completion evaluation for a sample of projects. The IEO also reviews project terminal evaluation reports submitted by the Agencies. Terminal evaluation reports focus on the ex post results of GEF projects and programs. 
51 The IEO Director prepares a four-year rolling work program and budget request and submits these directly to the Council for approval. The monitoring and evaluation budgetary needs of the Agencies and the GEF Secretariat are addressed separately in the GEF corporate budget and through project fees. The IEO four-year work program and budget is developed in consultation with the GEF partnership and is approved by the Council. It reflects a phased approach over a GEF replenishment period to ensure adequate evaluation coverage to promote accountability and learning. For every major evaluation, the IEO prepares an approach paper which is shared for comment with all the partners involved before finalization to allow for stakeholder feedback on the evaluation design.

52 The IEO ensures follow-up of evaluation recommendations through the management action record system, as part of its accountability function. A Management Action Record table containing all IEO evaluation recommendations, management responses and related Council decisions is compiled annually and circulated to the GEF Secretariat to rate and report progress on actions implemented on Council decisions. The IEO provides an independent assessment of the rate of adoption of Council decisions.

53 The IEO supports knowledge sharing and establishes systems to disseminate lessons learned and documents best practices from evaluations and provides independent evaluative evidence to the GEF knowledge base. The IEO supports knowledge sharing by ensuring the highest standards in accessibility and presentation for its published reports. The IEO develops learning products based on evaluations, disseminates findings through the IEO website, publications, a spectrum of conferences, communities of practice, web platforms such as Earth-Eval, social media, to share evaluation findings within and outside the GEF partnership.

54 The IEO establishes appropriate quality assurance mechanisms for its major evaluations and adopts the highest standards recognized in the international evaluation community. These quality assurance mechanisms address evaluation approaches and methods, data gathering and analysis, and include reporting on evaluation findings and conclusions.

55 The IEO works in close partnership with the global evaluation community. The IEO remains on the cutting edge of emerging and innovative methodologies in environmental evaluation. It consults and collaborates with all relevant partners to foster a network of evaluation professionals who may add value to GEF operations and results.

\section{GEF Secretariat}

56 The GEF Secretariat is responsible for monitoring and reporting on the results of the overall GEF Portfolio, in accordance with 
the results frameworks set by the Council in each replenishment period. The Secretariat reviews all projects and programs prior to their approval to ensure they meet GEF monitoring and evaluation requirements, including the use of indicators and targets to ensure alignment with focal area objectives.

57 The GEF Secretariat ensures that findings and recommendations from evaluations are followed up on with respect to GEF policies, programs, and procedures, and that related Council decisions are implemented. The Secretariat ensures that results and lessons are adequately reflected in public information about the GEF. This includes activities to gather and disseminate best practices to improve portfolio quality. In support of evaluation, the Secretariat responds promptly and fully to all IEO requests for information relating to GEF projects, programs, and policies; and coordinates the GEF management response to IEO evaluations.

\section{GEF Agencies}

\section{Operational Units}

58 In line with the Minimum Fiduciary Standards for GEF Partner Agencies, ${ }^{15}$ the Agencies are responsible for ensuring that projects and programs are properly designed with monitoring and evaluation plans, and that projects are adequately monitored during implementation. The GEF Agencies are responsible for developing monitoring plans with appropriate performance and results indicators for projects and programs; for adequately monitoring project and program activities, production of outputs, and progress toward outcomes. When designated as a program's Lead Agency, an Agency is responsible for monitoring the program as well as the child projects it directly implements. The Agencies implementing the other child projects in the program are responsible for their monitoring. To ensure that results can be analyzed across Agencies in a consistent manner, project logical frameworks and/or theories of change should be aligned with the GEF focal area results frameworks, as applicable.

59 Agencies must undertake midterm reviews for programs and full-sized projects under implementation for adaptive management purposes. Midterm reviews are also encouraged for medium-sized projects and enabling activities where appropriate and feasible. These reports are submitted to the GEF Secretariat as part of annual reporting.

60 The Agencies support the IEO by responding promptly and fully to requests for information or support relating to evaluation of GEF activities, and by making project and program documentation available to the IEO. As per the updated GEF Policy on Cofinancing, Agencies provide information on the actual amounts, sources, and types of cofinancing and investment mobilized in their 
midterm reviews and terminal evaluations. The Agencies encourage OFPs to be fully informed of and consulted on the conduct of terminal evaluations, and that they receive and comment on terminal evaluations.

\section{Evaluation Units}

61 Agencies ensure the conduct of required terminal evaluations of GEF-supported projects and programs in their portfolio. Depending on the Agency's institutional structure as well as internal rules and procedures, two scenarios exist: (1) the evaluation unit conducts project terminal evaluations, and (2) the evaluation unit validates the evaluations managed by operational units. Agencies are responsible for the terminal evaluation of the child projects they directly implement in a program. In addition, the Lead Agency will be responsible for submitting the terminal evaluation for the program. Consistent with the GEF Project and Program Cycle Policy, any project and program evaluations must be shared with the IEO.

62 GEF Agency Evaluation Units may be called upon to explore with the IEO possible areas of common interest and cooperation and opportunities for joint evaluations. For evaluations covering issues of GEF concern and the GEF portfolio, the evaluation units engage with the IEO on the terms of reference, approach, and scope.

63 The Agency evaluation units coordinate with the IEO on norms, standards, and quality of evaluations when it comes to GEF-financed activities. Agencies are expected to provide adequate financial support for their evaluation units to undertake their work in a way that does not compromise the independent conduct of evaluations.

\section{Scientific and Technical Advisory Panel}

64 Upon receipt of specific requests from the IEO, the STAP may contribute scientific and technical advice, data or other information that may be useful to evaluation. Such requests may pertain to opinions on the evaluability of scientific aspects and related methodologies for measuring global environmental impacts in response to evaluation approach papers, terms of reference, or reports. STAP members may also be requested for direct support to an evaluation while respecting the independence of the IEO.

\section{GEF Operational Focal Points}

65 Several entities in GEF member countries are involved in evaluation in different ways. Many systems on local and global environmental benefits. These initiatives may include improving basic census data, establishing national and project baselines, establishing participatory environment and natural resource monitoring schemes, using national communications and inventories of global environmental benefits, among others. 
66 In line with GEF operational principles on country ownership, evaluation activities will be consultative. The GEF OFPs will be fully consulted with and informed by the GEF Agencies and the IEO on the planning, conduct, and results of any evaluation activity performed in their country, and they in turn will respect the independence of the evaluation.

67 The GEF OFPs play a key role in facilitating access to staff members of government institutions involved in GEF projects during evaluations. They may promote the use of, follow-up to, and action on evaluation recommendations related to GEF matters and directed at the regional, national, and project levels. They also play an important role in keeping national stakeholders (including the civil society organizations involved in GEF activities) fully consulted with, informed on, and involved in the plans, conduct, and results of country-related GEF evaluation activities.

\section{Other stakeholders}

68 A considerable number of locally and internationally based stakeholders are involved in GEF evaluation activities. These stakeholders are the individuals, groups, or institutions that have an interest or stake in the outcome of a GEF-financed project or program, including those potentially affected by a project or program. Stakeholders may include national project or program executing agencies; groups contracted to conduct activities at various stages of the project or program; and other civil society groups including local community members who may have an interest in the project or program, or who are living in the project or program area, or who are dependent for part of their livelihoods or in times of stress on the natural resources of the project or program area. Their involvement in evaluation depends on the project or program and their role. For example, academic institutions or private sector companies may support evaluation activities directly and provide outside perspectives and expertise. CSOs may play an important role in providing feedback as beneficiaries or as representatives of community groups.

69 Consistent with provisions in the GEF Instrument and with the GEF Stakeholder Engagement Policy, there shall be transparency in the preparation, conduct, reporting, and evaluation of public involvement activities in all projects and programs. This includes full disclosure of all nonconfidential information, and consultation with major groups and representatives of local communities. GEF evaluations should involve project stakeholders, both as participants and contributors and as users and beneficiaries as appropriate. Local stakeholder participation and participatory approaches in evaluation are particularly necessary in projects and programs that affect the incomes and livelihoods of local groups, especially disadvantaged populations in and 
around project sites (for example, indigenous and other local communities, women, and poor households).

\section{Notes}

1. GEF IEO, "Work Program and Budget of the GEF Independent Evaluation Office," GEF/ME/C.46/01/Rev.01.

2. GEF IEO, "Semi-Annual Evaluation Report of the GEF Independent Evaluation Office: October 2015," GEF/ME/C.49/01.

3. GEF IEO, "An Evaluative Approach to Assessing GEF's Additionality," GEF/ME/ C.55/inf.01.

4. Adapted from the OECD DAC, "Glossary of Key Terms in Evaluation and Results Based Management" (www.oecd.org/dac/evaluation/2754804.pdf).

5. GEF, "GEF Focal Points," GEF/C.8/Inf.5 (www.thegef.org/sites/default/files/ council-meeting-documents/C.8.Inf_.5_5.pdf).

6. GEF, "Instrument for the Establishment of the Restructured Global Environment Facility" (www.thegef.org/sites/default/files/documents/GEF_Instrument-Interior-March23.2015.pdf).

7. "Fee Policy for GEF Partner Agencies," FI/PL/03 (www.thegef.org/sites/default/ files/documents/Agency_Fee_Policy.pdf); "Minimum Fiduciary Standards for GEF Partner Agencies," GA/PL/02 (www.thegef.org/sites/default/files/documents/ GA.PL_.02_Minimum_Fiduciary_Standards_0.pdf); “Operational Guidelines for the Application of the Incremental Cost Principle," GEF/C.31/12 (www. thegef.org/sites/default/files/documents/C.31.12_Operational_Guidelines_for_ Incremental_Costs-2007_0.pdf); "Policy on Cofinancing," FI/PL/01 (www.thegef. org/sites/default/files/documents/Cofinancing_Policy.pdf); "Policy on Gender Equality," SD/PL/02 (www.thegef.org/sites/default/files/documents/Gender_ Equality_Policy.pdf); "Policy on Stakeholder Engagement," SD/PL/01 (www. thegef.org/sites/default/files/documents/Stakeholder_Engagement_Policy.pdf); and "Project and Program Cycle Policy," OP/PL/01 (www.thegef.org/sites/ default/files/documents/Project_Program_Cycle_Policy_OPPL01.pdf).

8. The incremental cost principle does not apply to the Least Developed Countries Fund (LCDF) and the Special Climate Change Fund (SCCF).

9. OECD-DAC is currently reviewing the evaluation criteria in light of the 2030 Sustainable Development Goals (SDGs) Agenda.

10. IEO, "An Evaluative Approach to Assessing GEF's Additionality," GEF/ME/C.55/ inf.01 (www.thegef.org/sites/default/files/council-meeting-documents/EN_GEF. ME_C.55.inf_.01_Additionality_Framework_November_2018.pdf).

11. World Bank, "Bank Policy: Access to Information," EXC4.01-POL.01 (https:// policies.worldbank.org/sites/ppf3/PPFDocuments/Forms/DispPage.aspx?docid= 3693).

12. GEF, "Policy on Access to Information," GEF/C.55/06, para. 4 (www.thegef.org/ sites/default/files/council-meeting-documents/EN_GEF.C.55.06_Policy_on_ Access_to_Information.pdf).

13. GEF, "Instrument for the Establishment of the Restructured Global Environment Facility," para. 21.i (www.thegef.org/sites/default/files/documents/GEF_ Instrument-Interior-March23.2015.pdf).

14. IEO, "Guidelines for GEF Agencies in Conducting Terminal Evaluation for Fullsized Projects" (www.gefieo.org/evaluations/gef-guidelines-te-fsp-2017).

15. "Minimum Fiduciary Standards for GEF Partner Agencies," GA/PL/02 (www. thegef.org/sites/default/files/documents/GA.PL_.02_Minimum_Fiduciary_ Standards_0.pdf). 


\section{Appendix 2 \\ OPS6 Independent Advisory \\ Panel Statement}

\section{Introduction}

The Independent Advisory Panel prepared this Statement after reviewing the final draft of OPS6. The Panel acknowledges the impressive work that has been done by GEF's Independent Evaluation Office (IEO) to produce the OPS6 report, which takes into account the complexities that the GEF faces and synthesizes the enormous amount of information collected through 29 independent evaluations. These detailed reports were building blocks for the OPS6, which brought rigor and depth to its findings and conclusions, distilling the essence from those evaluations.

This Statement discusses the process followed for OPS6 and focuses on the OPS6 report, both on the quality of the evidence and methods used as well as on the quality of the arguments, considering first the links between evidence and conclusions and second the links between conclusions and recommendations. Finally, the Panel provides comments on a set of key issues.

\section{On the OPS6 process}

The evaluation briefs prepared by IEO of completed and ongoing evaluations summarized in a four-page format, including information on the status of the various evaluations, preliminary findings and collected evidence, as well as the construction of a dedicated website for OPS6, provided an appropriate means of communicating in real-time the results of the evaluation.

The Independent Advisory Panel reviewed and made observations on the approach paper for OPS6. It also provided comments and suggestions on an annotated outline of the report at a face-to-face meeting with the IEO. The Panel reviewed and provided comments on a zero draft of the report, which was prepared and circulated 6 weeks after that meeting. Finally, as mentioned in the Introduction, the Independent Advisory Panel prepared this statement after reviewing the final draft of OPS6, which to a great extent incorporated the comments of the Panel on the zero draft. 


\section{On the OPS6 report}

\section{Quality of the evidence and methods}

The Panel commends the use of multiple sources of evidence and the application of different methods, thus allowing for adequate triangulation to ensure the reliability and veracity of the findings. However, a more detailed presentation of the methods used would have been worthwhile.

\section{Quality of the arguments}

The conclusions are supported by the evidence, although this is not evident at a glance in all cases. The recommendations provide valuable guidance on how to deal with the issues identified in the report.

\section{Some key issues}

This section addresses some issues that the Panel feels are not fully considered in the conclusions or presented in the recommendations.

1 The GEF project data base is not yet comprehensive, consistent, updated and accessible. This information is a global public good and its consolidation and appropriate dissemination would make an important contribution if properly curated and placed in the public domain.

2 The fundamental systemic and urgent nature of the issues at stake should be acknowledged, moving beyond a largely project-driven logic in the funding cycle.

3 Although, as indicated in conclusion 4 of the OPS6 report, it is too early to assess the performance of the Integrated Approach Pilots, the Panel believes that the GEF should continue pursuing an integrated approach and that it would be appropriate to include a full assessment of the Pilots' performance in OPS7.

4 Although the quality of private sector engagement is improving there is still a need for greater clarity on how the GEF sees the role of the private sector and vice versa. Specifically, whether it is seen by the GEF primarily as a mechanism for securing additional funding, as a mechanism to achieving desired environmental outcomes or both, and whether the private sector sees the GEF as primarily creating the enabling environment for investment. To enhance the engagement strategy, there should be greater understanding and recognition that the private sector is not a single entity but a complex mosaic of for-profit businesses, including the financial sector.

5 Even though the report states that the GEF appears to have a greater risk appetite and tolerance than other financiers, the very high percent of 
completed GEF-4 projects, which had outcomes rated in the satisfactory range $(85 \%$, exceeding the $75 \%$ performance target set out in the replenishment), may be a sign of a rather risk averse, insufficiently innovative project portfolio. The Panel considers that the GEF is well placed to take more risks and play a more innovative and transformative role.

The Panel would also like to emphasize the importance and urgency of implementing a foreign exchange risk management mechanism, as indicated in the second part of recommendation 4.

Finally, the Panel commends the GEF for its excellent responsiveness to the Conventions, as reported in OPS6.

\section{Overall assessment}

The Independent Advisory Panel considers that the Sixth Comprehensive Evaluation of the GEF provides solid evaluative evidence to inform the negotiations for the seventh replenishment of the GEF and therefore OPS6 fulfills its purpose. 


\section{Appendix 3 \\ Selected global environment \\ facility evaluations and studies}

An Evaluative Approach to Assessing GEF's Additionality, 2018

www.thegef.org/council-meeting-documents/evaluative-approachassessing-gef-s-additionality

Annual Performance Report, 2014

www.gefieo.org/evaluations/apr-2014

Annual Performance Report, 2018

www.thegef.org/sites/default/files/council-meeting-documents/ EN_GE.ME_C.54.Inf_.02_Annual_Performance_Report_2017_0.pdf

Biodiversity Focal Area Study, 2017

www.gefieo.org/evaluations/biodiversity-study-2017

Climate Change Mitigation: GEF Support to Market Change in China, India, Mexico, and Russia, 2014

www.gefieo.org/evaluations/ccm-2014

Comparative Advantage, Adequacy of Funding/Financing, Health of the Expanded GEF Partnership and Governance Structure, 2017 www.gefieo.org/evaluations/gef-partnership-governance-2017

Evaluation of GEF Engagement with the Private Sector, 2017 www.gefieo.org/evaluations/private-sector-2017

Evaluation of GEF Support for Transformational Change, 2017 www.gefieo.org/evaluations/transformational-change

Evaluation of GEF Support to Scaling up Impact, 2019 www.gefieo.org/evaluations/scaling

Evaluation of GEF's Support to Mainstreaming Biodiversity, 2019 www.gefieo.org/evaluations/biodiversity-mainstreaming-2018

Evaluation of Incremental Cost Assessment, 2007 www.gefieo.org/evaluations/incremental-cost-assessment-2007

Evaluation of Programmatic Approaches in the GEF, 2018 www.gefieo.org/evaluations/programmatic-approaches-2016 


\section{Appendix 3}

Evaluation of the GEF-UNIDO Global Cleantech Innovation Programme, 2018

www.gefieo.org/evaluations/cleantech-programme-2018

Formative Review of the Integrated Approach Pilot Programs, 2018 www.gefieo.org/council-meetings/council-documents/gefmec53inf04

The GEF in the South China Sea and Adjacent Areas, 2012 www.gefieo.org/evaluations/scs-2012

The GEF Response to the Crisis - What Can We Learn from Evaluation?, 2020

www.gefieo.org/documents/gef-response-crisis-what-can-we-learnevaluation

IEO Brief: A Value for Money Analysis of GEF Interventions in Land Degradation and Biodiversity, 2018

www.gefieo.org/evaluations/synopsis/vfm-2016-land-degradation-brief

Impact Evaluation of GEF Support to Protected Areas and Protected Area Systems, 2016

www.gefieo.org/evaluations/impact-pa-support-2016

Impact of GEF Support on National Environmental Laws and Policies in Selected Countries, 2017

www.gefieo.org/evaluations/regulatory-reform-2017

OPS2: The First Decade of the GEF: Second Overall Performance Study, 2002

www.gefieo.org/evaluations/ops2

OPS3: Progressing Toward Environmental Results: Third Overall Performance Study of the Global Environment Facility, 2005

www.gefieo.org/evaluations/ops3

OPS4: Progress toward Impact: Fourth Overall Performance Study of the GEF, 2010

www.gefieo.org/evaluations/ops4

OPS5: At Crossroads for Higher Impact: Fifth Overall Performance Study of the GEF, 2014

www.gefieo.org/evaluations/ops5-final-report

OPS6: The GEF in the Changing Environmental Finance Landscape: Sixth Comprehensive Evaluation of the GEF (OPS6), 2017

www.gefieo.org/evaluations/ops6-report

OPS6: Sixth Comprehensive Evaluation of the GEF (OPS6) Approach Paper, 2016

www.gefieo.org/council-meetings/council-documents/gefmec5007

Program Evaluation of the Least Developed Countries Fund (LDCF), 2016 www.gefieo.org/evaluations/ldcf-2016 
Program Evaluation of the Special Climate Change Fund (SCCF), 2017 www.gefieo.org/evaluations/sccf-2017

The Role of Local Benefits in Global Environmental Programs, 2006 www.gefieo.org/evaluations/lb-global-environmental-programs-2006 Strategic Country Cluster Evaluation (SCCE): Small Island Developing States (SIDS), 2019

www.gefieo.org/evaluations/scce-sids

Strategic Country Cluster Evaluation (SCCE): Sahel and Sudan-Guinea Savanna Biomes, 2020

www.gefieo.org/evaluations/scce-biomes

A Study on the Health Co-benefits of GEF Chemicals and Waste Focal Area, 2020

www.gefieo.org/sites/default/files/documents/co-benefits-cw-study2019.pdf

Value for Money Analysis for GEF Land Degradation Projects, 2018 https://www.gefieo.org/evaluations/vfm-2016-land-degradation

Value for Money Analysis of GEF Interventions in Support of Sustainable Forest Management, 2019

www.gefieo.org/evaluations/vfm-2019-forest-management 


\section{Appendix 4 \\ Global environment facility \\ projects referenced in this book}

\begin{tabular}{|c|c|c|c|}
\hline Project or program name & $\begin{array}{l}\text { GEF ID } \\
\text { number }\end{array}$ & $\begin{array}{l}\text { Implementing } \\
\text { agency }\end{array}$ & Countries \\
\hline $\begin{array}{l}\text { Alternatives to DDT Usage for } \\
\text { the Production of Anti- } \\
\text { fouling Paint }\end{array}$ & 2932 & UNDP & China \\
\hline $\begin{array}{l}\text { Amazon Region Protected } \\
\text { Areas Program (ARPA) }\end{array}$ & 771 & WB & Brazil \\
\hline $\begin{array}{l}\text { Amazon Region Protected } \\
\text { Areas Program Phase } 2\end{array}$ & 4085 & WB & Brazil \\
\hline $\begin{array}{l}\text { China Renewal Energy } \\
\text { Scaling-Up Program } \\
\text { (CRESP) Phase II }\end{array}$ & 4493 & WB & China \\
\hline $\begin{array}{l}\text { China Utility-Based Energy } \\
\text { Efficiency Finance Program } \\
\text { (CHUEE) }\end{array}$ & 2624 & WB & China \\
\hline $\begin{array}{l}\text { Cities-IAP: Sustainable Cities } \\
\text { Integrated Approach Pilot } \\
\text { (IAP-PROGRAM) }\end{array}$ & 9077 & WB & $\begin{array}{l}\text { Global, Brazil, Cote } \\
\text { d'Ivoire, China, India, } \\
\text { Mexico, Malaysia, Peru, } \\
\text { Paraguay, Senegal, } \\
\text { Vietnam, South Africa }\end{array}$ \\
\hline $\begin{array}{l}\text { Climate Change Adaptation } \\
\text { Project, Phase I }\end{array}$ & 3243 & WB & Philippines \\
\hline $\begin{array}{l}\text { Comm-IAP: Taking } \\
\text { Deforestation Out of } \\
\text { Commodity Supply Chains } \\
\text { (IAP-PROGRAM) }\end{array}$ & 9072 & INDP & Global \\
\hline $\begin{array}{l}\text { Conservation and Sustainable } \\
\text { Use of the Mesoamerican } \\
\text { Barrier Reef }\end{array}$ & 837 & WB & $\begin{array}{l}\text { Regional, Belize, } \\
\text { Guatemala, Honduras, } \\
\text { Mexico }\end{array}$ \\
\hline $\begin{array}{l}\text { Coral Reef Rehabilitation and } \\
\text { Management Project } \\
\text { (COREMAP I) }\end{array}$ & 116 & WB & Indonesia \\
\hline Coral Reef Rehabilitation and & 1829 & WB & Indonesia \\
\hline
\end{tabular}

Management Project Phase II (COREMAP II) 


\begin{tabular}{|c|c|c|c|}
\hline Project or program name & $\begin{array}{l}\text { GEF ID } \\
\text { number }\end{array}$ & $\begin{array}{l}\text { Implementing } \\
\text { agency }\end{array}$ & Countries \\
\hline $\begin{array}{l}\text { DBSB: Agricultural Pollution } \\
\text { Control Project - under } \\
\text { WB-GEF Strategic } \\
\text { Partnership for Nutrient } \\
\text { Reduction in the Danube } \\
\text { River and Black Sea }\end{array}$ & 1159 & WB & Romania \\
\hline $\begin{array}{l}\text { DBSB: Integrated Nutrient } \\
\text { Pollution Control Project - } \\
\text { Under the WB-GEF } \\
\text { Investment Fund for Nutrient } \\
\text { Reduction in the Danube } \\
\text { River and Black Sea }\end{array}$ & 2970 & WB & Romania \\
\hline $\begin{array}{l}\text { Demonstrating and Promoting } \\
\text { Best Techniques and Practices } \\
\text { for Reducing Health-care } \\
\text { Waste to Avoid Environmental } \\
\text { Releases of Dioxins and } \\
\text { Mercury }\end{array}$ & 1802 & UNDP & $\begin{array}{l}\text { Global, Argentina, India, } \\
\text { Lebanon, Latvia, } \\
\text { Lebanon, the } \\
\text { Philippines, Senegal, } \\
\text { Tanzania, and Vietnam }\end{array}$ \\
\hline $\begin{array}{l}\text { Demonstration of Alternatives } \\
\text { to Chlordane and Mirex in } \\
\text { Termite Control }\end{array}$ & 2359 & WB & China \\
\hline $\begin{array}{l}\text { Demonstration project for } \\
\text { Phasing-out and Elimination } \\
\text { of PCBs and PCB-Containing } \\
\text { Equipment }\end{array}$ & 2875 & UNIDO & North Macedonia \\
\hline Ecomarkets & 671 & WB & Costa Rica \\
\hline $\begin{array}{l}\text { Enabling activities for the } \\
\text { Stockholm Convention on } \\
\text { Persistent Organic Pollutants } \\
\text { (POPs): National } \\
\text { Implementation Plan for } \\
\text { Mauritius }\end{array}$ & 1824 & UNDP & Mauritius \\
\hline $\begin{array}{l}\text { Enabling Activities to Facilitate } \\
\text { Early Action on the } \\
\text { Implementation of the } \\
\text { Stockholm Convention on } \\
\text { Persistent Organic Pollutants } \\
\text { (POPS) in the Republic of } \\
\text { Macedonia }\end{array}$ & 1518 & UNIDO & North Macedonia \\
\hline $\begin{array}{l}\text { Food-IAP: Fostering } \\
\text { Sustainability and Resilience } \\
\text { for Food Security in Sub- } \\
\text { Saharan Africa - An Integrated } \\
\text { Approach (IAP-PROGRAM) }\end{array}$ & 9070 & IFAD & $\begin{array}{l}\text { Regional, Burkina Faso, } \\
\text { Burundi, Ethiopia, } \\
\text { Ghana, Kenya, Malawi, } \\
\text { Niger, Nigeria, Senegal, } \\
\text { Eswatini, Tanzania, } \\
\text { Uganda }\end{array}$ \\
\hline
\end{tabular}

(Continued) 


\begin{tabular}{|c|c|c|c|}
\hline Project or program name & $\begin{array}{l}\text { GEF ID } \\
\text { number }\end{array}$ & $\begin{array}{l}\text { Implementing } \\
\text { agency }\end{array}$ & Countries \\
\hline Global Wildlife Program & 10200 & WB & $\begin{array}{l}\text { Global, Angola, Bhutan, } \\
\text { Belize, Ecuador, } \\
\text { Indonesia, India, } \\
\text { Cambodia, Madagascar, } \\
\text { Malaysia, Namibia, } \\
\text { Nigeria, Panama, } \\
\text { Pakistan, Chad, South } \\
\text { Africa, Congo DR }\end{array}$ \\
\hline $\begin{array}{l}\text { Hai River Basin Integrated } \\
\text { Water Resources Management }\end{array}$ & 1323 & WB & China \\
\hline High Efficiency Lighting Pilot & 575 & WB & Mexico \\
\hline $\begin{array}{l}\text { Improvement of DDT-based } \\
\text { Production of Dicofol and } \\
\text { Introduction of Alternative } \\
\text { Technologies Including IPM } \\
\text { for Leaf Mites Control in } \\
\text { China }\end{array}$ & 2629 & UNDP & China \\
\hline $\begin{array}{l}\text { IND-BD Mainstreaming } \\
\text { Coastal and Marine } \\
\text { Biodiversity Conservation } \\
\text { into Production Sectors in the } \\
\text { Godavari River Estuary in } \\
\text { Andhra Pradesh State }\end{array}$ & 3936 & UNDP & India \\
\hline $\begin{array}{l}\text { IND-BD: GEF Coastal and } \\
\text { Marine Program (IGCMP) }\end{array}$ & 3661 & UNDP & India \\
\hline $\begin{array}{l}\text { Institutional Capacity Building } \\
\text { for Protected Areas } \\
\text { Management and Sustainable } \\
\text { Use (ICB-PAMSU) }\end{array}$ & 101 & WB & Uganda \\
\hline $\begin{array}{l}\text { LAC Regional Sustainable } \\
\text { Transport and Air Quality } \\
\text { Project }\end{array}$ & 2767 & WB & $\begin{array}{l}\text { Regional, Argentina, } \\
\text { Brazil, Mexico }\end{array}$ \\
\hline $\begin{array}{l}\text { Lighting the "Bottom of the } \\
\text { Pyramid" }\end{array}$ & 2950 & WB & Regional, Ghana, Kenya \\
\hline $\begin{array}{l}\text { Mainstreaming Market-based } \\
\text { Instruments for } \\
\text { Environmental Management } \\
\text { Project }\end{array}$ & 2884 & WB & Costa Rica \\
\hline $\begin{array}{l}\text { MENA - Desert Ecosystems } \\
\text { and Livelihoods Program } \\
\text { (MENA-DELP) }\end{array}$ & 4620 & WB & $\begin{array}{l}\text { Regional, Algeria, Egypt, } \\
\text { Jordan, Morocco }\end{array}$ \\
\hline $\begin{array}{l}\text { Namib Coast Biodiversity } \\
\text { Conservation and } \\
\text { Management (NACOMA) }\end{array}$ & 1505 & WB & Namibia \\
\hline $\begin{array}{l}\text { Namibian Coast Conservation } \\
\text { and Management Project }\end{array}$ & 4669 & WB & Namibia \\
\hline
\end{tabular}




\begin{tabular}{|c|c|c|c|}
\hline Project or program name & $\begin{array}{l}\text { GEF ID } \\
\text { number }\end{array}$ & $\begin{array}{l}\text { Implementing } \\
\text { agency }\end{array}$ & Countries \\
\hline $\begin{array}{l}\text { PRC-GEF Partnership: An } \\
\text { IEM Approach to the } \\
\text { Conservation of Biodiversity } \\
\text { in Dryland Ecosystems } \\
\text { - Under the PRC-GEF } \\
\text { Partnership on Land } \\
\text { Degradation in Dryland } \\
\text { Ecosystem Program }\end{array}$ & 2369 & IFAD & China \\
\hline $\begin{array}{l}\text { PRC-GEF Partnership: } \\
\text { Capacity and Management } \\
\text { Support for Combating Land } \\
\text { Degradation in Dryland } \\
\text { Ecosystems }\end{array}$ & 3484 & $\begin{array}{l}\text { Asian } \\
\text { Development } \\
\text { Bank }\end{array}$ & China \\
\hline $\begin{array}{l}\text { PRC-GEF Partnership: } \\
\text { Forestry and Ecological } \\
\text { Restoration in Three } \\
\text { Northwest Provinces } \\
\text { (Formerly Silk Road } \\
\text { Ecosystem Restoration } \\
\text { Project) }\end{array}$ & 3483 & $\begin{array}{l}\text { Asian } \\
\text { Development } \\
\text { Bank }\end{array}$ & China \\
\hline $\begin{array}{l}\text { PRC-GEF Partnership: Land } \\
\text { Degradation in Dryland } \\
\text { Ecosystems: Project I } \\
\text { - Capacity Building to } \\
\text { Combat Land Degradation }\end{array}$ & 956 & $\begin{array}{l}\text { Asian } \\
\text { Development } \\
\text { Bank }\end{array}$ & China \\
\hline $\begin{array}{l}\text { PRC-GEF Partnership: } \\
\text { Mainstreaming Biodiversity } \\
\text { Protection within the } \\
\text { Production Landscapes and } \\
\text { Protected Areas of the Lake } \\
\text { Aibi Basin }\end{array}$ & 3611 & WB & China \\
\hline $\begin{array}{l}\text { PRC-GEF Partnership: } \\
\text { Sustainable Development in } \\
\text { Poor Rural Areas }\end{array}$ & 3608 & WB & China \\
\hline $\begin{array}{l}\text { Promoting Payments for } \\
\text { Environmental Services (PES) } \\
\text { and Related Sustainable } \\
\text { Financing Schemes in the } \\
\text { Danube Basin }\end{array}$ & 2806 & UNEP & $\begin{array}{l}\text { Regional, Bulgaria, } \\
\text { Romania }\end{array}$ \\
\hline $\begin{array}{l}\text { Protected Areas Management } \\
\text { and Sustainable Use (PAMSU) }\end{array}$ & 1830 & WB & Uganda \\
\hline $\begin{array}{l}\text { PSG: Sustainable Land } \\
\text { Management Project } 2\end{array}$ & 5220 & WB & Ethiopia \\
\hline $\begin{array}{l}\text { Reducing Transboundary } \\
\text { Degradation in the Kura-Aras } \\
\text { Basin }\end{array}$ & 1375 & UNDP & $\begin{array}{l}\text { Regional, Armenia, } \\
\text { Azerbaijan, Georgia }\end{array}$ \\
\hline $\begin{array}{l}\text { Renewable Energy } \\
\text { Development }\end{array}$ & 446 & WB & China \\
\hline
\end{tabular}




\begin{tabular}{|c|c|c|c|}
\hline Project or program name & $\begin{array}{l}\text { GEF ID } \\
\text { number }\end{array}$ & $\begin{array}{l}\text { Implementing } \\
\text { agency }\end{array}$ & Countries \\
\hline $\begin{array}{l}\text { Renewable Energy Scale Up } \\
\text { Program (CRESP), Phase I }\end{array}$ & 943 & WB & China \\
\hline $\begin{array}{l}\text { Rio de Janeiro Integrated } \\
\text { Ecosystem Management in } \\
\text { Production Landscapes of the } \\
\text { North-Northwestern } \\
\text { Fluminense }\end{array}$ & 1544 & WB & Brazil \\
\hline $\begin{array}{l}\text { Rural Electrification and } \\
\text { Renewable Energy } \\
\text { Development }\end{array}$ & 1209 & WB & Bangladesh \\
\hline $\begin{array}{l}\text { Sanjian Plain Wetlands } \\
\text { Protection Project }\end{array}$ & 1126 & $\begin{array}{l}\text { Asian } \\
\text { Development } \\
\text { Bank }\end{array}$ & China \\
\hline $\begin{array}{l}\text { Scaling up Risk Transfer } \\
\text { Mechanisms for Climate } \\
\text { Vulnerable Agriculture-based } \\
\text { Communities in Mindanao }\end{array}$ & 4967 & UNDP & Philippines \\
\hline $\begin{array}{l}\text { SFM: Promotion of Sustainable } \\
\text { Forest and Land Management } \\
\text { in the Vietnam Uplands }\end{array}$ & 3627 & IFAD & Vietnam \\
\hline $\begin{array}{l}\text { SIP: Country Program for } \\
\text { Sustainable Land Management } \\
\text { (ECPSLM) }\end{array}$ & 2794 & WB & Ethiopia \\
\hline $\begin{array}{l}\text { SP-SFIF: West Africa Regional } \\
\text { Fisheries Program (WARFP) }\end{array}$ & 3558 & WB & $\begin{array}{l}\text { Regional, Cabo Verde, } \\
\text { Liberia, Sierra Leone, } \\
\text { Senegal }\end{array}$ \\
\hline $\begin{array}{l}\text { SPWA-BD: Participatory } \\
\text { Biodiversity Conservation and } \\
\text { Low Carbon Development in } \\
\text { Pilot Ecovillages in Senegal }\end{array}$ & 4080 & UNDP & Senegal \\
\hline $\begin{array}{l}\text { Strengthening the Capacity of } \\
\text { the Protected Area System to } \\
\text { Address New Management } \\
\text { Challenges }\end{array}$ & 4729 & UNDP & Namibia \\
\hline $\begin{array}{l}\text { Sustainable Land, Water, and } \\
\text { Biodiversity Conservation and } \\
\text { Management for Improved } \\
\text { Livelihoods in Uttarakhand } \\
\text { Watershed Sector Project } \\
\text { (SLEM) }\end{array}$ & 3471 & WB & India \\
\hline $\begin{array}{l}\text { Sustainable Management of } \\
\text { POPs in Mauritius }\end{array}$ & 3205 & UNDP & Mauritius \\
\hline $\begin{array}{l}\text { The Global Cleantech } \\
\text { Innovation Programme for } \\
\text { SMEs }\end{array}$ & 9811 & UNIDO & Ukraine \\
\hline $\begin{array}{l}\text { Uruguay Wind Energy } \\
\text { Programme (UWEP) }\end{array}$ & 2826 & UNDP & Uruguay \\
\hline $\begin{array}{l}\text { West Africa Regional Fisheries } \\
\text { Program, Additional Financing }\end{array}$ & 9360 & WB & $\begin{array}{l}\text { Regional, Guinea, } \\
\text { Liberia, Sierra Leone }\end{array}$ \\
\hline
\end{tabular}




\section{Index}

Note: Page numbers followed by b denotes material in a box; $\mathrm{n}$, an endnote; italics, a figure; boldface, a table.

accountability 40, 115, 145

achievements 68-70, 69

adaptability 109, 127

additionality 44-46, 47b, 93-95, 129;

defined 46, 95; developmental 46; dimensions 47; environmental 47b; financial 46; innovation 47b; institutional $47 \mathrm{~b}$; legal and regulatory $47 \mathrm{~b}$; socioeconomic $47 \mathrm{~b}$; utility $46-49$ adoption 85, 94, 109-110 advisory panel 25

Africa 50-52, 90n2, 96, 99, 100, 103 agency evaluation units 16

Amazon Regional Protected Areas Program (ARPA) model 86, 98, 100, 108-111; ambition 98-99, 129; awareness 126

Ba Be Protected Area 70, 71, 71b

Bangladesh 106, 110, 111, 113

behavioral change 94

benefit boosting 115-121; clarity 115 , 118; credibility 115 , 116; engagement $115,117-118$; relevance $115,116-117$; responsiveness 116-117; timeliness 115 , 116

biodiversity $3,49,53-54,54,55,58-60$, 59, 72-74, 73, 76b, 87-88b, 123

biosphere, loss of integrity 3

book, organization 10-12

Brazil 96, 98, 100, 106, 108-111

budgeting 151; see also funding

capacities 131, 153

capacity-building 77, 111

catalytic effects $102-103$ challenges 120

change: depth and scale of 95 ; theory of 80, 93-97, 94

chemicals and waste $73,78-80$; health benefits and 126

child projects $85,89-90$

China 80, 86b, 96, 98, 100, 103, 106, 110

China Renewable Energy Scale-Up

Program (CRESP) 96, 98, 100, 103 clarity 115,118

climate change $3,5,73,75-78,110,122$, 123

coherence $43 b$

community health approach 126

compensation 83

competencies 153

complex situations 136

complexity 90, 91n 8

compromise 83

conflict resolution commissioner 10

context 122-123, 133b

Convention on Biological Diversity

(CBD) 13

coordination units 16

COREMAP 111

corruption 125

cost, incremental 45, 93; see also finance; funding

cost-effectiveness 86, 109, 112-113

Costa Rica 109, 111

country considerations 130; singlecountry programs 85

COVID-19 1, 3, 5, 6-7, 122-129, 133, 136-137; wildlife trade and 124-125; see also Ebola crisis credibility $115,134-135,152$ 
CRESP see China Renewable Energy Scale-Up Program criteria 153

Danube basin 97, 100

decision-making, evidence-based 132b, 133-134

deforestation $28,70,71,75 b, 88-90$

demand, reducing 125

demonstration 102

design $66,67,68,85,108$

developmental additionality 46

Director 163-164

disease, infectious 3, 122-123, 124-125; see also COVID-19; Ebola crisis donors 98, 111

\section{East Godavari River Estuarine Ecosystem} (EGREE) 76b

Ebola crisis 126-129; see also COVID-19 ecosystem: collapse 3 ; human health and 122-123

education see knowledge

effectiveness 43b, 64, 115, 129, 153

efficiency 43b, 74, 84, 133b, 153

electricity see solar lamps

engagement 115, 117-118

environment: additionality $47 \mathrm{~b}$; benefits 146-147; core components 3; COVID19 2; damage and disasters 3; enabling 77, 78; funding 123; global trends $3-5$; multilateral agreements 78-79; social and economic development and 123

Ethiopia 106, 112

Europe see Danube basin

evaluation 145-146; better 131-132, 132-133b; comprehensive 42b, 149; country and country cluster $42 \mathrm{~b}$, 149; defined 147-148; flowchart 147; follow-up 149-150; framework and recent innovations 43-49; GEF role 13-20; impact 149; independent 134 , 137n1; methods 41-43; norms 151-159; ongoing 116-117; ownership 135; partnership 15-17; performance 148; planning 132-133b, 155; policy 115, 142-168; principles 152-153; process 149; program 148; project 148; purpose 148; quality 118-120, 132; questions 32-33; role 24; systems approach 52-53; terminal 44, 62n1, 86, 155-156, 157-158b, 158; thematic 42b, 149; timely 131-132; types 42b, 148-149; units 167-168; use 118-120, 135-136, 148; value of 1

evaluative function 163

evidence 24,150

execution 129

feedback 116, 117, 150

fertilizer 3

finance 36; additionality 46, 47b; budgeting 151; climate change $4-5$; environmental 4; GEF role 6-7; incremental cost 45, 93; management 37; OPS6 36; requirements 5; stability 98-99; see also funding

fishing 127

flexibility 112-113, 127

focal areas 10, 105, 106-107, 113, 123; biodiversity $72-74,73$; chemicals and waste $73,78-80$; international waters 73, 80-81; land degradation 73; multifocal areas 73 ; performance $72-84$; protected areas $74-75,75 b$; single-focal area programs 85 ; strategy $81-82$

focal points 7,16 ; operational $158 \mathrm{~b}$, $167-168$

food security $28,89-90,126,127$

forests see deforestation

framework 42b, 43-49

funding 123; climate change 77-78; replenishment 21-23, 22; see also finance

GEF see Global Environment Facility gender equality $38,71-72,153$

geospatial analysis 53, 54, 55, 56, 137; efficiency measurement 56-60

Global Cleantech Innovation Programme (GCIP) 46-49

Global Commission on Adaptation 5 global environment benefits (GEBs) 93, 95; facility evaluations and studies 173-175, 176-180; OPS6 35

Global Environment Facility (GEF): Agency 10, 159, 161, 166-167; Assembly 8; constituencies 91n4; Conventions 8-9; Council 8, 16, 17, 25, 140, 146, 159, 160-161, 161, 162; effectiveness 64-92; evaluation 13-14, 18-19; funding 21; GEF-7 26-27, 116; institutional framework 7-10, 19n6; Instrument 146; Operational Focal Points (OFPs) 161; partnerships 8-10, 72, 161; performance 17-19, 31, 64-92; 
portfolio 2, 84-85; projects 14,16 ; relevance 28, 29-30, 29-30; replenishment 21-23, 22, 25-27, 116-117; role 6-7; Secretariat 9-10, 14, 16, 17, $159,160,161,165-166$; sustainability 64-92; Trustee 9; valuation architecture $15-17$

Global Environment Facility Evaluation Policy 140-169

Global Risk Report 20203

Global Wildlife Program $87-88$ b

GLOBALLAST 111

good practices 150

governance 36, 127, 130-131; additionality 47b; OPS6 36; structure 119

government: agencies 111; federal and state 102; ownership 99

guidance/guidelines 131, 147

Guinea, Ebola 127

housing, low-cost, quickly built 48b

human-environment nexus 1-2

human health see COVID-19;

disease, infectious; Ebola

IAP see Integrated Approach Pilot

IEO see Independent Evaluation Office

impact 42b, 43b, 96; additionality and 95

impartiality 152

implementation 66-67, 67, 68, 71-72, 94, 129; advocates 110-111; capacity, local institutions 99; national plan (NIP) 79; quality 99-100

independence 134, 137n1, 152, 163

Independent Evaluation Office (IEO) $9,15,16,40-41,115,160,161,162-$ 165; evaluations 41-49; independence 134; publications 41; replenishment and 24-26; reporting 115-120; role $15-17$

India 75, 76b, 85, 96, 98, 99, 100, 110, 111

indicators 153; attributable 153; measurable 153; relevant 154 ; specific 153 ; timely 154 ; trackable 154

indigenous peoples 72

Indonesia 106

industry 126

innovation, additionality $47 \mathrm{~b}$

institutions: additionality $47 \mathrm{~b}$; capacity 94; learning 115; systems 130-131
Integrated Approach Pilot (IAP) 27-28, 79, 84-85, 88-90, 116

integration: focus 37 ; organizing principle 28; programs 123

integrity 153

international cooperation 133

international waters $73,80-81$

knowledge/knowledge management 94 , 126, 133b, 136, 150-151

land degradation 57-58, 62n5, 73, 81-82; neutrality $91 \mathrm{n} 7$

land system change 3

learning 40, 145, 150

least developed countries (LDCs) 24; climate change fund 77-78

legal and regulatory framework 101-102b; additionality $47 \mathrm{~b}$

lessons learned 122-139, 150; applying 150; context 122-123; COVID-19

136-137; evaluations, better 131-132, 132-133b; pandemic 124-129; partnerships 130-131; political and global factors 133-136; sustainability of outcomes 130; systems approach to complex relationships 136; transformational change and scaling up 129-130

Liberia, Ebola 127

lighting. See solar lamps

Lighting Africa 50-52, 99, 100, 103

limitations $68-70,69$

livelihoods 85,125

local agency 126

M\&E. See monitoring and evaluation Macedonia 107

mainstreaming 75, 85, 86b, 100, 102; chemicals and waste projects $79-80$

Management Action Record (MAR) 118, 149-150

management response 149

manufacturing 110; disease and 126

market: change 98, 100; forces, harnessing 129; transformation 52

Mauritius 107, 112

messages, audience $133 \mathrm{~b}$

methodology;

credibility 134 ; mixed 52-53, 55, 61

Mexico 74, 75b, 106, 107

minimum requirements/standards 72 , 155-159, 156-158b

monitoring 145-146; flowchart 147 
monitoring and evaluation (M\&E) 13, 14-15, 86, 87-88b; application 157b; design 66, 67, 68, 156b; levels and responsible agencies 160

Montreal Protocol 79

multifocal areas and programs $73,82-84$, 85

Multilateral Organizations Performance Assessment Network (MOPAN) 17, 116

Namibia 96, 98, 99, 107, 109

National Commission on Natural Protected Areas (CONANP) 75b

National System of Natural Protected Areas (SINAP) $75 b$

normative function 163

North Africa 90n2

OECD see Organisation for Economic Co-operation and Development official development assistance (ODA) 21, 22,24

operational governance 38

OPS see Overall Performance Study

OPS6 23, 25-38, 132b; component evaluations and synthesis $27-31$; conclusions 34-36; evaluation process 134-135; feedback 116; gender equality 72 ; recommendations $37-38$

OPS7 23, 137; replenishment 117; theme 128 ; theme 231

organic pollutants, persistent (POPs) 79-80

Organisation for Economic Co-operation and Development (OECD) 5; DAC criteria $43 \mathrm{~b}$

outcomes 45, 64-65, 65; additionality and 95; influences on 84-86, 86b, 87-88b; sustainability 130

Overall Performance Study (OPS) 17; Independent Advisory Panel Statement 170-172; meetings 25-27, 117; OPS5 18-19, 31

\section{Pakistan $48 \mathrm{~b}$}

pandemic 124-129; see also COVID-19;

Ebola crisis

Paris Agreement 4, 76-77

participation 153

partnerships 8, 15-17, 82, 119, 130-131, 147; donor 98,111
Partnerships in Environmental Management for the Seas of East Asia (PEMSEA) 112, 113

payment for ecosystem services (PES) 109, 111

performance 35-36, 42b, 90n1; interven-

tions 64-71

pest management 80

Philippines 106, 107, 109

phosphorous 3

pilot programs 88-90; scaling up 108

planetary boundaries 3

planning, evaluation and 132-133b, 151

policies 77, 98, 131

policy-making, evidence-based 115

political and global factors 133-136

political will 125

POPs see organic pollutants, persistent population growth 3

prioritization 134

private enterprises 100

private sector 13,37

process evaluations $42 \mathrm{~b}$

program evaluations $42 \mathrm{~b}$

progress, tracking 146

projects: performance heterogeneity by regions 65-66, 65; size 100, 130

protected areas and area systems $74-75$, $75 b, 76 b$

quality, evaluations 131-132

quality-at-entry review 78

recommendations 37-38, 117

regions: governance 113; networks 113; sustainability 68-70, 69; variation 65-66, 65

relevance 43b, 95, 115, 116-117, 153

remote sensing 53

replenishment 21-23, 22, 85, 102, 116, 133 ; evaluation and $23-27,132$; funding 21-23, 22; meetings 116-117

reporting $88 \mathrm{~b}$

resilience 126, 127

Resource Allocation Framework 24

responsiveness $116-117$

roles and responsibilities 159-169

Romania 107

safeguard policies 38,72

satellite data 53

scaling up 85; defined 104; existing structures and mechanisms 111; factors 
influencing 109-113; focal areas 105, 106-107; GEF support 108; longterm 111-112; mechanisms 104-108; outcomes 108-109; transformational change 103-113, 129-130

Scientific and Technical Advisory Panel (STAP) 9, 14, 160, 161, 167

SDGs see Sustainable Development Goals Secretariat, GEF 9-10, 14, 16, 17, 159, $160,161,165-166$

Senegal 107, 108, 110-111, 112

sensing data 53

Sierra Leone 127

small island developing states (SIDS) 24

SMART indicators $156 \mathrm{~b}$

social and economic development 123; additionality $47 \mathrm{~b}$; co-benefits $60-61$

solar lamps 50-52, 100, 103

speeding up $96 \mathrm{~b}$

spill-over effects 95

stakeholders 135, 151, 161, 168-169

STAP see Scientific and Technical Advisory Panel

STAR see System for Transparent

Allocation of Resources

strategic positioning 37

Sub-Saharan Africa, food security 28

support, external $133 \mathrm{~b}$

surveys 53

sustainability $64,68-70,69,71,71 \mathrm{~b}$, 88-90, 95, 109, 110-111, 112, 127, 130, 153; cities 88-90; forest management 60-61

Sustainable Development Goals (SDGs) 2, $4,23,78-79,122,123$

synergies 130

System for Transparent Allocation of Resources (STAR) 24, 85

systems 36, 38; approaches 2; changes, policies and 98; complex relationships 136; evaluation 52-53; OPS6 36

technologies: adapting and promoting 128; new 128, 129

terminal evaluations $44,62 \mathrm{n} 1,86$, 155-156, 157-158b, 158 thematic evaluations 42b, 149

theory of change $80,93,94,95$; examples 96-97; transformational interventions 95-100, 97

timeliness 24-25, 115, 116, 131-132

trade-offs 130

transformation, time and 130

transformational change 49-52, 93-114, 129-130; creating 95-100; framework 50-52; outcomes 100-103; promoting 37; scaling up 103-113, 129-130; success, key factors $102 \mathrm{~b}$

transparency 133b, 152-153; credibility 134; stakeholders 168

\section{Uganda 107}

United Nations Development Programme (UNDP) 7, 13-14, 15-16

United Nations Environment Programme (UNEP) 7, 13-14, 15-16, 70

United Nations Framework Convention on Climate Change (UNFCCC) 4-5, 13-14, 38n2

urbanization 28

Uruguay 96, 98, 100, 101-102b, 103, 107

Uruguay Wind Energy Program (UWEP) 101b, 103

utility 152

validation $42 \mathrm{~b}$

valuation $57-58$

value addition $83-84$

value-for-money (VFM) 56-60, 74

viability $96 \mathrm{~b}$

Vietnam 70, 71, 71b

waste management 79 ; chemical 73 , 78-80; infectious 128-129; treatment technologies 128

weather 3

wildlife: disease transmission 124-125; trade 87-88b, 124-125; translocation 99-100

wind power, Uruguay 101-102b

World Bank 7, 13-14 